\title{
Evaluation of Recommended Revisions to Bulletin 17B
}

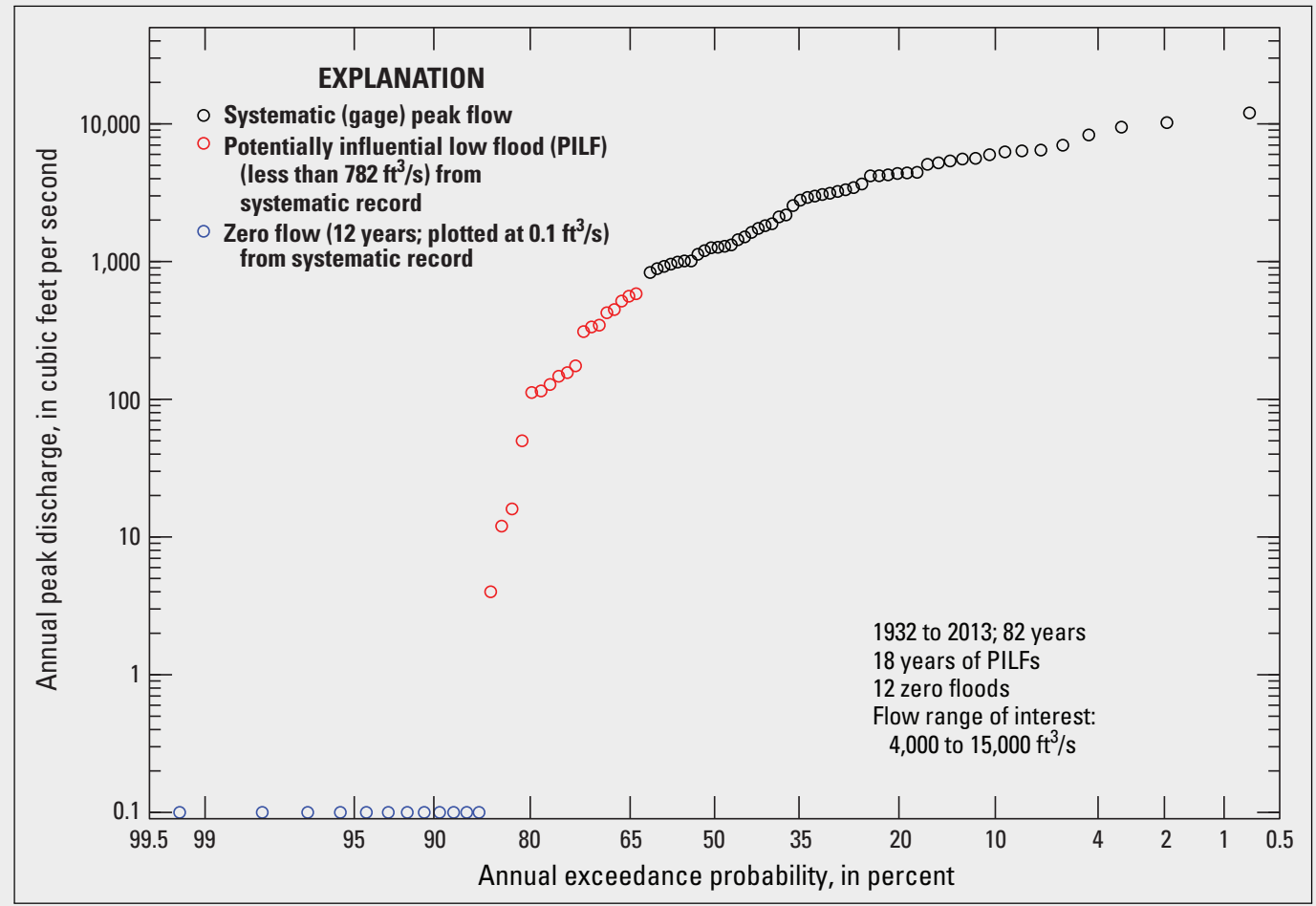

Open-File Report 2017-1064 
Cover. Graph showing an example empirical frequency distribution and potentially influential low floods (PILFs) at U.S. Geological Survey station 11274500, Orestimba Creek near Newman, California. 


\section{Evaluation of Recommended Revisions to Bulletin 17B}

By Timothy A. Cohn, U.S. Geological Survey (deceased)

Nancy A. Barth, U.S. Geological Survey

John F. England, Jr., U.S. Army Corps of Engineers

Beth A. Faber, U.S. Army Corps of Engineers

Robert R. Mason, Jr., U.S. Geological Survey

Jery R. Stedinger, Cornell University

Open-File Report 2017-1064 


\section{U.S. Department of the Interior \\ DAVID BERNHARDT, Acting Secretary

\author{
U.S. Geological Survey \\ James F. Reilly II, Director
}

U.S. Geological Survey, Reston, Virginia: 2019

For more information on the USGS - the Federal source for science about the Earth, its natural and living resources, natural hazards, and the environment—visit https://www.usgs.gov or call 1-888-ASK-USGS.

For an overview of USGS information products, including maps, imagery, and publications, visit https://store.usgs.gov/.

Any use of trade, product, or firm names in this publication is for descriptive purposes only and does not imply endorsement by the U.S. Government.

Although this information product, for the most part, is in the public domain, it also may contain copyrighted materials as noted in the text. Permission to reproduce copyrighted items must be secured from the copyright owner.

Suggested citation:

Cohn, T.A., Barth, N.A., England, J.F., Jr., Faber, B.A., Mason, R.R., Jr., and Stedinger, J.R., 2019, Evaluation of recommended revisions to Bulletin 17B: U.S. Geological Survey Open-File Report 2017-1064, 141 p., https://doi.org/10.3133/ofr20171064.

ISSN 2331-1258 (online) 


\section{Acknowledgments}

The work in this report was conceived by the Hydrologic Frequency Analysis Work Group (HFAWG) under the Subcommitee on Hydrology (SOH), Advisory Committee on Water Data. The HFAWG is currently chaired by Wilbert Thomas. A data subgroup and a testing subgroup were formed under HFAWG to examine potential changes to Bulletin 17B. The data subgroup consisted of Wilbert Thomas, Martin Becker, Don Woodward, Beth Faber, and Jerry Coffey. The HFAWG data subgroup provided a set of peak-flow datasets and suggested tests to perform in comparing Bulletin 17B and the Expected Moments Algorithm.

Lastly, our colleague and friend, Dr. Timothy A. Cohn, performed much of the work presented in this report. He wrote software that was critical to implementing these testing results and shared it with others. He gave freely of his time in teaching and instructing others in flood frequency and statistics. Tim was also instrumental in building support amongst HFAWG, SOH, and many Federal agencies. He will be missed.

Timothy A. Cohn

February 26, 1957-February 20, 2017 
This page intentionally left blank. 


\section{Contents}

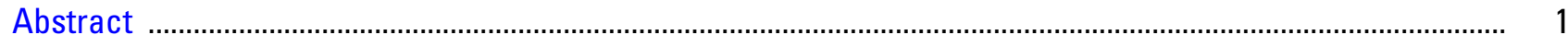

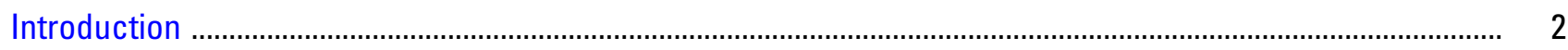

Literature Sources: The History of Flooding and Flood Risk Estimation ...........................................................

Metrics for Evaluating Flood-Frequency Estimators ....................................................................................... 4

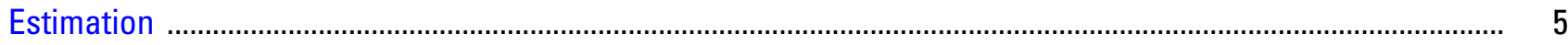

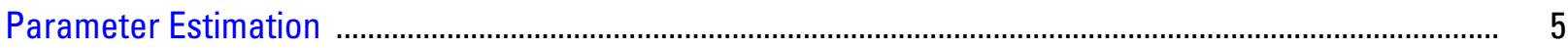

Identification of Outliers and Potentially Influential Low Floods ......................................................... 6

The MGB Test Algorithm for Identifying Potentially Influential Low Floods .............................................. 6

Would Identification of Fewer PILFs Yield Better Fits? ................................................................................ 7

Treatment of Floods Identified as Potentially Influential Low Floods: Conditional Probability Adjustment and Expected Moments Algorithm ................................................................................................ 9

Estimation Methods Considered in this Publication ............................................................................. 11

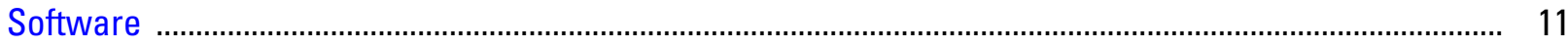

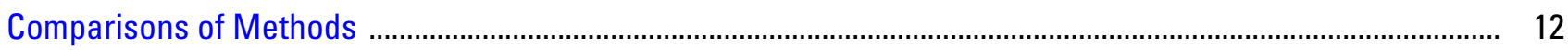

Understanding the Graphical Presentation of Results ............................................................................. 12

Studies with LP3 Distribution ............................................................................................................ 13

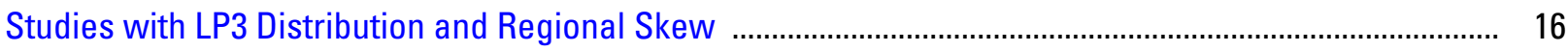

Robustness Studies .............................................................................................................................. 16

Robustness with Respect to Pearson Type 3 Population ................................................................... 16

Robustness with Respect to Mixed Population Constructed from Two LP3 Distributions ................. 18

Robustness with Respect to Population Constructed from Two LP3 Distributions ............................ 18

Robustness with Respect to Population Constructed from Two Generalized Extreme Value

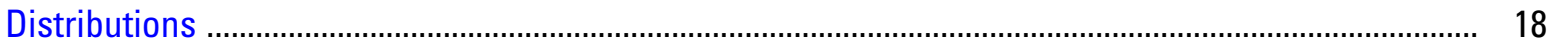

Examples Based on Real Data at Selected Test Sites .................................................................................. 22

Eighty-two Example Test Sites .......................................................................................................... 22

Sites With Systematic Gage Data and No PILFs or Historical Information ............................................. 22

Sites with Historical Information ............................................................................................................... 25

Sites with Systematic Gage Data and Potentially Influential Low Floods ............................................... 28

Sites With Potentially Influential Low Floods, Historical Information, and (or) High Outliers ................... 34

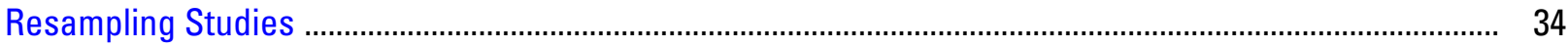

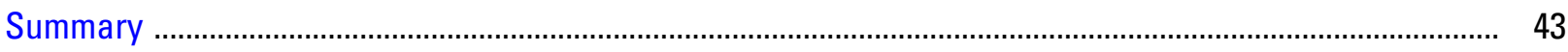

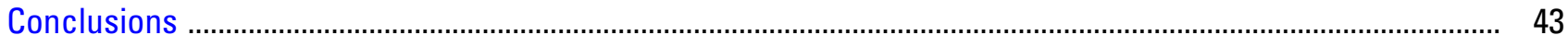

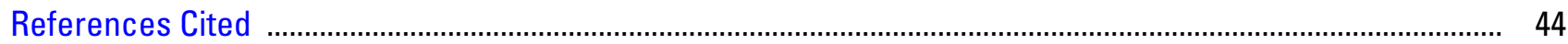

Appendix 1. Characteristics of 82 Test Sites ................................................................................................ 47

Appendix 2. Graphical Comparisons Between the EMA and B17B at 82 Test Sites .................................... 53

Systematic Data Sites .................................................................................................................. 54

Sites With Historical Information ........................................................................................................ 80

Sites With Potentially Influential Low Floods ........................................................................................ 99 


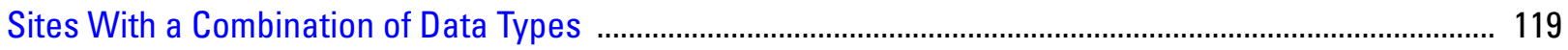

Studies With log-Pearson Type III (LP3) Distribution and Regional Skew ................................................... 136

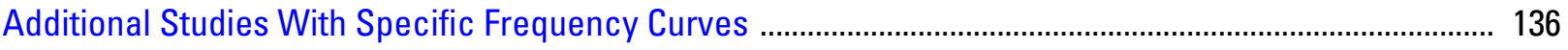

\section{Figures}

1. One-day peak floods from 1932 to 2008; discharge measured in cubic feet per second at Sacramento River at Shasta Dam

2. Monte Carlo results based on 10,000 replicate samples using systematic record, $N_{S}=40$, and historical record, $N_{H}=100$, drawn from a log-Pearson Type III (LP3) distribution with skew of 0.0

3. Monte Carlo results based on 10,000 replicate samples using systematic record, $N_{S}=40$, and historical record, $N_{H}=100$, drawn from a log-Pearson Type III (LP3) distribution with skew of $-0.5$

4. Monte Carlo results based on 10,000 replicate samples using systematic record, $N_{S}=40$, and historical record, $N_{H}=100$, drawn from a log-Pearson Type III (LP3) distribution with skew of 0.5

5. Monte Carlo results based on 10,000 replicate samples using systematic record, $N_{S}=40$, and historical record, $N_{H}=100$, drawn from robustness test curve 3

6. Monte Carlo results based on 10,000 replicate samples using systematic record, $N_{S}=40$, and historical record, $N_{H}=100$, drawn from a mixed population based on robustness test curve 4

7. Monte Carlo results based on 10,000 replicate samples using systematic record, $N_{S}=40$, and historical record, $N_{H}=100$, drawn from robustness test curve 5

8. Monte Carlo results based on 10,000 replicate samples using systematic record, $N_{S}=40$, and historical record, $N_{H}=100$, drawn from robustness test curve 6

9. Relative percent difference (RPD) for Bulletin 17B/Grubbs-Beck (B17B/GB) and Expected Moments Algorithm/multiple Grubbs-Beck (EMA/MGB) estimators for 10-percent (\%), 1-\%, and $0.2-\%$ exceedance probabilities $\left(Q_{p}\right)$. Includes 26 sites without historical flood information where no potentially influential low floods were identified by either test

10. Relative percent difference (RPD) for Bulletin 17B/Grubbs-Beck (B17B/GB) and Expected Moments Algorithm/multiple Grubbs-Beck (EMA/MGB) estimators for 10-percent (\%), 1-\%, and $0.2-\%$ exceedance probabilities $\left(Q_{p}\right)$. Figure represents 19 sites with historical information where no potentially influential low floods were identified by either GB test

11. Pryor Creek near Billings, Montana (06216500)

12. Relative percent difference (RPD) for Bulletin 17B/Grubbs-Beck (B17B/GB), Bulletin 17B/multiple Grubbs Beck (B17B/MGB), and Expected Moments Algorithm/multiple GrubbsBeck (EMA/MGB) estimators for 10-percent (\%), 1-\%, and 0.2-\% exceedance probabilities $\left(Q_{p}\right)$. The figure represents 20 sites where potentially influential low floods were identified by GB or MGB tests, and with no historical information

13. Number of floods identified as potentially influential low floods or below gage base using the standard Grubbs-Beck (GB) and multiple Grubbs-Beck (MGB) tests. Figure represents 20 sites without historical information 
14. Percent potentially influential low floods identified using the multiple Grubbs-Beck test.

Figure represents 20 sites without historical information

15. Orestimba Creek near Newman, California (11274500), fit after application of the multiple Grubbs-Beck (MGB) test to identify potentially influential low floods

16. Santa Cruz River near Lochiel, Arizona (09480000)

17. Relative percent difference (RPD) for Bulletin 17B/Grubbs Beck (B17B/GB), Bulletin 17B/multiple Grubbs Beck (B17B/MGB), and Expected Moments Algorithm/multiple Grubbs Beck (EMA/MGB) estimators for 10-percent (\%), 1-\%, and 0.2-\% exceedance probabilities $\left(Q_{p}\right)$. Represents 17 sites with historical flood information where potentially influential low floods were identified by the GB or MGB test

18. Arroyo Mocho near Livermore, California (11176000)

19. Tenmile Creek near Rimini, Montana (06062500)

20. Results based on resampled data using systematic record, $N_{S}=40$, and historical record, $N_{H}=100$, drawn from observed discharges at "Historical" category site 03011020

21. Results based on resampled data using systematic record, $N_{S}=40$, and historical record, $N_{H}=100$, drawn from observed discharges at "potentially influential low flood" category site 11152000

22. Results based on resampled data using systematic record, $N_{S}=40$, and historical record, $N_{H}=100$, drawn from observed discharges at "Gage Only" category site 14048000

23. Results based on resampled data using systematic record, $N_{S}=40$, and historical record, $N_{H}=100$, drawn from observed discharges at "potentially influential low flood" category site 14321000

24. Results based on resampled data using systematic record, $N_{S}=40$, and historical record, $N_{H}=100$, drawn from observed discharges at "Combination" category site 13185000

2-1. Site 01076500-Pemigewasset River at Plymouth, New Hampshire (NH) with systematic data only

2-2. Site 01439500-Bush Kill at Shoemakers, Pennsylvania (PA) with systematic data only

2-3. Site 01555500-East Mahantango Creek near Dalmatia, Pennsylvania (PA) with systematic data only

2-4. Site 01635500-Passage Creek near Buckton, Virginia (VA) with systematic data only

2-5. Site 02037500-James River near Richmond, Virginia (VA) with systematic data only

2-6. Site 02256500-Fisheating Creek at Palmdale, Florida (FL) with systematic data only

2-7. Site 03183500-Greenbrier River at Alderson, West Virginia (WV) with systematic data only 60

2-8. Site 05586500-Hurricane Creek near Roodhouse, Illinois (IL) with systematic data only 61

2-9. Site 06406000-Battle Creek at Hermosa, South Dakota (SD) with systematic data only 62

2-10. Site 06710500-Bear Creek at Morrison, Colorado (CO) with systematic data only 63

2-11. Site 07208500-Rayado Creek near Cimarron, New Mexico (NM) with systematic data only ......... 64

2-12. Site 07382000-Bayou Cocodrie near Clearwater, Louisiana (LA) with systematic data only .......... 65

2-13. Site 08380500-Gallinas Creek near Montezuma, New Mexico (NM) with systematic data only

2-14. Site 08387000-Rio Ruidoso at Hollywood, New Mexico (NM) with systematic data only ............. 67

2-15. Site 10128500-Weber River near Oakley, Utah (UT) with systematic data only 
2-16. Site 11266500-Merced River at Pohono Bridge near Yosemite, California (CA) with systematic data only

2-17. Site 12134500-Skykomish River near Gold Bar, Washington (WA) with systematic data only ....... 70

2-18. Site 12414500-St. Joe River at Calder, Idaho (ID) with systematic data only .................................. 71

2-19. Site 12437950-East Fork Foster Creek tributary near Bridgeport, Washington (WA) with systematic data only

2-20. Site 12451000-Stehekin River at Stehekin, Washington (WA) with systematic data only

2-21. Site 14021000-Umatilla River at Pendleton, Oregon (OR) with systematic data only ...

2-22. Site 14048000-John Day River at McDonald Ferry, Oregon (OR) with systematic data only .......... 75

2-23. Site 14137000-Sandy River near Marmot, Oregon (OR) with systematic data only ........................ 76

2-24. Site 15072000-Fish Creek near Ketchikan, Alaska (AK) with systematic data only ........................ 77

2-25. Site 16518000-West Wailuaiki Stream near Keanae, Hawaii (HI) with systematic data only ........ 78

2-26. Site 16587000-Honopou Stream near Huelo Maui, Hawaii (HI) with systematic data only ............ 79

2-27. Site 01350000-Schoharie Creek at Prattsville, New York (NY) with systematic and historical data

2-28. Site 01562000-Raystown Branch Juniata River at Saxton, Pennsylvania (PA) with systematic and historical data

2-29. Site 01636500-Shenandoah River at Millville, West Virginia (WV) with systematic and historical data

2-30. Site 02138500-Linville River near Nebo, North Carolina (NC) with systematic and historical data

2-31. Site 03011020-Allegheny River at Salamanca, New York (NY) with systematic and historical data

2-32. Site 03051000-Tygart Valley River at Belington, West Virginia (WV) with systematic and historical data

2-33. Site 03159500-Hocking River at Athens, Ohio $(\mathrm{OH})$ with systematic and historical data

2-34. Site 03550000-Valley River at Tomotla, North Carolina (NC) with systematic and historical data

2-35. Site 03558000-Toc coa River near Dial, Georgia (GA) with systematic and historical data

2-36. Site 03606500-Big Sandy River at Bruceton, Tennessee (TN) with systematic and historical data

2-37. Site 04293500-Missisquoi River near East Berkshire, Vermont (VT) with systematic and historical data

2-38. Site 06216500-Pryor Creek near Billings, Montana (MT) with systematic and historical data .......

2-39. Site 06600500-Floyd River at James, lowa (IA) with systematic and historical data ......................

2-40. Site 06898000-Thompson River at Davis City, lowa (IA) with systematic and historical data .........

2-41. Site 07067000-Current River at Van Buren, Missouri (MO) with systematic and historical data

2-42. Site 08167000-Guadalupe River at Comfort, Texas (TX) with systematic and historical data

2-43. Site 08378500-Pecos Rivert near Pecos, New Mexico (NM) with systematic and historical data

2-44. Site 09482500-Santa Cruz River at Tucson, Arizona (AZ) with systematic and historical data 
2-45. Site 12413000-North Fork (NF) Coeur D'Alene River at Enaville, Idaho (ID) with systematic and historical data

2-46. Site 01668000-Rappahannock River near Fredericksburg, Virginia (VA) with potentially influential low floods and no historical information

2-47. Site 03345500-Embarras River at Ste. Marie, Illinois (IL) with potentially influential low floods and no historical information

2-48. Site 05572000-Sangamon River at Monticello, Illinois (IL) with potentially influential low floods and no historical information 101

2-49. Site 06176500-Wolf Creek near Wolf Point, Montana (MT) with potentially influential low floods and no historical information 102

2-50. Site 07203000-Vermejo River near Dawson, New Mexico (NM) 103

2-51. Site 08133500-North Concho River at Sterling City, Texas (TX) with potentially influential low floods and no historical information. EMA, Expected Moments Algorithm; B17B, Bulletin 17B

2-52. Site 08150000 -Llano River near Junction, Texas (TX) with potentially influential low floods and no historical information 105

2-53. Site 08189500-Mission River at Refugio, Texas (TX) with potentially influential low floods and no historical information

2-54. Site 09241000-Elk River at Clark, Colorado (CO) with potentially influential low floods and no historical information

2-55. Site 09480000-Santa Cruz River near Lochiel, Arizona (AZ) with potentially influential low floods and no historical information

2-56. Site 10234500-Beaver River near Beaver, Utah (UT) with potentially influential low floods and no historical information

2-57. Site 11028500-Santa Maria Creek near Ramona, California (CA) with potentially influential low floods and no historical information

2-58. Site 11152000-Arroyo Seco near Soledad, California (CA) with potentially influential low floods and no historical information

2-59. Site 11274500-Orestimba Creek near Newman, California (CA) with potentially influential low floods and no historical information

2-60. Site 11383500-Deer Creek near Vina, California (CA) with potentially influential low floods and no historical information

2-61. Site 12307500-Moyie River at Eileen, Idaho (ID) with potentially influential low floods and no historical information

2-62. Site 13302500-Salmon River at Salmon, Idaho (ID) with potentially influential low floods and no historical information

2-63. Site 13343660-Smith Gulch tributary near Pataha, Washington (WA) with potentially influential low floods and no historical information

2-64. Site 14321000-Umpqua River near Elkton, Oregon (OR) with potentially influential low floods and no historical information

2-65. Site 16068000-East Branch (EB) of North Fork (NF) Wailua River near Lihue, Hawaii (HI) with potentially influential low floods and no historical information

2-66. Site 03289500-Elkhorn Creek near Frankfort, Kentucky (KY) with a combination of potentially influential low floods, historical, and (or) high outliers in the data 
2-67. Site 05270500-Sauk River near St. Cloud, Minnesota (MN) with a combination of potentially influential low floods, historical, and (or) high outliers in the data

2-68. Site 05291000-Whetstone River near Big Stone City, South Dakota (SD) with a combination of potentially influential low floods, historical, and (or) high outliers in the data

2-69. Site 05464500-Cedar River at Cedar Rapids, Iowa (IA) with a combination of potentially influential low floods, historical, and (or) high outliers in the data

2-70. Site 06062500-Tenmile Creek near Rimini, Montana (MT) with a combination of potentially influential low floods, historical, and (or) high outliers in the data

2-71. Site 06897000-East Fork Big Creek near Bethany, Missouri (MO) with a combination of potentially influential low floods, historical, and (or) high outliers in the data

2-72. Site 06933500-Gasconade River at Jerome, Missouri (MO) with a combination of potentially influential low floods, historical, and (or) high outliers in the data. EMA, Expected Moments Algorithm; B17B, Bulletin 17B

2-73. Site 07138600-White Woman Creek tributary near Selkirk, Kansas (KS) with a combination of potentially influential low floods, historical, and (or) high outliers in the data

2-74. Site 08164000-Lavaca River near Edna, Texas (TX) with a combination of potentially influential low floods, historical, and (or) high outliers in the data

2-75. Site 08171000-Blanco River at Wimberley, Texas (TX) with a combination of potentially influential low floods, historical, and (or) high outliers in the data

2-76. Site 09361500-Animas River at Durango, Colorado (CO) with a combination of potentially influential low floods, historical, and (or) high outliers in the data

2-77. Site 09471000-San Pedro River at Charleston, Arizona (AZ) with a combination of potentially influential low floods, historical, and (or) high outliers in the data

2-78. Site 11176000-Arroyo Mocho near Livermore, California (CA) with a combination of potentially influential low floods, historical, and (or) high outliers in the data

2-79. Site 11464500-Dry Creek near Cloverdale, California (CA) with a combination of potentially influential low floods, historical, and (or) high outliers in the data. EMA, Expected Moments Algorithm; B17B, Bulletin 17B

2-80. Site 11522500-Salmon River at Somes Bar, California (CA) with a combination of potentially influential low floods, historical, and (or) high outliers in the data

2-81. Site 12039500-Quinault River at Quinault Lake, Washington (WA) with a combination of potentially influential low floods, historical, and (or) high outliers in the data

2-82. Site 13185000-Boise River near Twin Springs, Idaho (ID) with a combination of potentially influential low floods, historical, and (or) high outliers in the data

2-83. Results are based on 10,000 replicate samples with systematic record, $N_{S}=40$, and historical record, $N_{H}=100$, drawn from a log-Pearson type III distribution with skew, $\gamma=0.0$. Regional skew is assumed to be 0.0 with mean square error of 0.15

2-84. Results are based on 10,000 replicate samples with systematic record, $N_{S}=40$, and historical record, $N_{H}=100$, drawn from a log-Pearson type III distribution with skew, $\gamma=-0.5$.

Regional skew is assumed to be -0.5 with mean square error of 0.15

2-85. Results are based on 10,000 replicate samples with systematic record, $N_{S}=40$, and historical record, $N_{H}=100$, drawn from a log-Pearson type III distribution with skew, $\gamma=0.5$. Regional skew is assumed to be 0.5 with mean square error of 0.15 
2-86. Results are based on 10,000 replicate samples with systematic record, $N_{S}=40$, and historical record, $N_{H}=100$, drawn from robustness test curve 1

2-87. Results are based on 10,000 replicate samples with systematic record, $N_{S}=40$, and historical record, $N_{H}=100$, drawn from robustness test curve 2

\section{Tables}

1. Impact of restricting search for potentially influential low floods to the bottom quartile of sample at the 13 sites where more than 25 percent of the observations had been identified as PILFs using the standard multiple Grubbs-Beck test

1-1. Characteristics of at-site streamflow records used in comparing Bulletin 17B and the Expected Moments Algorithm estimators 


\section{Conversion Factors}

U.S. customary units to International System of Units

\begin{tabular}{lll}
\hline Multiply & By & To obtain \\
\hline foot $(\mathrm{ft})$ & 0.3048 & meter $(\mathrm{m})$ \\
mile $(\mathrm{mi})$ & 1.609 & kilometer $(\mathrm{km})$ \\
square mile $\left(\mathrm{mi}^{2}\right)$ & 2.590 & square kilometer $\left(\mathrm{km}^{2}\right)$ \\
cubic foot per second $(\mathrm{ft} / 3)$ & 0.02832 & cubic meter per second $\left(\mathrm{m}^{3} / \mathrm{s}\right)$ \\
\hline
\end{tabular}

\section{Datum}

Horizontal coordinate information is referenced to the North American Datum of 1983 (NAD 83).

Vertical coordinate information is referenced to the National Geodetic Vertical Datum of 1929 (NGVD 29).

\section{Abbreviations}

$\begin{array}{ll}\text { ACWI } & \text { Advisory Committee on Water Information } \\ \text { AEP } & \text { annual exceedance probability } \\ \text { AG } & \text { average gain } \\ \text { AMS } & \text { annual maximum series } \\ \text { B17B } & \text { Bulletin 17B } \\ \text { CDF } & \text { cumulative distribution function } \\ \text { CPA } & \text { conditional probability adjustment } \\ \text { EMA } & \text { Expected Moments Algorithm } \\ \text { ERL } & \text { effective record length } \\ \text { GB } & \text { Grubbs-Beck } \\ \text { HFAWG } & \text { Hydrologic Frequency Analysis Work Group } \\ \text { IAWCD } & \text { Interagency Committee on Water Data } \\ \text { LP3 } & \text { log-Pearson Type III distribution } \\ \text { MGB } & \text { Multiple Grubbs-Beck } \\ \text { MGBT } & \text { Multiple Grubbs-Beck Test } \\ \text { MSE } & \text { mean square error } \\ \text { NWIS } & \text { USGS National Water Information System } \\ \text { P3 } & \text { Pearson Type III distribution } \\ \text { PILF } & \text { Potentially Influential Low Flood } \\ \text { RPD } & \text { relative percent difference } \\ \text { SOH } & \text { Subcommittee on Hydrology } \\ \text { USGS } & \text { U.S. Geological Survey } \\ \text { USWRC } & \text { U.S. Water Resources Council }\end{array}$




\title{
Evaluation of Recommended Revisions to Bulletin 17B
}

\author{
By Timothy A. Cohn, Nancy A. Barth, John F. England, Jr., Beth A. Faber, Robert R. Mason, Jr., and Jery R. \\ Stedinger
}

\section{Abstract}

For the past 36 years, Bulletin 17B, published by the Interagency Committee on Water Data in 1982, has guided flood-frequency analyses in the United States. During this period, much has been learned about both hydrology and statistical methods. In keeping with the tradition of periodically updating the Bulletin 17B guidelines in light of advances in our understanding and methods, the Hydrologic Frequency Analysis Work Group (HFAWG) was charged by the Subcommittee on Hydrology (SOH) of the Advisory Committee on Water Information (ACWI) to consider possible updates to Bulletin 17B.

The purpose of this report is to consider the statistical performance of possible revisions to Bulletin 17B procedures. Of particular interest are procedures designed to accommodate more general forms of flood information. The concern is how the proposed procedures would affect the precision, accuracy and robustness of flood-frequency estimates. The investigations reported here focus on techniques for the following:

- incorporating information related to historical flooding that occurred outside the period of systematic streamgaging; and

- identification of potentially influential low floods (PILFs).

The proposed changes, which mostly involve generalizing Bulletin 17B's method-of-moments procedures by using the Expected Moments Algorithm (EMA), are relatively modest, at least in the sense that they would not affect the main features of Bulletin 17B. The proposed methods include the following:

- continued use of the log-Pearson Type 3 (LP3) distribution;

- continued use of the Method-of-Moments fitting method applied to the logarithms of annual-peak-flow data; and

- a generalization of the Grubbs-Beck test used in Bulletin 17B to identify low outliers. The new multiple Grubbs-Beck test is sensitive to multiple PILFs.

The hydrological literature already provides extensive support for the theory behind the proposed changes. The remaining question is practical: How well do the proposed methods perform under typical and realistic conditions and, specifically, with difficult records occasionally encountered in practice? In order to answer these questions, the HFAWG commissioned the work reported here. The following four major sets of results are provided:

- Monte Carlo simulations of fitting procedures employing data drawn from simulated LP3 populations; 


\section{Evaluation of Recommended Revisions to Bulletin 17B}

- Monte Carlo simulations of fitting procedures employing data drawn from non-LP3 populations that were selected to reflect likely deviations of flood series from LP3 distributions, based on the experience of HFAWG members;

- a direct comparison of the fitted LP3 distributions for 82 real "test sites" identified by an independent data group as both "typical" and "challenging" for flood-frequency estimation; and

- simulations of fitting procedures using records obtained by resampling with replacement from the longest of the 82 test-site records.

Collectively, these studies provide a reasonably comprehensive, valid, and robust assessment of the properties of the Bulletin 17B methods and proposed alternatives. The experiments and analysis indicate that the flood quantile estimators, proposed as a revision of Bulletin 17B, do the following:

- perform generally as well as, and in some cases much better than, Bulletin 17B estimators in terms of the mean square error of flood quantiles estimates;

- allow for incorporation and efficient statistical treatment of broader classes of flood-frequency data and information, including historical information, binomial data and interval data; and

- generally confirm studies and the theoretical findings reported in the hydrological literature that would support use of updated estimation procedures that have been developed since Bulletin 17B was published.

\section{Introduction}

Flooding is the costliest natural hazard facing the United States in terms of loss of both life and property (Mileti, 1999; ACWI, 2011). While policymakers and planners have an array of tools to reduce flood losses through structural and nonstructural mitigation, doing so in practice requires a quantitative, uniform, and consistent approach for estimating flood risk (Tasker and Thomas, 1978; Thomas, 1985; Griffis and Stedinger, 2007). Recognizing this, the Federal Government has developed standard guidelines for performing floodfrequency analyses, and published these guidelines in a document known as "Bulletin 17B" by the Interagency Advisory Committee on Water Data (IACWD, 1982). The methods defined in Bulletin 17B (B17B) inform literally millions of decisions about land use and construction, emergency response and recovery, and countless other governmental and private-sector activities in the United States. The practical value of Federal guidelines is not in dispute.

Nonetheless, Bulletin 17B (IACWD, 1982) has its limitations. The document itself recognized that additional work was needed to improve some of its procedures (IACWD, 1982, p. 27, "Future Studies"). In light of additional research conducted to address these concerns, both researchers and practicing hydrologists have recently called for updates to the Bulletin 17B Guidelines. The purpose of this report is to evaluate some proposed modifications to the flood-frequency methods specified in Bulletin 17B.

In November of 2005, the Hydrologic Frequency Analysis Workgroup (HFAWG) proposed the following (Hydrologic Frequency Analysis Work Group, 2006):

Based on recently completed research, the HFAWG proposes to investigate the following possible improvements in Bulletin 17B:

1. Evaluate and compare the performance of the Expected Moments Algorithm (EMA) (Cohn and others, 1997) to the weighted-moments approach of Bulletin 17B (appendix 6) for analyzing datasets with historic information and paleoflood data. 
- Apply EMA and Bulletin 17B to gaging station data that include low and high outliers and historic data and those that do not. Develop criteria for determining if EMA provides more accurate and consistent flood estimates.

- Review and evaluate the published literature for comparisons of EMA to conventional Bulletin 17B procedures.

- Recommend improved plotting position formula when historic data are available.

2. Evaluate and compare the performance of EMA to the conditional probability adjustment of Bulletin 17B for analyzing datasets with potentially influential low floods (PILFs) and zero flows.

- Apply EMA and Bulletin 17B to gaging station data that include low and high outliers and historic data and those that do not (same dataset as noted above). Develop criteria for determining if EMA provides more accurate and consistent flood estimates.

3. Describe improved procedures for estimating generalized/regional skew.

- Evaluate revisions needed in Bulletin 17B to describe improved procedures for estimating generalized/regional skew based on recently completed research.

4. Describe improved procedures for defining confidence limits.

- Evaluate revisions needed in Bulletin 17B to describe new procedures for defining confidence limits that include the uncertainty in the skew coefficient.

- Describe confidence limit procedures for EMA (if adopted).

This report presents results of analyses that focus on items 1 and 2. Items 3 and 4 are addressed in previous literature. Advances in regional skew analyses are described in a series of U.S. Geological Survey (USGS) reports (Lamontagne and others, 2012; Veilleux and Stedinger, 2010; Veilleux and others, 2012). Confidence interval issues have been discussed in Cohn and others (2001) and earlier in Chowdhury and Stedinger (1991); see also Cohn and others (2013).

Note that none of the proposed changes to Bulletin 17B methods address issues that arise when fitting flood-frequency curves to nonstationary conditions that may arise due to land use change, changes to watermanagement practices, or climate variability or change. This is left to future work.

This report is organized in the following manner: Section Literature Sources: The History of Flooding and Flood Risk Estimation provides a brief review of literature on the topic addressed herein and, through references, a more general review of the larger field of flood frequency an alysis. Section Metrics for Evaluating Flood-Frequency Estimators discusses criteria for judging estimator performance, including statistical, practical, and operational concerns. Section Estimation reviews the statistical methods that are considered in this report, primarily the existing Bulletin 17B recommendations and the proposed EMA. Section Comparisons of Methods presents a set of Monte Carlo results based on synthetic samples from a variety of assumed and alternative distributional families, as well as based on resampling at long-record sites. Section Examples Based on Real Data at Selected Test Sites reviews the performance of the Bulletin 17B and the EMA procedures at 82 real sites that were selected to represent conditions that exist at sites throughout the United States. Section Conclusions presents conclusions - a summary of the main findings of the research as reported in the earlier sections. Two appendixes are included that provide metadata on the real-world sites employed in this study and additional figures illustrating estimator performance. 


\section{Literature Sources: The History of Flooding and Flood Risk Estimation}

Bulletin 17B (IACWD, 1982) defines the current method for conducting peak-flow frequency analyses in the United States. It descends from a series of studies and guidelines beginning with Bulletins 13 (Interagency Committee on Water Resources, 1966), 15 (U.S. Water Resources Council, 1967), 17 (U.S. Water Resources Council, 1976), and 17A (U.S. Water Resources Council, 1977). Each of these reports includes a list of relevant citations. The history of these bulletins and a discussion of the methods recommended in Bulletin 17B appear in Thomas (1985), Stedinger and others (1993), and Griffis and Stedinger (2007). There is also a vast amount of literature on methods for flood-frequency estimation, and an extensive list of citations can be found in Stedinger and others (1993), Griffis and Stedinger (2007), and Dawdy and others (2012). American Institutes for Research (2005) provides a comprehensive chronology of the history of flood-risk estimation, as well as a comprehensive bibliography of the flood-frequency literature prior to 2000. Stedinger and others (1993) provides a bibliography of statistical techniques employed in flood-frequency analyses.

\section{Metrics for Evaluating Flood-Frequency Estimators}

In practice, the benefits of more accurate flood information depend on many factors that are site specific. In particular, benefits depend on the physical, geological, social, and other characteristics of the site. However, in trying to assess the performance of flood-risk estimation techniques, one typically simplifies the problem by considering a small number of generally accepted criteria that are believed to characterize adequately an estimator's performance.

The criteria employed in this study can be divided into several groups.

\section{- Operational}

1. Ease of Application-Methods should be relatively easy to implement.

2. Applicability to Available Data-Methods should be able to make efficient use of the data types available for flood investigations.

3. Uniformity of Methods - Where possible, standardized methods and software should be used to ensure that different people performing the same analysis will obtain the same risk estimates. This will also ensure that frequency estimates are fully reproducible.

\section{- Statistical}

1. Bias and consistency - On average, risk estimates should approximately equal the true risk; as more information becomes available, risk estimates should converge to the true risk.

2. Efficiency-Estimators should extract as much information from the data as possible so as to minimize the mean square error of estimated statistics.

3. Quantified uncertainty-Estimates should be accompanied by quantitative assessments of their uncertainty.

- Political, Legal, and Institutional Criteria Standard methods should be consistent, uniform, and easily explained. They should satisfy legal requirements and should serve institutional requirements of the Federal Government and its National Flood Insurance Program, among others.

In this report, the following set of metrics is used to quantify the differences among different parameter estimation procedures: 
BIAS The expected difference between the estimate and true value of the parameter of interest.

MSE Mean square error (MSE) is defined as the expected squared difference between the estimate and true value of the parameter of interest. This is sometimes expressed as the sum of the variance plus the bias squared.

ERL The efficiency of estimators that employ historical flood information is quantified in terms of effective record length (ERL), the amount of equivalent systematic record that, by itself, would provide the precision achieved with the combination of both systematic and historical information.

AG A more general measure of estimator efficiency is the average gain (AG), which expresses the benefit of each year of historical information in terms of the information in a year of systematic data.

RPD The relative percent difference (RPD) statistic is used to quantify differences among estimators.

Taken as a whole, these metrics provide the quantitative foundation for characterizing the performance of Bulletin 17B flood-frequency methods and proposed alternatives.

\section{Estimation}

For most of this study, flood quantile estimates were computed using two parameter estimation methods (B17B and EMA) and two PILF identification procedures (Grubbs-Beck [GB] and multiple Grubbs-Beck [MGB]). Section Identification of Outliers and Potentially Influential Low Floods discusses the motivation of the GB procedure in Bulletin 17B and of a proposed replacement, MGB. The characteristics of the MGB method are discussed in section The MGB Test Algorithm for Identifying Potentially Influential Low Floods. Section Treatment of Floods Identified as Potentially Influential Low Floods: Conditional Probability Adjustment and Expected Moments Algorithm provides a discussion of the conditional probability adjustment (CPA) used by Bulletin 17B and the proposed EMA approach to analyze records containing zero flows, PILFs, and other events described as being less than a specified threshold. Section Estimation Methods Considered in this Publication discusses three specific combinations of parameter estimators and PILF identification procedures considered in this publication. Section Software identifies the software used in the studies.

\section{Parameter Estimation}

Bulletin 17B (IACWD, 1982) recommends use of the method of moments to estimate the first three sample moments, although a number of additional procedures are employed for dealing with special situations. All of the procedures are documented in the Bulletin, and additional information on the procedures is found in Thomas (1985), Stedinger and others (1993), and Griffis and Stedinger (2007).

The EMA is a straightforward generalization of the method of moments that is designed to accommodate both the point data envisioned in Bulletin 17B (IACWD, 1982), as well as various forms of nonstandard interval data. The details of EMA are discussed in Cohn and others (1997), Cohn and others (2001), and Griffis and others (2004). At most sites across the United States, where only systematic annual peak flow data are currently available, the B17B and EMA frequency estimates are essentially identical. However, where nonstandard data are present, the two estimates will differ. In some cases, the differences can be substantial (see section Examples Based on Real Data at Selected Test Sites). 


\section{Evaluation of Recommended Revisions to Bulletin 17B}

\section{Identification of Outliers and Potentially Influential Low Floods}

Among the proposed improvements to Bulletin 17B is a new MGB test (MGBT) for PILFs. The MGBT is a natural generalization of the Bulletin 17B Grubbs-Beck test, and addresses item 3 in the Bulletin 17B list of needed future work (IACWD, 1982): "The treatment of outliers both as to identification and computational procedures."

PILF identification and treatment are important issues in flood-frequency analysis guidelines because unusually small observations, which often result from physical processes that are of little relevance to the estimation of large floods, can nevertheless have a large influence on statistical estimates of extreme flood quantiles. In arid regions, for example, channel losses often result in annual flood peaks that are zero. As a result, an LP3 distribution cannot fit the entire flood record. Moreover, samples from an LP3 distribution with substantial negative log-space skew ( $\gamma \leq-0.5$ ) often contain very low flood values and, using log-space moments, those unusually small values have undue influence and can result in poor estimates of the large flood quantiles of interest in flood risk management. Unusually small values are, therefore, a real concern because it is imperative that the estimators defined in a Bulletin 17C analysis, in addition to being efficient, possess the characteristic of robustness, meaning that they perform reasonably well, even when underlying assumptions are violated.

Robustness is sometimes achieved in statistical analyses through explicit adaptation: The analyst looks for problems and then addresses the critical issues. In frequency analyses, for example, one often uses a probability plot to examine if sample data are consistent with a fitted curve (Stedinger and others, 1993). The authors of Bulletin 17B dealt with the robustness issue by explicitly identifying low outliers that "depart significantly from the trend of the remaining data." They note that "The retention, modification and deletion of these outliers can significantly affect the statistical parameters computed from the data." Thus, the authors of Bulletin 17B explicitly recognized that we do not want small flood values distorting the model that describes the distribution of large floods (the "trend of the remaining data"). They explicitly note that failure to address this issue would "significantly affect the [computed] statistical parameters."

Barnett and Lewis (1994, p. 7-9) discuss this idea of using outlier tests to identify unusual observations that otherwise might have undue influence in an analysis. Low-outlier identification tests provide an objective and standard method for identifying PILFs, ensuring that different hydrologists analyzing the same data will arrive at the same conclusions.

The purpose of using the Bulletin 17B GB test, and the MGB extension considered here, is to identify potentially influential low floods, or PILFs. The defining characteristic of PILFs is that they potentially have a large influence on the upper tail of the fitted frequency curve. For example, when datasets are highly negatively skewed, the smallest observations can be very influential in determining the estimated skewness coefficient, and, as a result, the estimated value of the 1 percent exceedance probability flood (100-year flood).

\section{The MGB Test Algorithm for Identifying Potentially Influential Low Floods}

The Bulletin 17B GB test provides an objective method for identifying values that should be treated as "low outliers," in the terminology employed in that report. However, the Bulletin 17B GB test "low-outlier" threshold is based on the assumption that only the smallest observation in the sample might be a PILF. As a result, even though multiple PILFs in flood data are common, the GB test rarely identifies more than one (Lamontagne and others, 2013). To provide an objective criterion for identification of multiple PILFs, a multiple Grubbs-Beck test was developed that employs the actual distribution of the $i^{\text {th }}$ smallest observation in a sample of $n$ independent LP3 variates with zero skew (Cohn and others, 2013). 
Cohn and others (2013) provides the probability $p(i ; n)$ that the $i^{\text {th }}$ smallest observation in a normal sample of size $n$ might be as small or smaller than the value observed. If $p(i ; n)$ is small enough, then the $i^{t h}$ smallest observation is considered unusual, and all values equal to and less than the $i^{\text {th }}$ smallest observation are recoded as censored values. Rosner (1975) explains the advantages of this generalization of the GB statistic in the context of an analogous two-sided multiple outlier test. The specialized test adopted here considers only outliers in the lower tail. Spencer and McCuen (1996) and McCuen (2003) also discuss outlier tests based upon a generalized GB statistic.

The procedure for actually identifying PILFs includes the two following steps:

1. Starting at the median and sweeping outward towards the smallest observation, each observation is tested and is identified as a PILF if $p(i ; n) \leq 0.5 \%$. If the $k^{\text {th }}$ observation is identified as a PILF, the outward sweep stops and the $k^{t h}$ and all smaller observations are also identified as PILFs.

2. Then, as with the current GB procedure in Bulletin 17B, an inward sweep starts at the $(k+1)^{s t}$ smallest observation, where the observation is identified as a PILF if $p(k+1 ; n) \leq 10 \%$. This is repeated, sweeping towards the median, until an observation $m$ fails to be identified as a PILF by the inward sweep, at which point the inward sweep stops.

The number of PILFs identified by the procedure is then the larger of $k$ and $m-1$.

Bulletin 17B also used a 10 percent significance test but employed only a single inward sweep. A second critical difference is that the new inward sweep uses the $p(i ; n)$ function, which correctly describes whether the $i^{\text {th }}$ largest observation is unusual in a sample of size $n$. The MGB's first outward sweep seeks to determine if there is some break in the lower half of the data that would suggest the sample is best treated as if it had a number of PILFs. The second sweep using a less severe significance level, $p(i ; n) \leq 10 \%$, mimics Bulletin 17B's willingness to identify one or more of the smallest observations as PILFs so that the analysis is more robust.

If a record has, for example, five zero flows, then the smallest nonzero flow is considered to be the sixth smallest observation in the record. This correctly reflects the fact that the flood record included five smaller values. The GB test in Bulletin 17B includes no mechanism for correcting its threshold when testing the smallest nonzero flood value in a record containing one or more zeros, or below-threshold discharges at sites with crest-stage gages. This is particularly problematic because sites with zero flows are likely to include one or more small or near-zero flood values that should be identified as PILFs. The MGB test (MGBT) solves this problem.

\section{Would Identification of Fewer PILFs Yield Better Fits?}

The MGBT was defined to search for PILFs - potentially influential low floods-in the bottom 50 percent of the sample. Citing various reasons, some practicing hydrologists have expressed concern about declaring half of a sample to be PILFs. In part, this reflects concern about the number of PILFs; however, the focus should be on achieving robustness in estimating large floods, not to utilize as many point observations as possible.

In any case, one can determine the consequence of limiting the number of identified PILFs to, for example, one quarter of the sample rather than half. This question is addressed here through consideration of the 82 test sites. One immediate observation is that the question is relevant to only a handful of cases; the MGBT identifies fewer than 25 percent of PILFs at 69 of the 82 test sites. The 25-percent constraint would not be binding at these sites, and the results at these sites are not affected by limiting the number of PILFs to 25 percent. 


\section{Evaluation of Recommended Revisions to Bulletin 17B}

Table 1. Impact of restricting search for potentially influential low floods to the bottom quartile of sample at the 13 sites where more than 25 percent (\%) of the observations had been identified as PILFs using the standard multiple Grubbs-Beck test. The change in the $1 \%$-exceedance event appears in the right-most column, and ranged from $-20 \%(0.20)$ to $+58 \%(0.58)$, with a median increase of $+6 \%$ and average increase of $+9 \%$. Here, $\hat{Q}_{0.01,[50]}$ and $N_{[50]}$ refer to the estimated $1 \%$-exceedance flood with the $50 \%$ limit and the corresponding number of identified PILFs; $\hat{Q}_{0.01,[25]}$ and $N_{[25]}$ refer to the corresponding statistics for the $25 \%$ limit.

\begin{tabular}{crrrrrc}
\hline Site & USGS ID & $\hat{Q}_{0.01,[50]}$ & $N_{[50]}$ & $\hat{Q}_{0.01,[25]}$ & $N_{[25]}$ & $\left(\frac{Q_{0.01,[25]}-Q_{0.01,[50]}}{Q_{0.01,[50]}}\right)$ \\
\hline 17 & 03345500 & 49,700 & 34 & 54,100 & 1 & 0.09 \\
23 & 05291000 & 16,000 & 29 & 12,800 & 20 & -0.20 \\
37 & 07138600 & 1,110 & 12 & 983 & 5 & -0.12 \\
41 & 08133500 & 26,800 & 23 & 34,900 & 0 & 0.30 \\
45 & 08171000 & 113,000 & 27 & 110,000 & 19 & -0.02 \\
50 & 09241000 & 4,810 & 22 & 4,550 & 17 & -0.05 \\
56 & 10234500 & 1,110 & 45 & 1,360 & 0 & 0.22 \\
58 & 11152000 & 30,800 & 46 & 32,100 & 18 & 0.04 \\
59 & 11176000 & 2,440 & 19 & 3,860 & 1 & 0.58 \\
61 & 11274500 & 13,600 & 29 & 14,500 & 19 & 0.06 \\
63 & 11464500 & 21,600 & 15 & 25,400 & 5 & 0.18 \\
65 & 12039500 & 50,400 & 47 & 56,500 & 0 & 0.12 \\
73 & 13302500 & 18,000 & 42 & 18,500 & 16 & 0.03 \\
\hline
\end{tabular}

Table 1 reports the impact of the 25-percent (25\%) limit at the remaining 13 test sites. At these sites, limiting the number of PILFs to $25 \%$ of the sample will affect estimates of the 1-percent exceedance event, which appears in the right-most column. The changes ranged from -20 percent to +58 percent with a median difference of +6 percent and average increase of +9 percent.

On average, use of the lower quartile ( 25 percent limit) resulted in a modest increase in the 100-year-flood estimate. The question then becomes essentially subjective: Are the fitted frequency curves "better" with the 25-percent limit or the 50-percent limit? In the three cases where the absolute value of the change exceeded 20 percent, the 100-year flood increased by 22 percent, 30 percent, and 50 percent. If the MGBT has been censoring too heavily, we would expect to see no consistent increase or decrease from censoring less. To see an average increase of 9 percent, with such consistently positive increases when large differences occur, suggests that the 25-percent constraint leads to admitting small peaks that unduly affect the 1-percent exceedance flood estimate.

Appendix 2 includes figures showing flood magnitude plotted against annual exceedance probability (AEP) for these three cases. Visual examination of the plots suggests that the algorithm that was started searching at the median resulted in reasonable decisions, as can be seen in the following three figures:

08133500 MGBT [50] identifies 23 PILFS while MGBT[25] identifies none. Note the sharp break in the data just above the lower quartile that MGBT[50] catches and MGBT[25] would not (fig. 2-51).

11176000 Note a weak break in the data just above the lower quartile. Using the MGBT[50] identifies this discontinuity and results in a fit that is much more consistent with the eight largest observations. B17B/GB with one "low outlier" seems to overestimate the 1-percent exceedance flood when compared with the data (fig. 2-78).

10234500 Note kink visible just below the median that MGBT[50] identifies, with the result that the MGBT 
recommends censoring almost half the data. Given the shape of the data, that seems reasonable. Which approach provided the best fit? With the more extreme censoring, less weight is placed on the smallest observations and the B17B/MGB and EMA/MGB fits are much more consistent with the seven largest observations in the sample. In short, the MGB as defined seems to achieve the goal of matching the trend in the largest observations (fig. 2-56).

In 10 of 13 cases, the differences were small. In three cases, the differences were greater than 20 percent and all were positive. In at least two of the three cases, better fits were obtained with the more aggressive censoring, and it is arguable that this is the case in all three. Thus, MGBT[50] is arguably a good choice for identifying PILFs.

\section{Treatment of Floods Identified as Potentially Influential Low Floods: Conditional Probability Adjustment and Expected Moments Algorithm}

The logarithm of zero is minus infinity, so zero flows cannot be employed in a standard method-ofmoments fit using the logarithms of the flood magnitudes. As discussed here, the two estimation methodsB17B and EMA — deal with zeros and PILFs in different ways.

To deal with such zeros and PILFs, B17B employs the conditional probability adjustment (CPA) developed by Jennings and Benson (1969). If the $r$ smallest floods in a record of length $n$ are identified as outliers less than some threshold, $q_{T}$, then the CPA fits a LP3 distribution to the retained $(n-r)$ largest values. Then for any large flood value, $q>q_{T}$, its nonexceedance probability is estimated as $r / n$ plus $(1-r / n)$ times the probability it would not be exceeded given the distribution fit to the $(n-r)$ retained observations. Then for convenience and computation of confidence intervals, the 50,90, and 99 percentiles of that "probabilityadjusted" distribution are computed and used to compute the three parameters of a "synthetic" LP3 distribution that is used to represent flood risk at the site. This procedure is relatively robust, and has been shown to work well with zeros and PILFs (Griffis and others, 2004).

The EMA uses ranges and thresholds to describe historical flood information, floods measured with limited precision, and PILFs. In particular, PILFs can be represented as being less than the smallest retained observation when the LP3 distribution parameters are estimated. This allows the EMA to address a large range of circumstances, while appropriately representing all of the available information. Censoring several of the smallest observations in a sample results in almost no decrease of precision in flood quantile estimates with the EMA or with the CPA (Griffis and others, 2004). However, the EMA can be much more sensitive than the CPA to PILFs that are not afforded special treatment. Suppose a record had three PILFs, and we identified two. Then using the CPA, the value of the smallest two observations are completely ignored, and the frequency adjustment (CPA) corrects for omitting two observations in the curve fitting step. Thus, 66.7 percent of the PILFs have been dropped, greatly reducing their impact. With the EMA, if there are three PILFs and two are identified, the EMA represents the two smallest observations as being less than the third. This can make things worse.

Consider, for example, the Sacramento River 1-day-flood record discussed in Cohn and others (2013, fig. 3) (reproduced here as fig. 1), which has three small values that are each at least a factor of two smaller than the other observations. The GBT identifies one PILF in this case; MGBT correctly identifies all three, which can be seen immediately to be the most reasonable decision. Because EMA in some sense takes the data seriously, one needs to identify all of the PILFs to reliably avoid potential problems. Grubbs-Beck frequently fails to identify obvious PILFs, other than the smallest flow.

Given the well understood sensitivity of the EMA method to PILFs, no EMA/GB combination is considered in this report. The EMA does not perform reliably when paired with GB. As will be shown, the MGB criterion identifies obvious outliers and PILFs in the lower half of troublesome datasets. As a result, as will be 
10 Evaluation of Recommended Revisions to Bulletin 17B

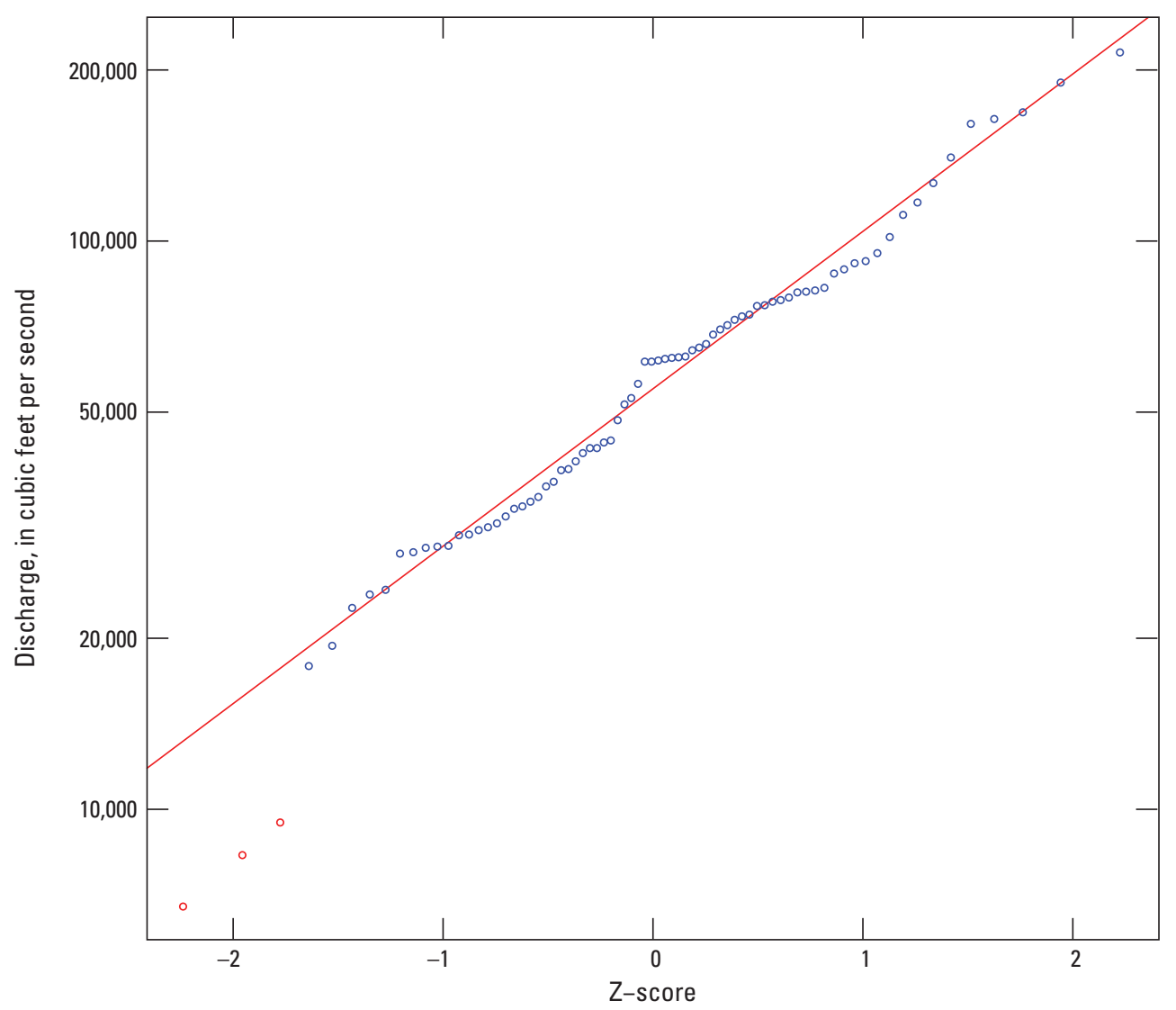

Figure 1. One-day peak floods from 1932 to 2008; discharge measured in cubic feet per second at Sacramento River at Shasta Dam, California (Cohn and others, 2013, fig. 3). (Z-score, distance from the mean as measured by standard deviations). 
shown here, both B17B and the EMA, when used with the MGB PILF identification procedure, are reliable flood-quantile estimators in terms of their ability to avoid problems caused by unusually small peaks.

\section{Estimation Methods Considered in this Publication}

Bulletin 17B (IACWD, 1982) procedures include a GB outlier identification procedure, a weighted moment computation if a historical record period is included with a perception threshold that was exceeded at least once, use of CPA if a record contains zero flows, low outliers, or peaks below gage base, and, finally, computation of a weighted skewness coefficient (Griffis and Stedinger, 2007, fig. 2); (IACWD, 1982, p. 12-2 through 12-3). All four of those steps, as needed, are components of the flood-frequency method denoted here as B17B.

The proposal under consideration is to replace those procedures with the MGB test for identification of PILFs (Cohn and others, 2013), and the EMA for the estimation of the parameters of an LP3 distribution simultaneously considering zeros and PILFs as censored data, one or more periods with different perception thresholds for historical floods, and a regional skewness coefficient with specified MSE (Cohn and others, 1997; Griffis and others, 2004). An advantage of the EMA approach is that all of the data is treated consistently in a single parameter estimation step, rather than as a sequence of procedures that first address historical information, then zeros and PILFs, and finally, regional skew information (or the opposite ordering of PILFs and historical adjustments when the skew coefficient is less than -0.4). Uncertainty analysis of the B17B sequence of steps is more difficult than that of the unified EMA procedure, and the EMA is more efficient because it allows simultaneous use of all of the data. For example, an informative regional skew should be used to inform the interpretation of historical and interval information, rather than being introduced as a separate and independent final adjustment of just the skewness coefficient as recommended by B17B. The EMA also allows for different thresholds to describe historical information from different periods, and the use of interval estimates of flood peaks to represent measurement uncertainty, which is often appropriate when representing the magnitude of historical flood information.

The studies that follow consider three estimation combinations:

1. The EMA (Cohn and others, 1997), with a generalized MGBT (Cohn and others, 2013) for detecting multiple PILFs in a flood series (EMA/MGB);

2. B17B (IACWD, 1982), with the standard GB method for identifying low outliers followed by the CPA to address zeros, low outliers, and peaks below gage base (B17B/GB); and

3. B17B, where the new MGBT was employed to identify multiple PILFs, followed by the CPA (IACWD, 1982) to address zeros, PILFs, and peaks below gage base (denoted by "B17B/MGB").

\section{Software}

The USGS PEAKFQ version 7.0 program was used to create the comparisons between B17B and the EMA estimates. PeakfqSA version 0.995, a development version of PEAKFQ written by Tim Cohn, was used to check the EMA results generated in PEAKFQ 7.0.

The Monte Carlo and resampling results reported in section Comparisons of Methods are based on the underlying code employed in PEAKFQ, with analysis routines prepared by Tim Cohn, and a front-end "driver" routine developed by Jery Stedinger called "monte.f."

Results based on the Bulletin 17B Guidelines are referred to as "B17B" or "PEAKFQ/B17B". Results based on the proposed EMA methods are denoted by "EMA" or "PeakfqSA". Additional letters are appended, yielding names of the form "B17B/GB," "B17B/MGB," and "EMA/MGB," to specify explicitly which PILF test procedure was used. 


\section{Evaluation of Recommended Revisions to Bulletin 17B}

\section{Comparisons of Methods}

Hundreds of distinct Monte Carlo and resampling experiments were conducted, each involving 10, 000 replicate samples, in order to determine how well the B17B/GB, B17B/MGB, and EMA/MGB estimators satisfy the criteria listed in the section Metrics for Evaluating Flood-Frequency Estimators. These Monte Carlo experiments are described in this section.

\section{Understanding the Graphical Presentation of Results}

In order to simplify the discussion, comparisons between estimators for cases with different historical information are presented concisely using a single graphical format. Each figure considers the performance of the estimators when data are drawn from a specific population. Figure 2, for example, corresponds to an LP3 distribution with a log-skew $\gamma=0.0$; later graphs consider estimator performance when data are drawn from other populations.

Each graphic has two parts. The top panel contains 12 boxplots (Tukey, 1977), divided into four groups of three, showing the distribution of three estimators for $Q_{1 \%}$, the 1-percent exceedance event (that is, the "100-year flood"). The central colored rectangle spans the 25 th to 75 th percentiles of the estimators' distributions. The central line indicates the median. Additional information about the distribution of the estimations is shown by the whiskers and hinges. The whisker length is 1.5 times the interquartile range. Observations beyond the whiskers are plotted as individual circles. For those cases where the population mean is known, an additional symbol is present on each box - a circle with a cross - indicating the location of the mean.

The three estimators are defined below and in IACWD (1982), Cohn and others (1997), Griffis and others (2004), and Cohn and others (2013). Although flood quantiles other than the 1-percent exceedance were investigated, the results were found to be insensitive as to which quantile was considered. Because $Q_{1 \%}$ is the flood of interest for many Federal activities, this case is reported.

Each of the four groups corresponds to $N_{S}=40$ years of systematic data. The first group involves no historical information $(E[H]=0)$. The other three have a historical period with $N_{H}=100$ years, during which different perception thresholds are set so that, in expectation, 1, 2 or 10, historic floods would have been recorded. The red-dashed line indicates the true value of $Q_{1 \%}$, where it is known; in some later plots, where $Q_{1 \%}$ is estimated by interpolation between real observations, a purple line is used to indicate an estimate of $Q_{1 \%}$ because the true value of $Q_{1 \%}$ is unknown.

The colored dots appearing in the lower panel in each graph indicate the effective record length (ERL) of each estimator. ERL is defined in this case, where $N_{S}=40$ and $N_{H}=100$, as the ratio:

$$
\mathrm{ERL} \equiv N_{S}\left\{\frac{\operatorname{MSE}\left[\log \left(\hat{Q}_{1 \%}\left(N_{S}=40, N_{H}=0\right)\right)\right]}{\operatorname{MSE}\left[\log \left(\hat{Q}_{1 \%}\left(N_{S}=40, N_{H}=100\right)\right)\right]}\right\}
$$

where $N_{S}$ is the length of the systematic record, $N_{H}$ is the length of the historical period, and

$$
\begin{aligned}
\operatorname{MSE}\left[\log \left(\hat{Q}_{1 \%}\left(N_{S}, N_{H}\right)\right)\right] \equiv & \left(\operatorname{Bias}\left[\log \left(\hat{Q}_{1 \%}\left(N_{S}, N_{H}\right)\right)\right]\right)^{2}+ \\
& \operatorname{Var}\left[\log \left(\hat{Q}_{1 \%}\left(N_{S}, N_{H}\right)\right)\right]
\end{aligned}
$$

ERL expresses, in a rough way, how well an estimator exploits historical information by expressing its effect in terms of an equivalent number of years of exclusively systematic data. Note that the estimator variance, denoted by "Var" in equation 2, is simply the variance of the 10,000 replicate estimates of $\hat{Q}_{1 \%}$. The bias, however, is not always so easily defined. Where the flood distribution is known, the bias is defined in the conventional manner as the average difference between $\hat{Q}_{1 \%}$ and the true mean. When dealing with real data (for 
example, in section Examples Based on Real Data at Selected Test Sites), however, the true value $Q_{1 \%}$ is not known. In these cases, for want of a better assumption, the bias is assumed to be zero for all estimators. Thus, the ERL is computed using only the estimated variance.

The bottom left-most box contains three numbers in lavender. These are, respectively, the percentage of observations identified as PILFs by the GB test with Bulletin 17B (B17B/GB), the MGB test with Bulletin 17B (B17B/MGB), and the MGB test with the EMA (EMA/MGB). The number of PILFs with B17B/MGB and EMA/MGB are in fact always identical because the tests do not depend on the fitting procedure.

The triplets of black numbers in the three boxes to the right indicate the average gain (AG), in percent, associated with each year of historical flood information, for B17B/GB, B17B/MGB, and EMA/MGB, respectively. The $A G$ quantifies the relative value of an additional year of historical information to an additional year of systematic gage record, and is defined as the following:

$$
\mathrm{AG} \equiv 100\left(\frac{\mathrm{ERL}-N_{S}}{N_{H}}\right)
$$

where AG is the percentage increase of ERL for each year in the historical period.

Where the expected number of historic floods is high (on the right side of the graph) the AG is typically also high. Where no historic floods can be expected (the group on the left) the average gain is zero. Note that the AG results are based on 10,000 replicate samples, and have a corresponding uncertainty of about 1 percent. The three colored circles in the bottom box represent the ERL corresponding to each estimator and censoring threshold.

\section{Studies with LP3 Distribution}

Figures 2 through 4 correspond to the case where we are fitting the LP3 distribution to LP3 data assuming we have no regional information. In these cases, we expect good results for all the estimators because we are applying the correct model for the population from which the data are drawn. The distribution of the Monte Carlo population, depicted as a frequency plot and as a probability density function of the logarithm of Q, appears below the main plot. Cases with regional skew information are addressed in Section Studies with LP3 Distribution and Regional Skew.

Figure 2 depicts the case when the population skew $\gamma$ is zero and PILFs are rare. The figure shows that the three estimators are identical when there is no historical information (the left-most three boxplots). If historical information is present with a perception threshold at approximately the 1-percent exceedance flood level (Stedinger and Cohn, 1986), the EMA/MGB ( $\mathrm{AG}=39)$ method performs substantially better than B17B/GB $(\mathrm{AG}=27)$ or $\mathrm{B} 17 \mathrm{~B} / \mathrm{MGB}(\mathrm{AG}=29)$. The same conclusion applies when the threshold is at the 2-percent exceedance level, where the average gains are 42, 44, and 53 for B17B/GB, B17B/MGB, and EMA/MGB, respectively. When the threshold is at the 10-percent exceedance level, which corresponds to a rare situation, all of the estimators perform extremely well, with average gains of 77, 80, and 72 .

Figure 3 depicts the case when the population skew is $\gamma=-0.5$. In this case, many PILFs are to be expected. Figure 3 reveals several interesting properties of the estimators. First, the center of the boxplots are substantially above the hashed line (the true 1-percent exceedance level), indicating that all of the estimators are biased upward when only systematic data are employed. This phenomenon is actually well known (Kirby, 1974; Stedinger and others, 1993). The method-of-moments estimator for the skew coefficient is biased toward zero and, thus, method-of-moments quantile estimators are biased upwards for populations with negative skews and downwards for populations with positive skews (see fig. 4). When historical information is present, the EMA/MGB method performs substantially better than B17B/GB or B17B/MGB. 

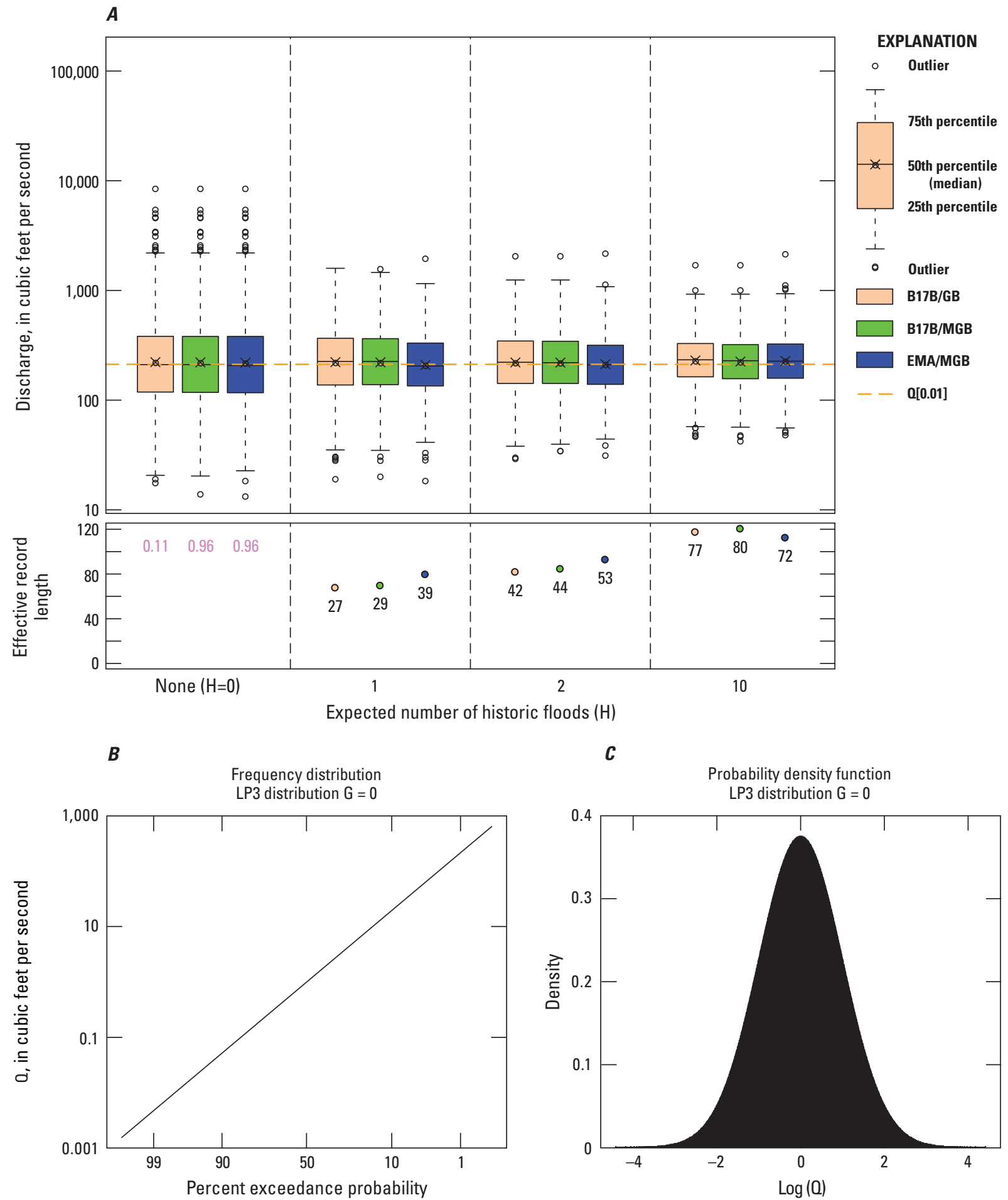

Figure 2. Monte Carlo results based on 10,000 replicate samples using systematic record, $N_{S}=40$, and historical record, $N_{H}=100$, drawn from a log-Pearson Type III (LP3) distribution with skew of 0.0. Terms within graph are defined as follows: B17B/GB, Bulletin 17B/Grubbs-Beck; B17B/MGB, Bulletin 17B/multiple Grubbs-Beck; EMA/MGB, Expected Moments Algorithm/multiple Grubbs-Beck; G, skew; and $\mathrm{Q}[0.01]$, discharge for annual exceedance probability of 0.01 . 


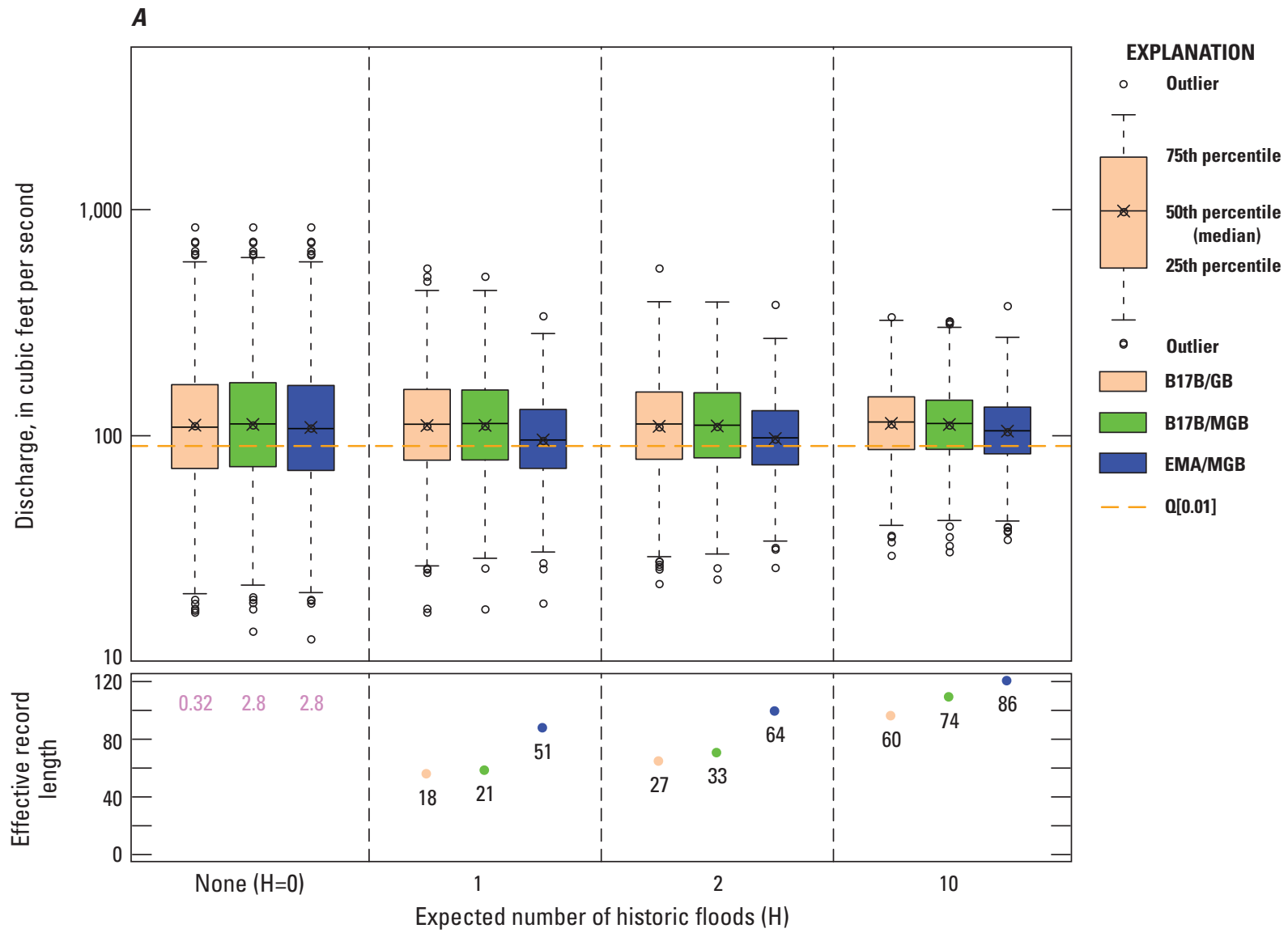

B

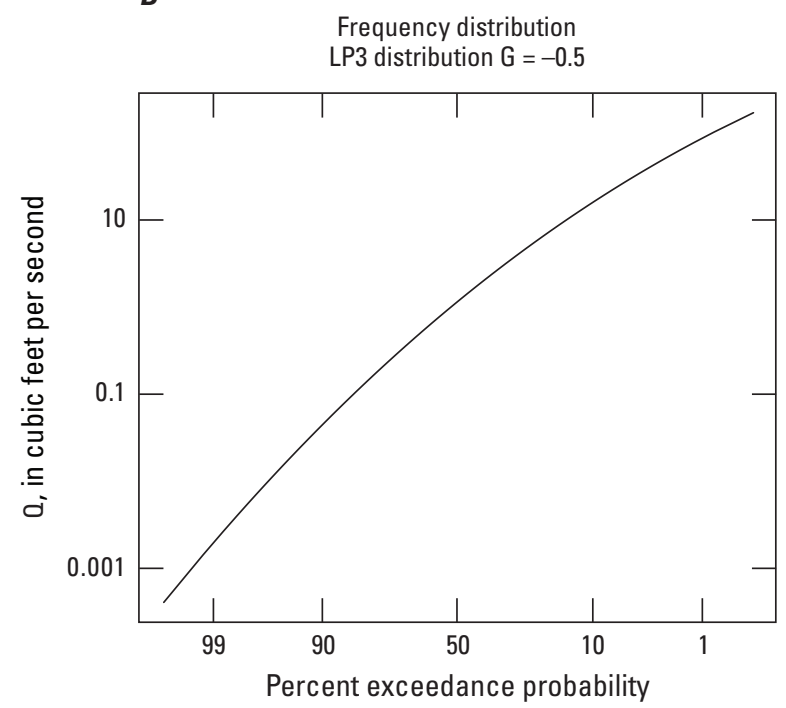

C

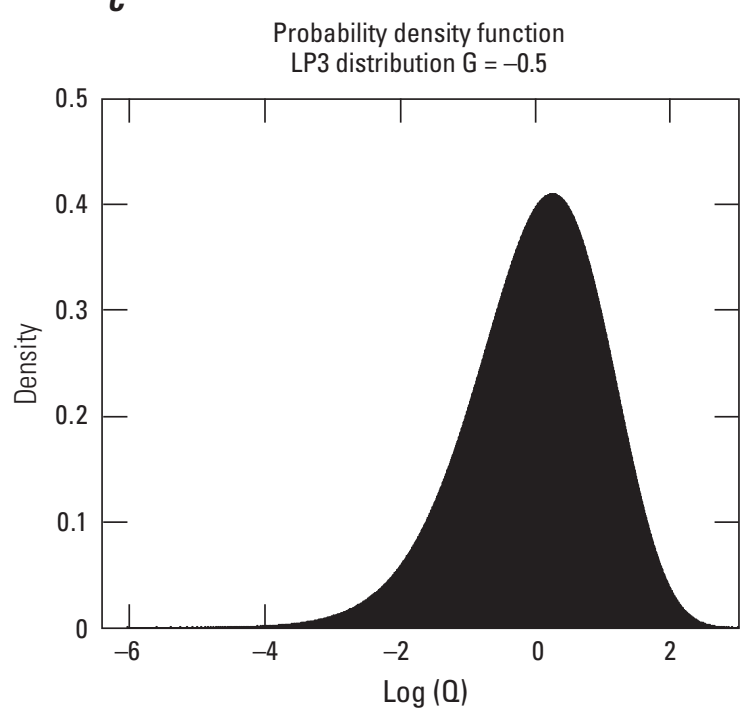

Figure 3. Monte Carlo results based on 10,000 replicate samples using systematic record, $N_{S}=40$, and historical record, $N_{H}=100$, drawn from a log-Pearson Type III (LP3) distribution with skew of -0.5 . Terms within graph are defined as follows: B17B/GB, Bulletin 17B/Grubbs-Beck; B17B/MGB, Bulletin 17B/multiple Grubbs-Beck; EMA/MGB, Expected Moments Algorithm/multiple Grubbs-Beck; G, skew; and Q[0.01], discharge for annual exceedance probability of 0.01 . 


\section{Evaluation of Recommended Revisions to Bulletin 17B}

Figure 4 depicts the case when the population skew is $\gamma=0.5$ and no PILFs are to be expected. This case reveals the opposite bias seen in figure 3. However, in this case, all of the estimators make good use of the historical information because, for positively skewed populations, the smaller values in the dataset have little impact on the sample moments and, therefore, do not influence the results, regardless of which estimator is employed. In figures 2 and 4 with $\mathrm{H}=10$ expected floods, both B17B estimators do a little better than the EMA, though visually the boxplots are indistinguishable. In all other cases, the EMA did essentially as well as the B17B estimators.

\section{Studies with LP3 Distribution and Regional Skew}

Figures 2-83 through 2-85 show the same cases as figures 2 through 4, except that regional skew information has been added. Synthetic regional skews are modeled and generated as normal variate with a mean of the observed skew and a variance of 0.15-a typical value consistent with Bayesian Generalized Least Squares (GLS) skew maps (Lamontagne and others, 2012; Parrett and others, 2011; Gotvald and others, 2009). The addition of regional skew information improves all of the estimators, including EMA/MGB and B17B/GB. The impact is essentially the same for all of the estimators and most pronounced for the negative skew example.

In conclusion, while accurate regional skew is a valuable addition to frequency analyses, it does not need to be considered as an important factor in determining the relative performance of the three estimators. For the cases with historical information where one or two historical floods are expected, the EMA again provides more precise quantile estimators than the B17B estimators. For the case where 10 historical floods are expected and $\gamma=0.5$, there is a virtual tie; when $\gamma=0.5$ and $\gamma=0$ (figs. 2-83 and 2-84), B17B/MGB does a little better than EMA, while B17B/GB does slightly better only when $\gamma=0$ (fig. 2-83). However, it is noteworthy that the value of historical information, when carefully employed with the EMA (see fig. 2), ranges from an average gain of 39 percent when one historical flood is expected, to 72 percent when when ten historical floods are expected.

\section{Robustness Studies}

To test their robustness to data with different distributions, the three estimators-B17B/GB, B17B/MGB, and EMA/MGB - were applied to six test curves. These are referred to as "robustness test curves 1-6." The first two of these test curves are based on LP3 data with different skew values, and are similar to those discussed in section Studies with LP3 Distribution. Figures 2-86 and 2-87 in the appendix also depict these two test curves. The remaining four test curves are used to test the performance of the three estimatorsB17B/GB, B17B/MGB, and EMA/MGB-when applied to non-LP3 data.

There are an infinite number of distribution "curves" that could be used to test robustness. While these curves represent only a tiny portion of the non-LP3 universe, they were chosen because it is believed they reflect at least some of the non-LP3 populations that have been observed in practice. For example, mixed populations may arise due to the existence of multiple peak-flow-generating processes in a watershed.

\section{Robustness with Respect to Pearson Type 3 Population}

Figure 5 depicts the performance of the estimators when data are drawn from a Pearson Type 3 (P3) population, not the LP3 (robustness test curve 3). As can be seen in the figure, the P3 has a substantially different shape than the LP3. All of the estimators are biased when fitting this population, as is expected because it is not the assumed population. However, the EMA/MGB estimator does perform slightly better than the two 


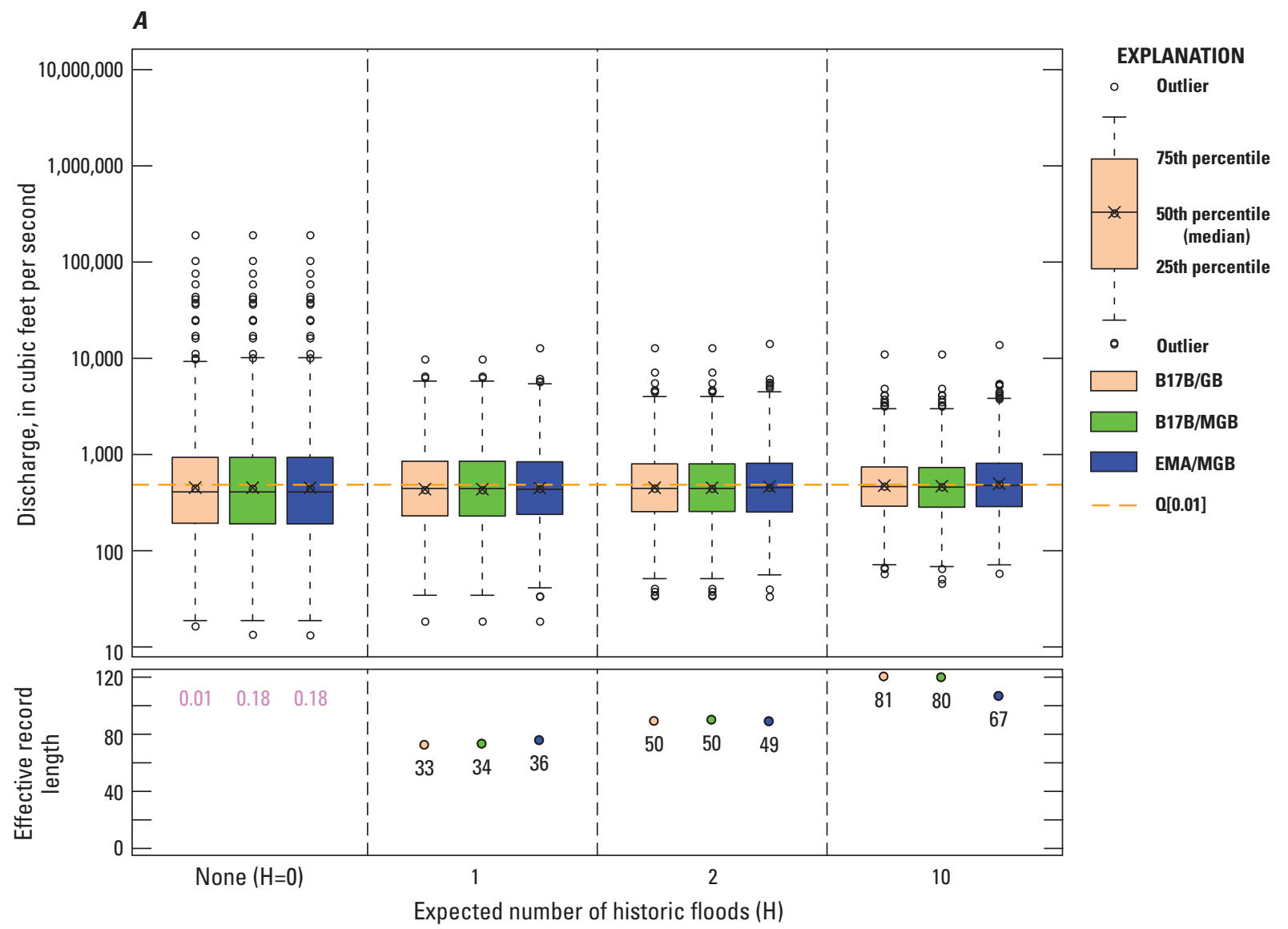

B

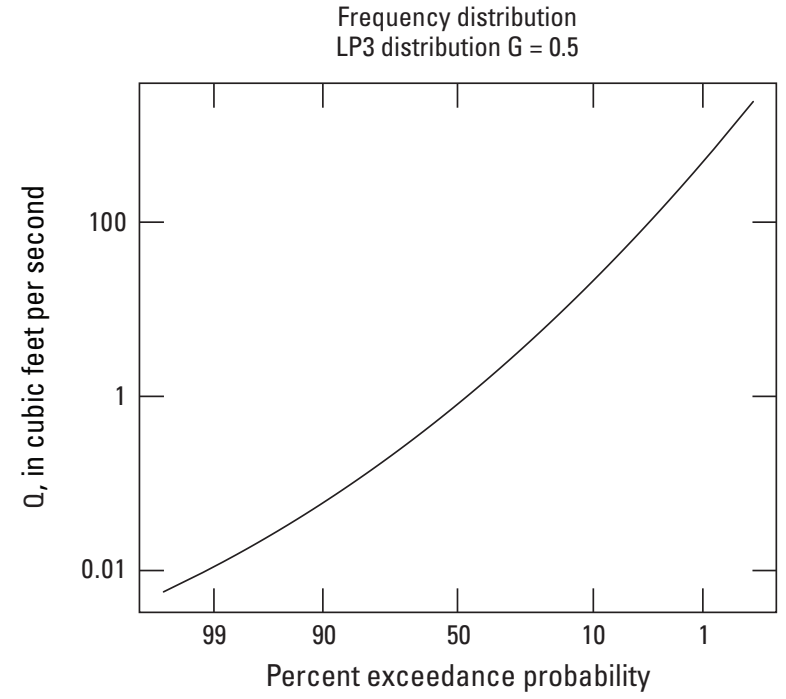

$c$

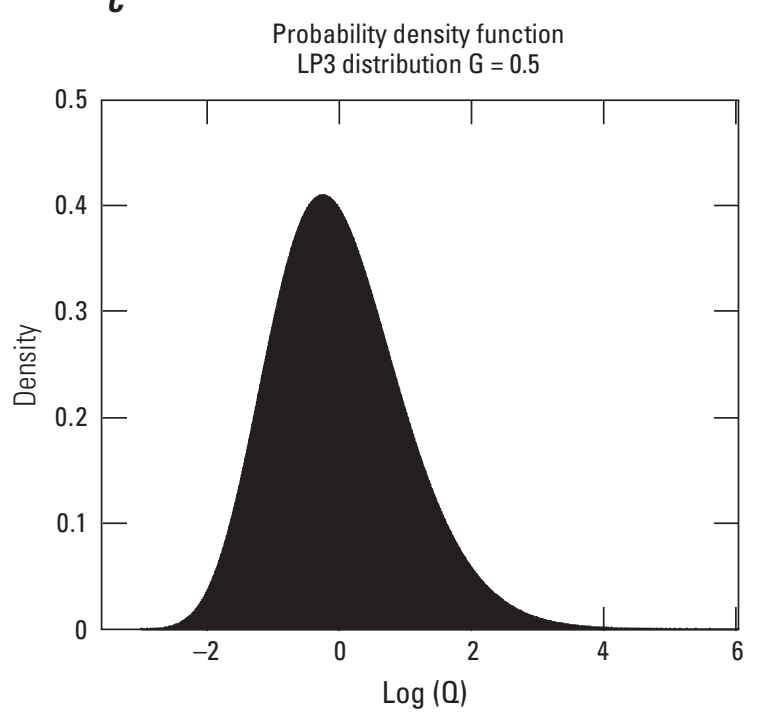

Figure 4. Monte Carlo results based on 10,000 replicate samples using systematic record, $N_{S}=40$, and historical record, $N_{H}=100$, drawn from a log-Pearson Type III (LP3) distribution with skew of 0.5. Terms within graph are defined as follows: B17B/GB, Bulletin 17B/Grubbs-Beck; B17B/MGB, Bulletin 17B/multiple Grubbs-Beck; EMA/MGB, Expected Moments Algorithm/multiple Grubbs-Beck; G, skew; and Q[0.01], discharge for annual exceedance probability of 0.01 . 


\section{Evaluation of Recommended Revisions to Bulletin 17B}

other estimators when historical information is present. In the absence of historical information, differences arise only due to outliers.

\section{Robustness with Respect to Mixed Population Constructed from Two LP3 Distributions}

Figure 6 depicts the performance of the estimators when data are drawn from robustness test curve 4, a mixed population created by choosing the maximum of observations drawn from two different LP3 distributions, the first with parameters

$$
\left\{M, S^{2}, G\right\}=\left\{4.1212,0.29^{2}, 1.00\right\}
$$

and the second with parameters

$$
\left\{M, S^{2}, G\right\}=\left\{4.0900,0.13^{2}, 0.15\right\}
$$

Without historical information, all three estimators are nearly identical. When historical information is present, the estimators are no longer identical, with EMA/MGB performing slightly better.

\section{Robustness with Respect to Population Constructed from Two LP3 Distributions}

Figure 7 depicts the performance of the estimators when data are drawn from robustness test curve 5, a constructed population based on two LP3 distributions, the first with parameters

$$
\left\{M, S^{2}, G\right\}=\left\{4.3438,0.41^{2},-1.00\right\}
$$

and the second with parameters

$$
\left\{M, S^{2}, G\right\}=\left\{4.3936,0.50^{2},-0.20\right\} \text {. }
$$

The lower half of the distribution function employs the first parameters, and the upper half is based on the second parameters. The two parent distributions are spliced together at their shared median. Fitting data from this population again tests the robustness of the estimators with a misspecified population, but this time when PILFs are present. Without historical information, EMA/MGB and B17B/MGB are nearly identical, and both perform better than B17B/GB. When historical information is present, EMA/MGB performs much better than the other estimators.

\section{Robustness with Respect to Population Constructed from Two Generalized Extreme Value Distributions}

Figure 8 depicts the performance of the estimators when data are drawn from robustness test curve 6, a constructed population based on two Generalized Extreme Value (GEV) distributions, the first with location, scale, and shape parameters

$$
\{\kappa, \alpha, \xi\}=\{0.08,24326,6378\}
$$

and the second with parameters

$$
\{\kappa, \alpha, \xi\}=\{-0.55,10000,17330\}
$$



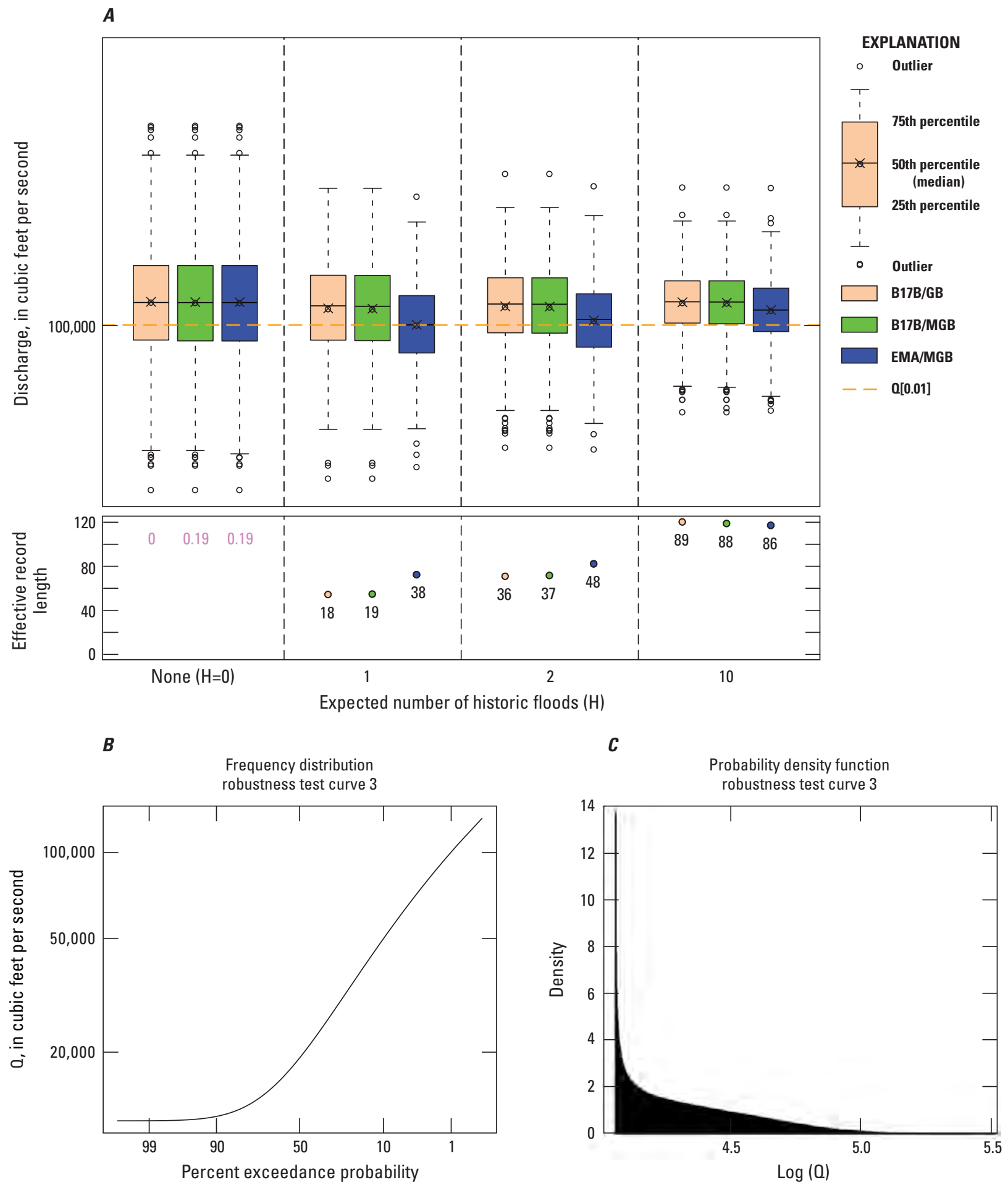

Figure 5. Monte Carlo results based on 10,000 replicate samples using systematic record, $N_{S}=40$, and historical record, $N_{H}=100$, drawn from robustness test curve 3. Terms within graph are defined as follows: B17B/GB, Bulletin 17B/Grubbs-Beck; B17B/MGB, Bulletin 17B/multiple Grubbs-Beck; EMA/MGB, Expected Moments Algorithm/multiple Grubbs-Beck; G, skew; and $\mathrm{O}[0.01]$, discharge for annual exceedance probability of 0.01 . 


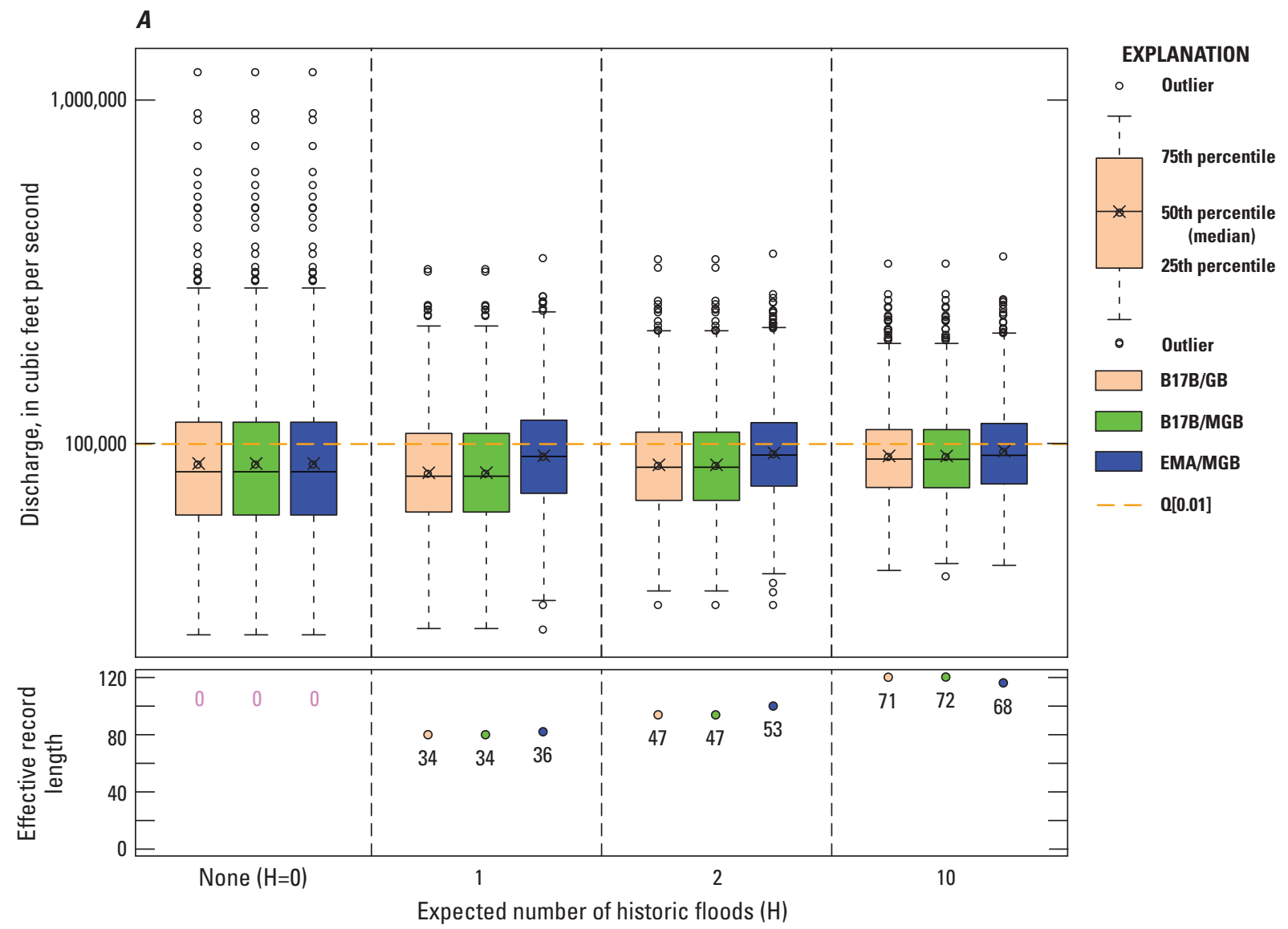

B

Frequency distribution robustness test curve 4

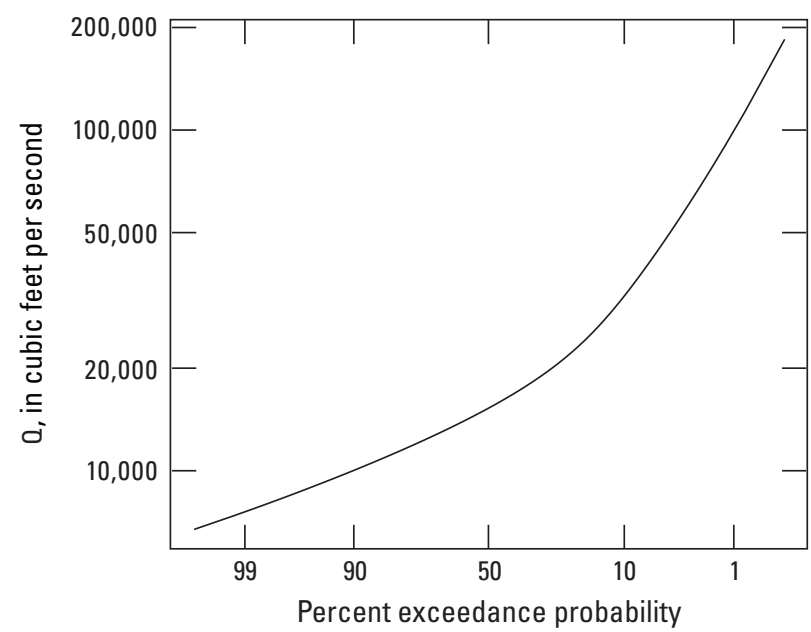

C

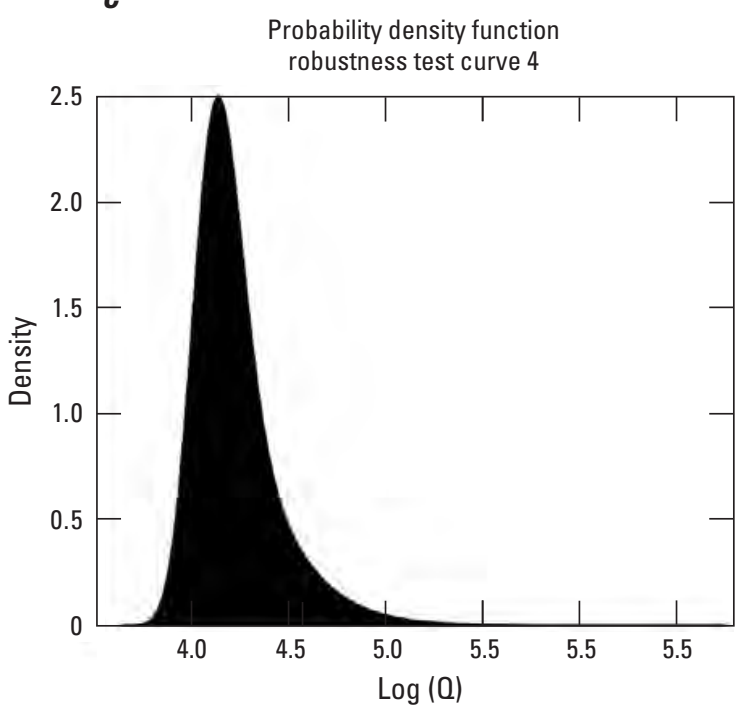

Figure 6. Monte Carlo results based on 10,000 replicate samples using systematic record, $N_{S}=40$, and historical record, $N_{H}=100$, drawn from a mixed population based on robustness test curve 4. Terms within graph are defined as follows: B17B/GB, Bulletin 17B/Grubbs-Beck; B17B/MGB, Bulletin 17B/multiple Grubbs-Beck; EMA/MGB, Expected Moments Algorithm/multiple Grubbs-Beck; G, skew; and $\mathrm{Q}[0.01]$, discharge for annual exceedance probability of 0.01 . 


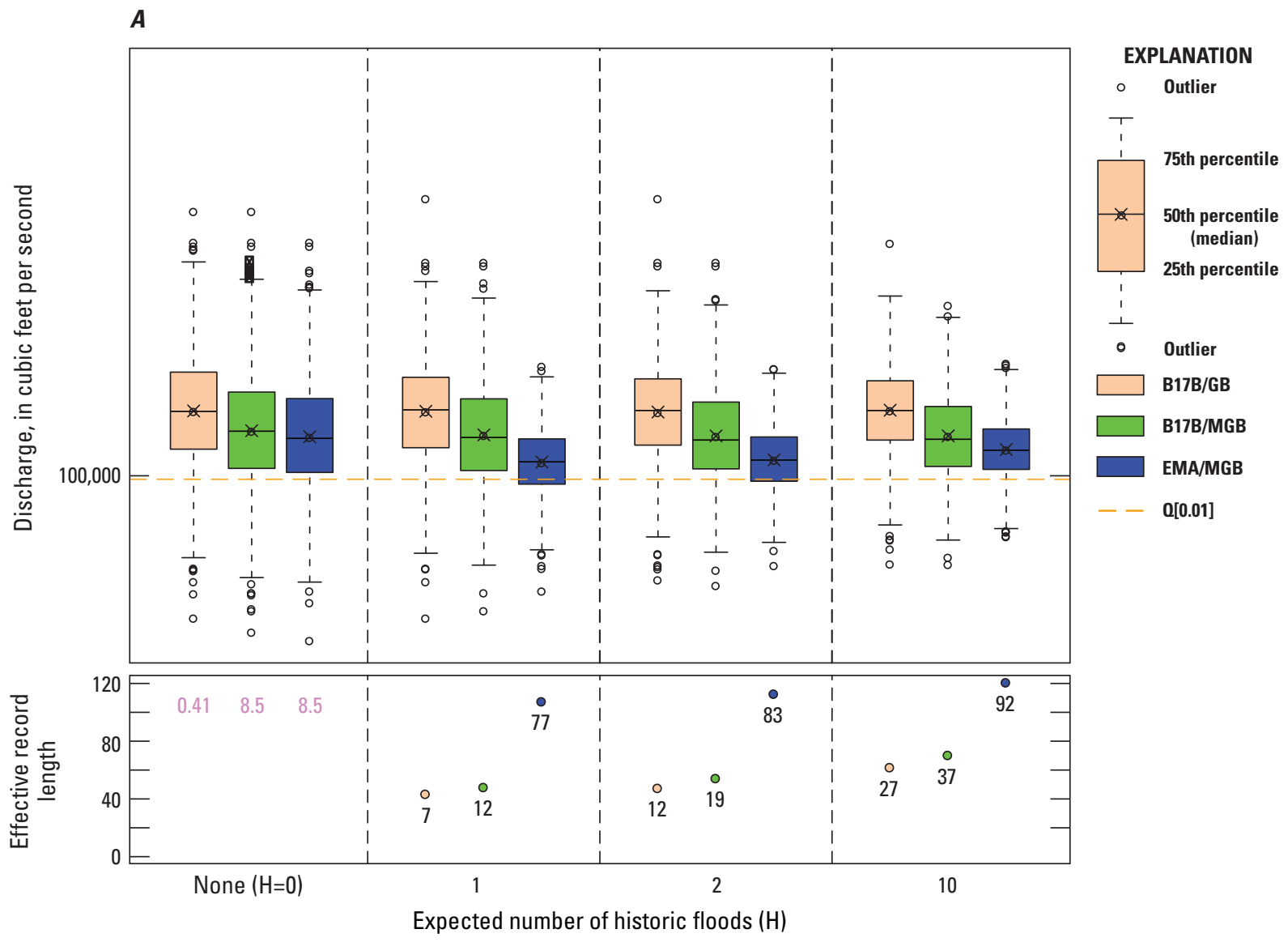

B

Frequency distribution

Robustness test curve 5

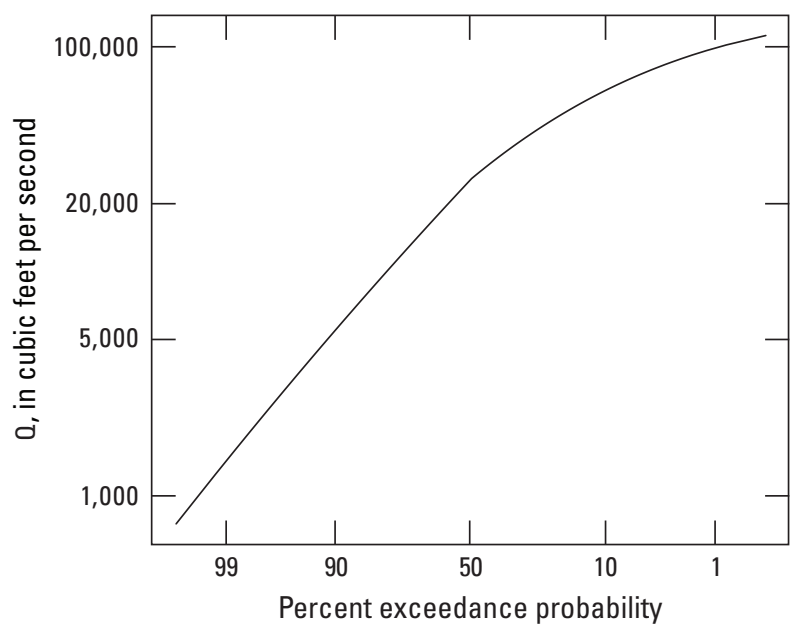

C

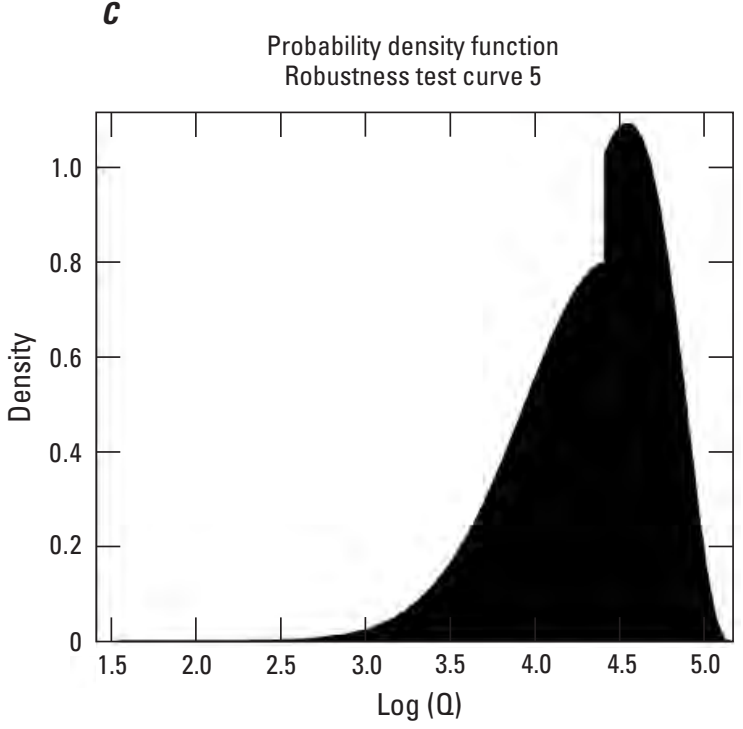

Figure 7. Monte Carlo results based on 10,000 replicate samples using systematic record, $N_{S}=40$, and historical record, $N_{H}=100$, drawn from robustness test curve 5 . Terms within graph are defined as follows: B17B/GB, Bulletin 17B/Grubbs-Beck; B17B/MGB, Bulletin 17B/multiple Grubbs-Beck; EMA/MGB, Expected Moments Algorithm/multiple Grubbs-Beck; G, skew; and $\mathrm{Q}[0.01]$, discharge for annual exceedance probability of 0.01 . 


\section{Evaluation of Recommended Revisions to Bulletin 17B}

The lower three quarters of the distribution function employs the second parameters, and the upper quarter is based on the first parameters. The distributions have the same upper quartile, which is where they join. As was seen in figure 7 and many other examples, when historical information is present, EMA/MGB performs much better than the other estimators.

\section{Examples Based on Real Data at Selected Test Sites}

\section{Eighty-two Example Test Sites}

Eighty-two USGS streamflow-gaging (streamgages) stations (listed in appendix 1) were selected by a subset of the HFAWG named the "Data Group." The types of data found at these sites are organized into four categories in this publication:

1. Systematic gage data, no historical data or PILFs (26 sites);

2. Historical data, possibly including high outliers (19 sites);

3. PILFs; no historical information (20 sites); and

4. PILFs, historical and (or) high outliers (17 sites).

These 82 sites include all of the sites used as examples in Bulletin 17B (B17B), which were also included in this study. Clearly, 82 sites is a limited sample of the many thousands of streamgage records throughout the Nation. However, the set is believed to cover the range of situations, and particularly the most difficult situations, that arise in practice.

The respective estimated frequency curves for the sites are presented graphically in appendix 2. Because we do not know the true frequency curve, judgments about the various estimates are necessarily subjective; graphs provide a convenient way to visualize the differences. The magnitude of observed differences, however, can be summarized in terms of a statistic, the RPD, defined as

$$
R P D \equiv 100\left(\frac{\hat{Q}_{p}^{E M A / M G B}-\hat{Q}_{p}^{B 17 B / *}}{\hat{Q}_{p}^{B 17 B / *}}\right)
$$

where $p$ corresponds to the quantile of interest and $B 17 B / *$ refers to $B 17 B / G B$ or $B 17 B / M G B$, respectively, depending on which estimators are being compared. Although the $R P D$ does not tell us which estimator is better, it does quantify the magnitude of observed differences between the estimators.

\section{Sites With Systematic Gage Data and No PILFs or Historical Information}

The first category, "Gage Only" data, included 26 sites. The sites have systematic data with no historical information, no below-gage-base floods, and no PILFs identified by either using the GB or MGB tests. Almost all RPDs were zero, as expected. In this case all of the estimators are, in theory, identical. Apparent differences between PEAKFQ/B17B and PeakfqSA results of less than 1 percent in RPD occur because PEAKFQ/B17B rounds quantile estimates to between two and three significant digits; PeakfqSA does no rounding. The estimated moments, which are not rounded, are identical in these cases. As can be seen in figure 9, however, there were two sites where, in fact, the RPD was not zero.

At site 02037500, James River near Richmond (fig. 2-5), the RPD ranged between 3 to 5 percent for the three quantiles. This was because the 1937 peak discharge was recorded with a qualification code indicating the discharge was greater than the reported 152,000 cubic feet per second (cfs) value. PEAKFQ/B17B, the USGS software that implements Bulletin 17B, by default omitted the 1937 peak. A user-supplied point discharge value of $152,000 \mathrm{cfs}$ was instead used to characterize the 1937 peak. This is a "known problem" with 


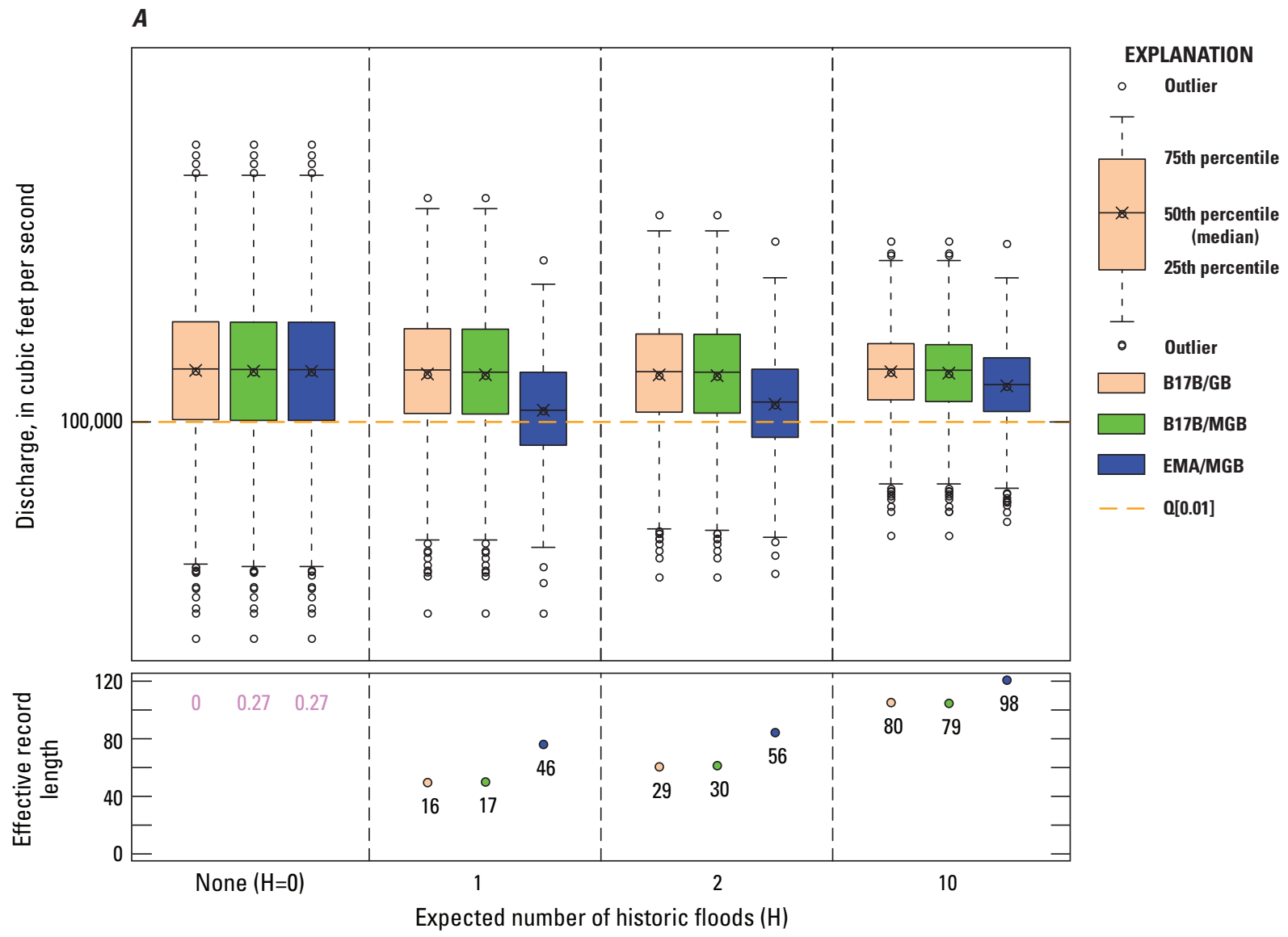

$\boldsymbol{B}$

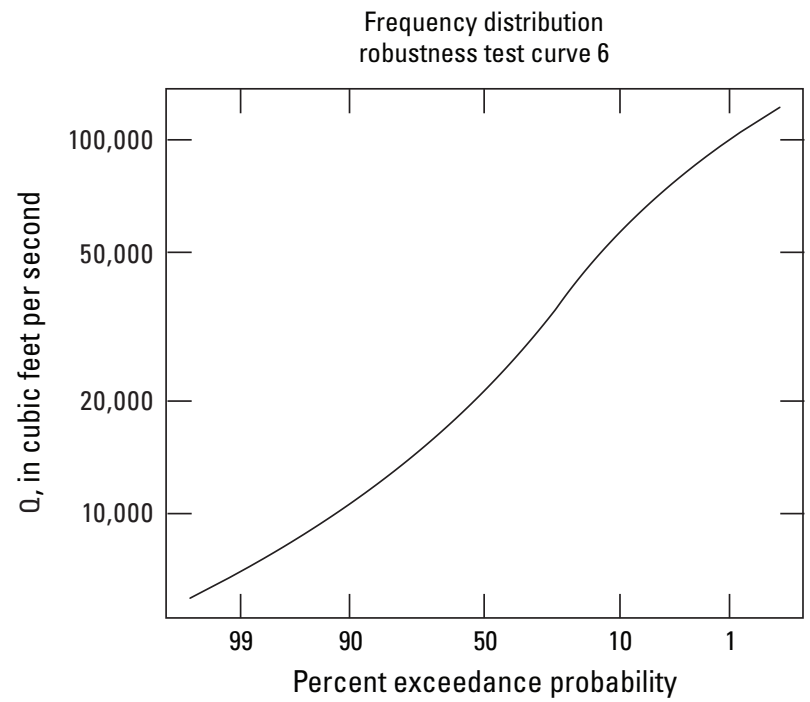

C

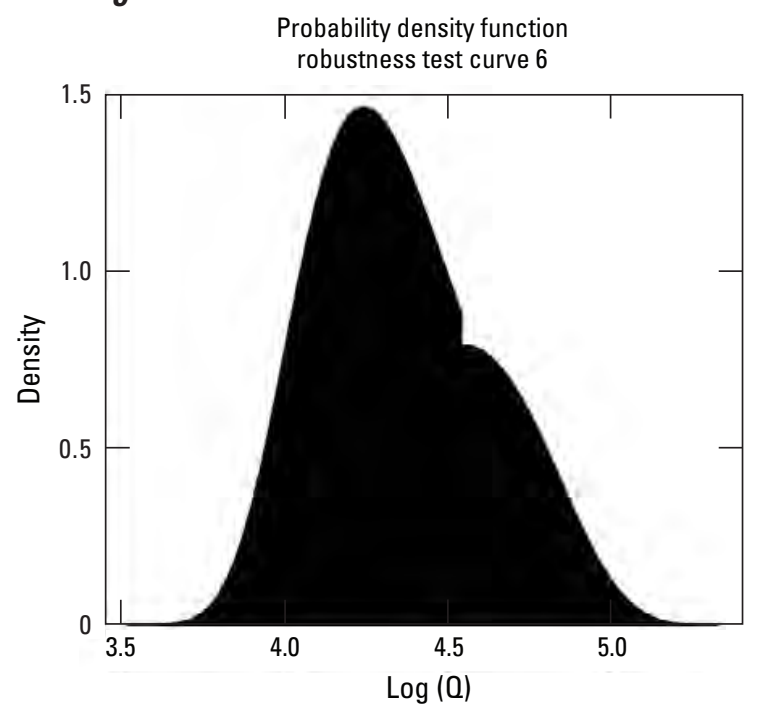

Figure 8. Monte Carlo results based on 10,000 replicate samples using systematic record, $N_{S}=40$, and historical record, $N_{H}=100$, drawn from robustness test curve 6 . Terms within graph are defined as follows: B17B/GB, Bulletin 17B/Grubbs-Beck; B17B/MGB, Bulletin 17B/multiple Grubbs-Beck; EMA/MGB, Expected Moments Algorithm/multiple Grubbs-Beck; G, skew; and $\mathrm{Q}[0.01]$, discharge for annual exceedance probability of 0.01 . 


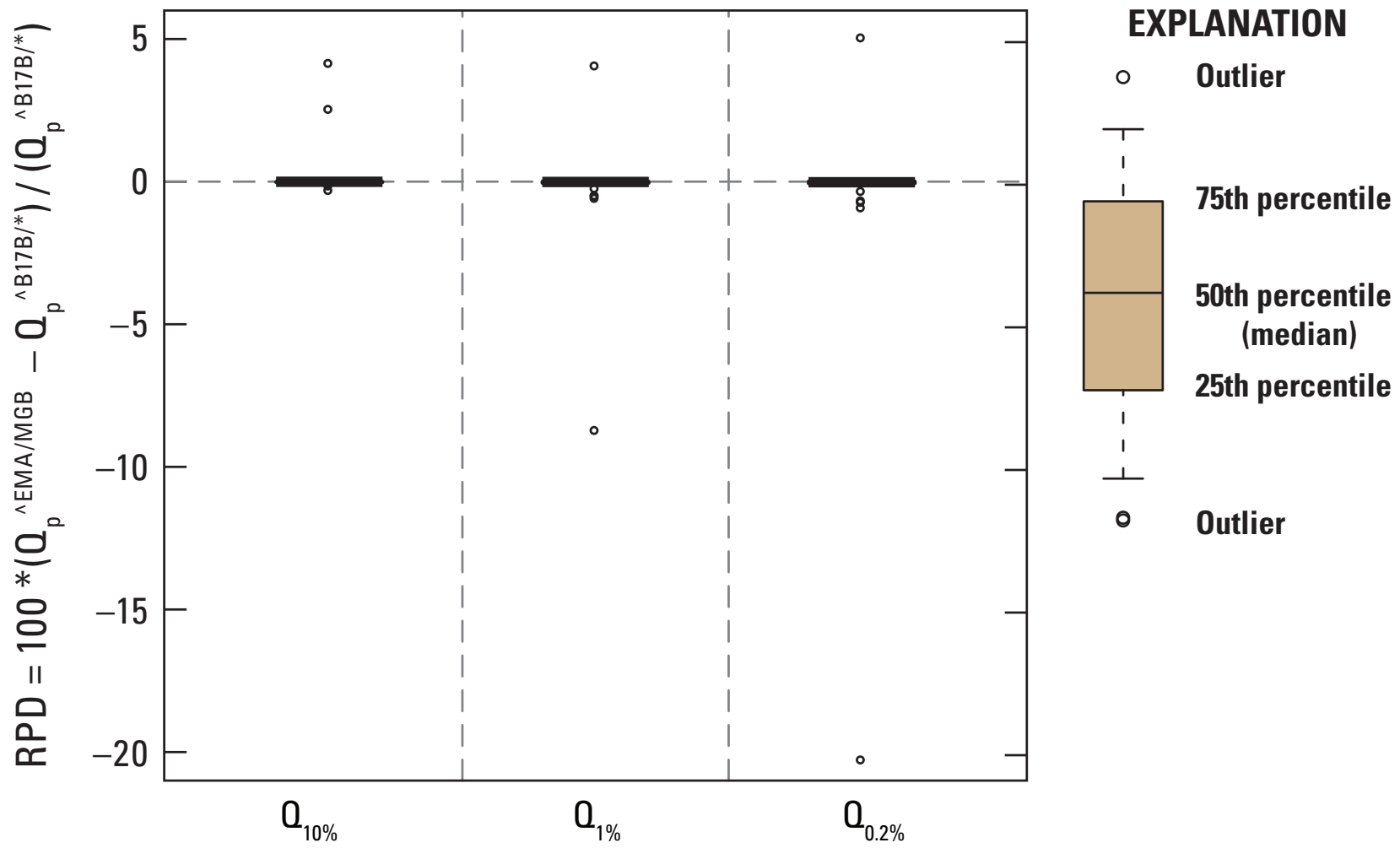

Annual exceedence probability, in percent

Figure 9. Relative percent difference (RPD) for Bulletin 17B/Grubbs-Beck (B17B/GB) and Expected Moments Algorithm/multiple Grubbs-Beck (EMA/MGB) estimators for 10-percent (\%), 1-\%, and 0.2-\% exceedance probabilities $\left(Q_{p}\right)$. Includes 26 sites without historical flood information where no potentially influential low floods were identified by either test. 
B17B, but it bears repeating: PEAKFQ/B17B is not well adapted to incorporating nonstandard discharge values; in some cases, the way it handles them is to ignore them altogether. As a result, the PEAKFQ/B17B estimates, which reflect B17B methods, do not properly employ the data.

The EMA, the alternative method, does accommodate interval data. Thus, the 1937 peak could be correctly described as inside an interval from $152,000 \mathrm{cfs}$ to infinity. This was used in the EMA analysis to capture the additional information associated with the 1937 peak. Because the EMA employs an interval range greater than 152,000 cfs for the large 1937 peak, the EMA estimated higher values for the upper portion of the frequency curve.

Site 05586500, Hurricane Creek near Roodhouse (fig. 2-8), had a similar problem. It showed a RPD range from 4 to -20 percent. The sixth lowest recorded discharge had a qualification code indicating the recorded value was less than $70 \mathrm{cfs}$. PEAKFQ/B17B employed a gage base at $70 \mathrm{cfs}$, consequently omitting five additional recorded point discharge values below $70 \mathrm{cfs}$. No PILFs were identified by either the GB or MGB test. Thus, PEAKFQ/B17B unnecessarily truncated a portion of the left hand tail due to the qualification code of one observation. A user-supplied interval discharge range from 0 to $70 \mathrm{cfs}$ was properly set in the EMA for that single water year, and the five recorded point discharges below $70 \mathrm{cfs}$ were included in the flood-frequency analysis. Because the EMA used all recorded discharges and the 0 to $70 \mathrm{cfs}$ censored data, the EMA's estimates were lower particularly at the upper end of the curve. In both cases where the estimates differed, it was because EMA can accommodate data properly that PEAKFQ/B17B cannot accommodate.

\section{Sites with Historical Information}

The testing for the "Historical Data" category included 19 sites, some of which included high outliers. The historical data sites illustrate a fundamental difference between the EMA and B17B (Stedinger and Cohn, 1986; England and others, 2003).

The EMA estimates and, therefore, the RPDs, are sensitive to the historic threshold and historical period employed. All attempts were made to manually enter the same values into both software programs. However, some adjustments were made to accommodate PEAKFQ/B17B's inability to use interval discharge ranges. Many sites had one to three recorded historic peaks that exceeded the historic threshold. A few sites had recorded gage heights at or near the record value with missing discharges. Interval discharge values were set in the EMA to accommodate these observations. As PEAKFQ/B17B has no corresponding capability, point discharge values were estimated by relating log-space discharge to log-space gage height for those years and these were entered into PEAKFQ/B17B with the use of similar historic thresholds. Additionally, as a default, PEAKFQ/B17B sets an historic threshold at the lowest recorded historic value for a user-specified historic period. Thus, all missing years of information in the historic record are effectively set to the lowest historic threshold. If a systematic record is missing any discharges (a broken systematic record) in a historical period, the missing data is set to the same historic threshold. This is not the case if there is missing data in a purely systematic record. PEAKFQ/B17B will operate under the assumption that no information is known about those missing years of systematic record.

Overall, the majority of sites with historical information showed a positive RPD in the flood estimates (fig. 10). The interquartile distances ranged from approximately 0 to 10 percent for $\hat{Q}_{1 \%}$. Three sites had higher RPD for $\hat{Q}_{1 \%}$, ranging from 11 to 37 percent. The EMA and B17B provide substantially different estimates for these three sites, all of which include historical information and high outliers. Site 06216500, Pryor Creek near Billings, Montana, had one large flood that was the largest in an extended historical period of 99 years. Figure 11 shows the frequency plots for both B17B and the EMA. Based on visual inspection of the frequency curves, the EMA seems to provide a better fit to the data, most clearly to the high outlier in the righthand tail. 


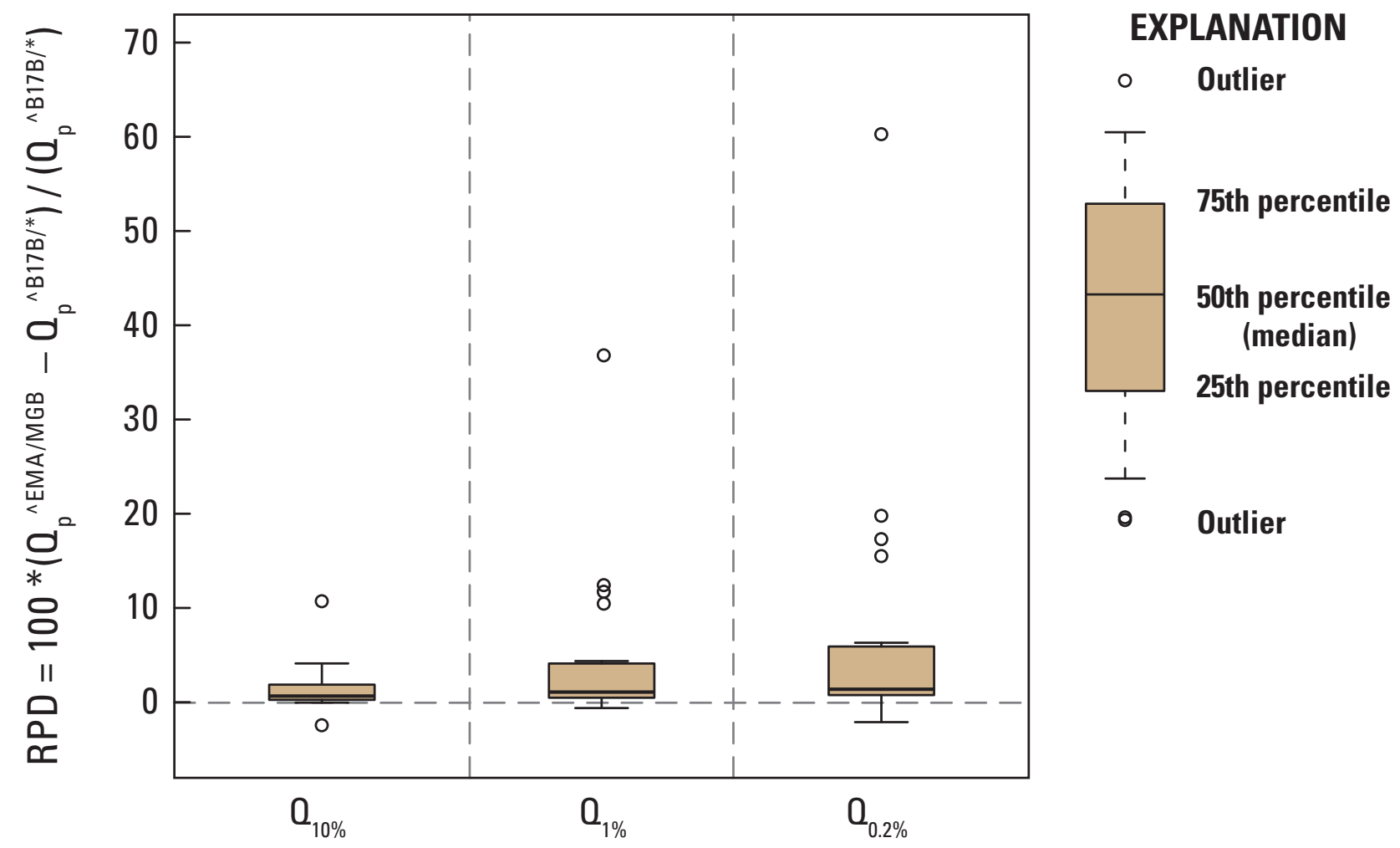

Annual exceedence probability, in percent

Figure 10. Relative percent difference (RPD) for Bulletin 17B/Grubbs-Beck (B17B/GB) and Expected Moments Algorithm/multiple Grubbs-Beck (EMA/MGB) estimators for 10-percent (\%), 1-\%, and 0.2-\% exceedance probabilities $\left(Q_{p}\right)$. Figure represents 19 sites with historical information where no potentially influential low floods were identified by either GB test. 


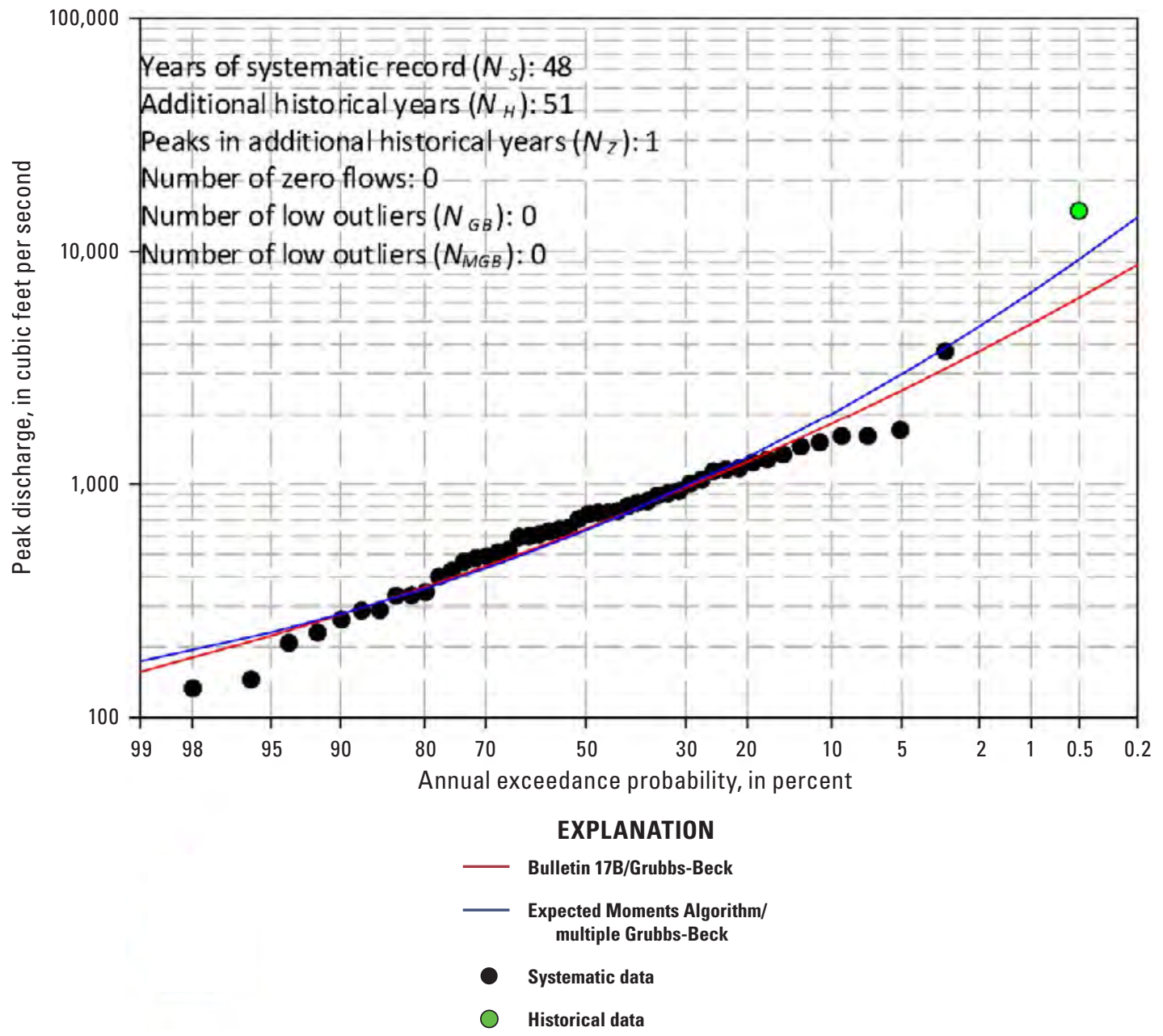

Figure 11. Pryor Creek near Billings, Montana (06216500). 


\section{Evaluation of Recommended Revisions to Bulletin 17B}

\section{Sites with Systematic Gage Data and Potentially Influential Low Floods}

The testing for the PILFs category utilized 20 sites with PILFs identified using either the standard GB test recommended by B17B or the MGBT (Cohn and others, 2013). These sites did not include historic data. Two sets of comparisons were made between the results of EMA/MGB as follows:

1. B17B using the GB test followed by the CPA (B17B/GB); and

2. B17B using the MGB PILF threshold followed by the CPA (B17B/MGB).

Current PEAKFQ/B17B software does not include a MGB test option, so, where needed, the MGB threshold was computed independently and then entered into PEAKFQ as a user-supplied threshold.

The systematic flood series for site 08133500, North Concho River at Sterling City, Texas (fig. 2-51), included three peaks with a qualification code indicating the discharge was less than the reported value of 300 cfs. As discussed in the systematic "Gage Only" section (Sites With Systematic Gage Data and No PILFs or Historical Information), PEAKFQ/B17B arbitrarily set a gage base for the entire record, in this case omitting an additional 17 systematic point discharges less than $300 \mathrm{cfs}$ that did not have remark codes. In the EMA, the three peaks were recoded as between 0 and $300 \mathrm{cfs}$. However, the MGB test identified a PILF threshold of 634 cfs. Thus, EMA/MGB identified 23 PILFs and B17B/GB (with a default-set gage base of $300 \mathrm{cfs}$ ) identified 20 PILFs. The result is that the estimated flood quantiles do not differ by very much.

Flood estimate comparisons between EMA/MGB and B17B/GB for figure 12 show the median RPD is essentially zero. However, the RPD has substantial variability, indicating that the B17B/GB and EMA/MGB estimators behave differently when PILFs are present. This increased variability in RPD is attributed to the very different number of PILFs identified in the flood series and the methods used to handle PILFs in the frequency analysis (that is, the EMA's PILF censoring versus B17B's CPA). Of the 20 sites in this PILF category, the GB test found only 0 to 2 low outliers per site above gage base, while the MGB test found 1 to 46 PILFs

(fig. 13). At some sites, the MGB identified nearly 50 percent of the recorded floods (fig. 14) as PILFs. This is the upper bound on the percentage of peaks that MGB will test and designate as PILFs.

The observed RPDs were both positive and negative, a result of complex interactions between different PILF tests and different fitting procedures. However, use of the EMA/MGB method seems to produce a better fit to the upper portion of the frequency curve than is obtained with B17B/GB.

Orestimba Creek near Newman, California (site 11274500, fig. 15), which is also presented in B17B, represents an extreme case of PILFs - a flood series of 79 years, including 11 zero floods. The LP3 distribution cannot describe the full range of observed flood flows at this site because the support for the LP3 distribution vanishes for $Q \leq 0$ (Cohn and others, 2013). PEAKFQ/B17B treats all zero flows as below gage base, while the EMA regards them as PILFs.

The Grubbs-Beck (GB) test yields a low-outlier threshold of $10.8 \mathrm{cfs}$ and identification of a single additional low outlier. The MGB test, in contrast, yields a PILF threshold of $782 \mathrm{cfs}$, identifying 29 peaks, or 37 percent of the data, as PILFs. The RPD between EMA/MGB and B17B/GB ranges from 9 percent to 21 percent for the 1-percent and 0.2-percent exceedance probability estimates, respectively (fig. 15).

It is interesting to note that $\mathrm{B} 17 \mathrm{~B} / \mathrm{MGB}$, while close to EMA/MGB in this case, provides a different and much poorer fit to the data, as can be seen in figure 15. The B17B/MGB curve lies above the data for exceedance probabilities between 40 and 50 percent, and below the data for exceedance probabilities between 10 and 40 percent. Above the 10-percent level, the B17B/MGB curve rises more sharply than the EMA/MGB curve, which appears to match the concave downward trend in the data.

The pattern seen at Orestimba is also observed at other sites with multiple PILFs. For example, at Santa Cruz River near Lochiel, Arizona (09480000, fig. 16), one sees that EMA/MGB, by treating the influential small peaks as PILFs, results in a reasonably close fit in the right-hand tail. On the other hand, the B17B/GB estimator generates a frequency curve that is greatly exceeded by two of the sample values. 


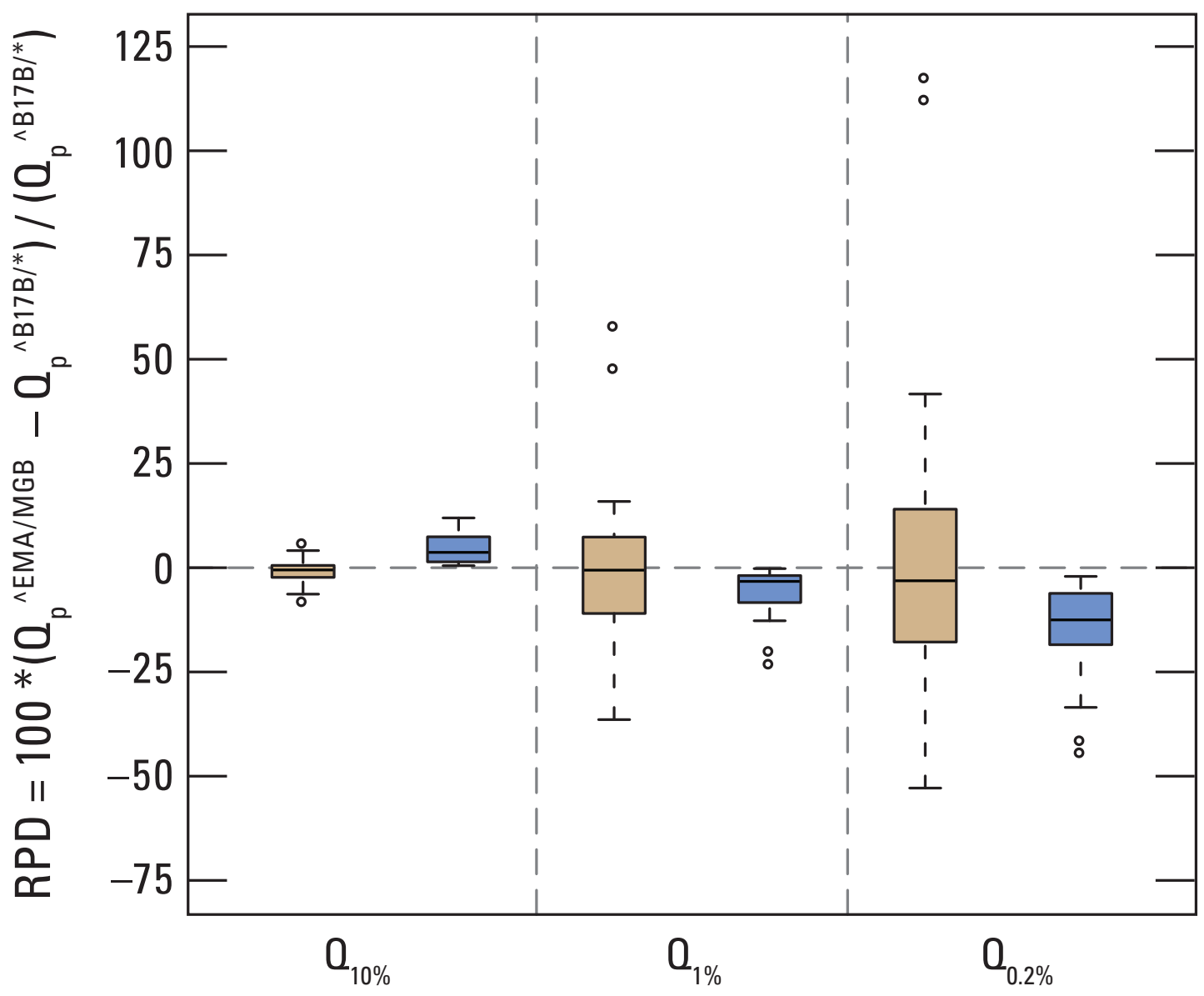

Annual exceedence probability, in percent

\section{EXPLANATION}

- Outlier

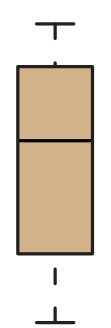

75th percentile

50th percentile

(median)

25th percentile

- Outlier

\section{Bulletin 17B/Grubbs-Beck}

\section{Bulletin 17B/multiple Grubbs-Beck}

Figure 12. Relative percent difference (RPD) for Bulletin 17B/Grubbs-Beck (B17B/GB), Bulletin 17B/multiple Grubbs Beck (B17B/MGB), and Expected Moments Algorithm/multiple Grubbs-Beck (EMA/MGB) estimators for 10-percent (\%), 1-\%, and 0.2$\%$ exceedance probabilities $\left(Q_{p}\right)$. The figure represents 20 sites where potentially influential low floods were identified by $\mathrm{GB}$ or MGB tests, and with no historical information. 


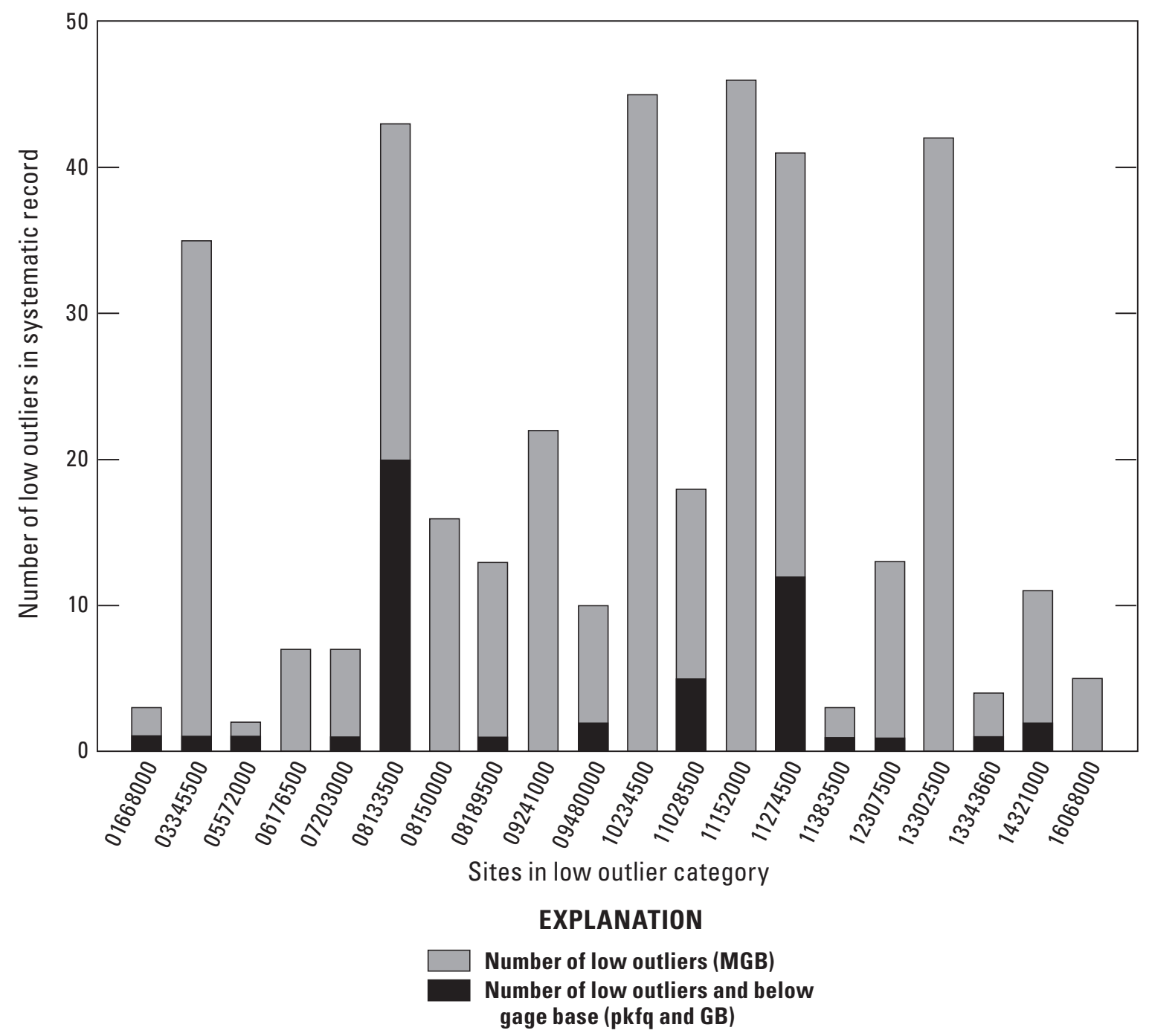

Figure 13. Number of floods identified as potentially influential low floods or below gage base using the standard Grubbs-Beck (GB) and multiple Grubbs-Beck (MGB) tests. Figure represents 20 sites without historical information. 


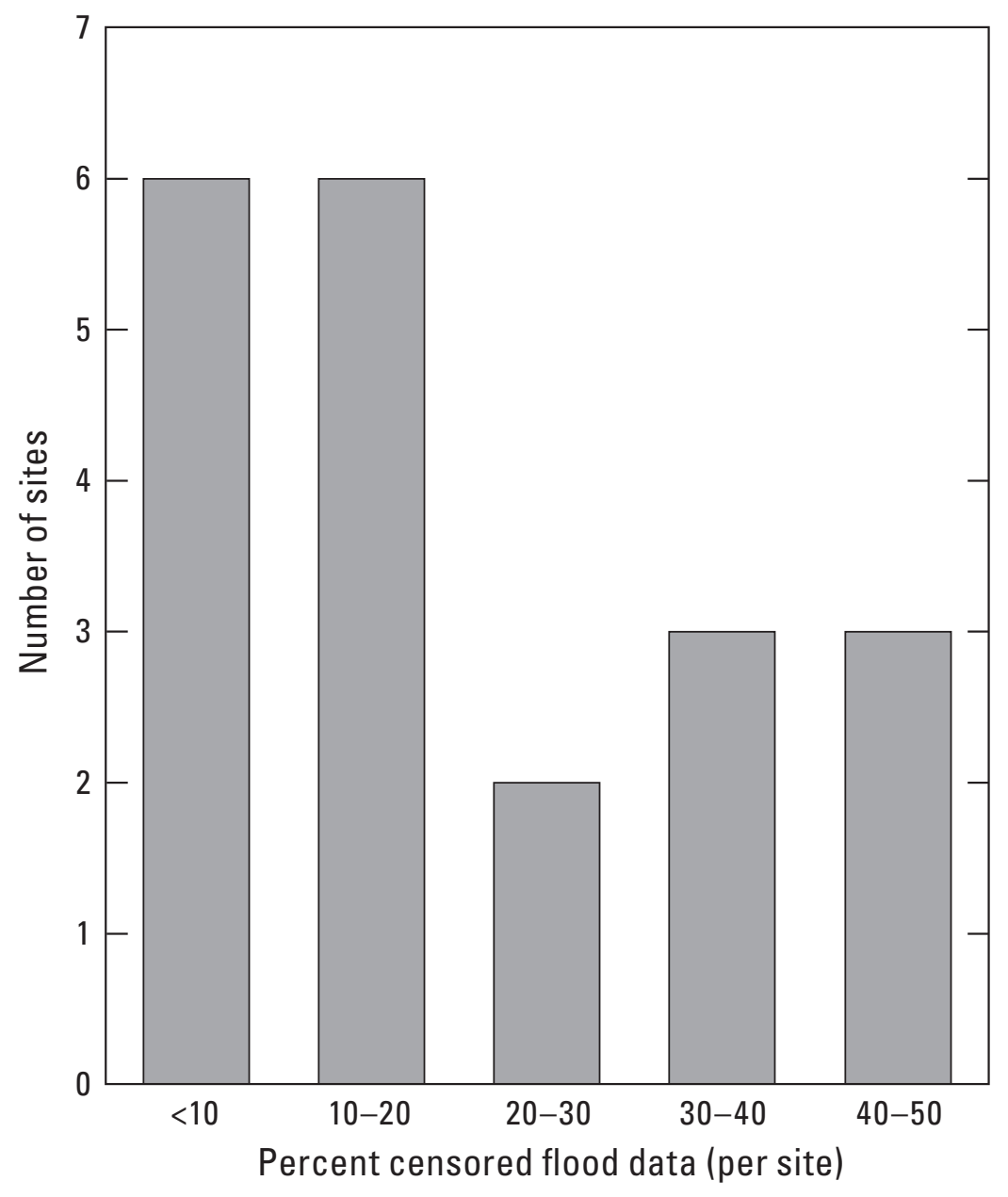

Figure 14. Percent potentially influential low floods identified using the multiple Grubbs-Beck test. Figure represents 20 sites without historical information. 


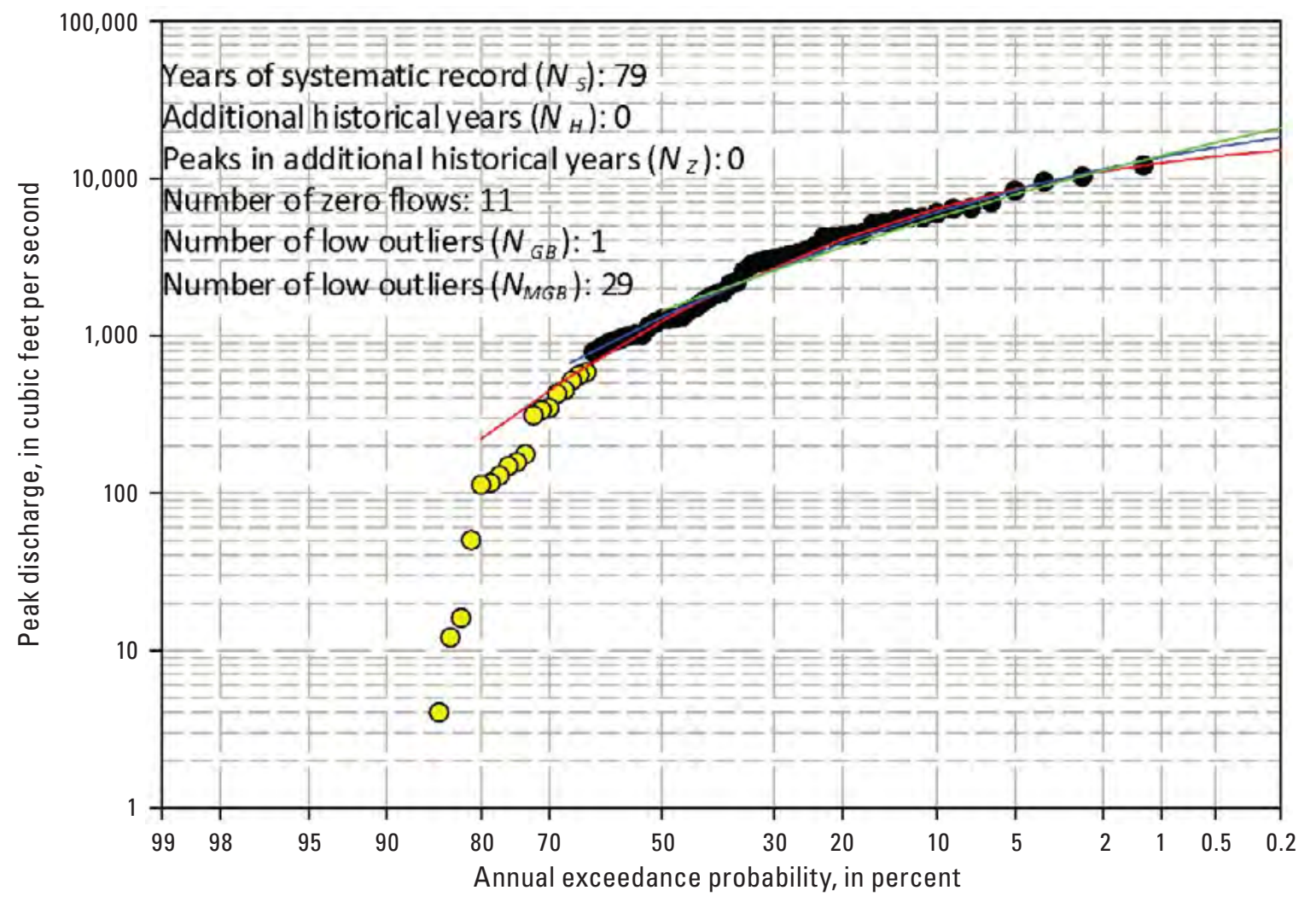

EXPLANATION

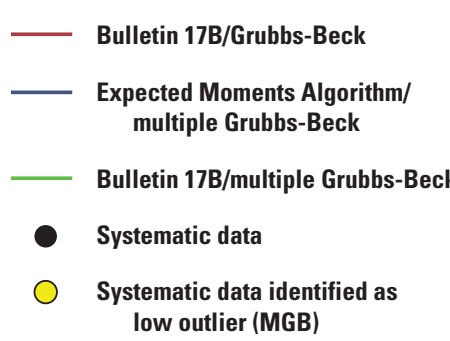

Figure 15. Orestimba Creek near Newman, California (11274500), fit after application of the multiple Grubbs-Beck (MGB) test to identify potentially influential low floods. 


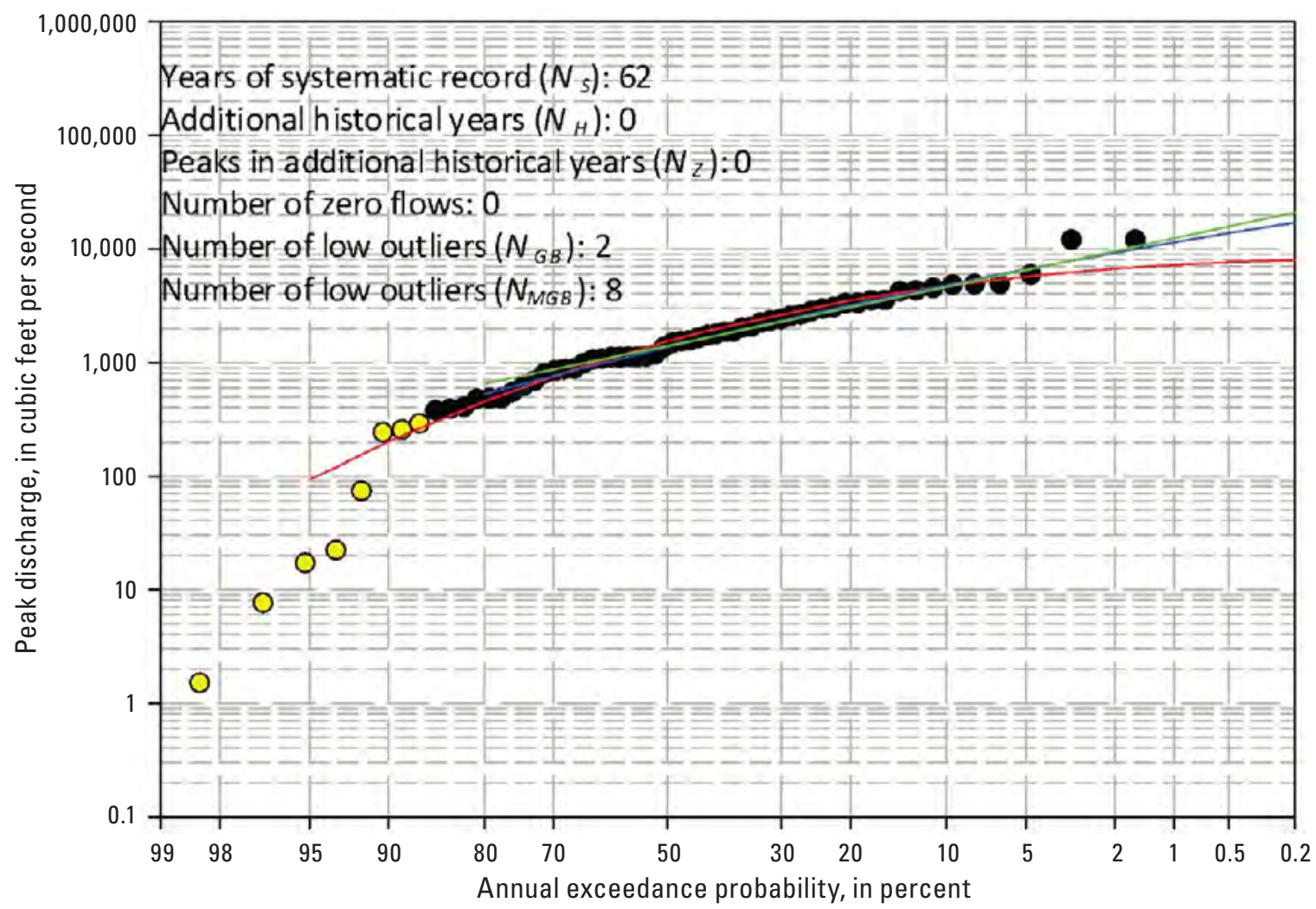

EXPLANATION

__ Bulletin 17B/Grubbs-Beck

Expected Moments Algorithm/ multiple Grubbs-Beck

Bulletin 17B/multiple Grubbs-Beck

- Systematic data

Systematic data identified as

low outlier (MGB)

Figure 16. Santa Cruz River near Lochiel, Arizona (09480000). 


\section{Evaluation of Recommended Revisions to Bulletin 17B}

\section{Sites With Potentially Influential Low Floods, Historical Information, and (or) High Outliers}

Seventeen of the 82 sites included the combination "PILFs, historical information and (or) high outlier." This category contains sites whose flood series have PILFs and also the following:

1. High outliers in a systematic record, or

2. High outliers in a historical period.

Nothing fundamentally new appeared in these cases. The RPD between EMA/MGB and B17B/GB are similar to those found in both the "PILF" and "Historical" categories. The median RPD for the $Q_{10 \%}$ estimates remained near zero, while the median RPD were slightly positive for the $Q_{1 \%}$ and $Q_{0.2 \%}$ estimates (fig. 17). About one-third of the sites in this category showed a RPD greater than 15 percent for the 0.2-percent estimates and three sites were less than 18 percent. The largest RPD between EMA/MGB and B17B/GB was found at site 11176000, Arroyo Mocho near Livermore, California. The RPDs for the estimates were between -48 and -68 percent, for the $Q_{1 \%}$ and $Q_{0.2 \%}$, respectively. EMA/MGB found 19 PILFs in the systematic record (fig. 18) while B17B/GB found only one PILF above gage base. Additionally, one historic peak was recorded in the flood series. By censoring multiple PILFs, EMA/MGB more accurately fit the right-hand tail.

A large positive RPD between EMA/MGB and B17B/GB was found at site 06062500, Tenmile Creek near Rimini, Montana. A 10-percent and 19-percent RPD difference was found for the $Q_{1 \%}$ and the $Q_{0.2 \%}$ estimates, respectively. EMA/MGB found two PILFs, while B17B/GB found none (fig. 19). Here, the EMA seems to provide a fit that is more consistent with the trends exhibited by the largest seven observations.

Figures 18 and 19 illustrate an important point—both B17B/GB and EMA/MGB often provide a good fit to the data they employ. However, B17B/GB can be highly influenced by PILFs with the result being a poor fit at the high end of the distribution. EMA/MGB, on the other hand, avoids this problem by identifying and recoding PILFs so that their exact magnitudes do not distort the fit in the right-hand tail.

The RPD between EMA/MGB and B17B/MGB, when a flood series has both PILFs and high outlier data, is similar to that found when only PILFs are present. The median value and interquartile range for the estimates in the "combination category" were slightly positive, while the median values and interquartile ranges for the estimates in the "PILF" category were slightly negative. As expected, the variance in the RPD was minimized for all estimates when the same PILF threshold was used. The higher estimate from B17B/MGB is illustrated by figure 18 (site 11176000, Arroyo Mocho near Livermore, California) where a -21-percent RPD difference for the $Q_{1} \%$ was found. The MGB PILF threshold of $106 \mathrm{cfs}$ was used in B17B/MGB. The MGB test identified almost 33 percent of the peaks as PILFs. Using the same MGB test, based on visual inspection, EMA/MGB and B17B/MGB both show an improved fit versus B17B/GB.

\section{Resampling Studies}

Figures 20-24 depict results from applying the three estimators-B17B/GB, B17B/MGB, and EMA/MGB - to resampled data from five of the longest-record ( $>100$ observations) sites among the 82 "test" sites considered in section Eighty-two Example Test Sites. In these cases, we do not know what the true value of the 1-percent exceedance event is, so the figures instead employ an interpolated value based on the two largest observations in the dataset. However, this is an unreliable estimator; as noted in the section Summary, many of the "test" sites were selected specifically because they contained high outliers. In reviewing figures 20-24, it is likely best to use one's judgment about the reasonableness of the results, possibly referring back to the test-site results, rather than trying to conjure up a strict quantitative assessment. However, it is noteworthy that, when historical information is present, the EMA/MGB estimator generally outperforms the other estimators in terms of ERL, with site 03011020 in figure 20 being an exception. 


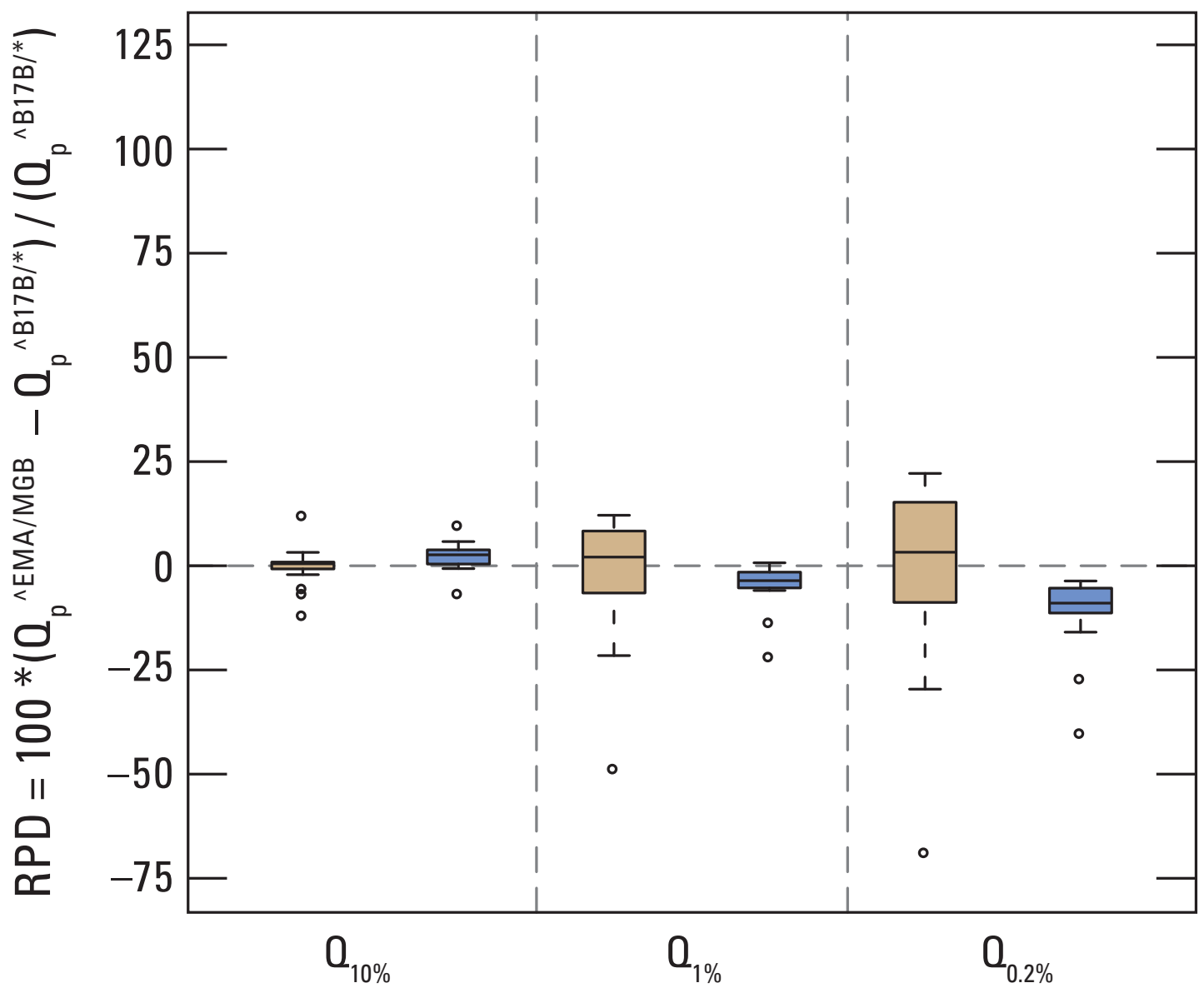

Annual exceedence probability, in percent

\section{EXPLANATION}

- Outlier

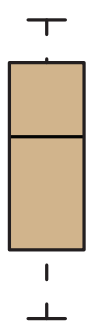

75th percentile

50th percentile

(median)

25th percentile

$\perp$

- Outlier

$\square$ Bulletin 17B/Grubbs-Beck

\section{$\square$ Bulletin 17B/multiple Grubbs-Beck}

Figure 17. Relative percent difference (RPD) for Bulletin 17B/Grubbs Beck (B17B/GB), Bulletin 17B/multiple Grubbs Beck (B17B/MGB), and Expected Moments Algorithm/multiple Grubbs Beck (EMA/MGB) estimators for 10-percent (\%), 1-\%, and 0.2$\%$ exceedance probabilities $\left(Q_{p}\right)$. Represents 17 sites with historical flood information where potentially influential low floods were identified by the GB or MGB test. 


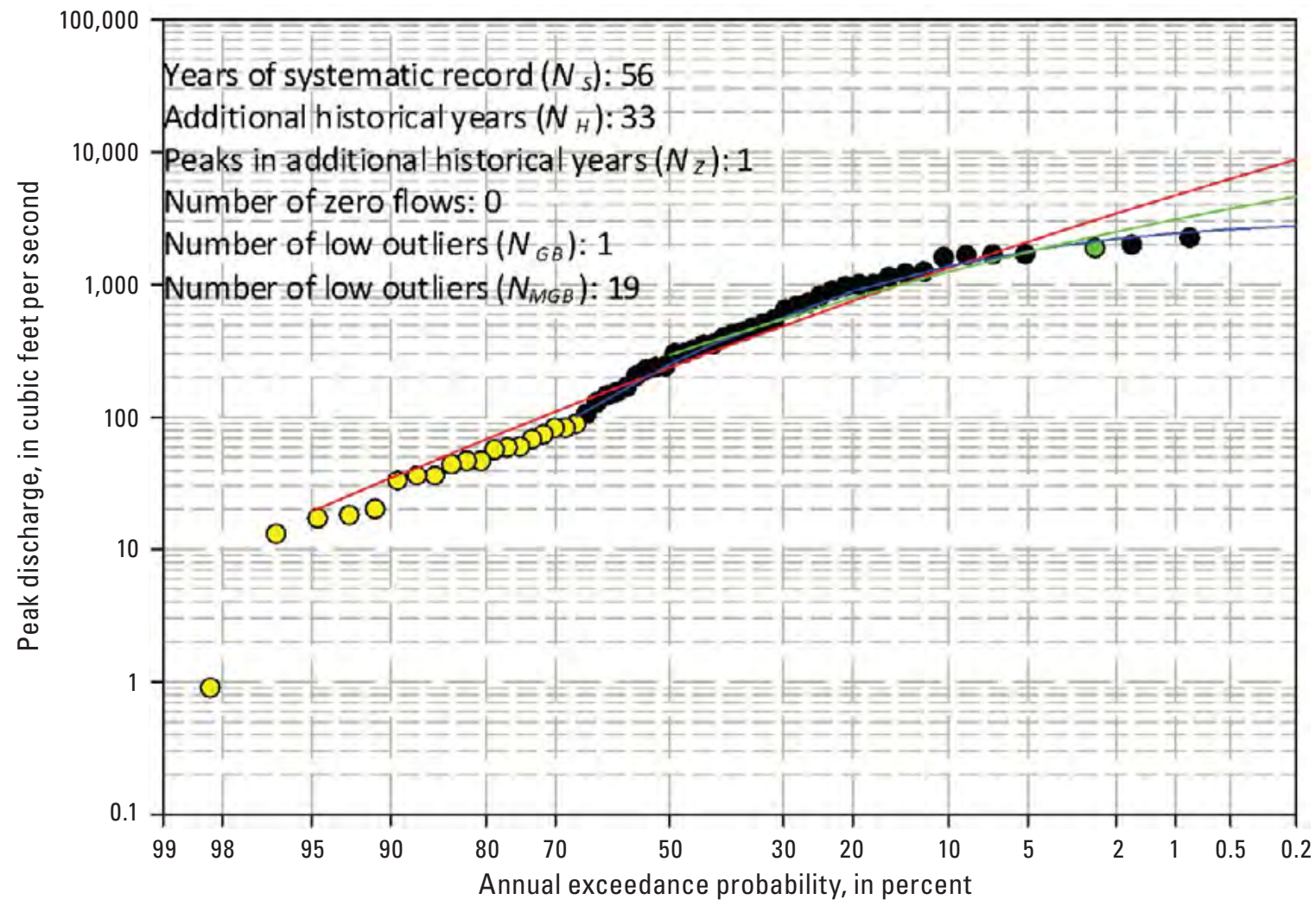

EXPLANATION

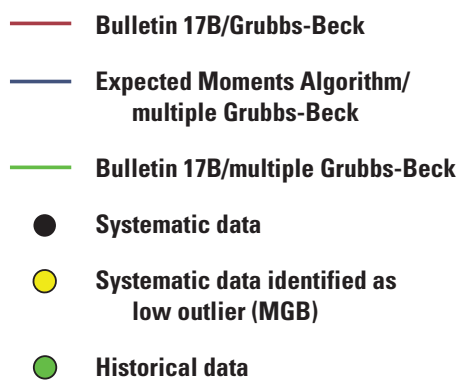

Figure 18. Arroyo Mocho near Livermore, California (11176000). 


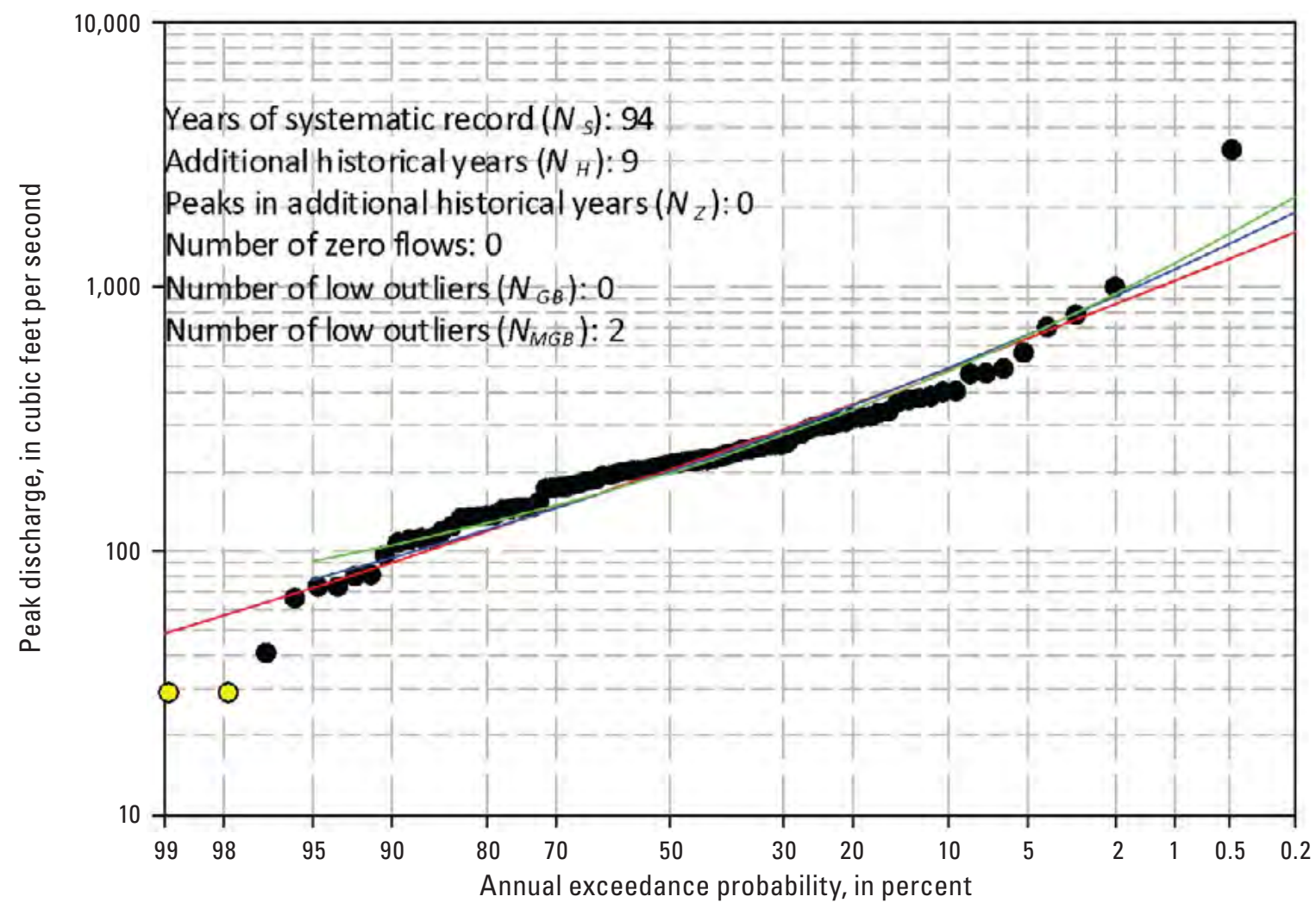

EXPLANATION

Bulletin 17B/Grubbs-Beck

Expected Moments Algorithm/ multiple Grubbs-Beck

- Systematic data

$\bigcirc$ Systematic data identified as

low outlier (MGB)

Figure 19. Tenmile Creek near Rimini, Montana (06062500). 


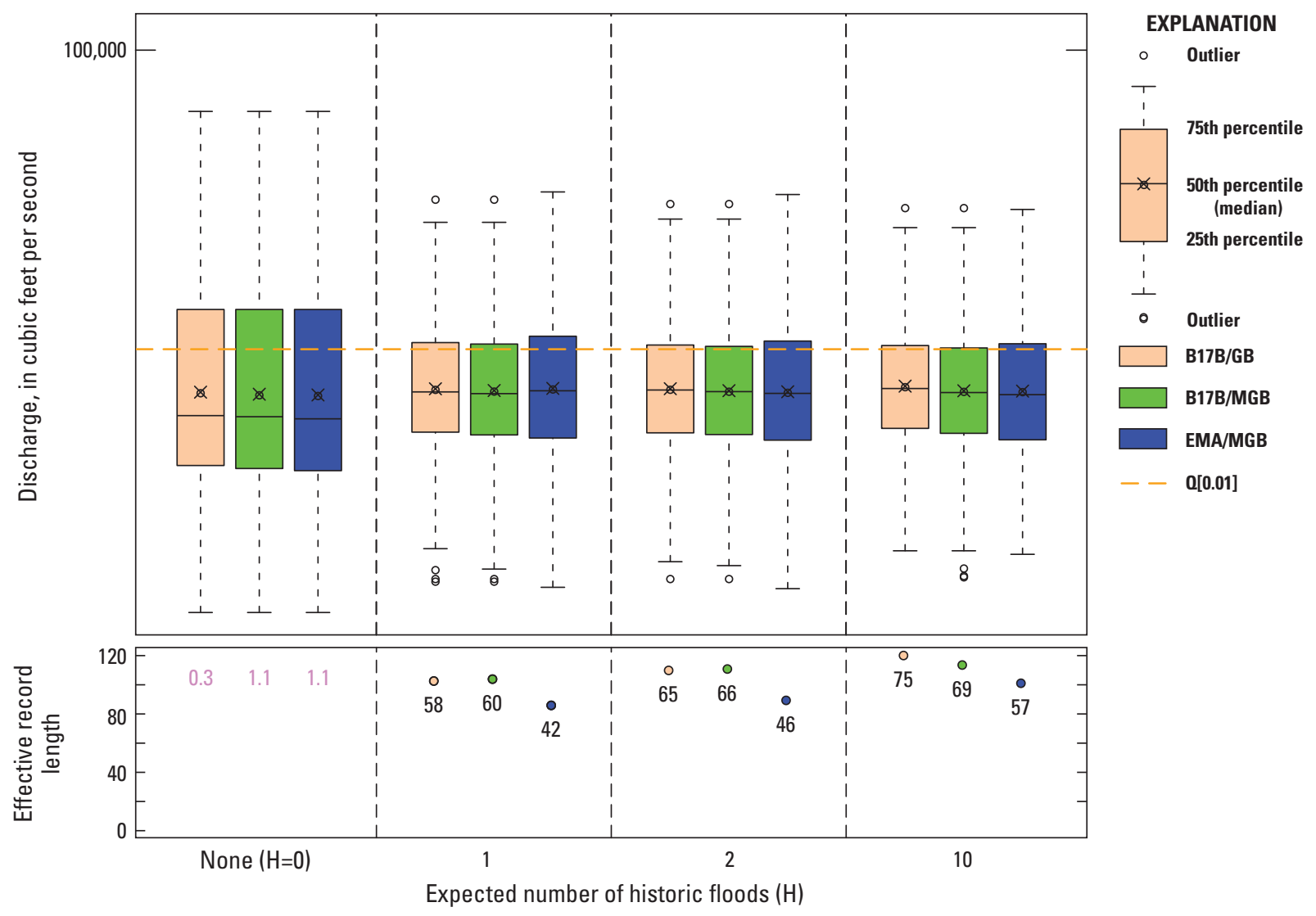

Figure 20. Results based on resampled data using systematic record, $N_{S}=40$, and historical record, $N_{H}=100$, drawn from observed discharges at "Historical" category site 03011020. Terms within graph are defined as follows: B17B/GB, Bulletin 17B/Grubbs-Beck; B17B/MGB, Bulletin 17B/multiple Grubbs-Beck; EMA/MGB, Expected Moments Algorithm/multiple GrubbsBeck; G, skew; and $\mathrm{Q}[0.01]$, discharge for annual exceedance probability of 0.01 . 


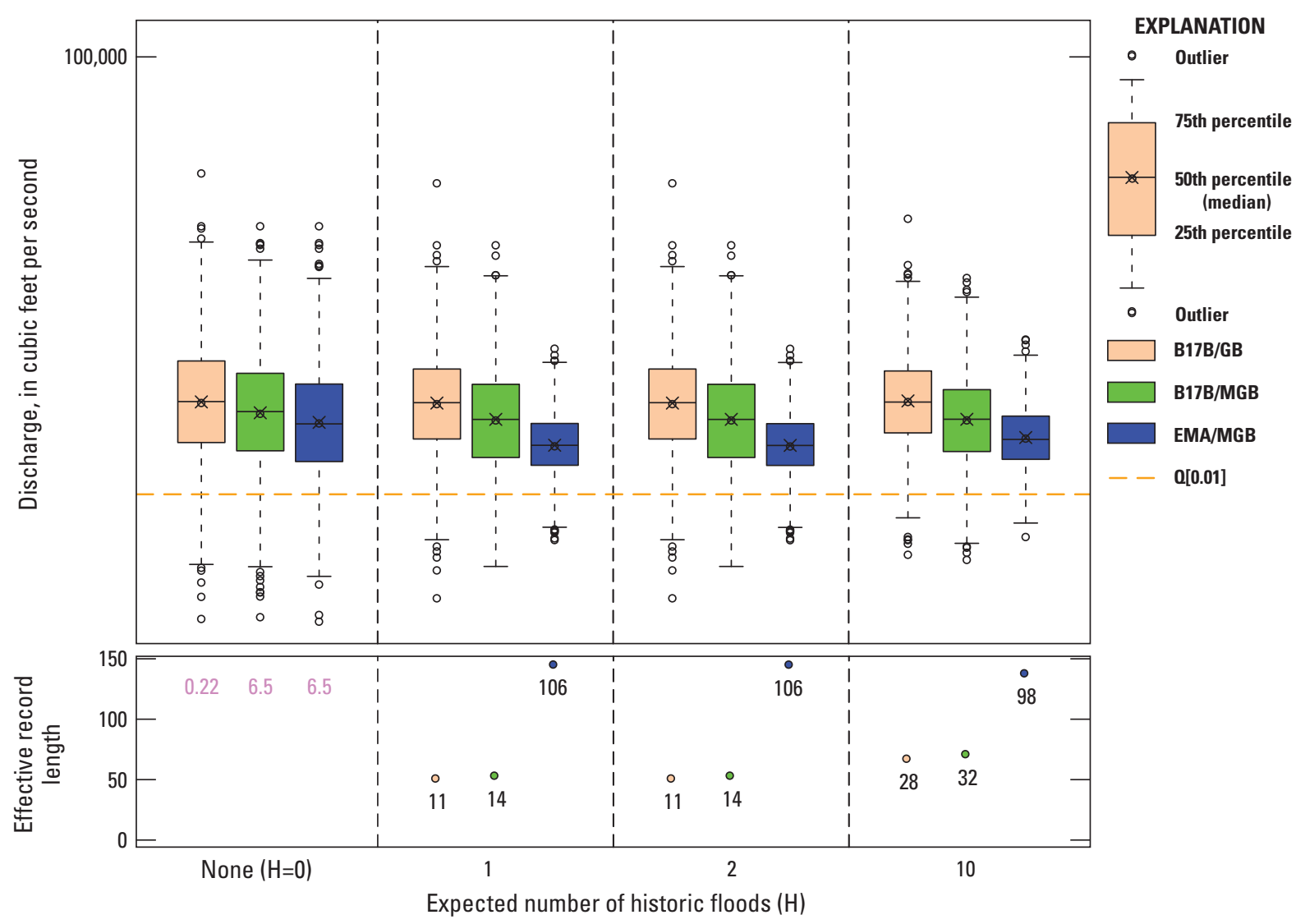

Figure 21. Results based on resampled data using systematic record, $N_{S}=40$, and historical record, $N_{H}=100$, drawn from observed discharges at "potentially influential low flood" category site 11152000. Terms within graph are defined as follows: B17B/GB, Bulletin 17B/Grubbs-Beck; B17B/MGB, Bulletin 17B/multiple Grubbs-Beck; EMA/MGB, Expected Moments Algorithm/multiple Grubbs-Beck; G, skew; $0[0.01]$, discharge for annual exceedance probability of 0.01 ) . 


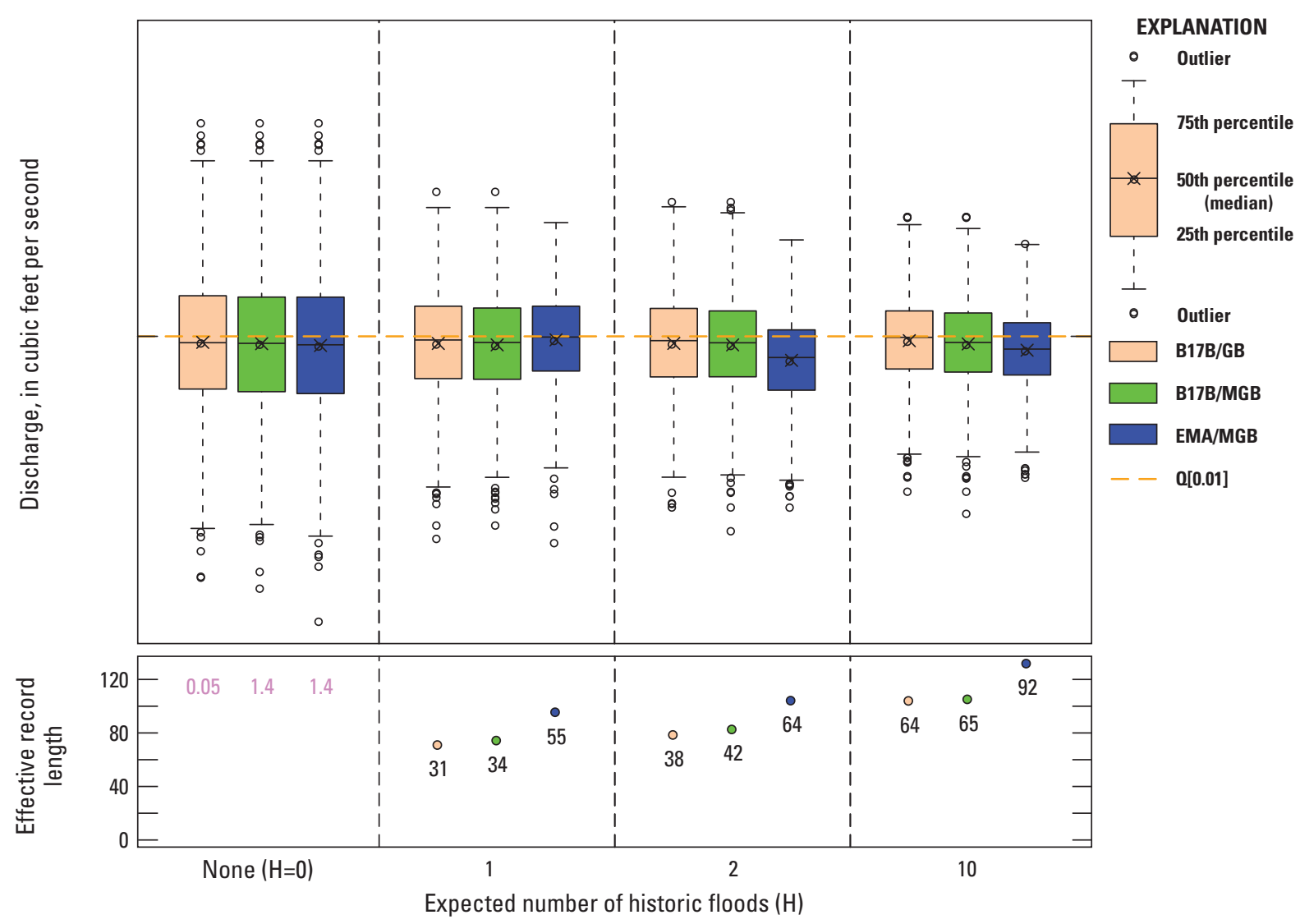

Figure 22. Results based on resampled data using systematic record, $N_{S}=40$, and historical record, $N_{H}=100$, drawn from observed discharges at "Gage Only" category site 14048000. Terms within graph are defined as follows: B17B/GB, Bulletin 17B/Grubbs-Beck; B17B/MGB, Bulletin 17B/multiple Grubbs-Beck; EMA/MGB, Expected Moments Algorithm/multiple GrubbsBeck; G, skew; and $\mathrm{Q}[0.01]$, discharge for annual exceedance probability of 0.01 . 


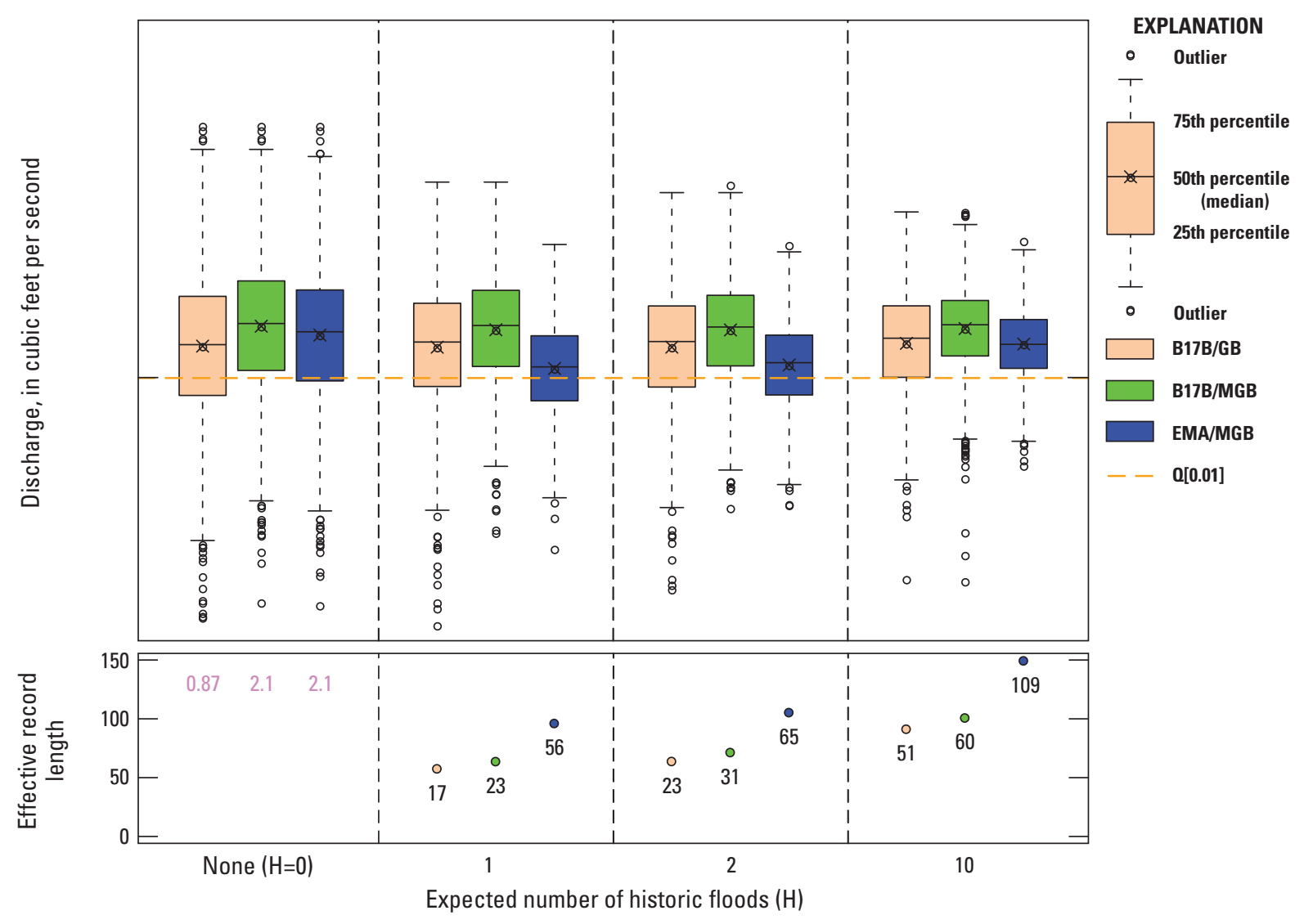

Figure 23. Results based on resampled data using systematic record, $N_{S}=40$, and historical record, $N_{H}=100$, drawn from observed discharges at "potentially influential low flood" category site 14321000. Terms within graph are defined as follows: B17B/GB, Bulletin 17B/Grubbs-Beck; B17B/MGB, Bulletin 17B/multiple Grubbs-Beck; EMA/MGB, Expected Moments Algorithm/multiple Grubbs-Beck; G, skew; and $0[0.01]$, discharge for annual exceedance probability of 0.01 . 


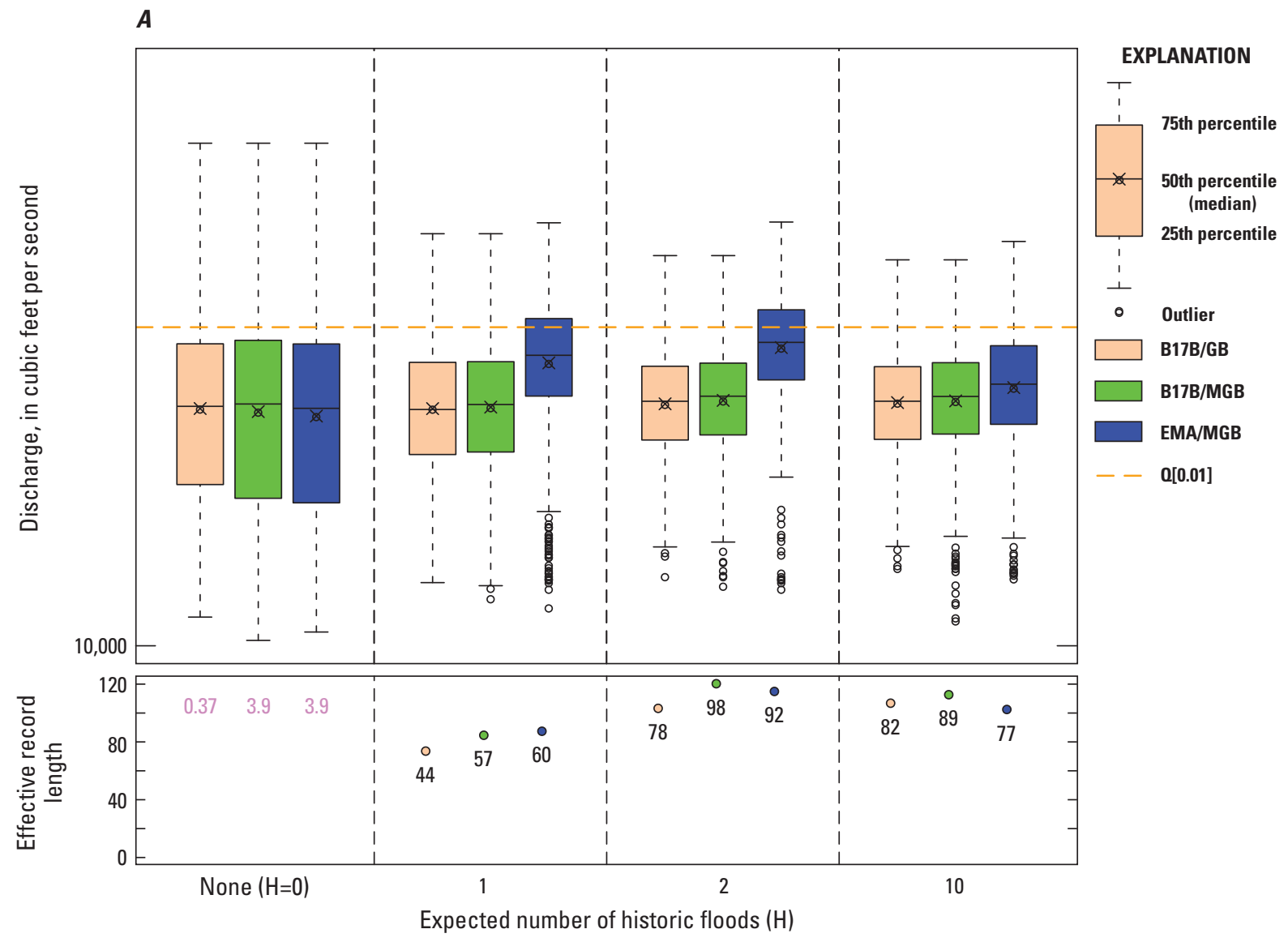

Figure 24. Results based on resampled data using systematic record, $N_{S}=40$, and historical record, $N_{H}=100$, drawn from observed discharges at "Combination" category site 13185000. Terms within graph are defined as follows: B17B/GB, Bulletin 17B/Grubbs-Beck; B17B/MGB, Bulletin 17B/multiple Grubbs-Beck; EMA/MGB, Expected Moments Algorithm/multiple GrubbsBeck; G, skew; and $\mathrm{Q}[0.01]$, discharge for annual exceedance probability of 0.01 . 


\section{Summary}

Eighty-two streamflow-gaging stations were chosen as a representative sample of long-term sites, where flood series include a variety of situations and problems that are believed to be found throughout the United States. The flood data were divided into four categories:

1. Systematic gage data, and no PILFs or historical information,

2. Historical and (or) high outliers,

3. PILFs, and

4. PILFs with historical and (or) high outliers.

The performances of EMA/MGB, B17B/GB, and B17B/MGB methods were compared visually for each of the sites, and a RPD statistic was calculated corresponding to each of three exceedance probabilities to compare the EMA and B17B estimates.

When only systematic flood data were present, identical flood estimates (RPD equal to zero) were obtained, except for those cases where B17B cannot accommodate nonstandard data correctly. When historical and (or) high outliers were present, observed RPDs were positive more than half of the time. This is at least in part due to the 82 sites that were selected for testing, many of which included historical "high outliers." The EMA tends to attach more "weight" to historical flood information than does B17B (Stedinger and Cohn, 1987), so where the historical period includes an unusually high peak, the EMA/MGB estimate will tend to be higher than the B17B/GB estimate.

Flood series that contain multiple PILFs exhibited a range of results, primarily due to the very different number of PILFs identified by the GB and MGB tests and the methods used to handle PILFs in the frequency analysis (that is, EMA's censoring versus B17B's CPA). When the same PILF threshold was used for the EMA and B17B's CPA fitting procedure, the RPDs were usually smaller and negative. For those sites with PILFs and historical and (or) high-outlier data, similar RPDs were found to those in the historical and PILF categories. This combination group included both PILFs and high outliers. The RPDs were notably more positive for these estimates. EMA/MGB generally identified more PILFs when PILFs were present. In these cases, based on subjective assessment, EMA/MGB always provided a closer fit to the largest peaks in the dataset.

Additional studies were conducted that involved resampling data from sites with the longest records. Although the true value of the 1-percent exceedance event is not known for these sites, the resampling experiments confirmed that the EMA/MGB estimator performed reasonably well in all cases and generally provided higher average gains than the alternative estimators.

\section{Conclusions}

The study reported here was designed to determine how well proposed changes to Bulletin 17B (B17B) would perform in practice compared to the current recommendations in Bulletin 17B. In particular, the investigations focused on techniques for the following:

- incorporating information related to historical flooding that occurred outside the period of systematic streamgaging, and

- addressing the identification and treatment of PILFs. 


\section{Evaluation of Recommended Revisions to Bulletin 17B}

In order to answer these questions, Monte Carlo studies were conducted by resampling from real records, or by drawing random samples from specified LP3 and non-LP3 distributions. In addition, problematic datasets from across the country were selected to serve as test cases for comparing the estimators. To summarize, results are presented for the following:

- Monte Carlo simulations employing data drawn from specific LP3 populations;

- Monte Carlo simulations employing data drawn from non-LP3 populations that were selected to reflect likely deviations, based on the experience of the Data Group, from the hypothesized LP3 distribution;

- a direct subjective comparison of results at 82 real "test sites" identified by an independent Data Group as both "typical" and "challenging" for flood-frequency estimation; and

- resampling with replacement of the data at the 82 sites.

It is believed that, taken together, these studies provide a reasonably comprehensive, valid, and robust assessment of the properties of the Bulletin 17B procedures and proposed extensions and improvements. The results demonstrate that the proposed alternative method, denoted by "EMA/MGB," is as follows:

- generally performs at least as well as, and in some cases much better than, Bulletin 17B procedures, in terms of the mean square error of flood quantile estimates; and

- allows for incorporation of more general types of flood-frequency information, thereby avoiding some annoying problems that arise when applying Bulletin 17B in practice with datasets containing nonstandard flood data (exceedances of thresholds, and "less-than" values).

In summary, the results here generally confirmed other studies published in the hydrological literature that have found that the EMA generally provides improved flood-frequency estimates.

\section{References Cited}

Advisory Committee on Water Information, 2011, Advisory Committee on Water Information, Subcommittee on Hydrology, Hydrologic Frequency Analysis Work Group, accessed September 16, 2018, at https://acwi.gov/hydrology/Frequency/.

American Institutes for Research, 2005, A chronology of major events affecting the National Flood Insurance Program, American Institutes for Research, Washington, D.C., 86 p., accessed September 16, 2018, at https://www.fema.gov/media-library/assets/documents/9612.

Barnett, V., and Lewis, T., 1994, Outliers in statistical data: New York, Wiley 604 p.

Chowdhury, J.U., and Stedinger, J.R., 1991, Confidence interval for design floods with estimated skew coefficient: Journal of Hydraulic Engineering, v. 117, p. 811-831.

Cohn, T.A., England, J.F., Berenbrock, C.E., Mason, R.R., Stedinger, J.R., and Lamontagne, J.R., 2013, A generalized Grubbs-Beck test statistic for detecting multiple potentially influential low outliers in flood series: Water Resources Research, v. 49, no. 8, p. 5047-5058, accessed June 27, 2017, at https://doi.org/ 10.1002/wrcr.20392.

Cohn, T.A., Lane, W.L., and Baier, W.G., 1997, An algorithm for computing moments-based flood quantile estimates when historical flood information is available: Water Resources Research, v. 33, no. 9, p. 20892096. 
Cohn, T.A., Lane, W.L., and Stedinger, J.R., 2001, Confidence intervals for Expected Moments Algorithm flood quantile estimates: Water Resources Research, v. 37, no. 6, p. 1695-1706.

Dawdy, D.R., Griffis, V.W., and Gupta, V.K., 2012, Regional flood-frequency analysis: How we got here and where we are going: Journal of Hydrologic Engineering, v. 17, no. 9, p. 953-959, accessed September 16, 2018, at https://doi.org/10.1061/(ASCE)HE.1943-5584.0000584.

England, J.F., Jarrett, R.D., and Salas, J.D., 2003, Data-based comparisons of moments estimators using historical and paleoflood data: Journal of Hydrology, v. 278, no. 1, p. 172-196, accessed October 30, 2017, at https://doi.org/10.1016/S0022-1694(03)00141-0.

Gotvald, A.J., Feaster, T.D., and Weaver, J.C., 2009, Magnitude and frequency of rural floods in the Southeastern United States, 2006; v. 1, Georgia: U.S. Geological Survey Scientific Investigations Report 2009-5043, 120 p., accessed October 30, 2017, at http://pubs.usgs.gov/sir/2009/5043/.

Griffis, V.W., and Stedinger, J.R., 2007, Evolution of flood frequency analysis with Bulletin 17: Journal of Hydrologic Engineering, v. 12, no. 3, p. 283-297.

Griffis, V.W., Stedinger, J.R., and Cohn, T.A., 2004, Log Pearson type 3 quantile estimators with regional skew information and low outlier adjustments: Water Resources Research, v. 40, no. 7.

Hydrologic Frequency Analysis Work Group, 2006, Flood frequency research needs. Memorandum to Subcommittee on Hydrology, accessed August 30, 2017, at http://acwi.gov/hydrology/Frequency/minutes/ HFAWG_for_revising_Bulletin17B_4.pdf.

Interagency Committee on Water Data [IACWD], 1982, Guidelines for determining flood flow frequency, Bulletin 17B: Interagency Committee on Water Data, Hydrology Subcommittee, Technical Report.

Interagency Committee on Water Resources, 1966, Methods of flow frequency analysis, Bulletin No. 13: Interagency Committee on Water Resources, Subcommittee on Hydrology, Washington, D.C.

Jennings, M.E., and Benson, M.A., 1969, Frequency curves for annual flood series with some zero events or incomplete data: Water Resources Research, v. 5, no. 1, p. 276-280.

Kirby, William, 1974, Algebraic boundedness of sample statistics: Water Resources Research, v. 10, no. 2 , p. 220-222.

Lamontagne, J.R., Stedinger, J.R., Berenbrock, Charles, Veilleux, A.G., Ferris, J.C., and Knifong, D.L., 2012, Development of regional skews for selected flood durations for the Central Valley Region, California, based on data through water year 2008: U.S. Geological Survey Scientific Investigations Report 2012-5130, 60 p., accessed October 30, 2017, at http://pubs.usgs.gov/sir/2012/5130/.

Lamontagne, J.R., Stedinger, J.R., Cohn, T.A., and Barth, N.A., 2013, Robust national flood frequency guidelines; what is an outlier?, in Showcasing the future: American Society of Civil Engineers, p. 2454-2466, accessed August 30, 2017, at https://doi.org/10.1061/9780784412947.242.

McCuen, R.H., 2003, Modeling hydrologic change; Statistical methods: Boca Raton, Fla., Lewis Publishers, $433 \mathrm{p}$.

Mileti, D.S., 1999, Disasters by design: Washington, D.C., Joseph Henry Press, 371 p.

Parrett, Charles, Veilleux, Andrea, Stedinger, J.R., Barth, N.A., Knifong, D.L., and Ferris, J.C., 2011, Regional skew for California, and flood frequency for selected sites in the Sacramento-San Joaquin River basin, based on data through water year 2006: U.S. Geological Survey Scientific Investigations Report 2010-5260, 94 p., accessed October 30, 2017, at https://pubs.usgs.gov/sir/2010/5260/.

Rosner, B., 1975, On the detection of many outliers: Technometrics, v. 17, no. 2, p. 221-227. 


\section{Evaluation of Recommended Revisions to Bulletin 17B}

Spencer, C.S., and McCuen, R.H., 1996, Detection of outliers in Pearson type III data: Journal of Hydrologic Engineering, v. 1, p. 2.

Stedinger, J.R., and Cohn, T.A., 1986, Flood frequency analysis with historical and paleoflood information: Water Resources Research, v. 22, no. 5, p. 785-793.

Stedinger, J.R., and Cohn, T.A., 1987, Historical flood-frequency data: Its value and use, in Singh, V.P., ed., Regional flood frequency analysis: D. Reidel Publishing Company, p. 273-286.

Stedinger, J.R., Vogel, R.M., and Foufoula-Georgiou, Efi, 1993, Frequency analysis of extreme events, in Maidment, D.R., ed., Handbook of hydrology: McGraw Hill, Inc., p. 18.1-18.66.

Tasker, G.D., and Thomas, W.O., 1978, Flood frequency analysis with pre-record information: ASCE Journal of the Hydraulics Division (HY2), v. 104, no. 2, p. 249-259.

Thomas, W.O., 1985, A uniform technique for flood frequency analysis: Journal of Water Resources Planning and Management, v. 111, no. 3, p. 321-337.

Tukey, J.W., 1977, Exploratory data analysis: Reading, MA, Addison-Wesley, 712 p.

U.S. Water Resources Council, 1967, A uniform technique for determining flood flow frequencies, Bulletin No. 15: U.S. Water Resources Council, Subcommittee on Hydrology, Washington, D.C.

U.S. Water Resources Council, 1976, Guidelines for determining flood flow frequency, Bulletin No. 17: U.S. Water Resources Council, Subcommittee on Hydrology, Washington, D.C.

U.S. Water Resources Council, 1977, Guidelines for determining flood flow frequency, Bulletin No. 17A: U.S. Water Resources Council, Subcommittee on Hydrology, Washington, D.C.

Veilleux, A.G., and Stedinger, J.R., 2010, Bayesian GLS analysis of california regional skew, in World Environmental and Water Resources Congress 2010: Challenges of Change, ASCE, p. 2422-2431.

Veilleux, A.G., Stedinger, J.R., and Eash, D.A., 2012, Bayesian WLS/GLS regression for regional skewness analysis for regions with large crest stage gage networks, in World Environmental and Water Resources Congress 2012: Crossing Boundaries, ASCE, p. 2253-2263. 


\section{Appendix 1. Characteristics of 82 Test Sites}




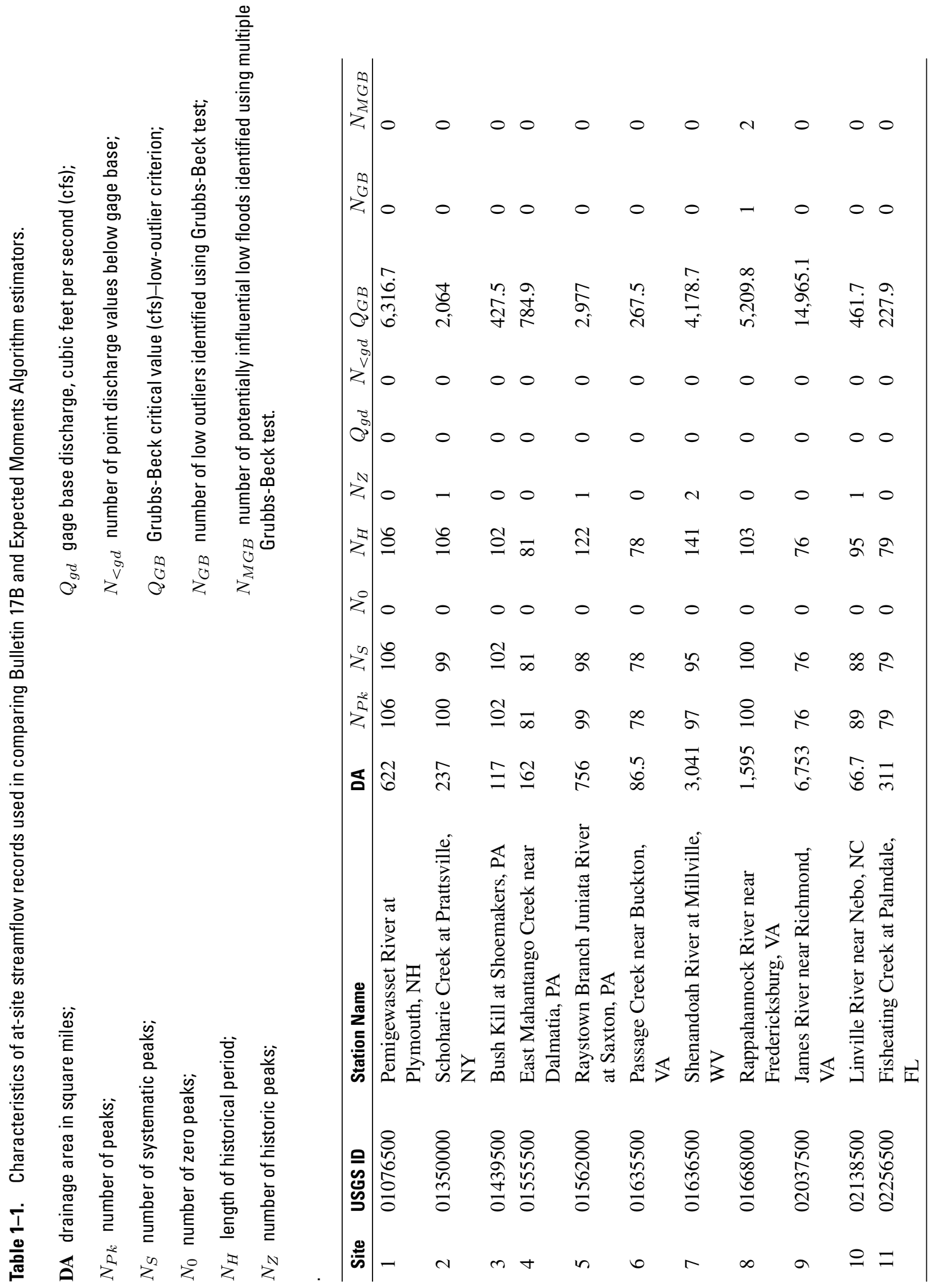




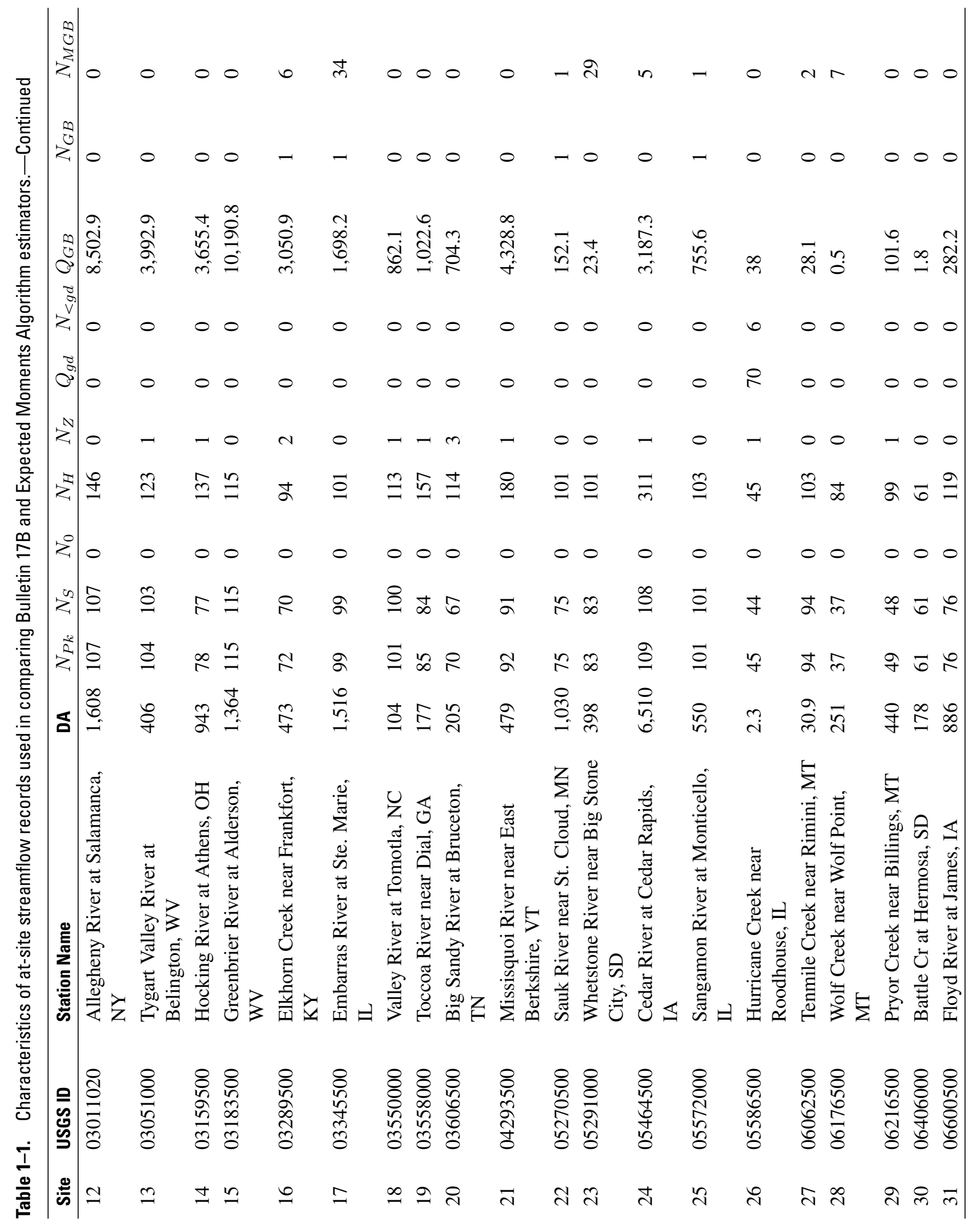




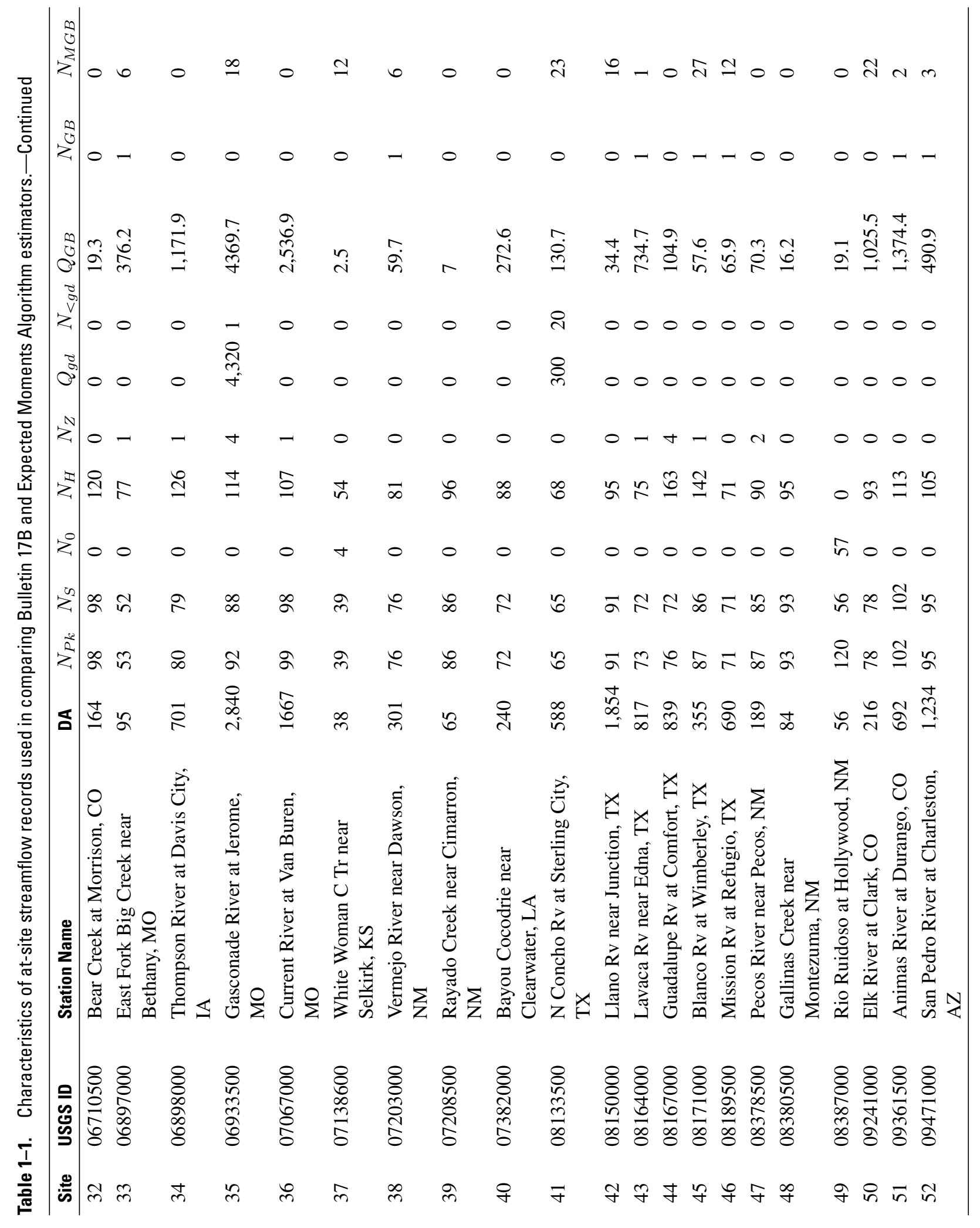




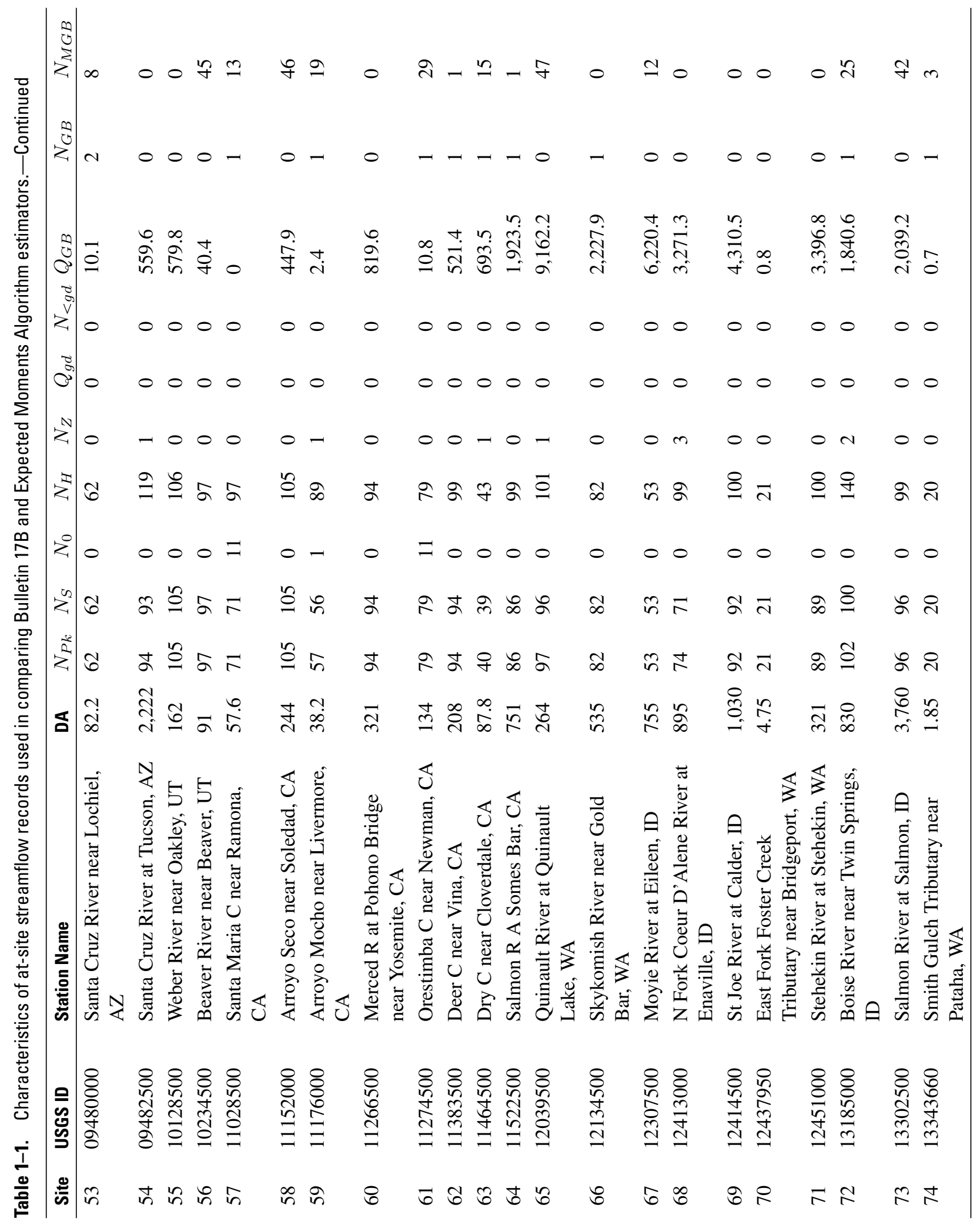




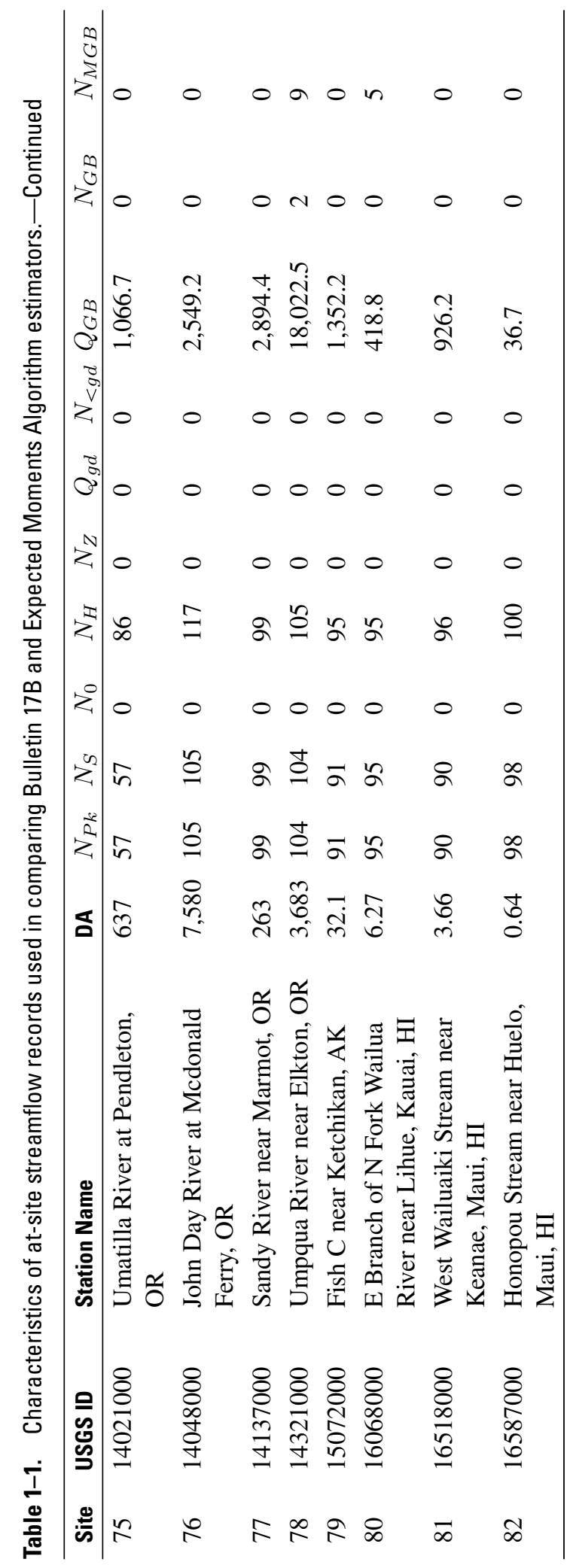




\section{Appendix 2. Graphical Comparisons Between the EMA and B17B at 82 Test Sites}




\section{Evaluation of Recommended Revisions to Bulletin 17B}

\section{Systematic Data Sites}

$\mathrm{N}_{\mathrm{S}}=\quad$ number of systematic peaks

$\mathrm{N}_{\mathrm{H}}=\quad$ length of the historical period

$\mathrm{N}_{\mathrm{Z}}=\quad$ number of historic peaks

$\mathrm{N}_{\mathrm{GB}}=\quad$ number of low outliers identified using Grubbs-Beck test

$\mathrm{N}_{\mathrm{MGB}}=$ number of potentially influential low floods

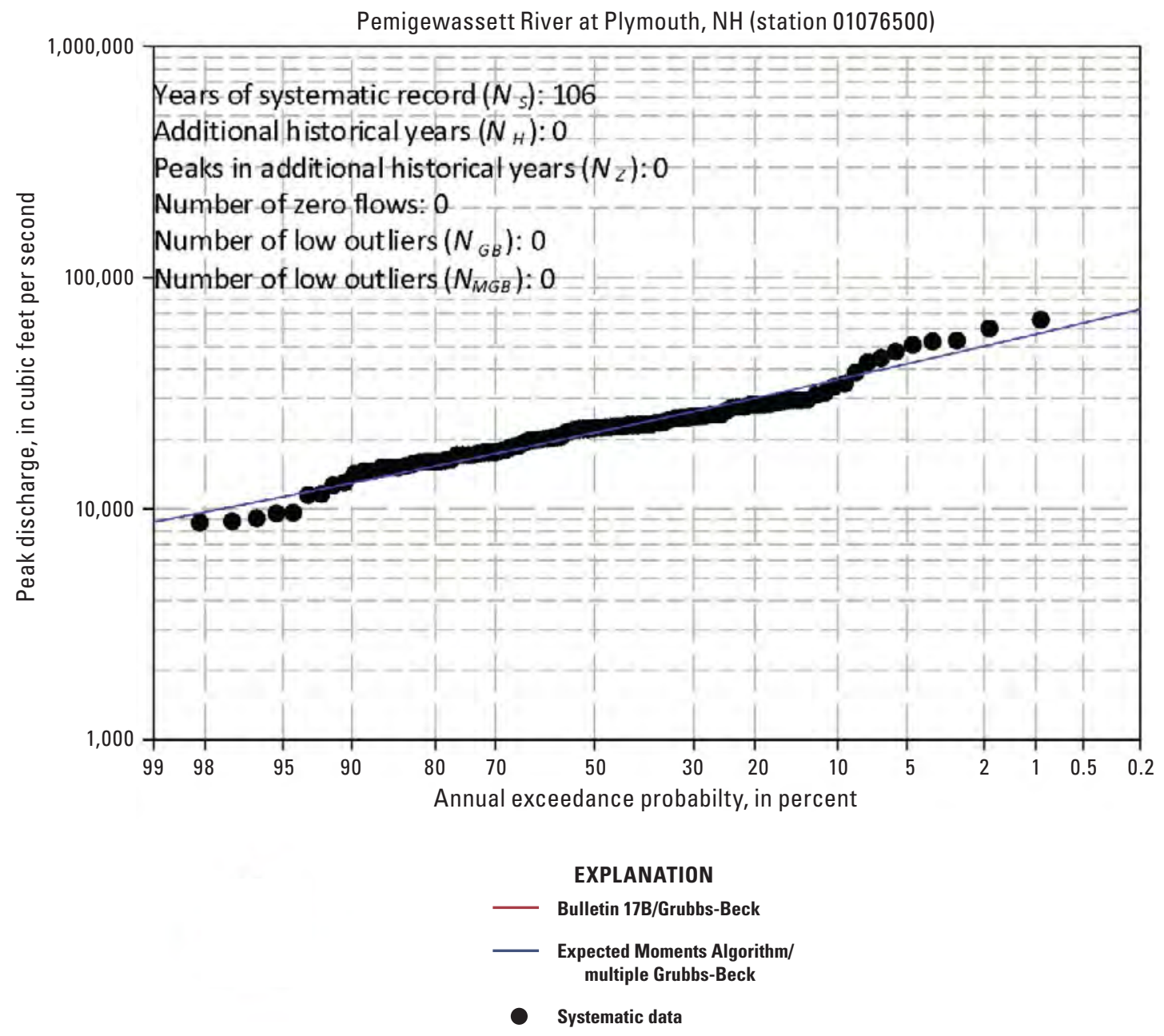

Figure 2-1. Site 01076500-Pemigewasset River at Plymouth, New Hampshire (NH) with systematic data only. 


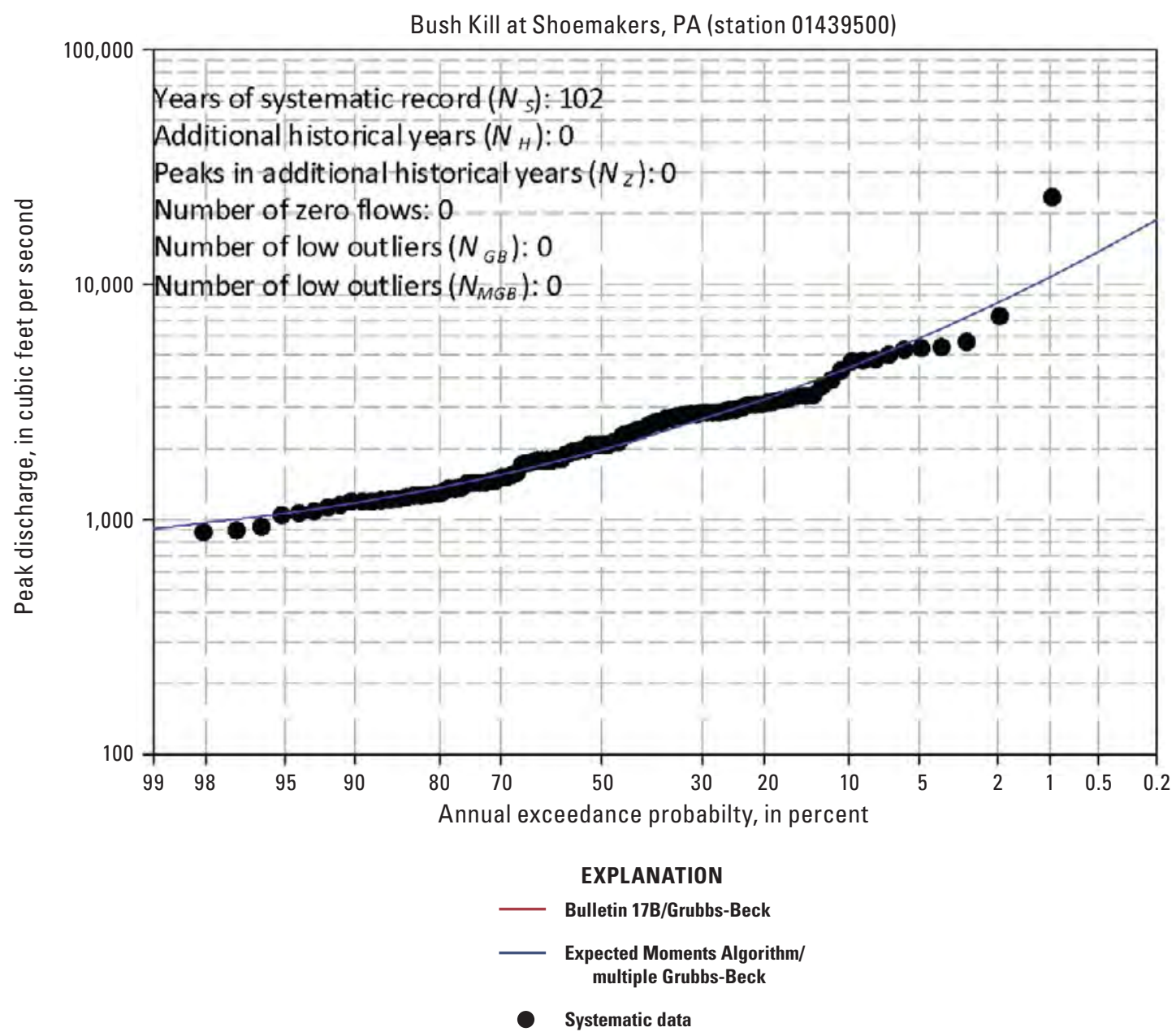

Figure 2-2. Site 01439500-Bush Kill at Shoemakers, Pennsylvania (PA) with systematic data only. 


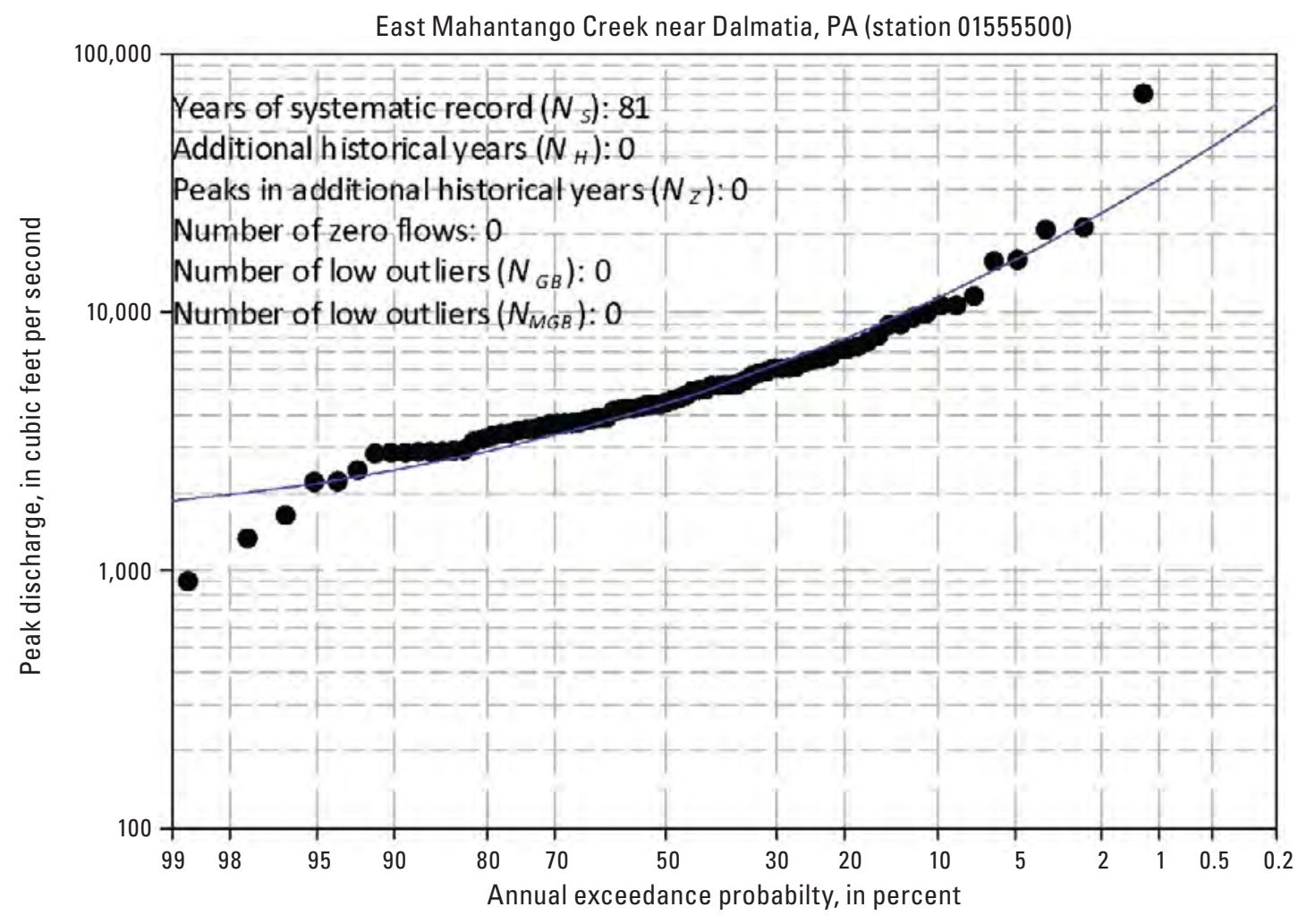

EXPLANATION

- Bulletin 17B/Grubbs-Beck

Expected Moments Algorithm/ multiple Grubbs-Beck

Systematic data

Figure 2-3. Site 01555500-East Mahantango Creek near Dalmatia, Pennsylvania (PA) with systematic data only. 


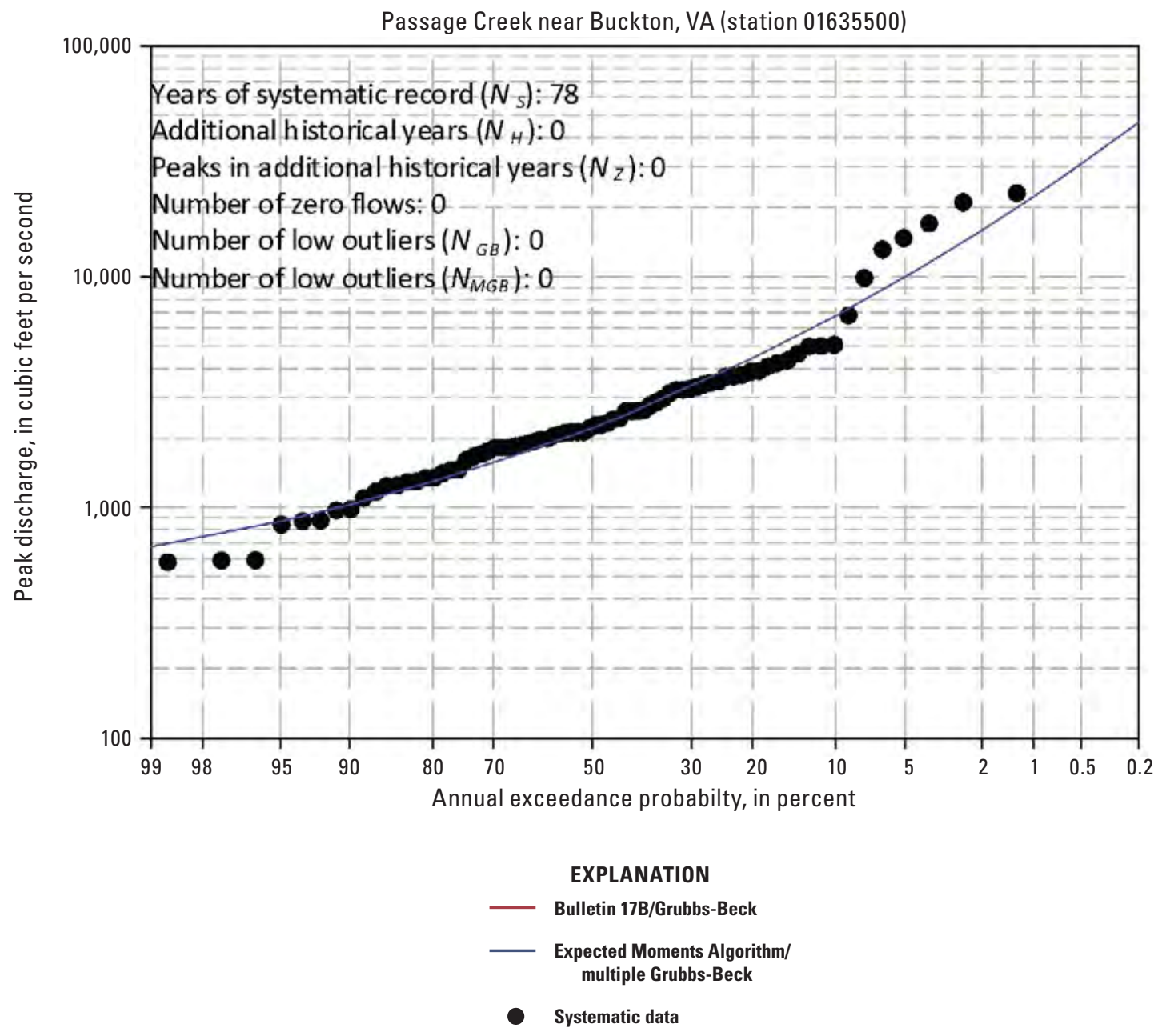

Figure 2-4. Site 01635500-Passage Creek near Buckton, Virginia (VA) with systematic data only. 


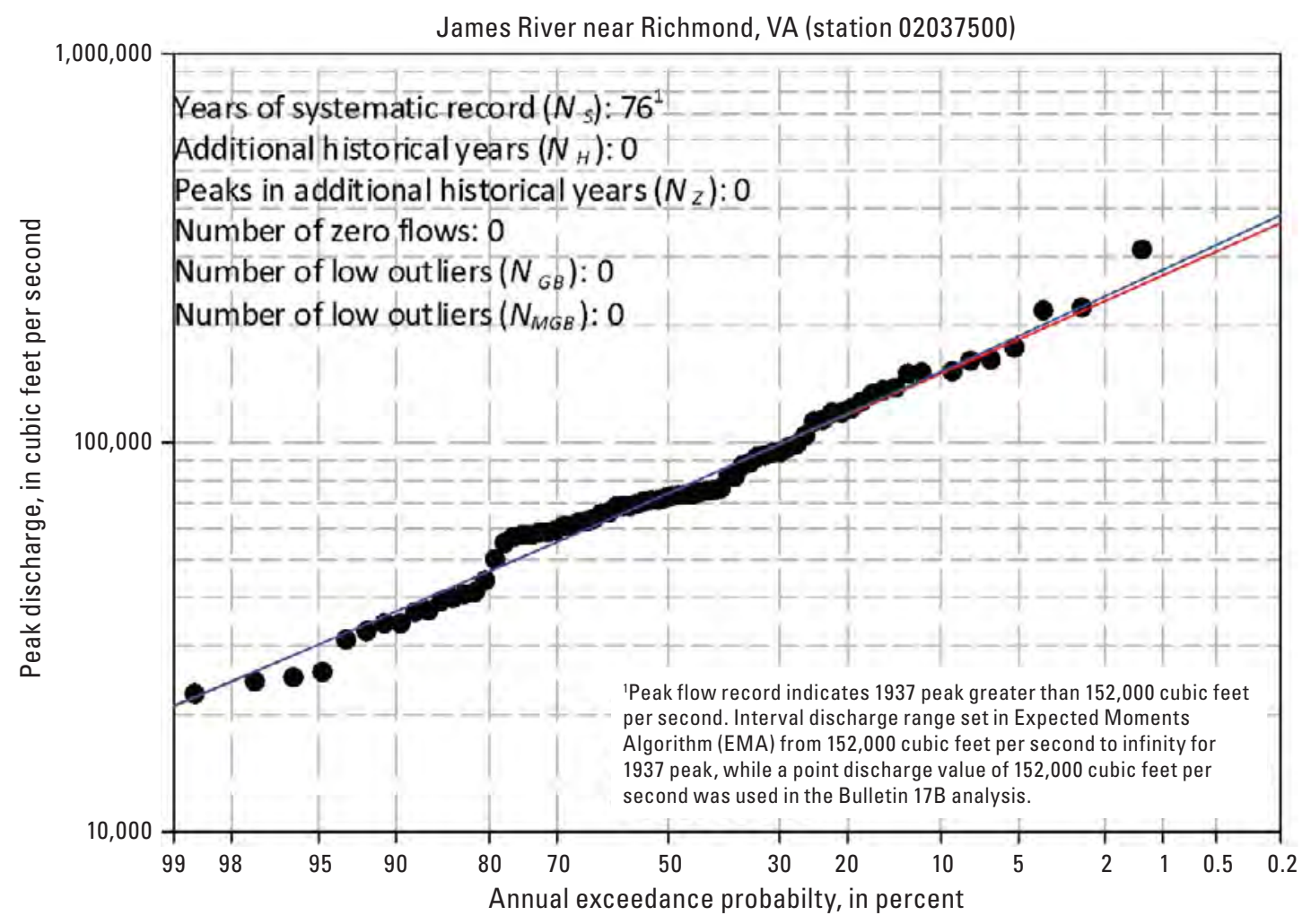

EXPLANATION

- Bulletin 17B/Grubbs-Beck

Expected Moments Algorithm/ multiple Grubbs-Beck

Systematic data

Figure 2-5. Site 02037500-James River near Richmond, Virginia (VA) with systematic data only. 


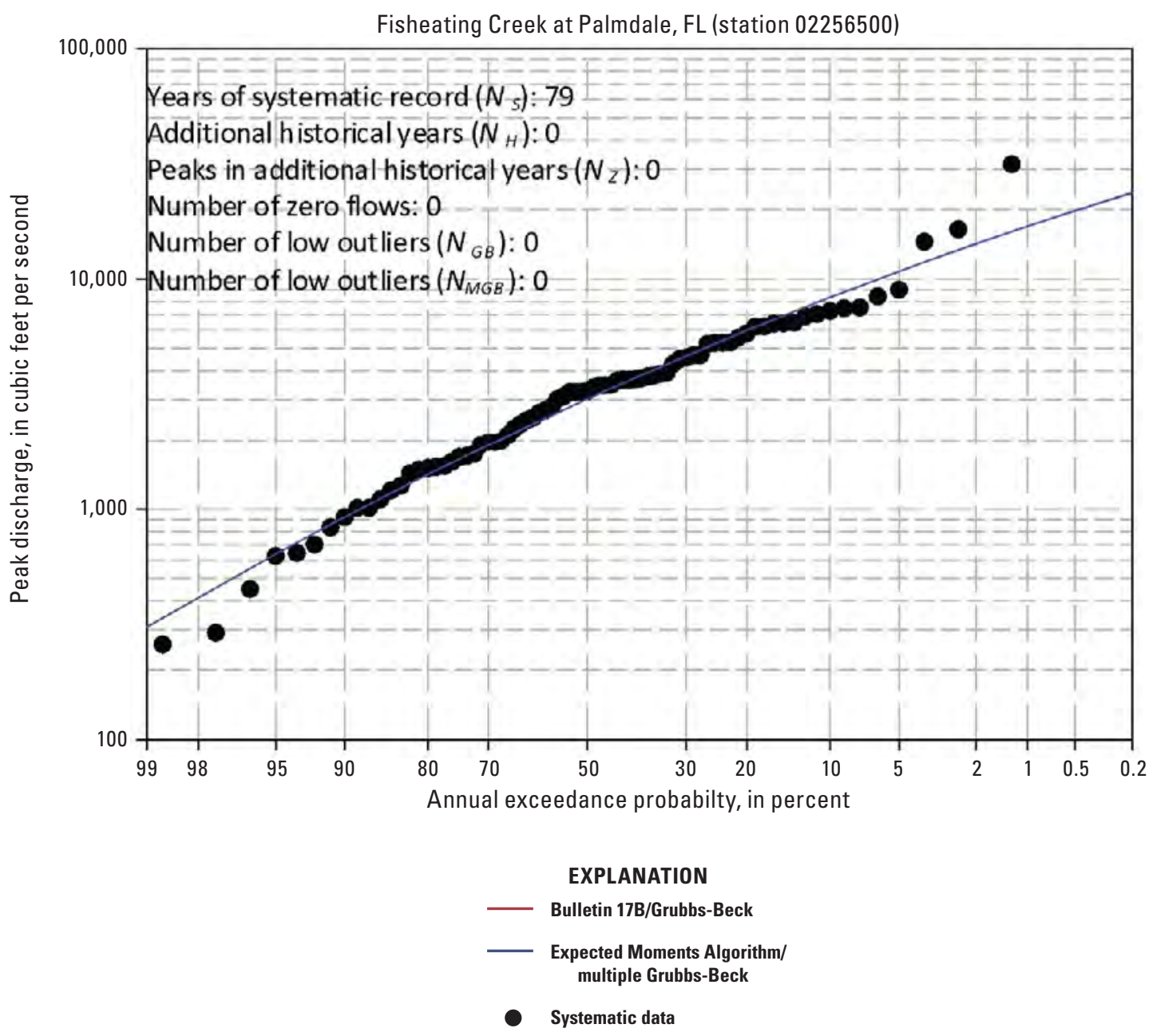

Figure 2-6. Site 02256500-Fisheating Creek at Palmdale, Florida (FL) with systematic data only. 


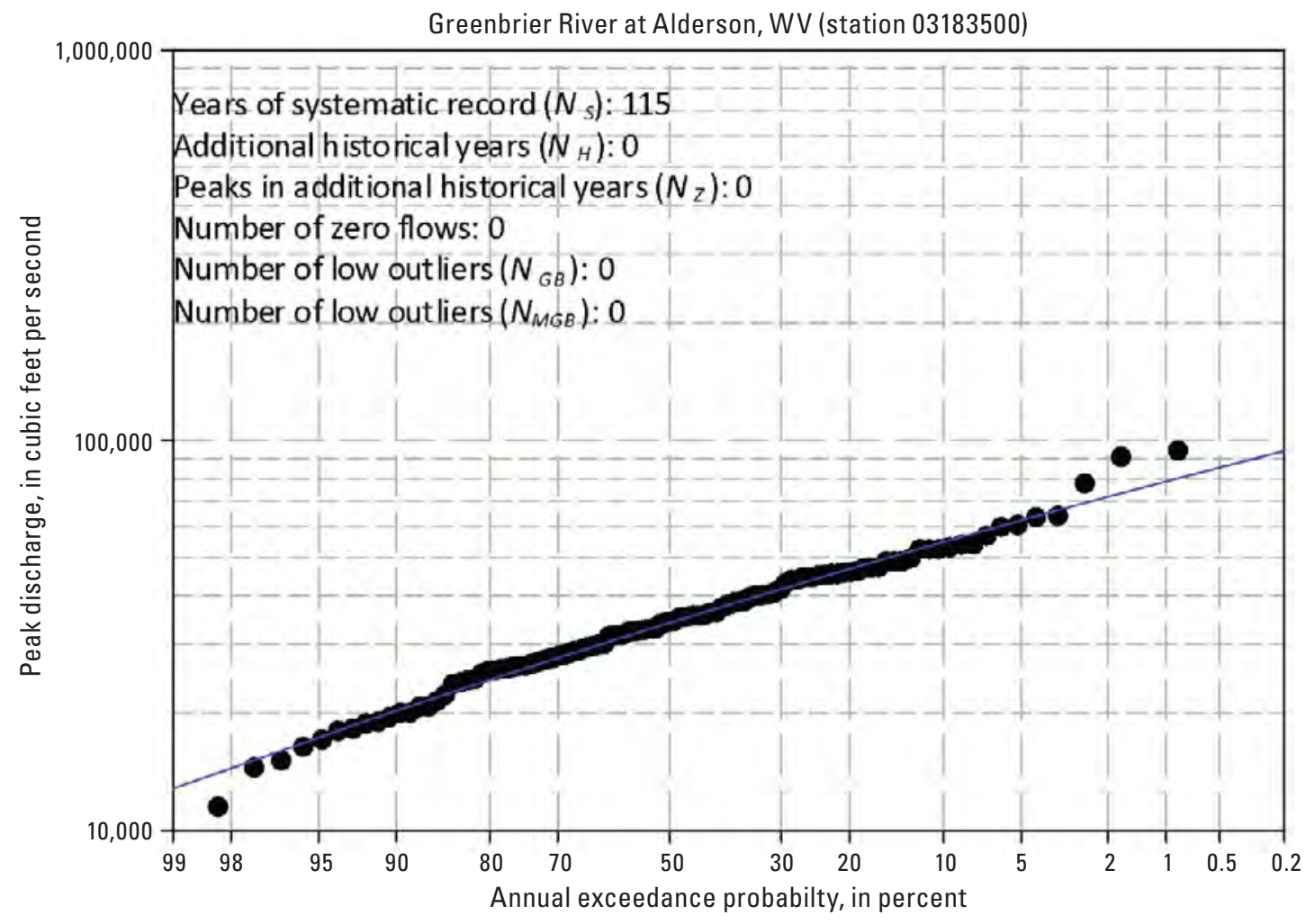

EXPLANATION

_ Bulletin 17B/Grubbs-Beck

Expected Moments Algorithm/ multiple Grubbs-Beck

- Systematic data

Figure 2-7. Site 03183500-Greenbrier River at Alderson, West Virginia (WV) with systematic data only. 


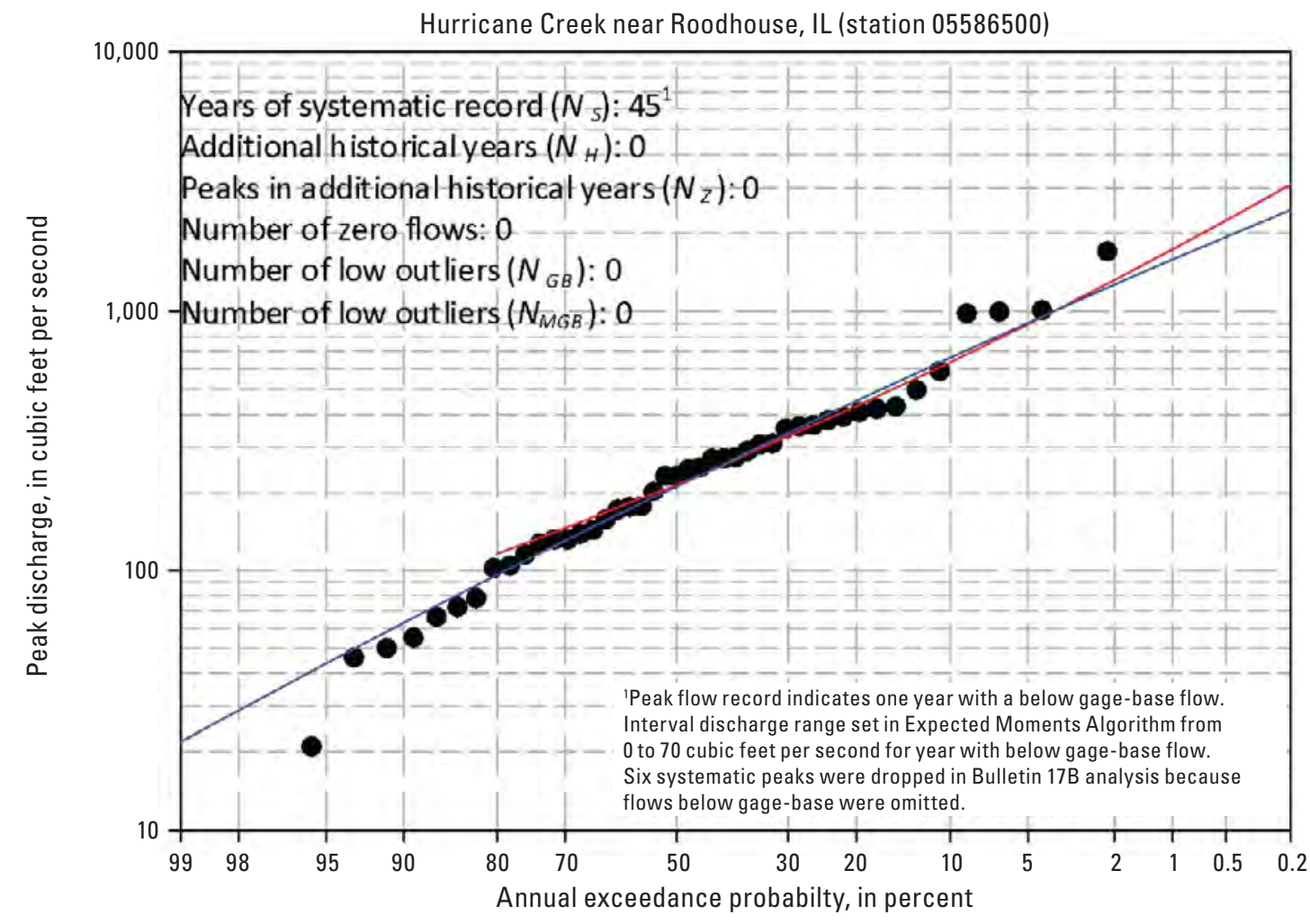

EXPLANATION

Expected Moments Algorithm/ multiple Grubbs-Beck

- Systematic data

Figure 2-8. Site 05586500-Hurricane Creek near Roodhouse, Illinois (IL) with systematic data only. 


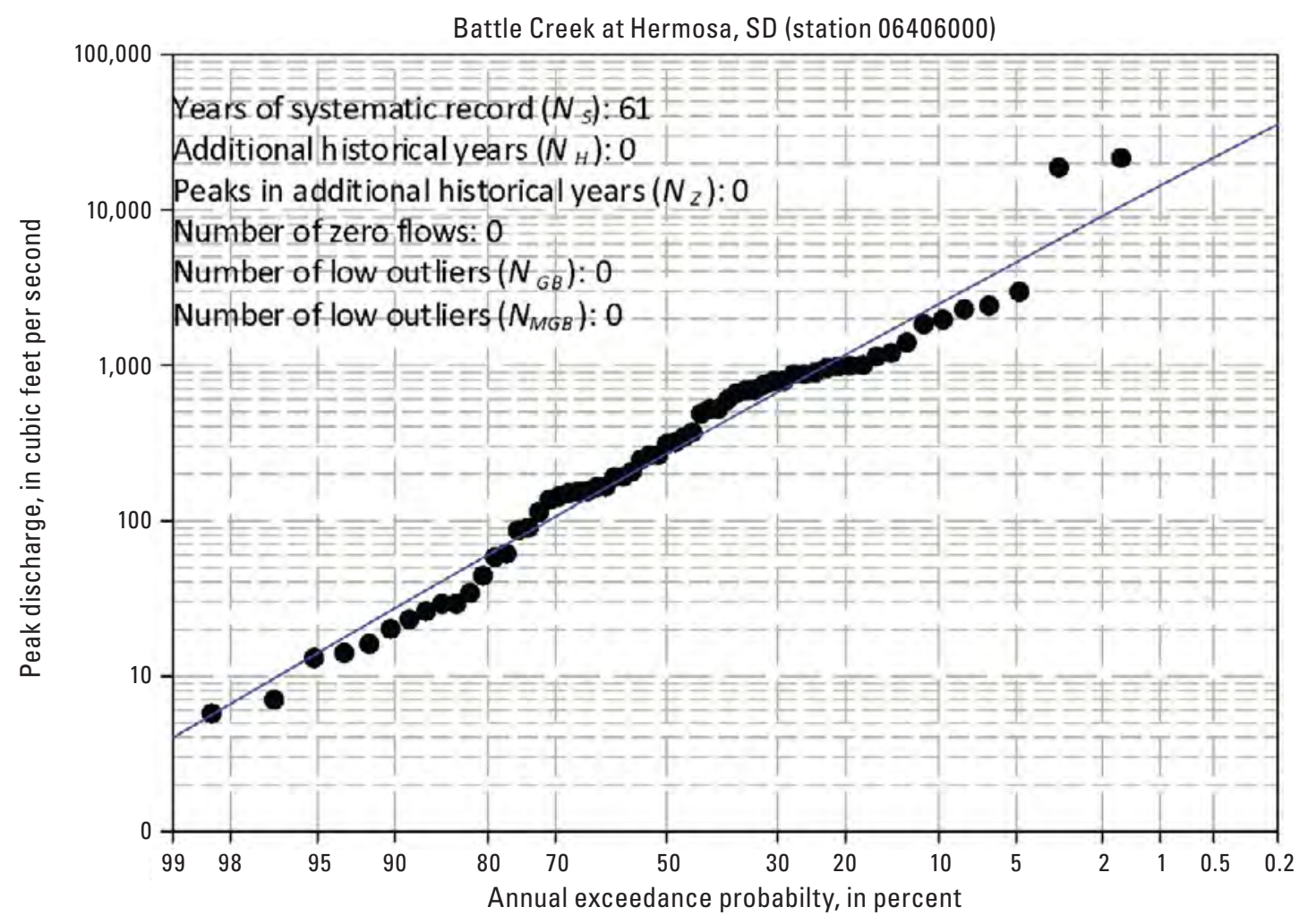

EXPLANATION

- Bulletin 17B/Grubbs-Beck

Expected Moments Algorithm/ multiple Grubbs-Beck

- Systematic data

Figure 2-9. Site 06406000-Battle Creek at Hermosa, South Dakota (SD) with systematic data only. 


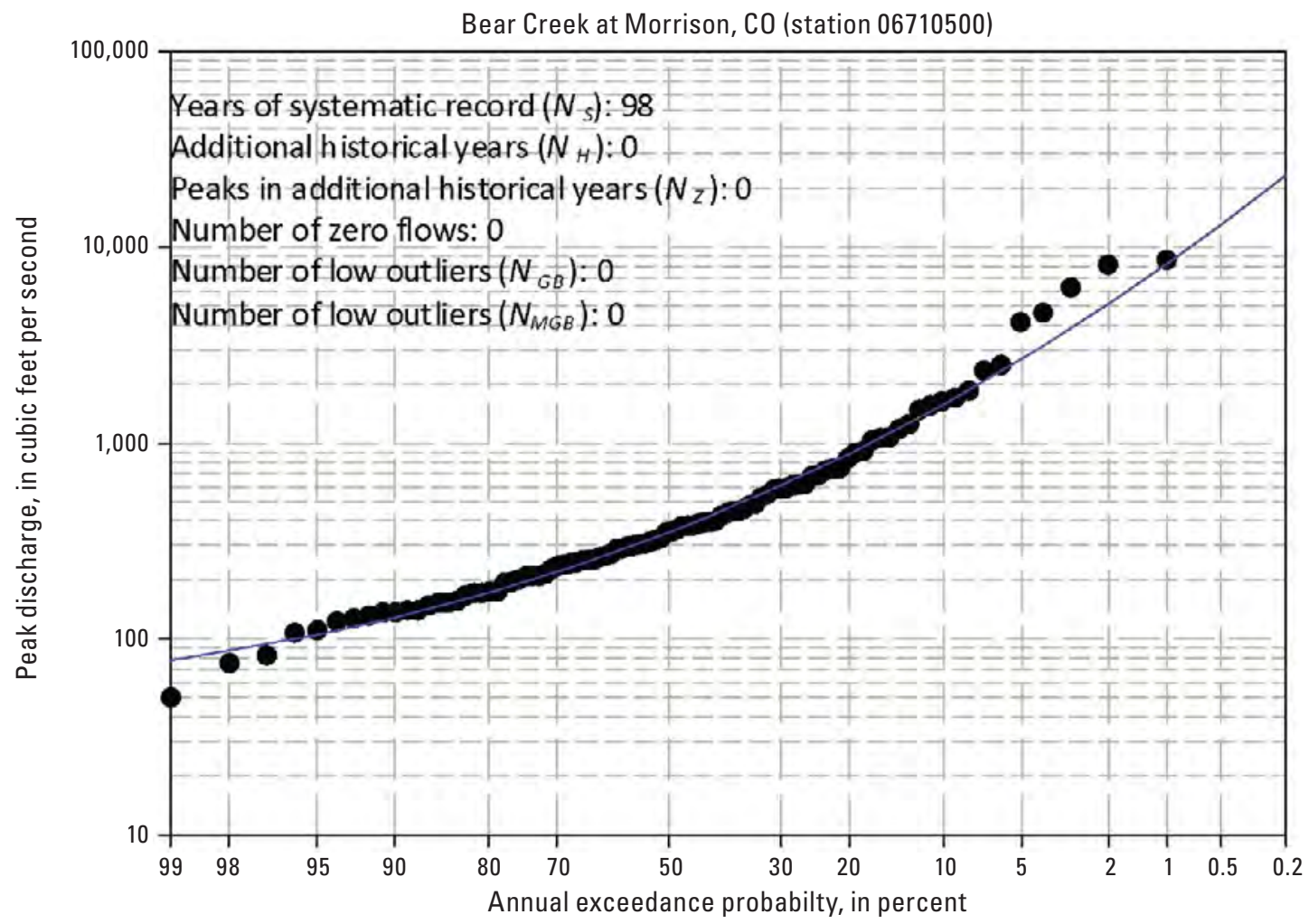

EXPLANATION

- Bulletin 17B/Grubbs-Beck

Expected Moments Algorithm/ multiple Grubbs-Beck

- Systematic data

Figure 2-10. Site 06710500-Bear Creek at Morrison, Colorado (CO) with systematic data only. 


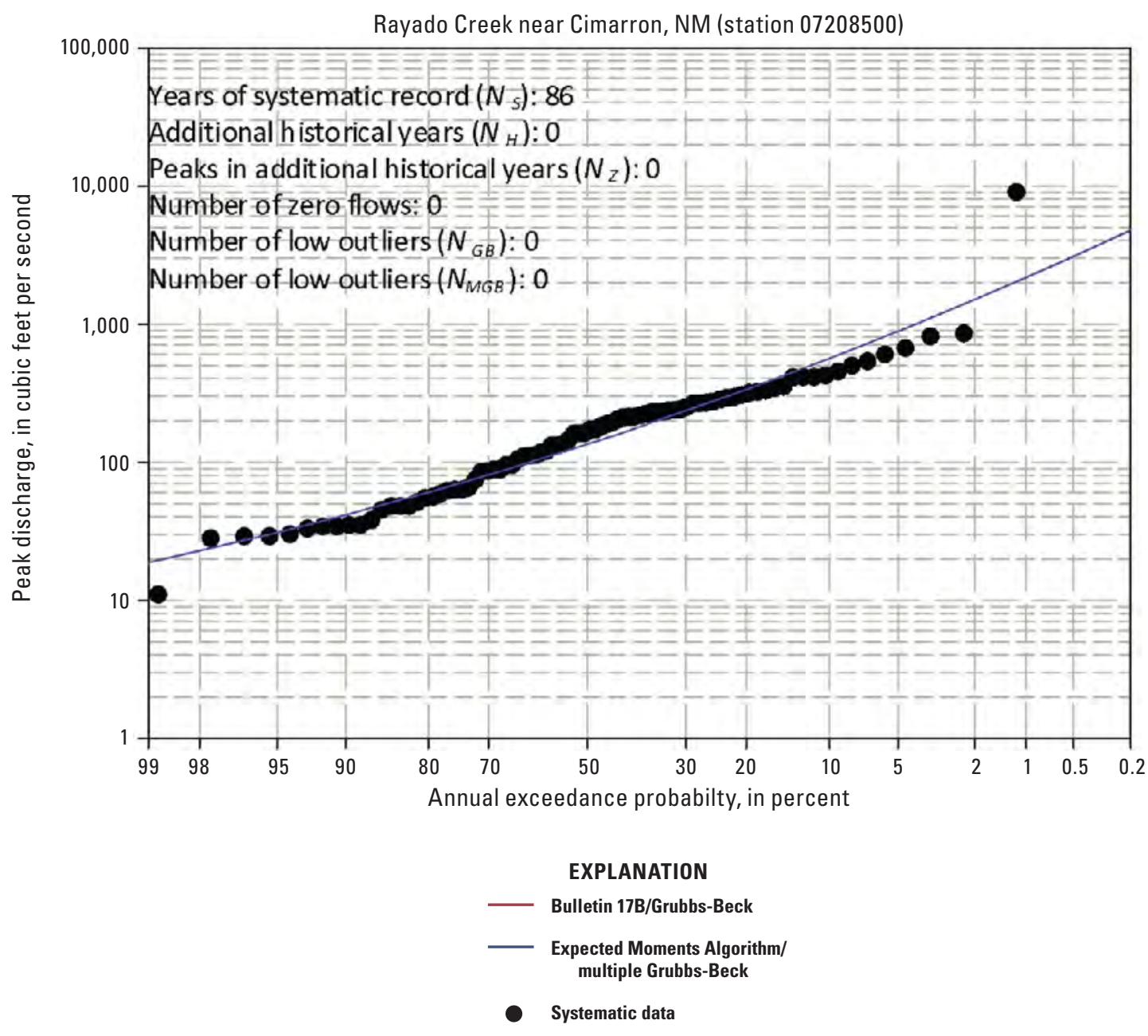

Figure 2-11. Site 07208500-Rayado Creek near Cimarron, New Mexico (NM) with systematic data only. 


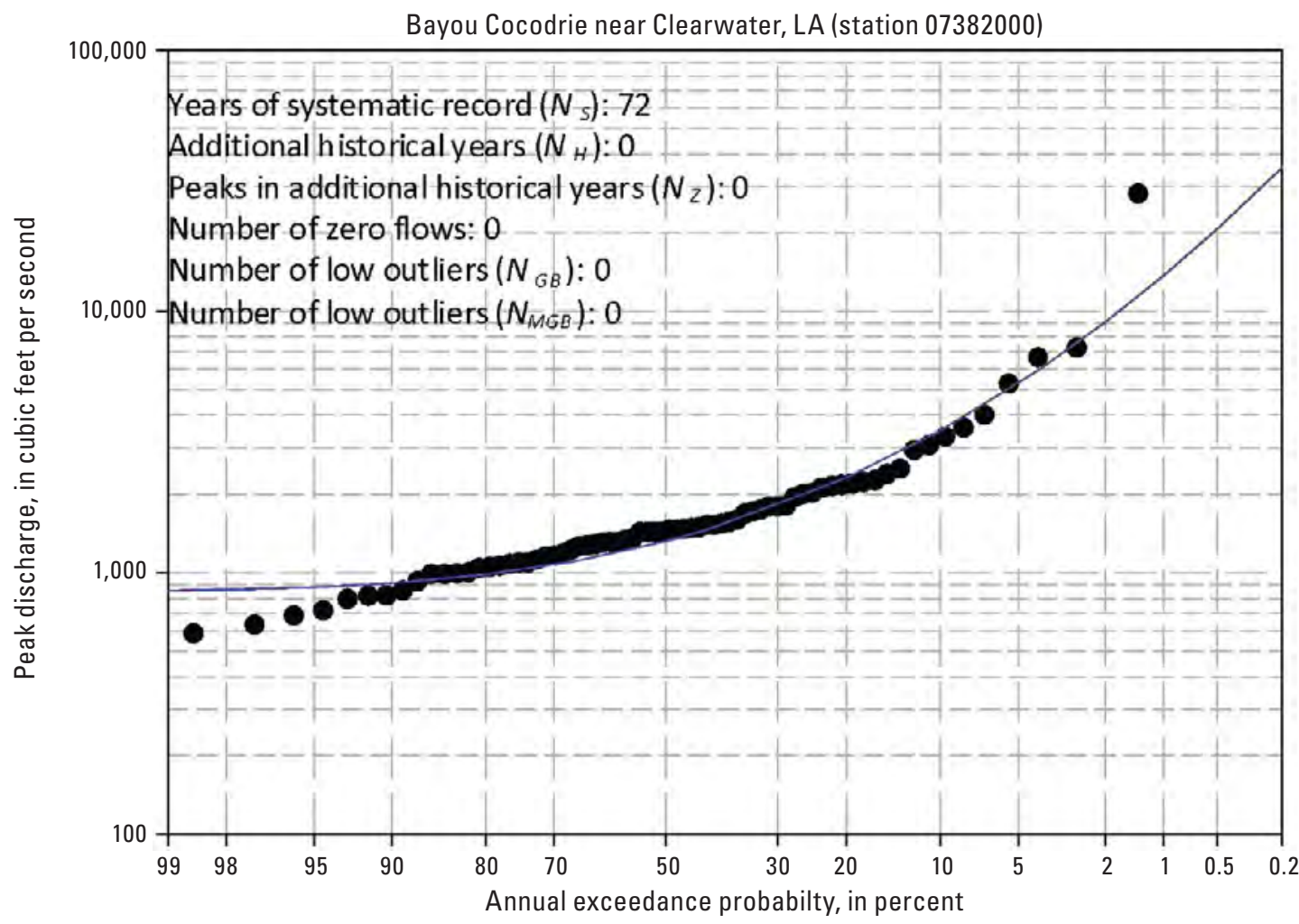

EXPLANATION

- Bulletin 17B/Grubbs-Beck

Expected Moments Algorithm/ multiple Grubbs-Beck

- Systematic data

Figure 2-12. Site 07382000-Bayou Cocodrie near Clearwater, Louisiana (LA) with systematic data only. 


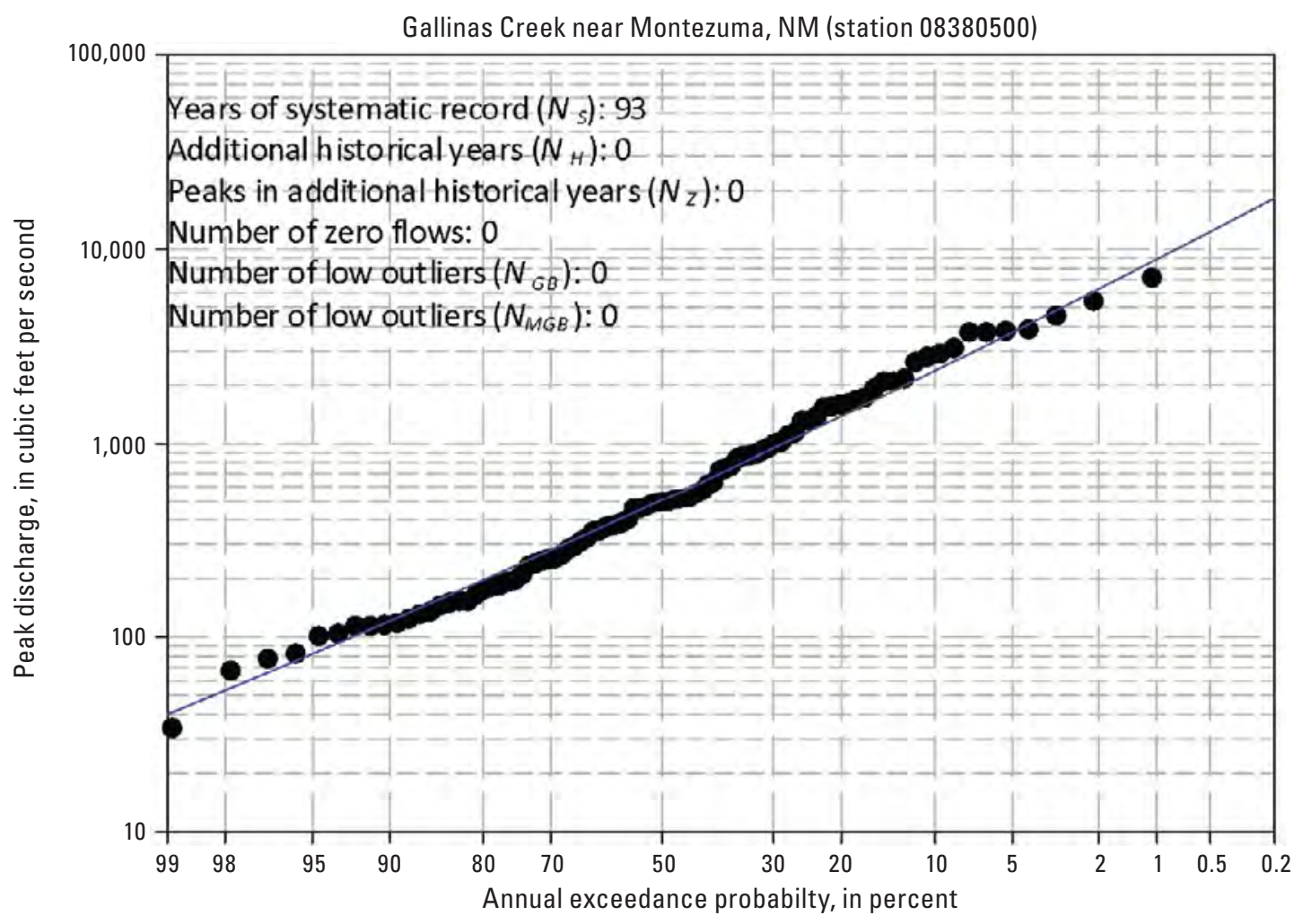

EXPLANATION

_ Bulletin 17B/Grubbs-Beck

Expected Moments Algorithm/ multiple Grubbs-Beck

- Systematic data

Figure 2-13. Site 08380500-Gallinas Creek near Montezuma, New Mexico (NM) with systematic data only. 


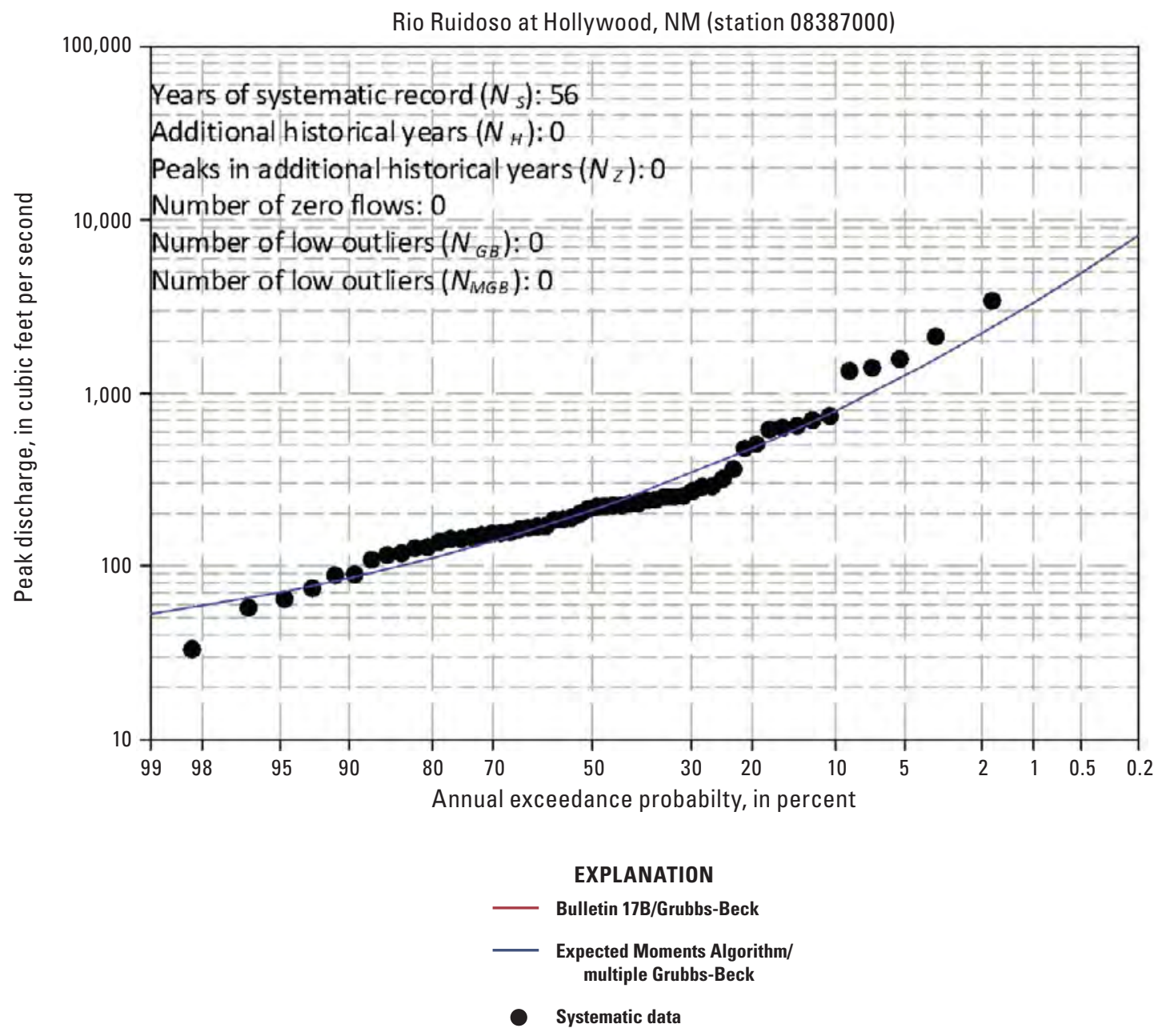

Figure 2-14. Site 08387000-Rio Ruidoso at Hollywood, New Mexico (NM) with systematic data only. 


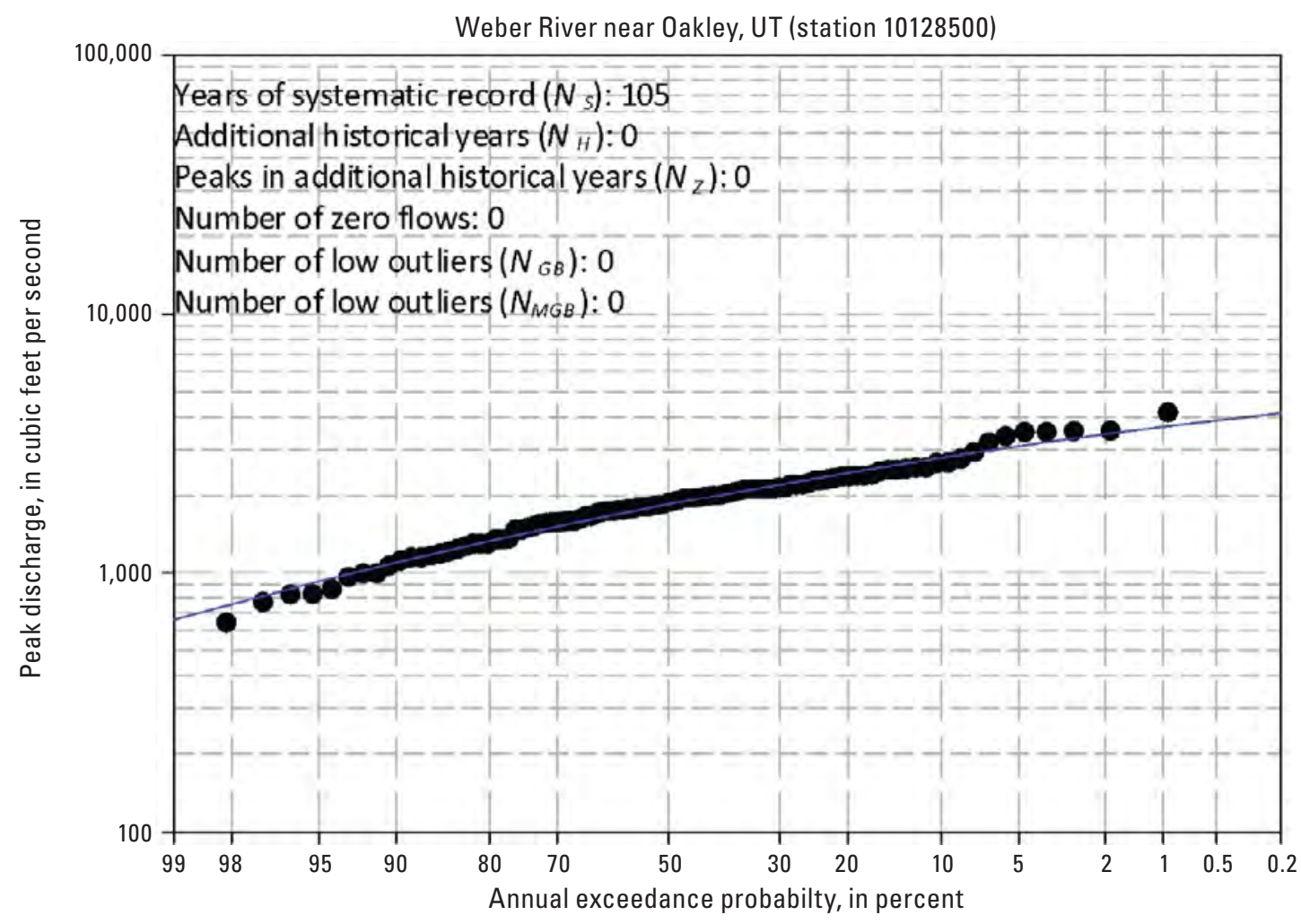

EXPLANATION

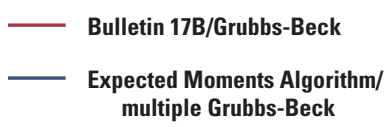

- Systematic data

Figure 2-15. Site 10128500-Weber River near Oakley, Utah (UT) with systematic data only. 


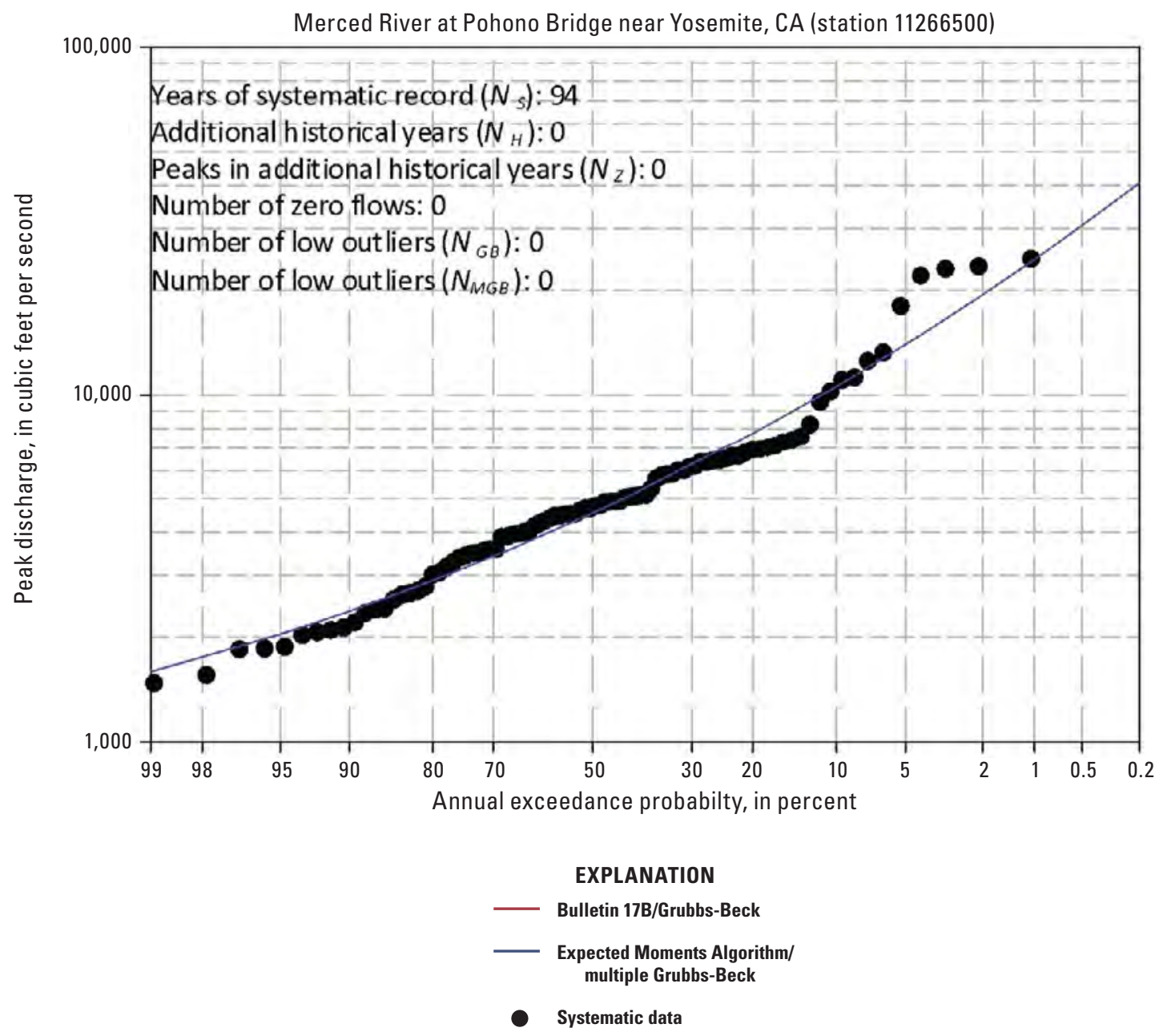

Figure 2-16. Site 11266500-Merced River at Pohono Bridge near Yosemite, California (CA) with systematic data only. 


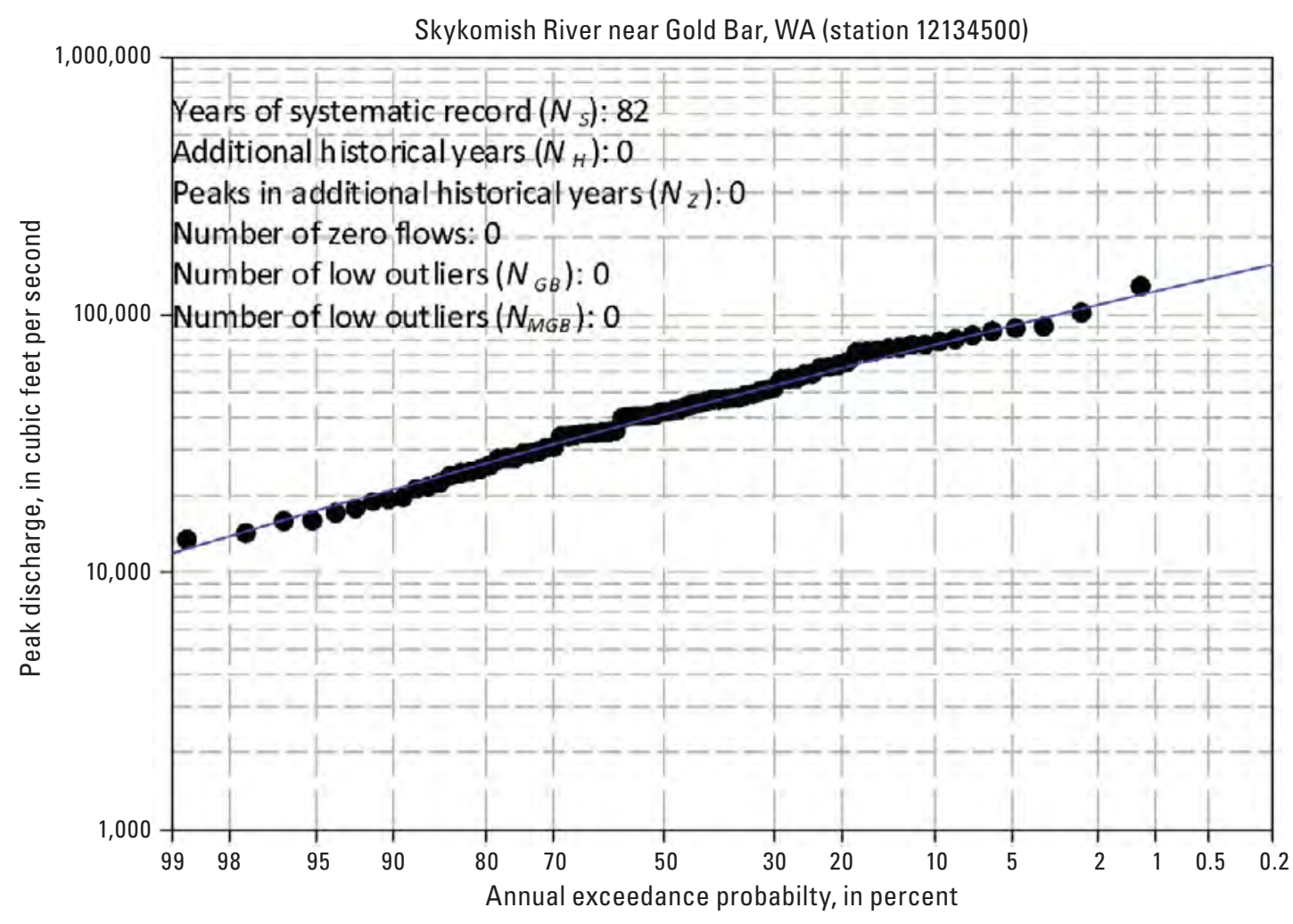

EXPLANATION

- Bulletin 17B/Grubbs-Beck

Expected Moments Algorithm/ multiple Grubbs-Beck

Systematic data

Figure 2-17. Site 12134500-Skykomish River near Gold Bar, Washington (WA) with systematic data only. 


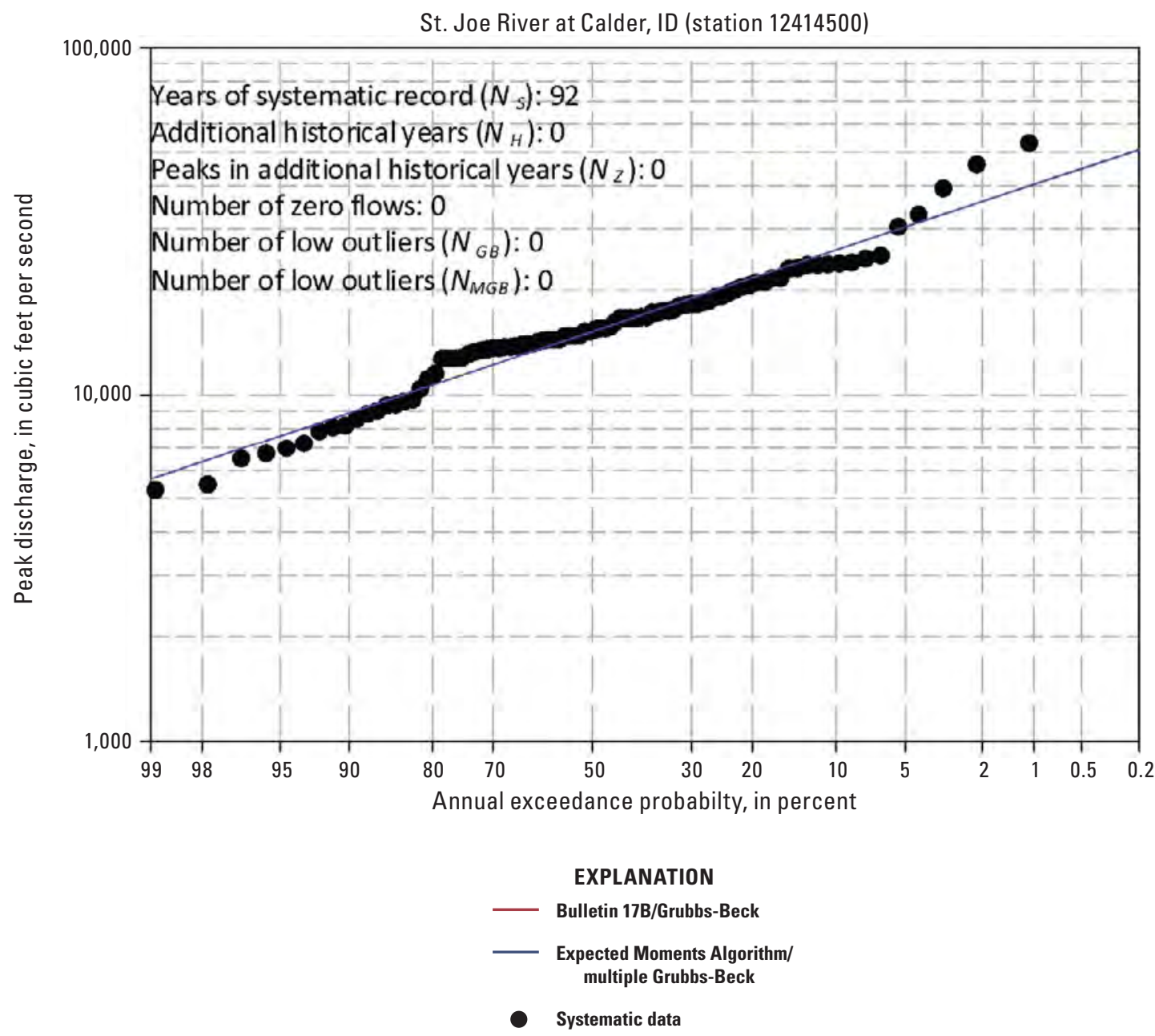

Figure 2-18. Site 12414500-St. Joe River at Calder, Idaho (ID) with systematic data only. 


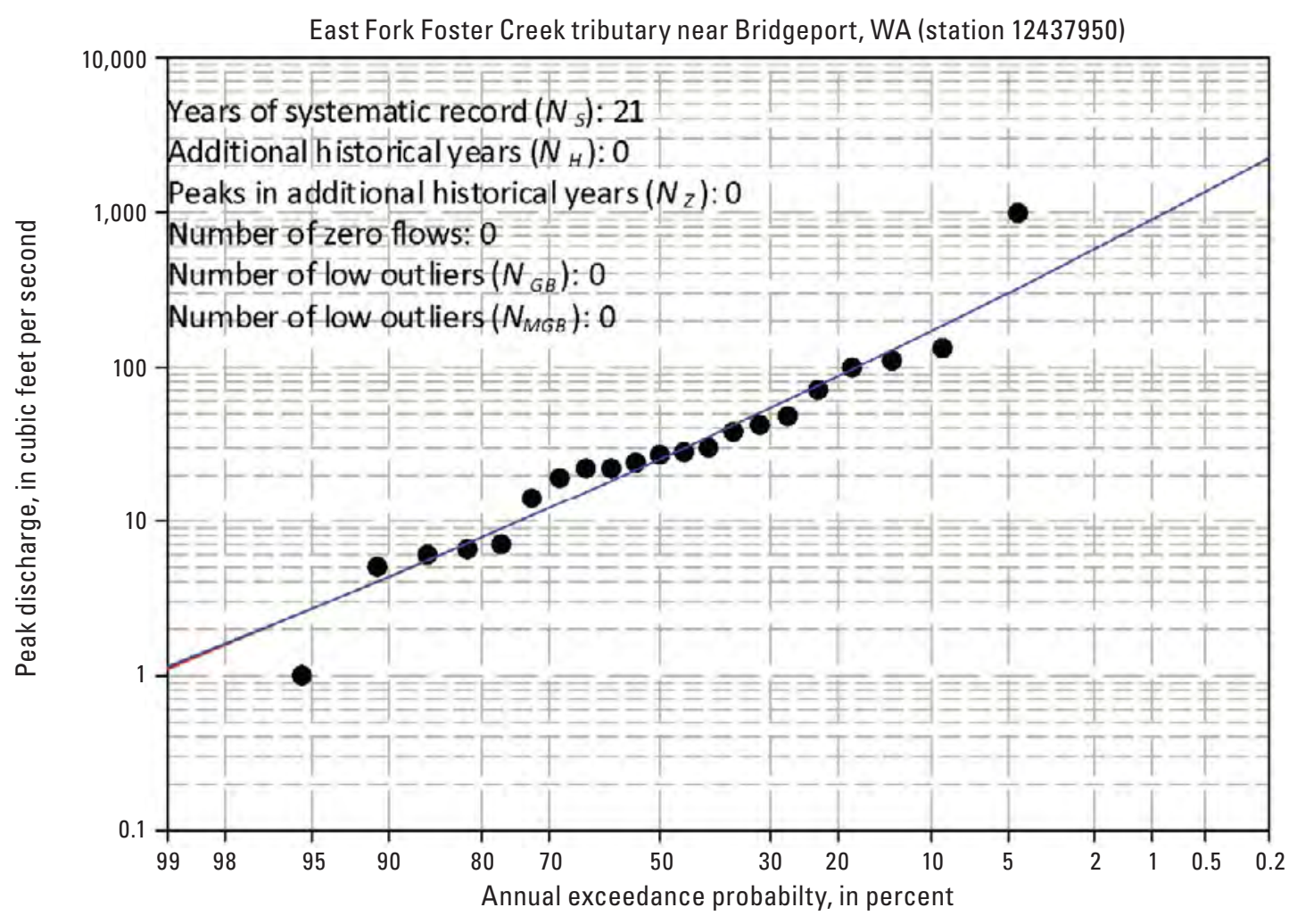

EXPLANATION

Bulletin 17B/Grubbs-Beck

Expected Moments Algorithm/ multiple Grubbs-Beck

Systematic data

Figure 2-19. Site 12437950-East Fork Foster Creek tributary near Bridgeport, Washington (WA) with systematic data only. 


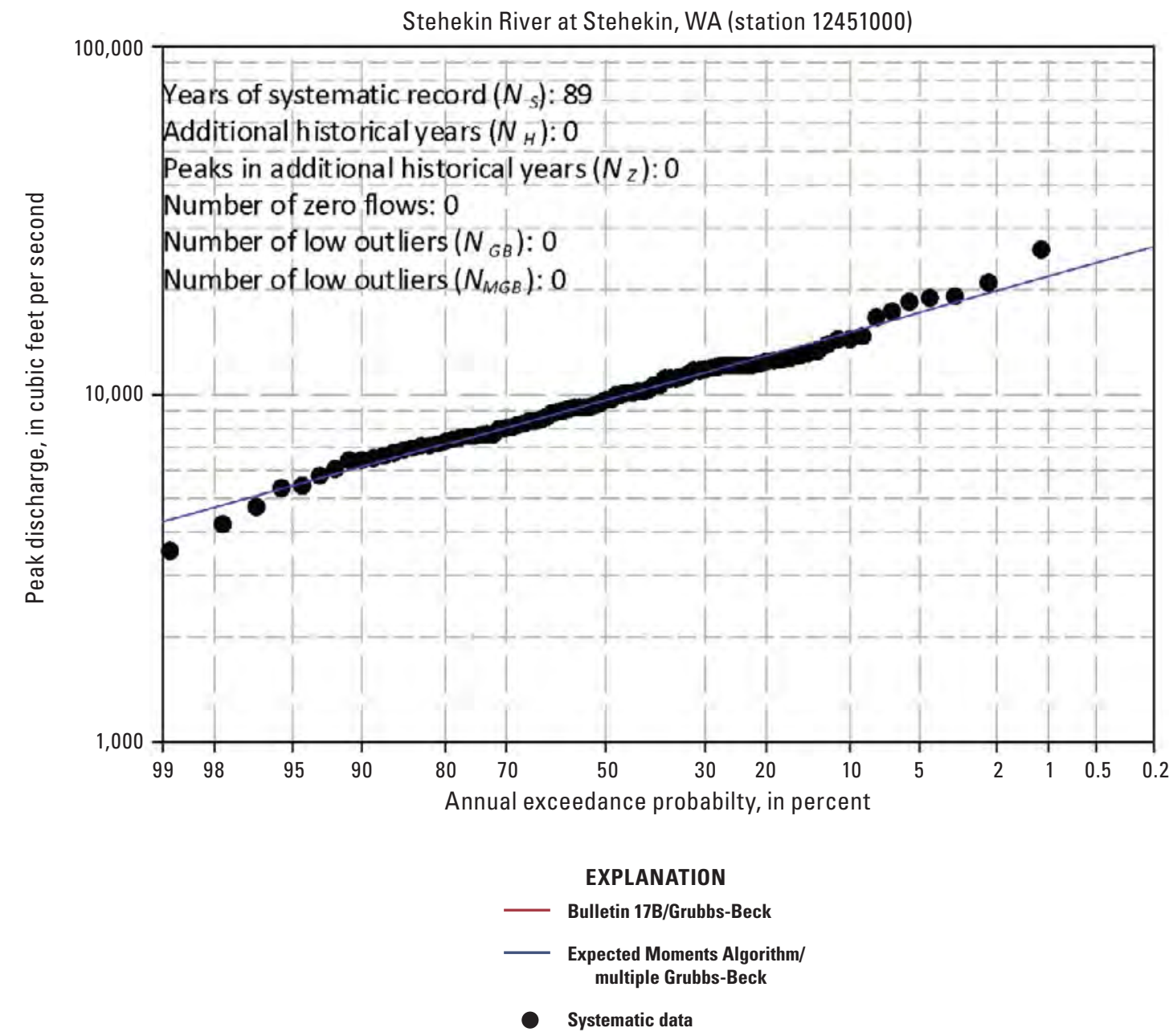

Figure 2-20. Site 12451000-Stehekin River at Stehekin, Washington (WA) with systematic data only. 


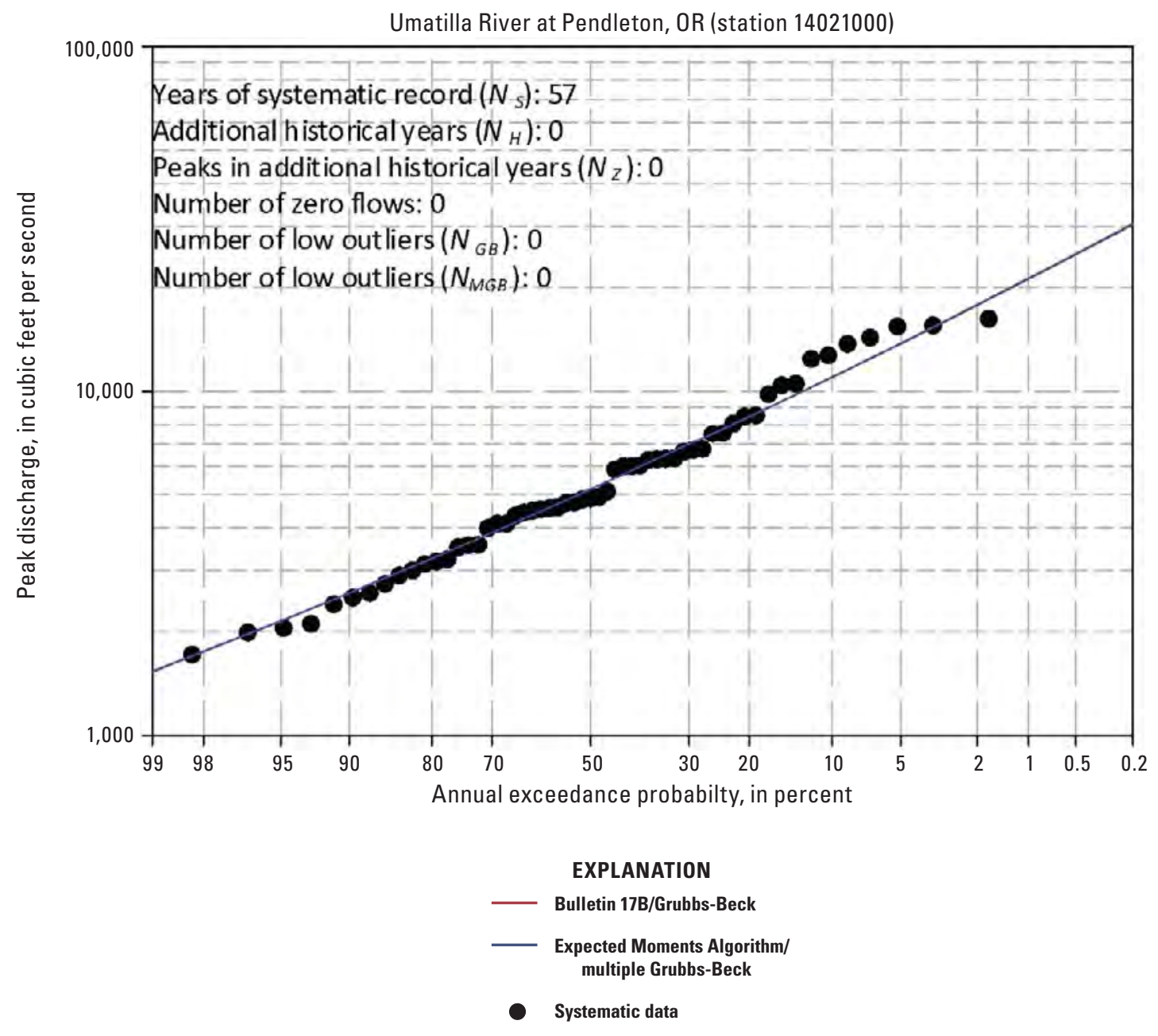

Figure 2-21. Site 14021000-Umatilla River at Pendleton, Oregon (OR) with systematic data only. 


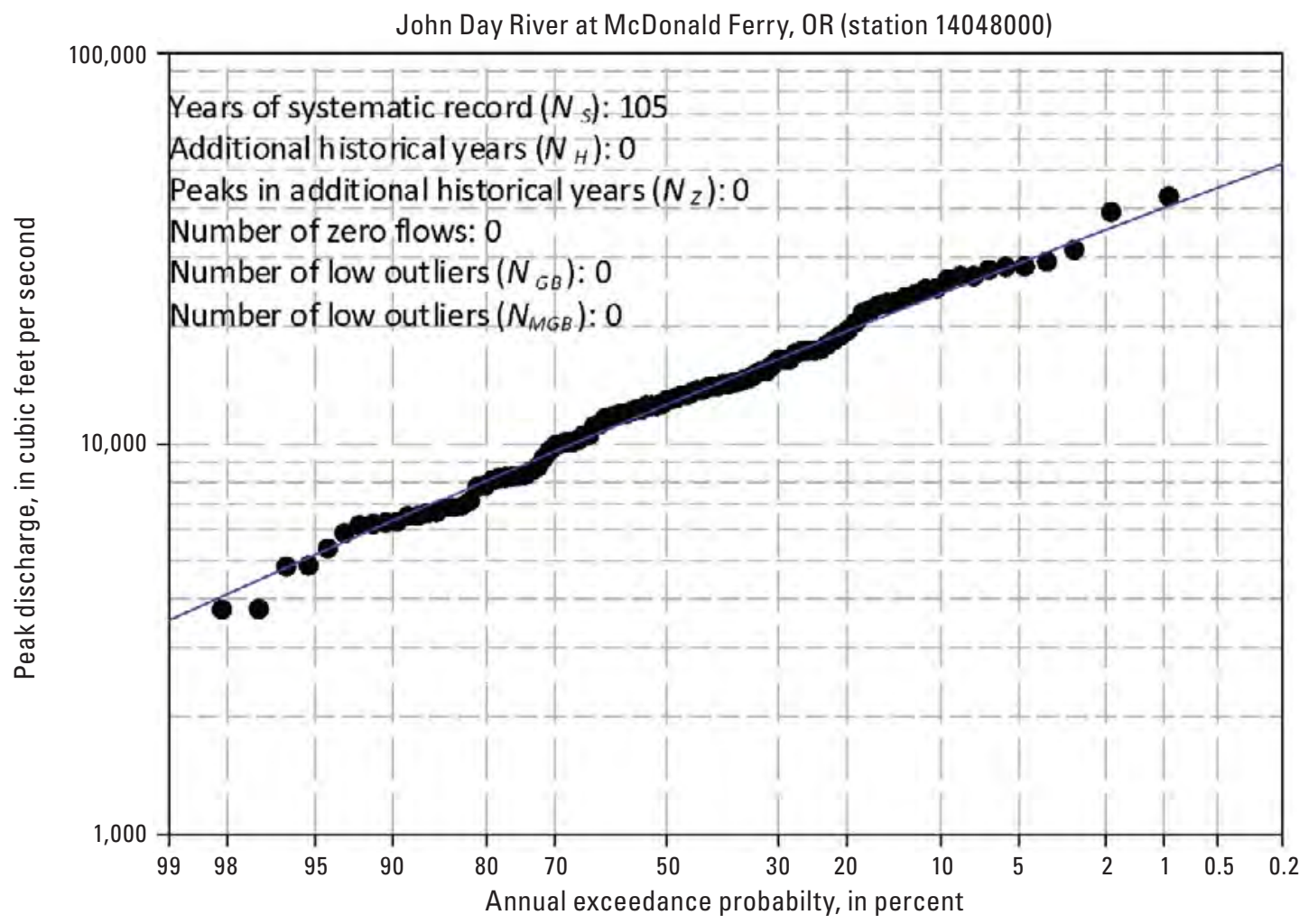

EXPLANATION

- Bulletin 17B/Grubbs-Beck

Expected Moments Algorithm/ multiple Grubbs-Beck

- Systematic data

Figure 2-22. Site 14048000-John Day River at McDonald Ferry, Oregon (OR) with systematic data only. 


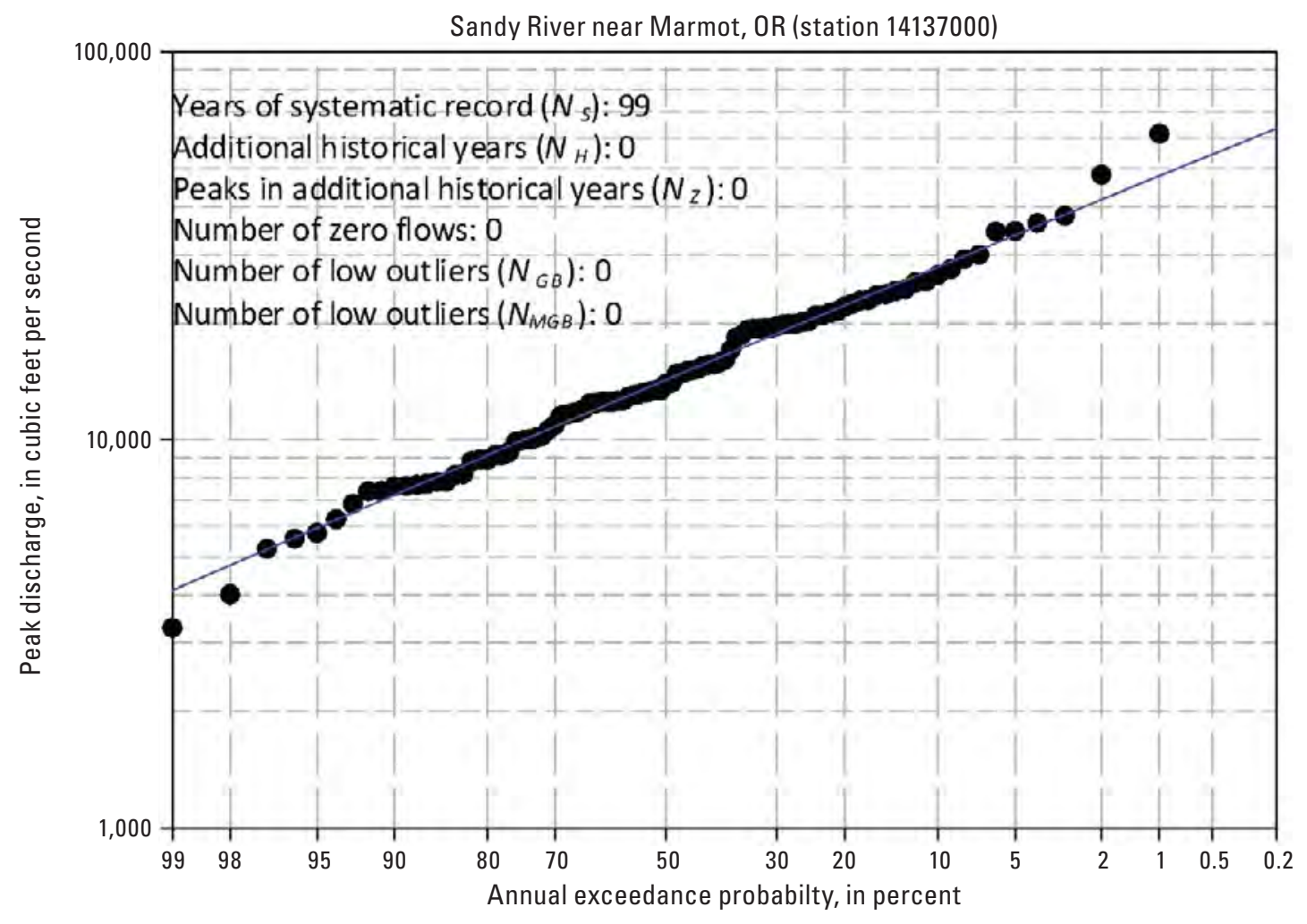

EXPLANATION

- Bulletin 17B/Grubbs-Beck

Expected Moments Algorithm/ multiple Grubbs-Beck

- Systematic data

Figure 2-23. Site 14137000-Sandy River near Marmot, Oregon (OR) with systematic data only. 


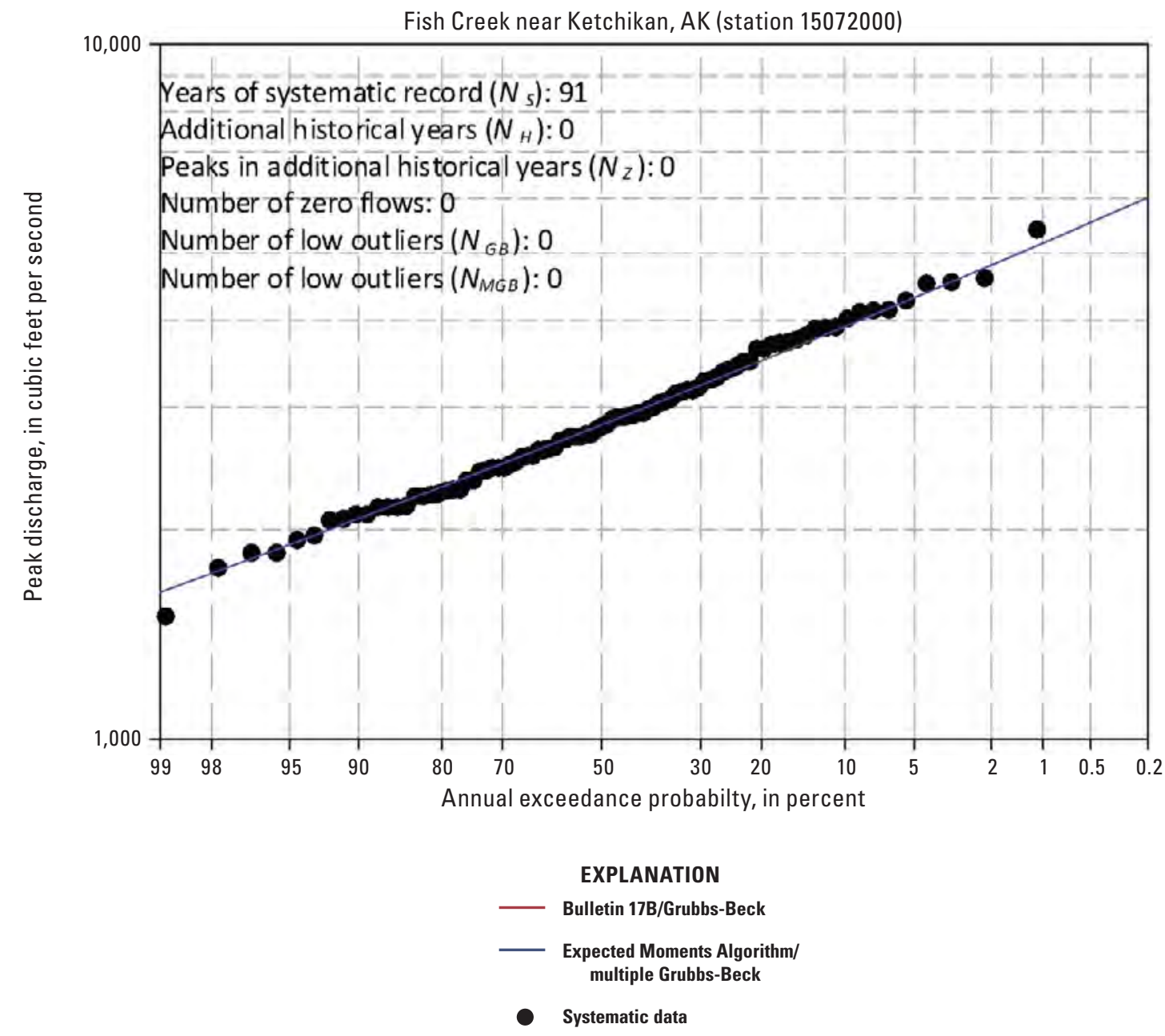

Figure 2-24. Site 15072000-Fish Creek near Ketchikan, Alaska (AK) with systematic data only. 


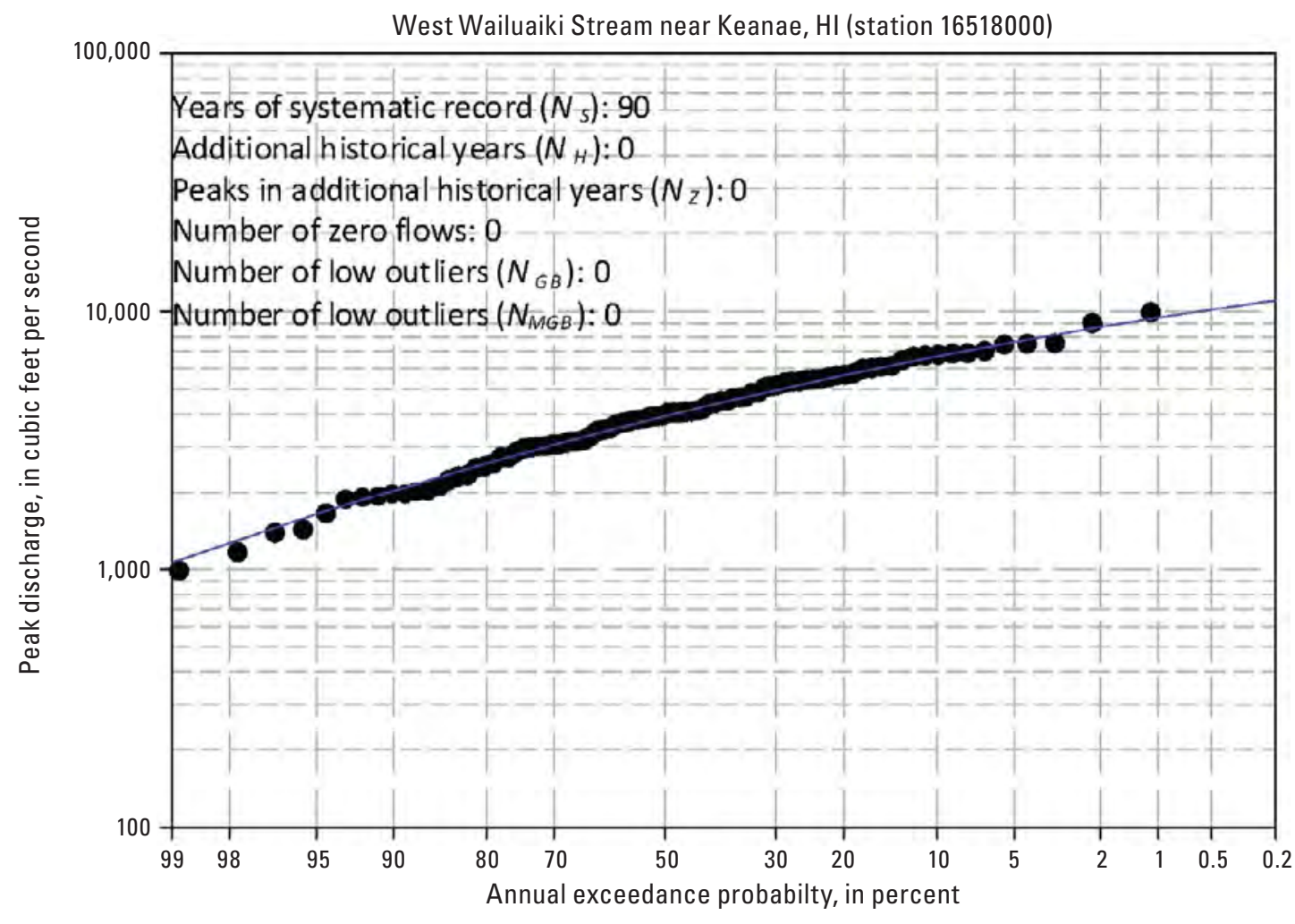

EXPLANATION

- Bulletin 17B/Grubbs-Beck

Expected Moments Algorithm/ multiple Grubbs-Beck

Systematic data

Figure 2-25. Site 16518000-West Wailuaiki Stream near Keanae, Hawaii (HI) with systematic data only. 


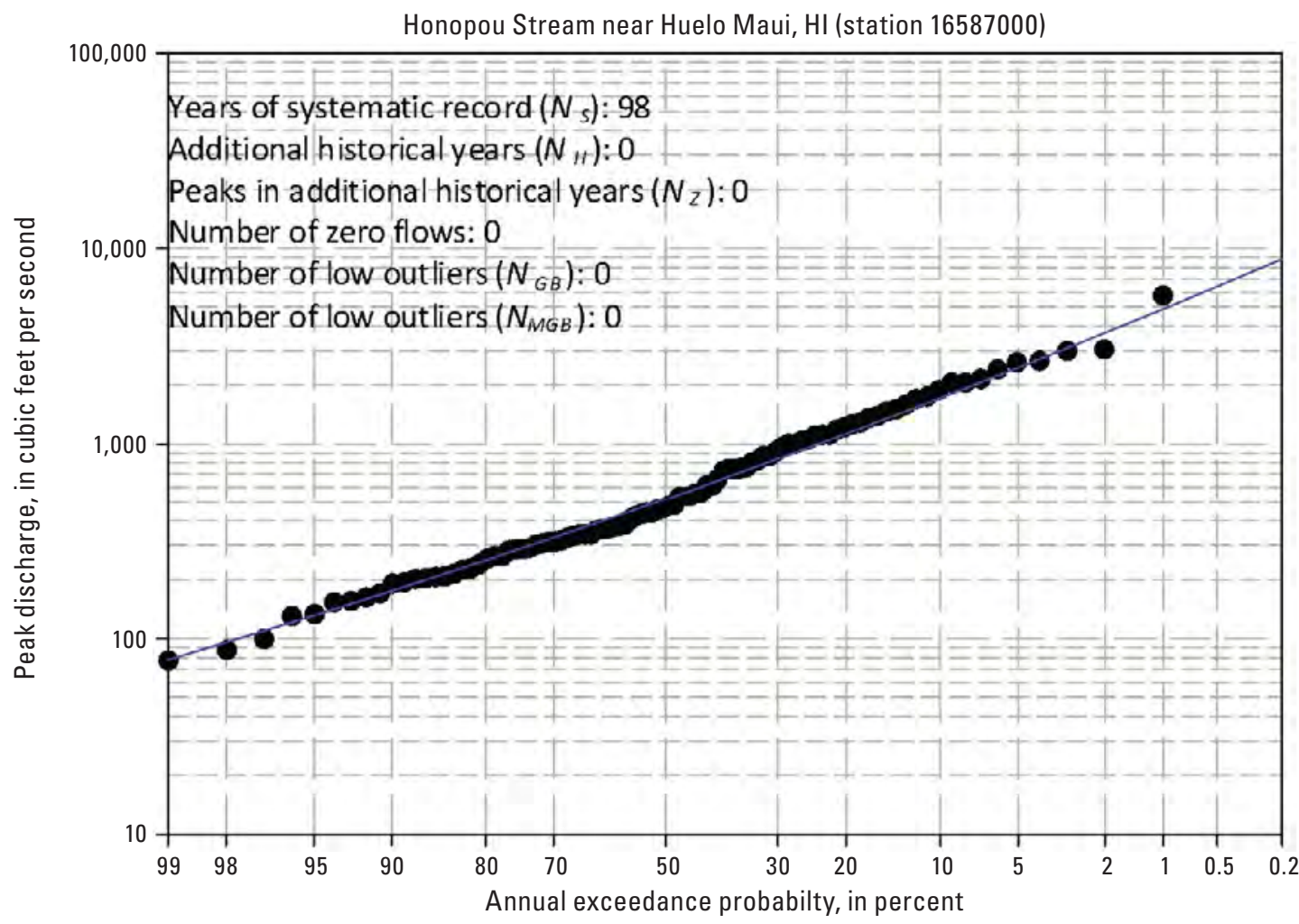

EXPLANATION

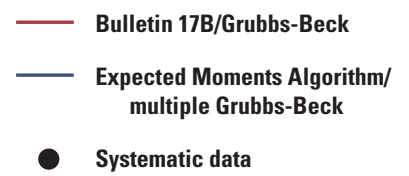

Figure 2-26. Site 16587000-Honopou Stream near Huelo Maui, Hawaii (HI) with systematic data only. 


\section{Sites With Historical Information}

Schoharie Creek at Prattsville, NY (station 01350000)

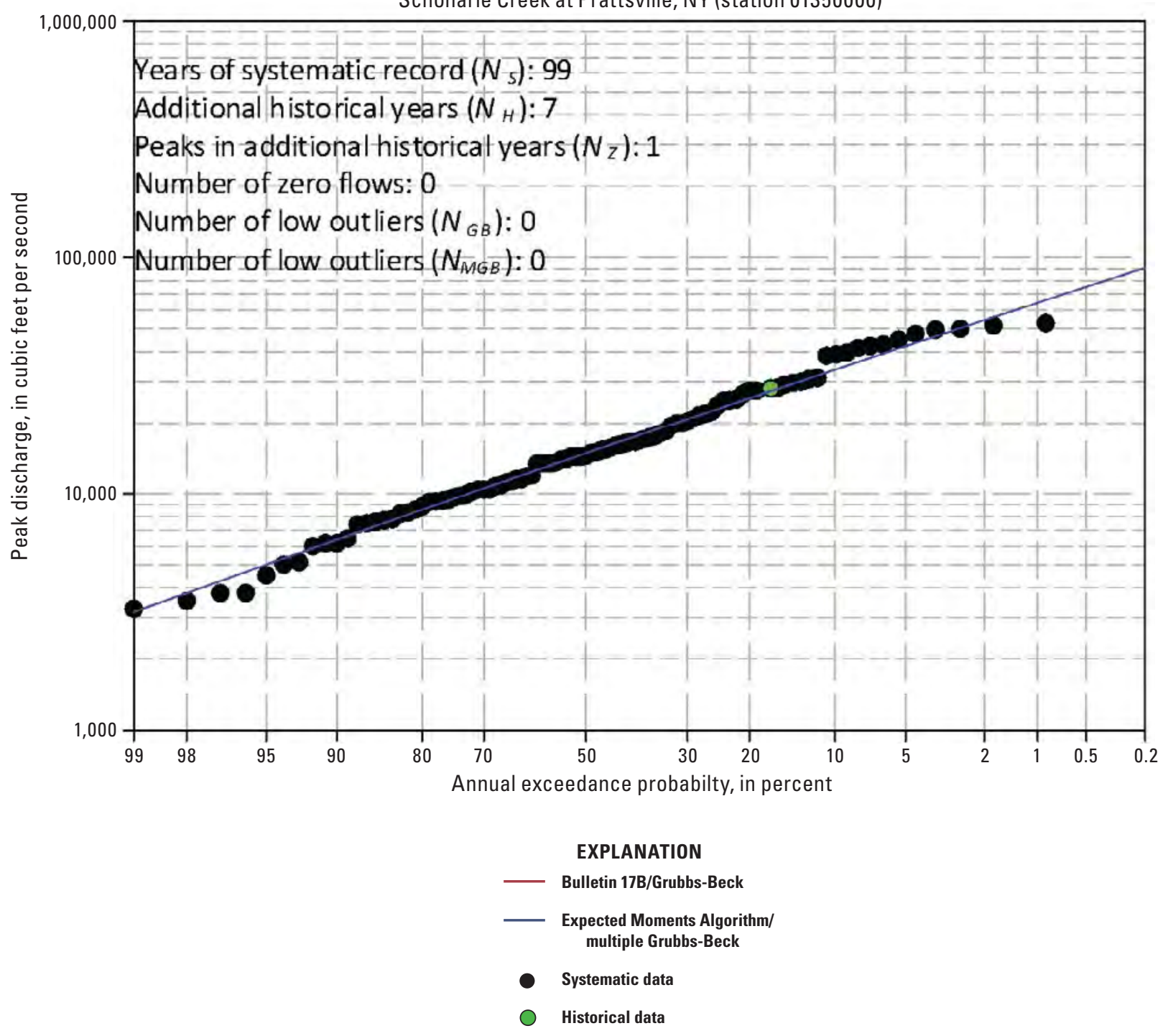

Figure 2-27. Site 01350000-Schoharie Creek at Prattsville, New York (NY) with systematic and historical data. 


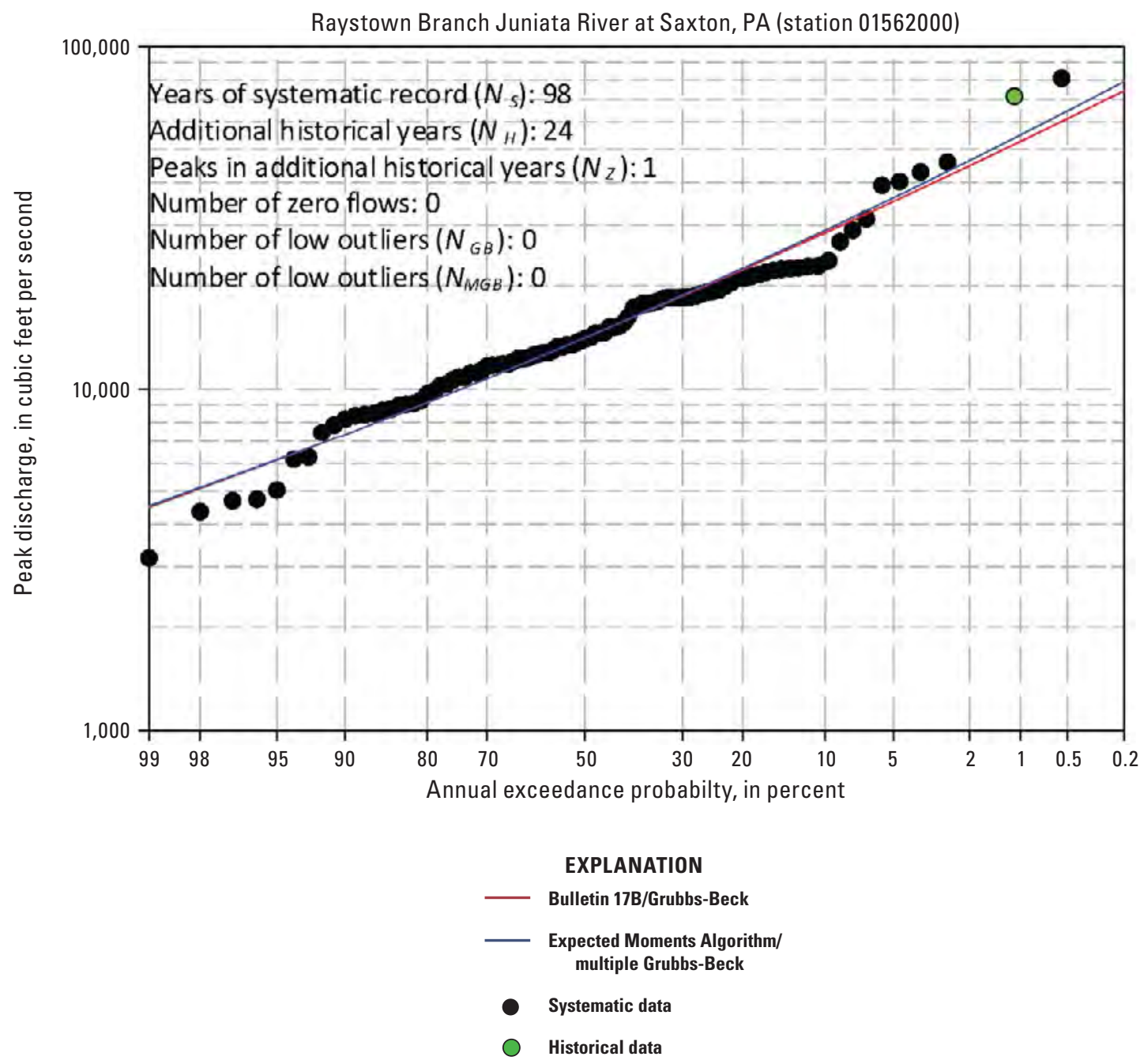

Figure 2-28. Site 01562000-Raystown Branch Juniata River at Saxton, Pennsylvania (PA) with systematic and historical data. 


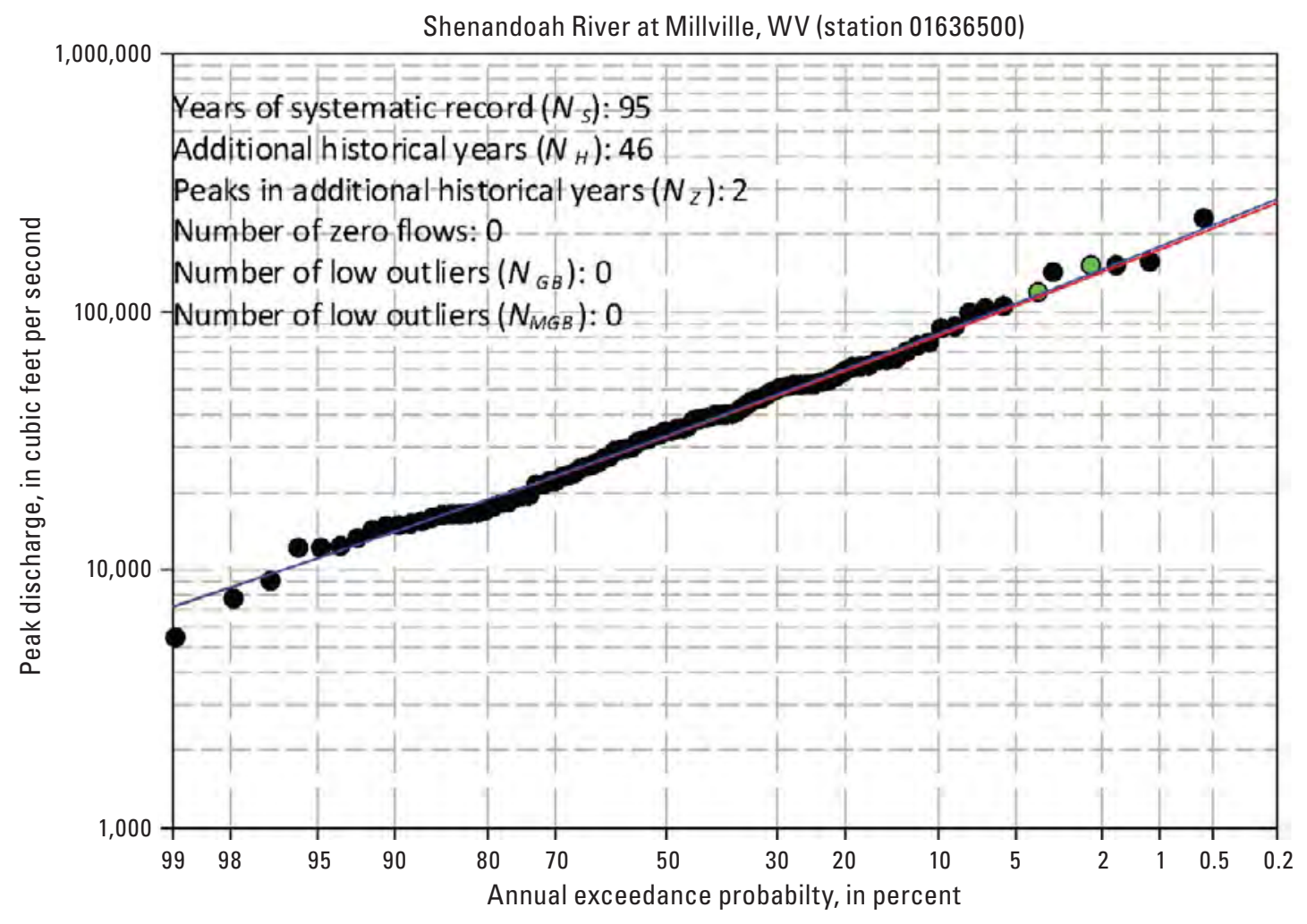

EXPLANATION

_ Bulletin 17B/Grubbs-Beck

_ Expected Moments Algorithm/ multiple Grubbs-Beck

- Systematic data

Historical data

Figure 2-29. Site 01636500-Shenandoah River at Millville, West Virginia (WV) with systematic and historical data. 


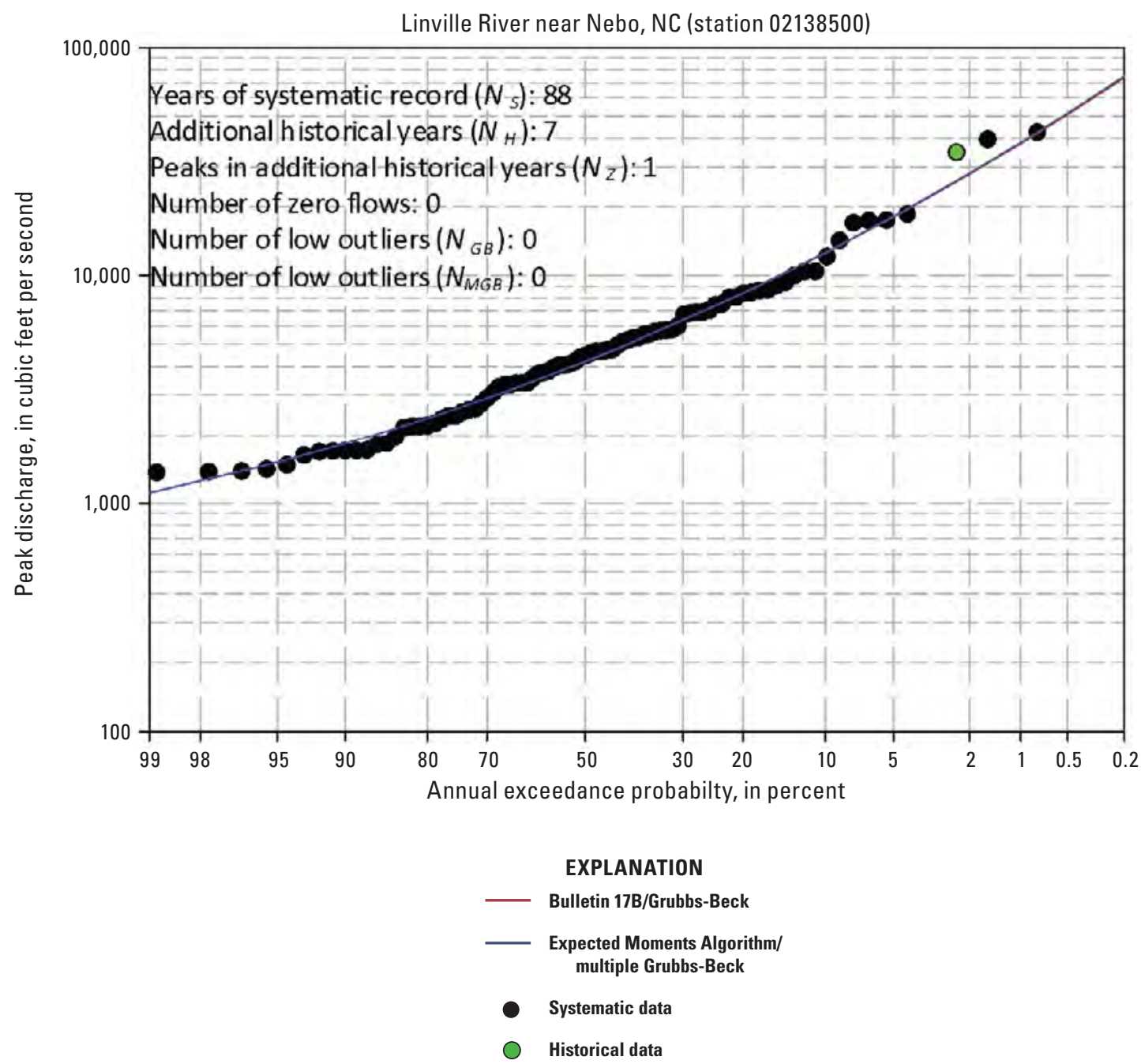

Figure 2-30. Site 02138500-Linville River near Nebo, North Carolina (NC) with systematic and historical data. 


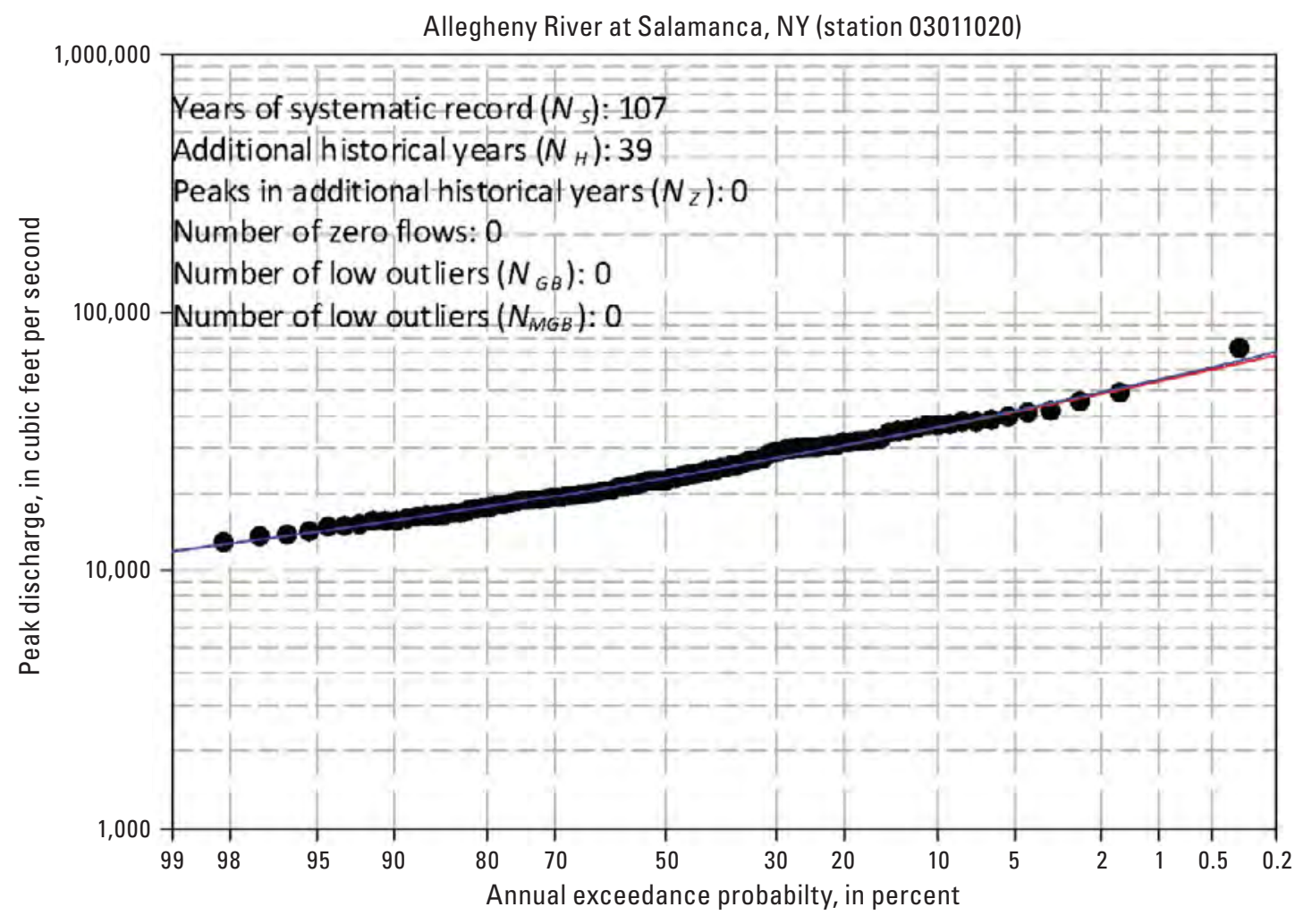

EXPLANATION

- Bulletin 17B/Grubbs-Beck

Expected Moments Algorithm/ multiple Grubbs-Beck

Systematic data

Figure 2-31. Site 03011020-Allegheny River at Salamanca, New York (NY) with systematic and historical data. 


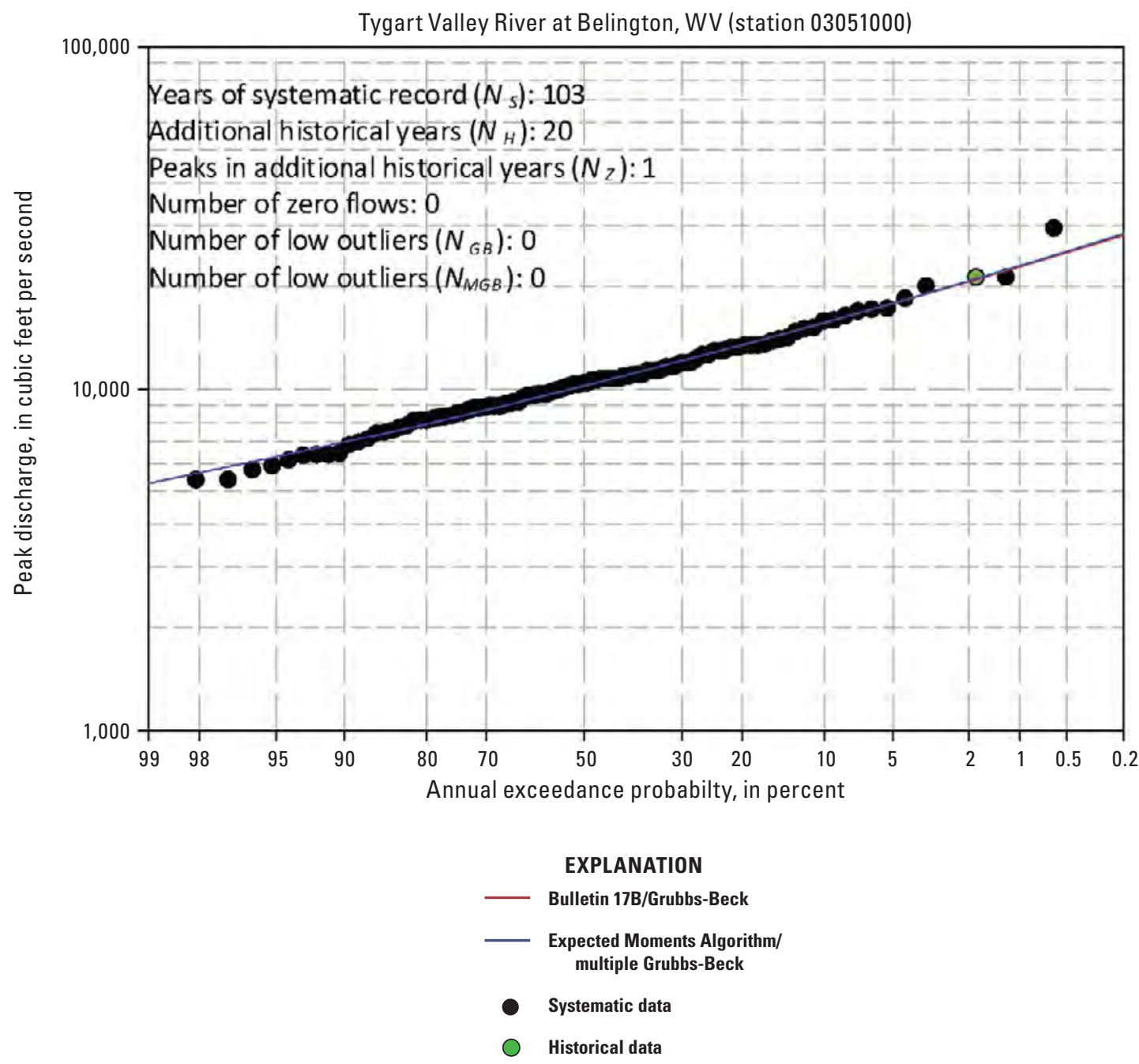

Figure 2-32. Site 03051000-Tygart Valley River at Belington, West Virginia (WV) with systematic and historical data. 


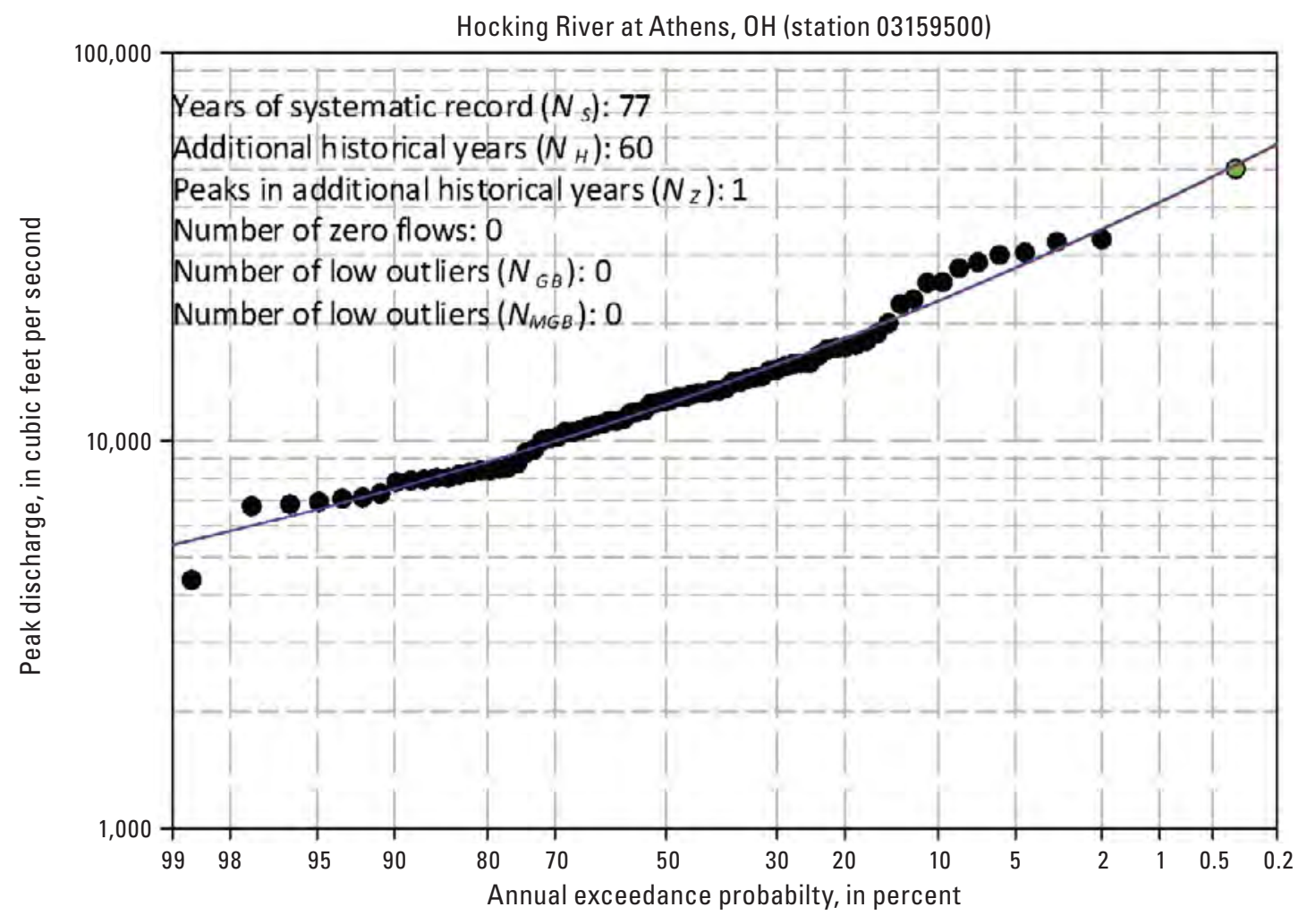

EXPLANATION

Bulletin 17B/Grubbs-Beck
$\begin{gathered}\text { Expected Moments Algorithm/ } \\ \text { multiple Grubbs-Beck }\end{gathered}$

- Systematic data

Historical data

Figure 2-33. Site 03159500-Hocking River at Athens, Ohio $(\mathrm{OH})$ with systematic and historical data. 


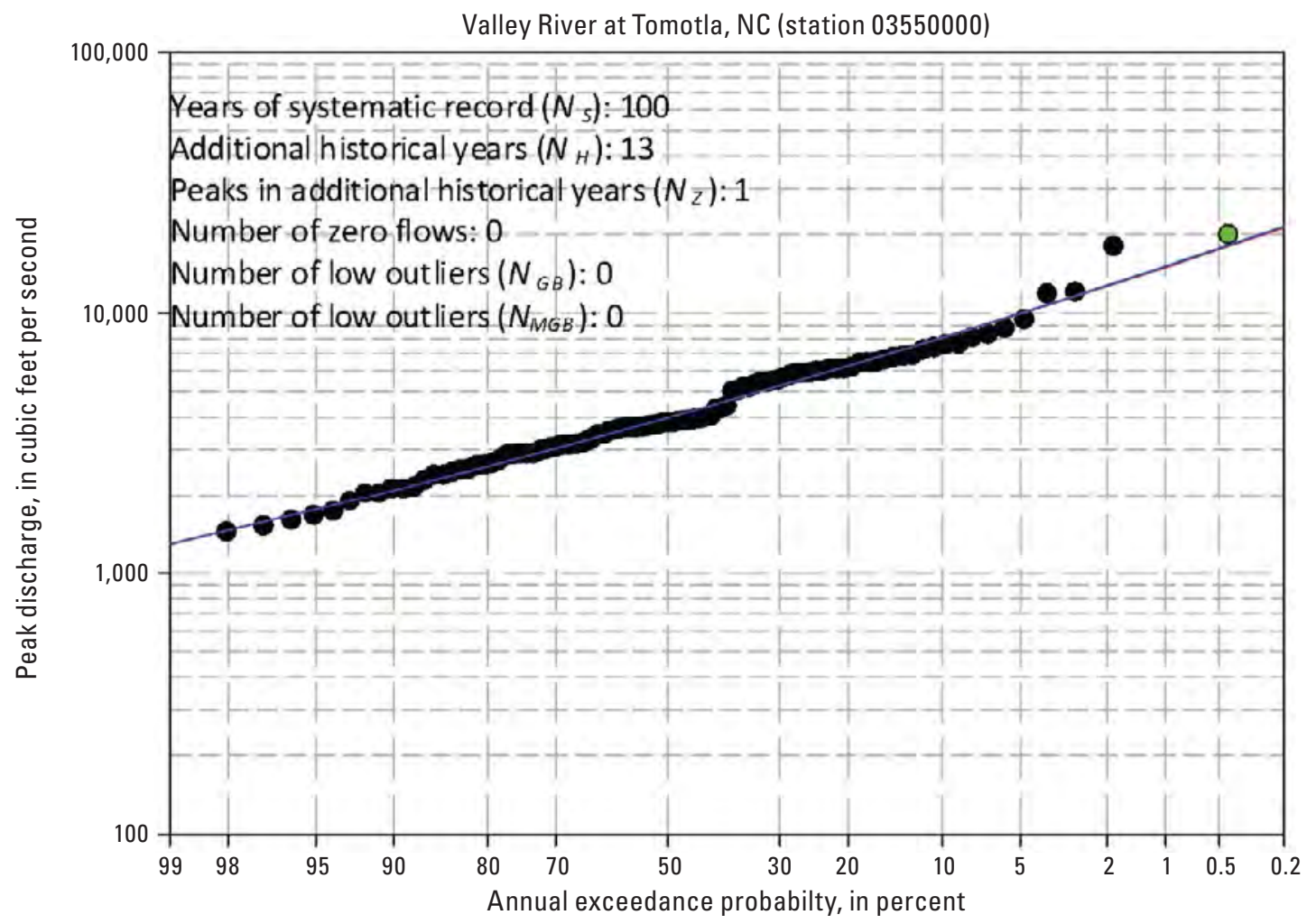

EXPLANATION

\footnotetext{
- Bulletin 17B/Grubbs-Beck

_ Expected Moments Algorithm/ multiple Grubbs-Beck

- Systematic data

Historical data
}

Figure 2-34. Site 03550000-Valley River at Tomotla, North Carolina (NC) with systematic and historical data. 


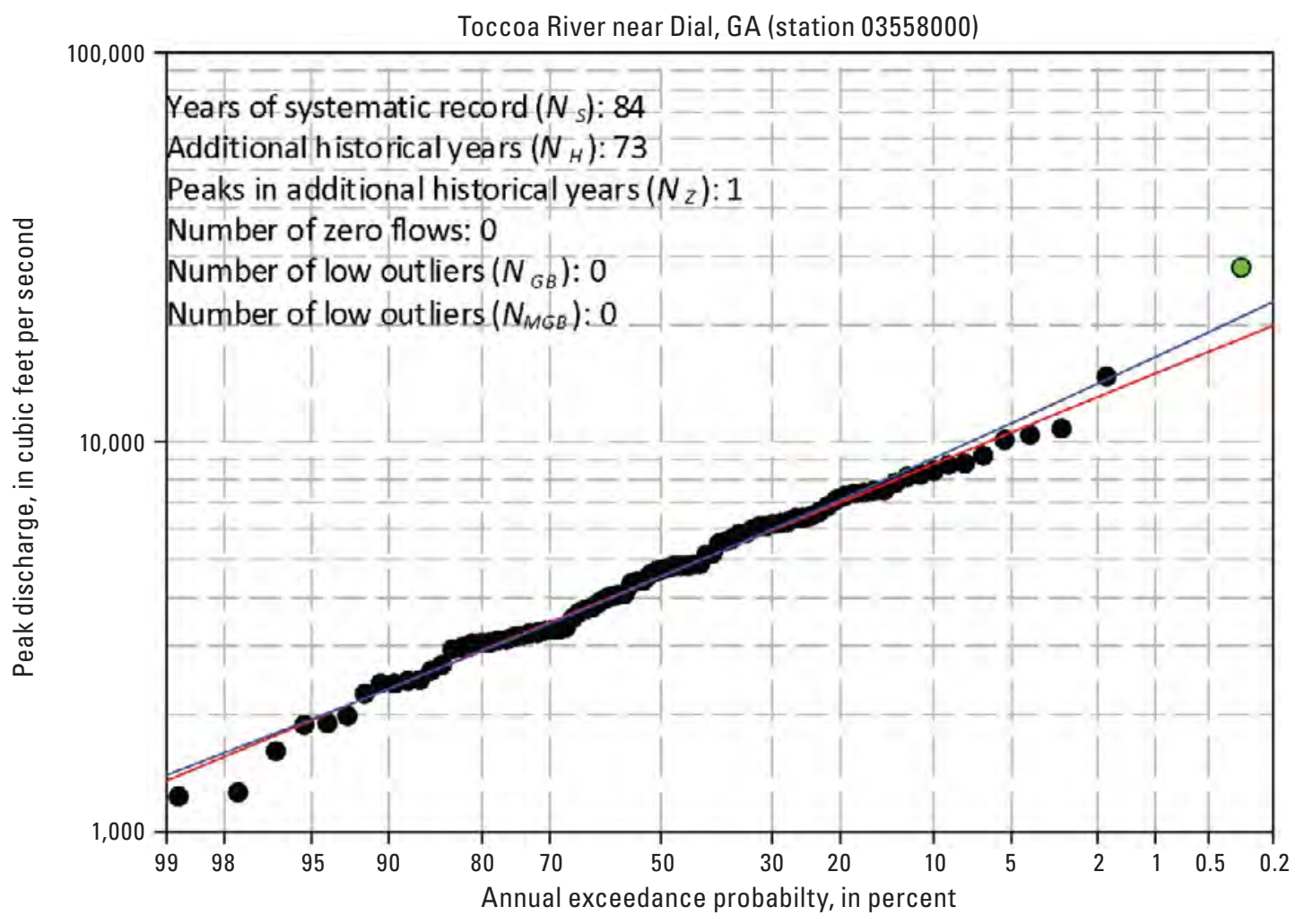

EXPLANATION

— Bulletin 17B/G

_ Expected Moments Algorithm/ multiple Grubbs-Beck

- Systematic data

Historical data

Figure 2-35. Site 03558000-Toccoa River near Dial, Georgia (GA) with systematic and historical data. 


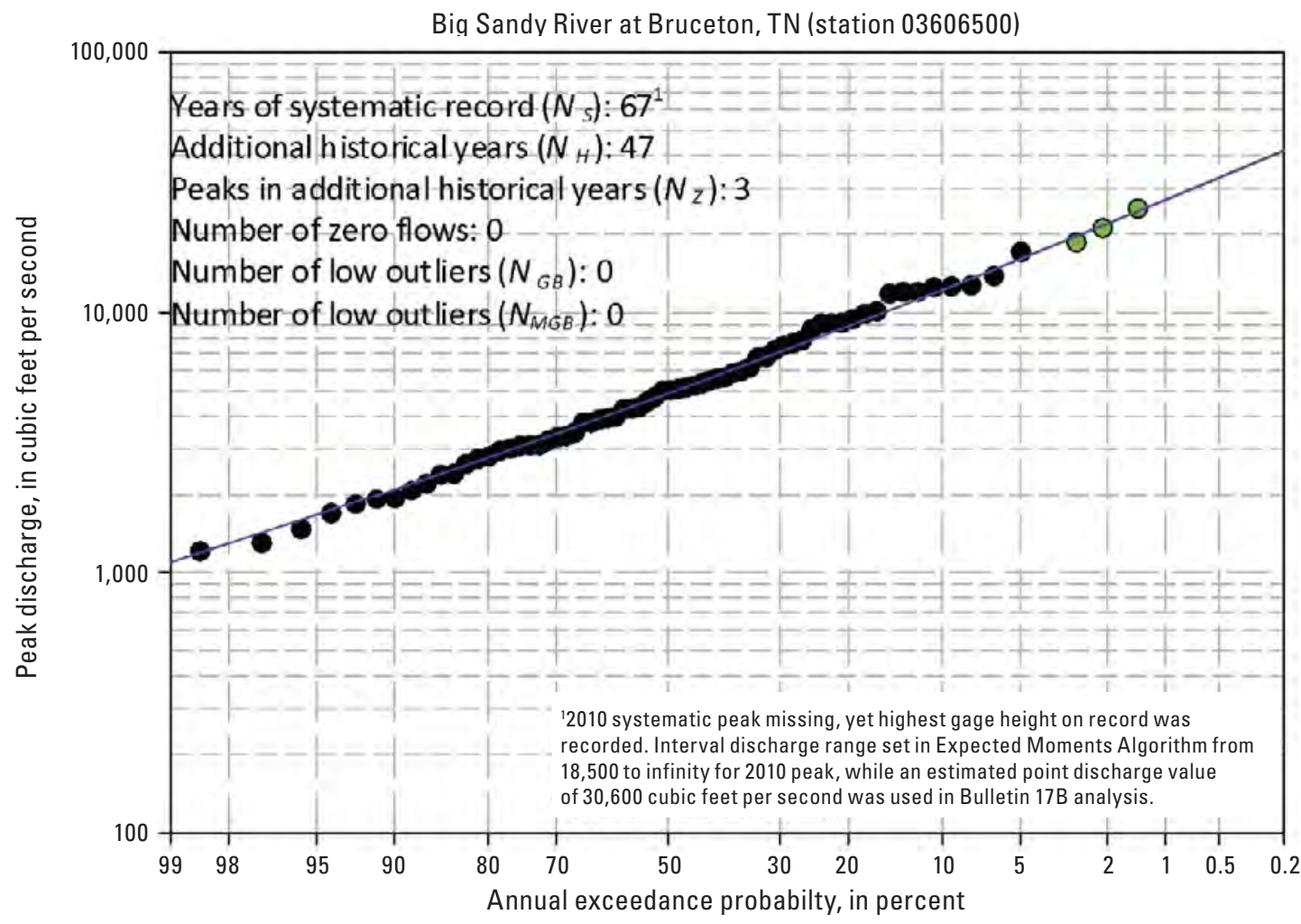

EXPLANATION

_ Expected Moments Algorithm/ multiple Grubbs-Beck

- Systematic data

Historical data

Figure 2-36. Site 03606500-Big Sandy River at Bruceton, Tennessee (TN) with systematic and historical data. 


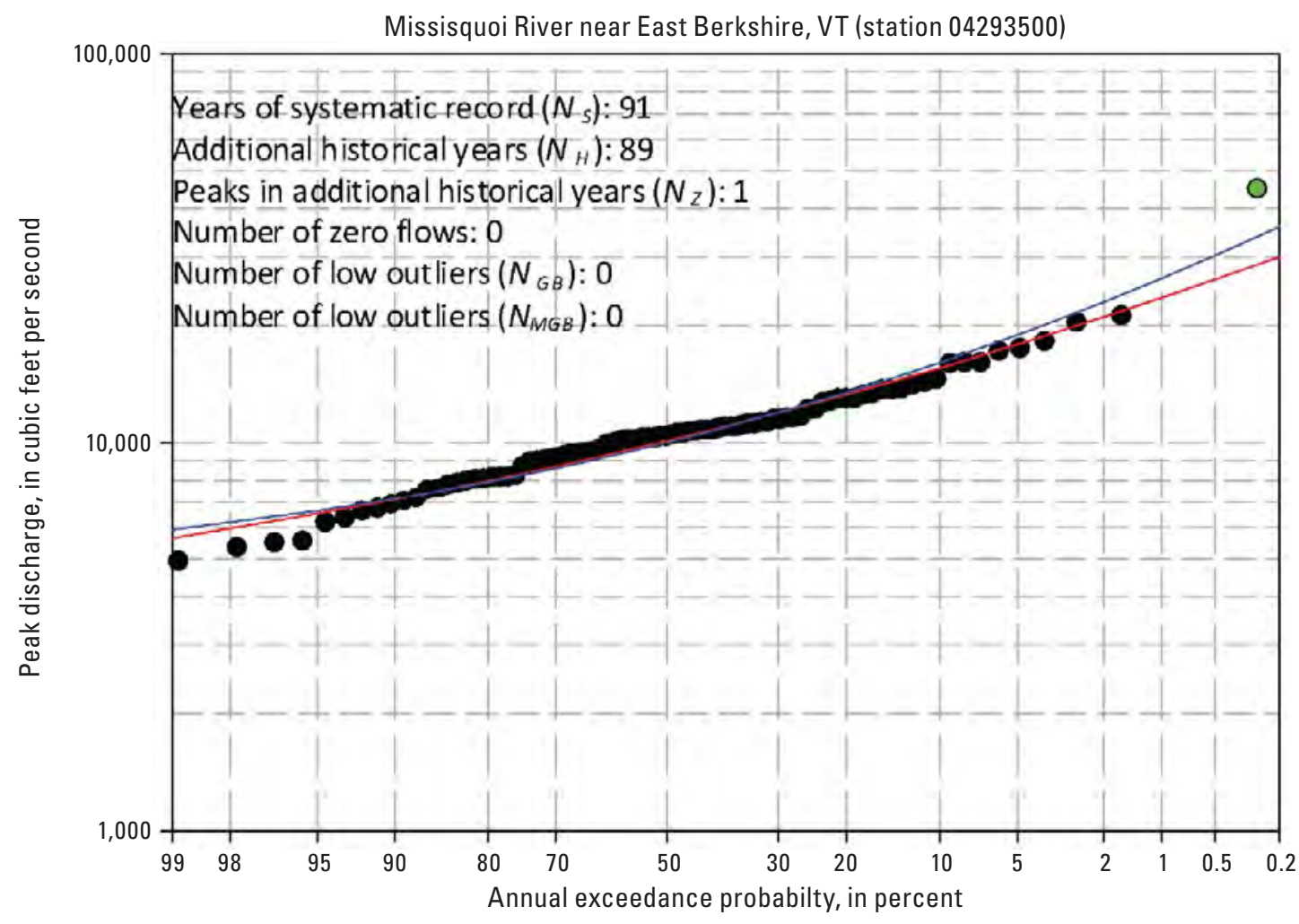

EXPLANATION

— Bulletin 17B/Grubbs-Beck

- Expected Moments Algorithm/ multiple Grubbs-Beck

- Systematic data

Historical data

Figure 2-37. Site 04293500-Missisquoi River near East Berkshire, Vermont (VT) with systematic and historical data. 


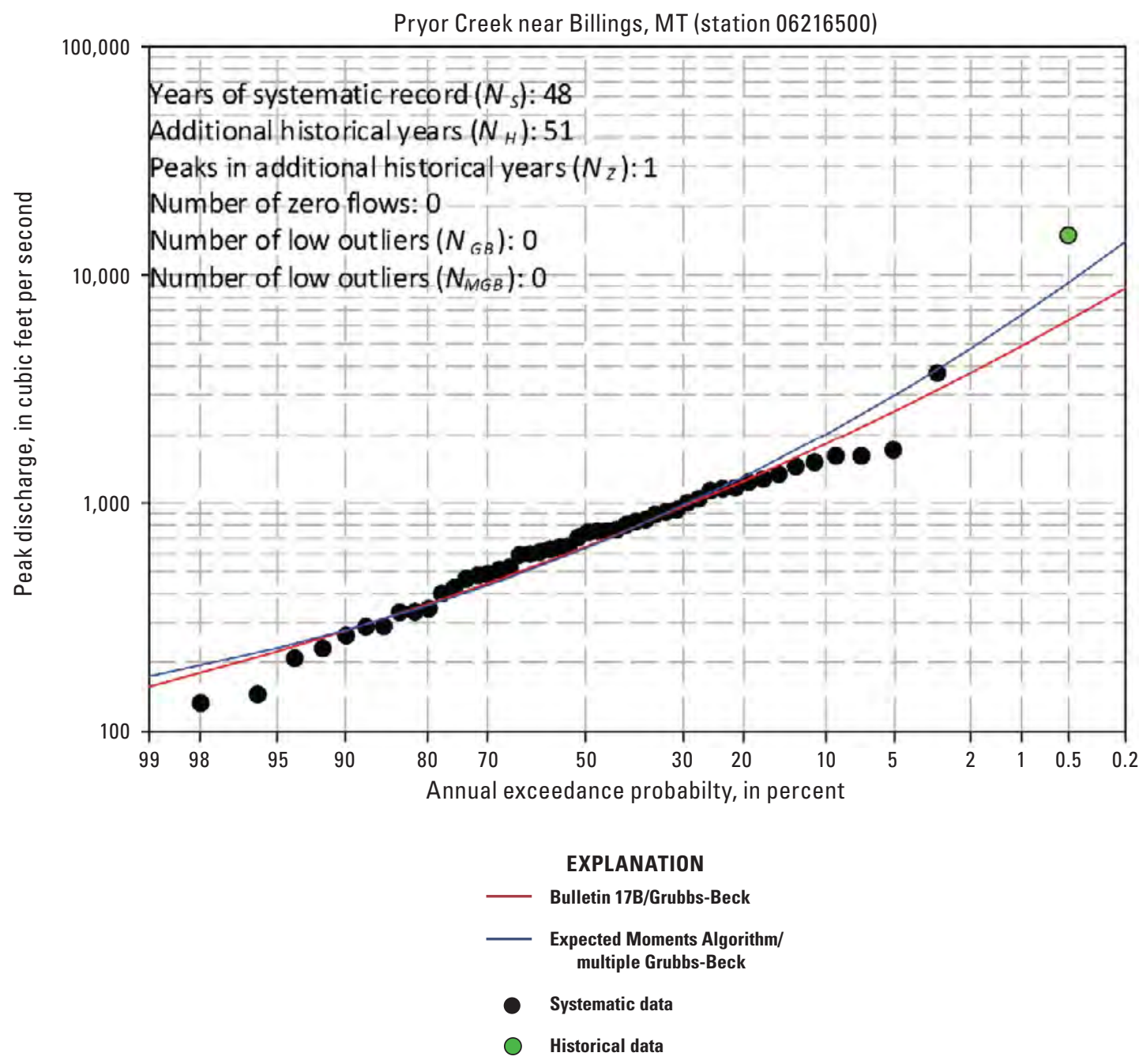

Figure 2-38. Site 06216500-Pryor Creek near Billings, Montana (MT) with systematic and historical data. 


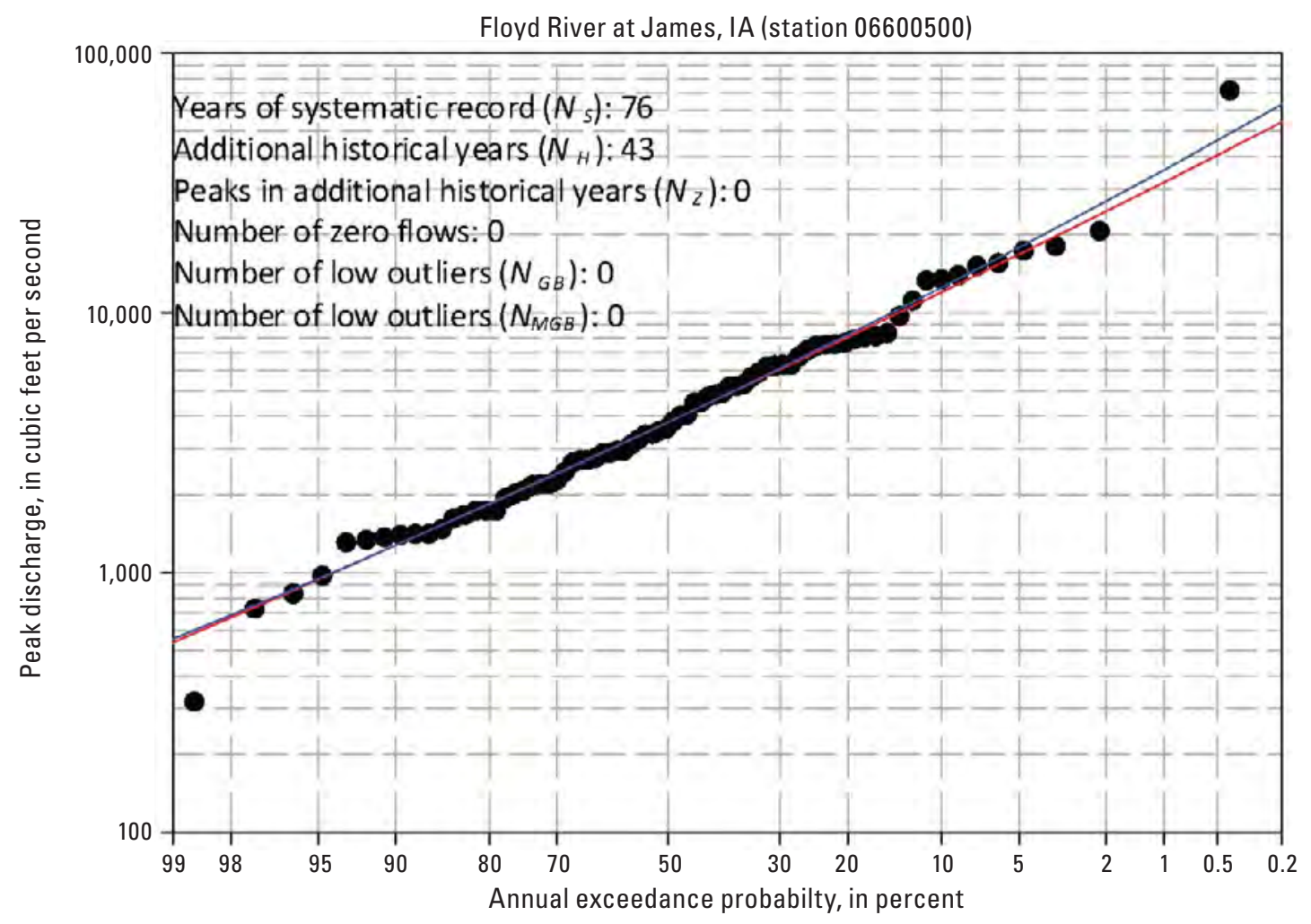

EXPLANATION

- Bulletin 17B/Grubbs-Beck

—_ Expected Moments Algorithm/ multiple Grubbs-Beck

- Systematic data

Historical data

Figure 2-39. Site 06600500-Floyd River at James, lowa (IA) with systematic and historical data. 


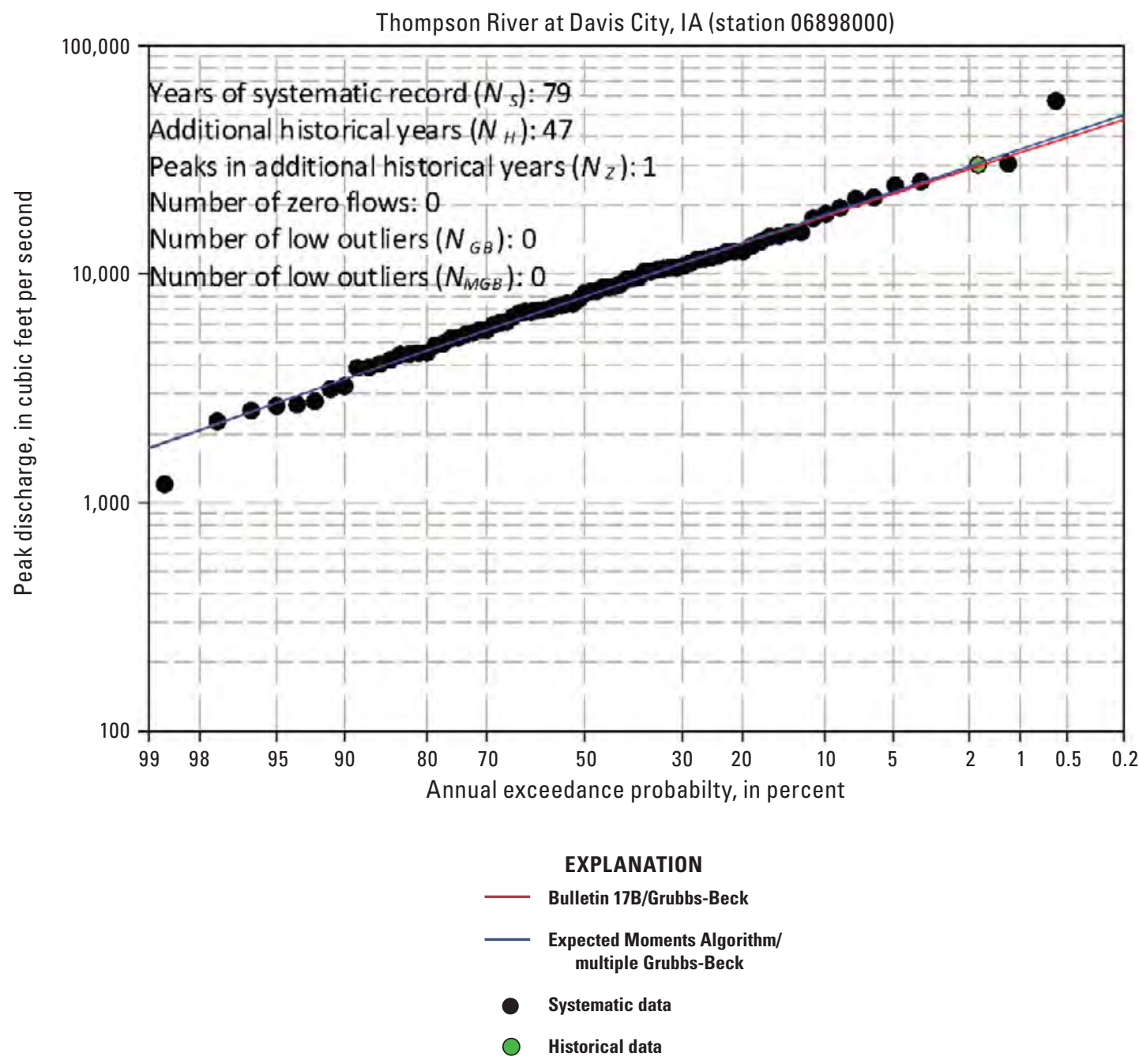

Figure 2-40. Site 06898000-Thompson River at Davis City, lowa (IA) with systematic and historical data. 


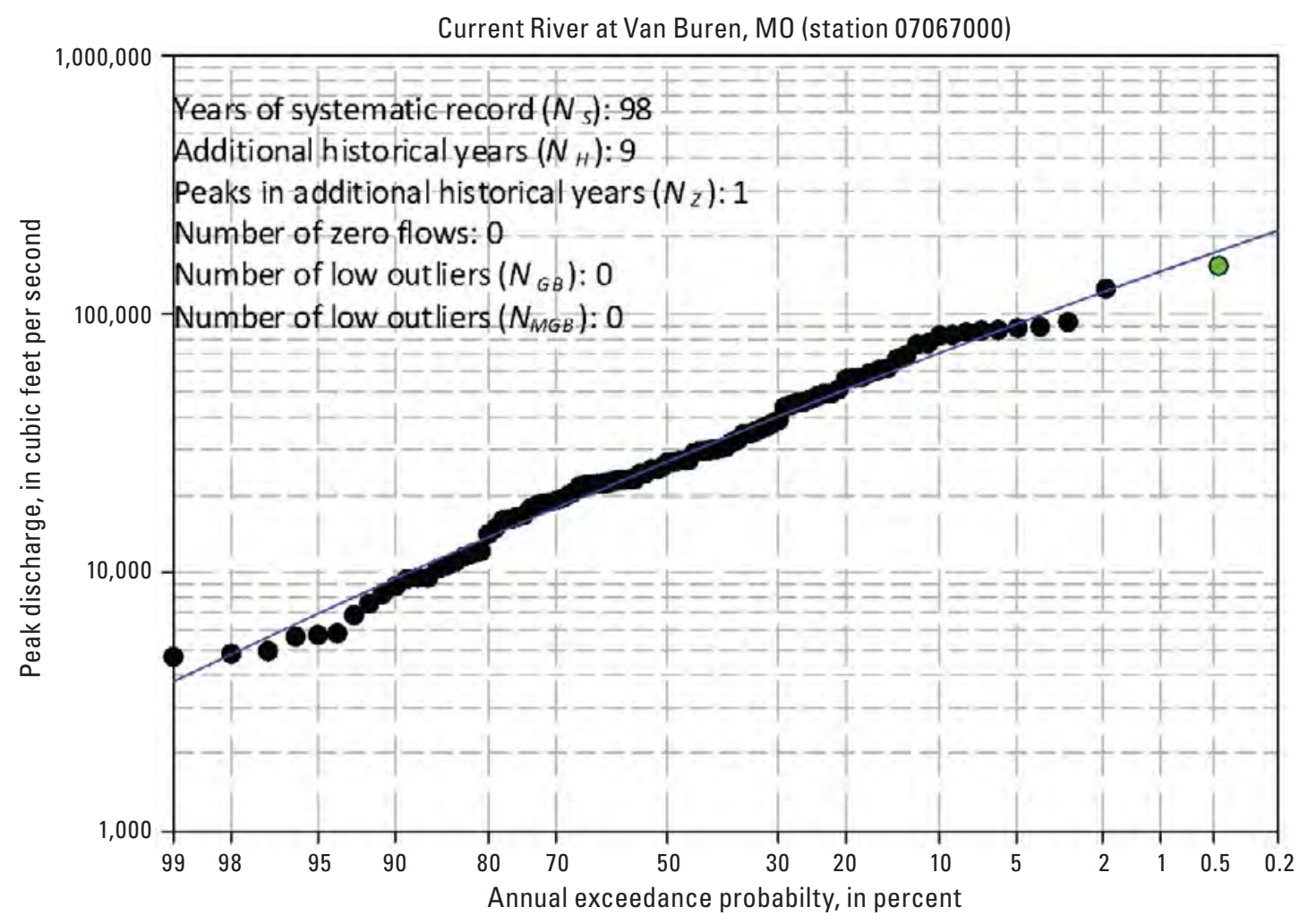

EXPLANATION

- Bulletin 17B/Grubbs-Beck

_ Expected Moments Algorithm/ multiple Grubbs-Beck

- Systematic data

Historical data

Figure 2-41. Site 07067000-Current River at Van Buren, Missouri (MO) with systematic and historical data. 


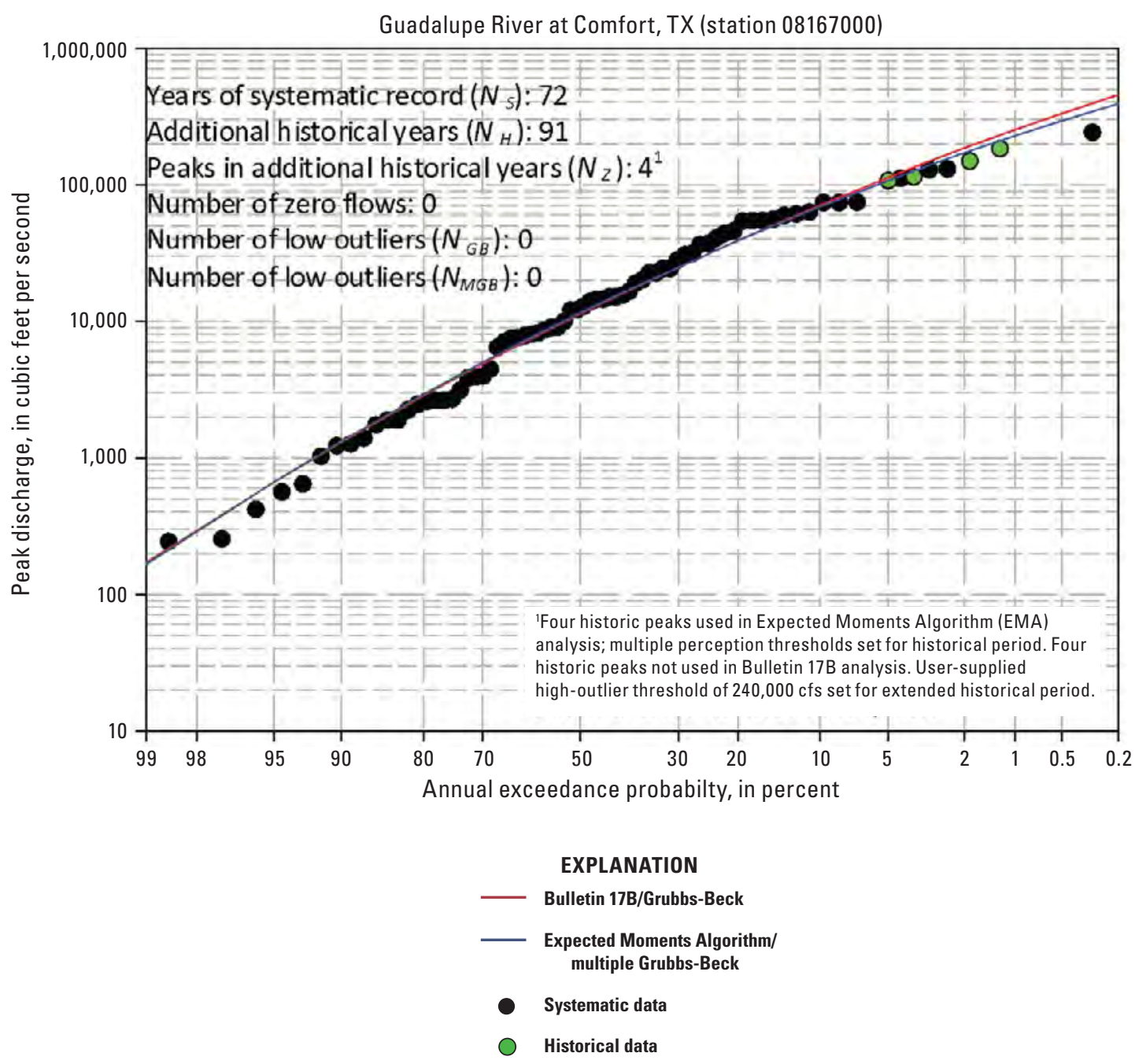

Figure 2-42. Site 08167000-Guadalupe River at Comfort, Texas (TX) with systematic and historical data. 


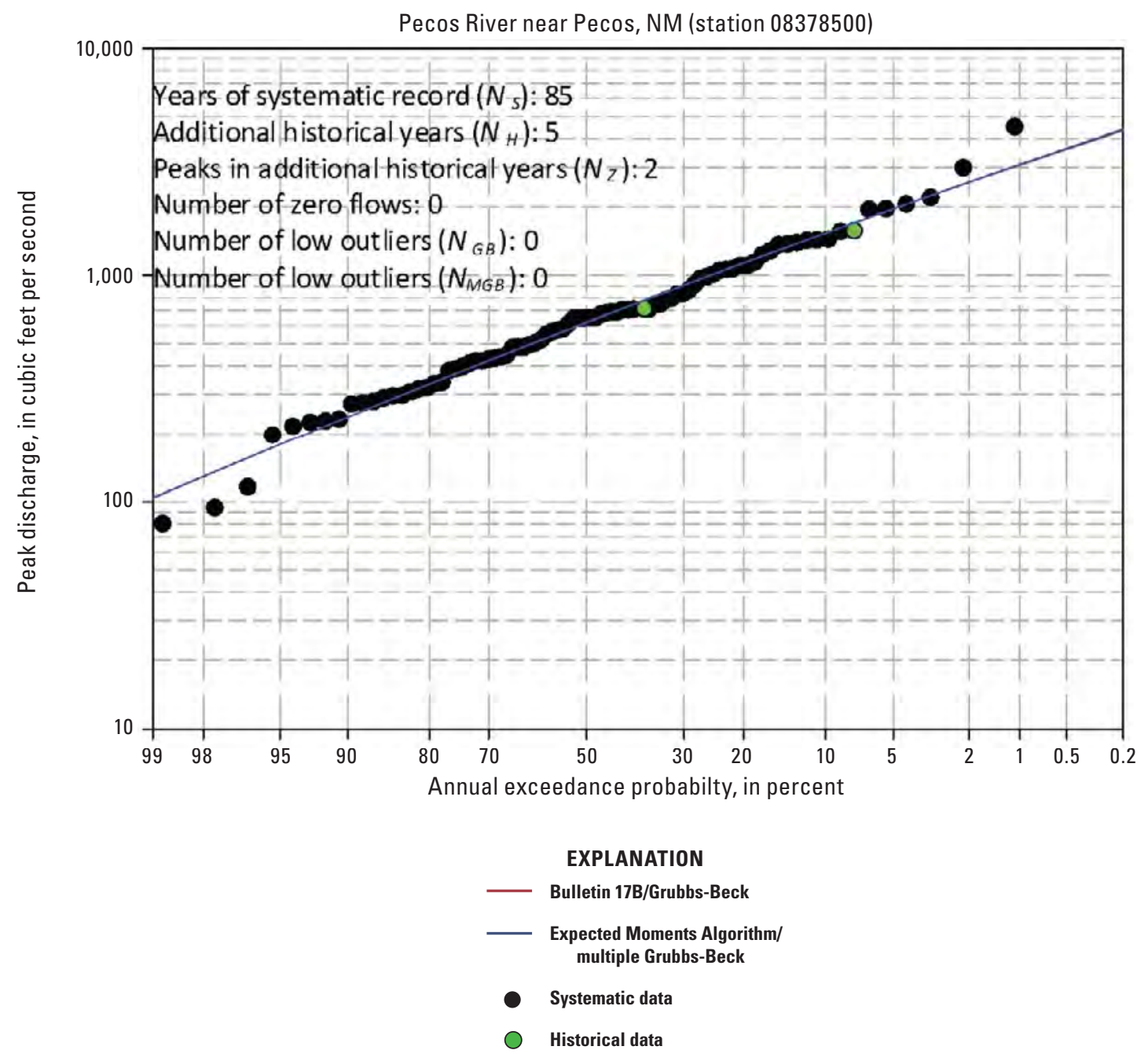

Figure 2-43. Site 08378500-Pecos Rivert near Pecos, New Mexico (NM) with systematic and historical data. 


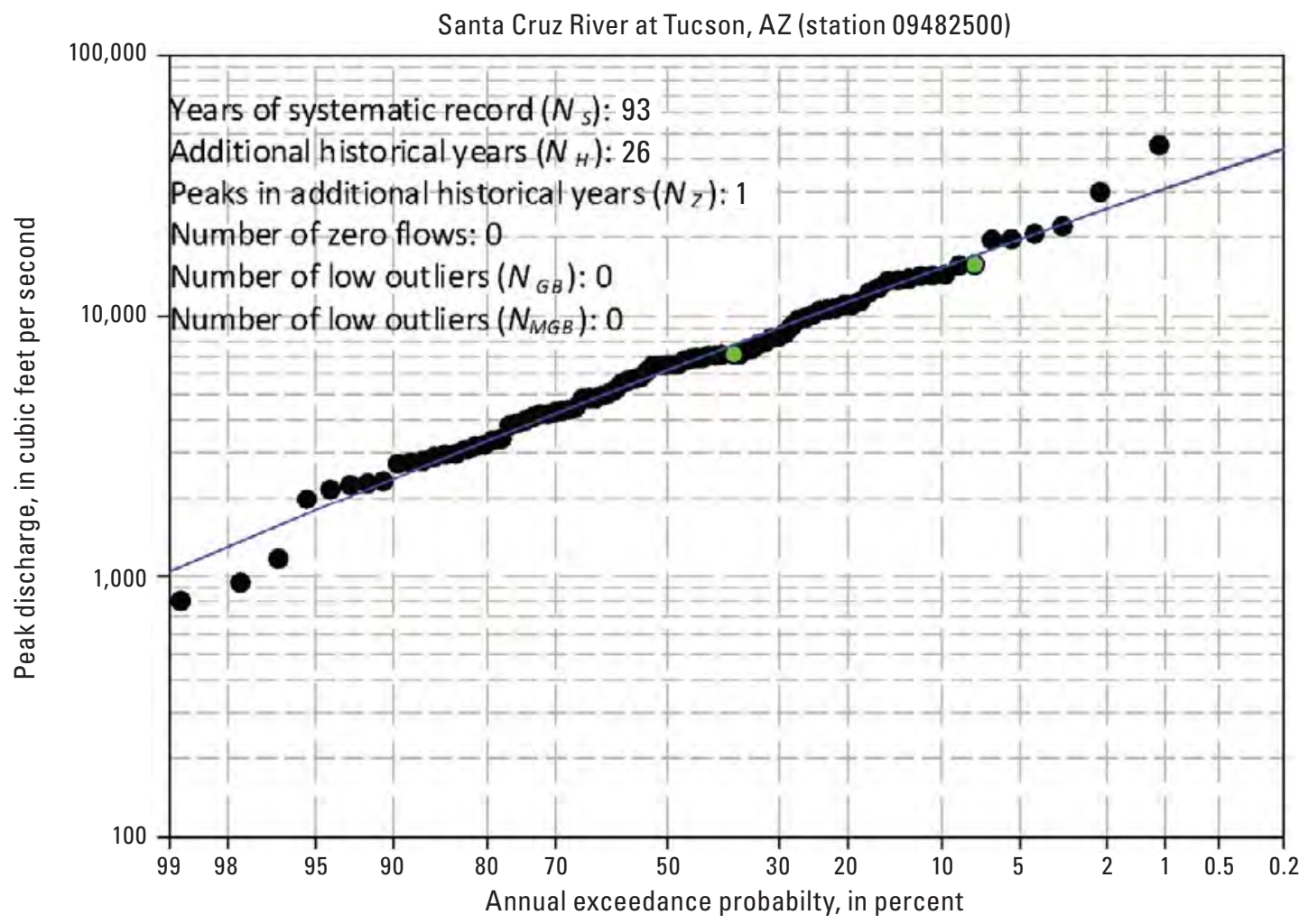

EXPLANATION

\footnotetext{
- Bulletin 17B/Grubbs-Beck

Expected Moments Algorithm/ multiple Grubbs-Beck

- Systematic data

O Historical data
}

Figure 2-44. Site 09482500-Santa Cruz River at Tucson, Arizona (AZ) with systematic and historical data. 


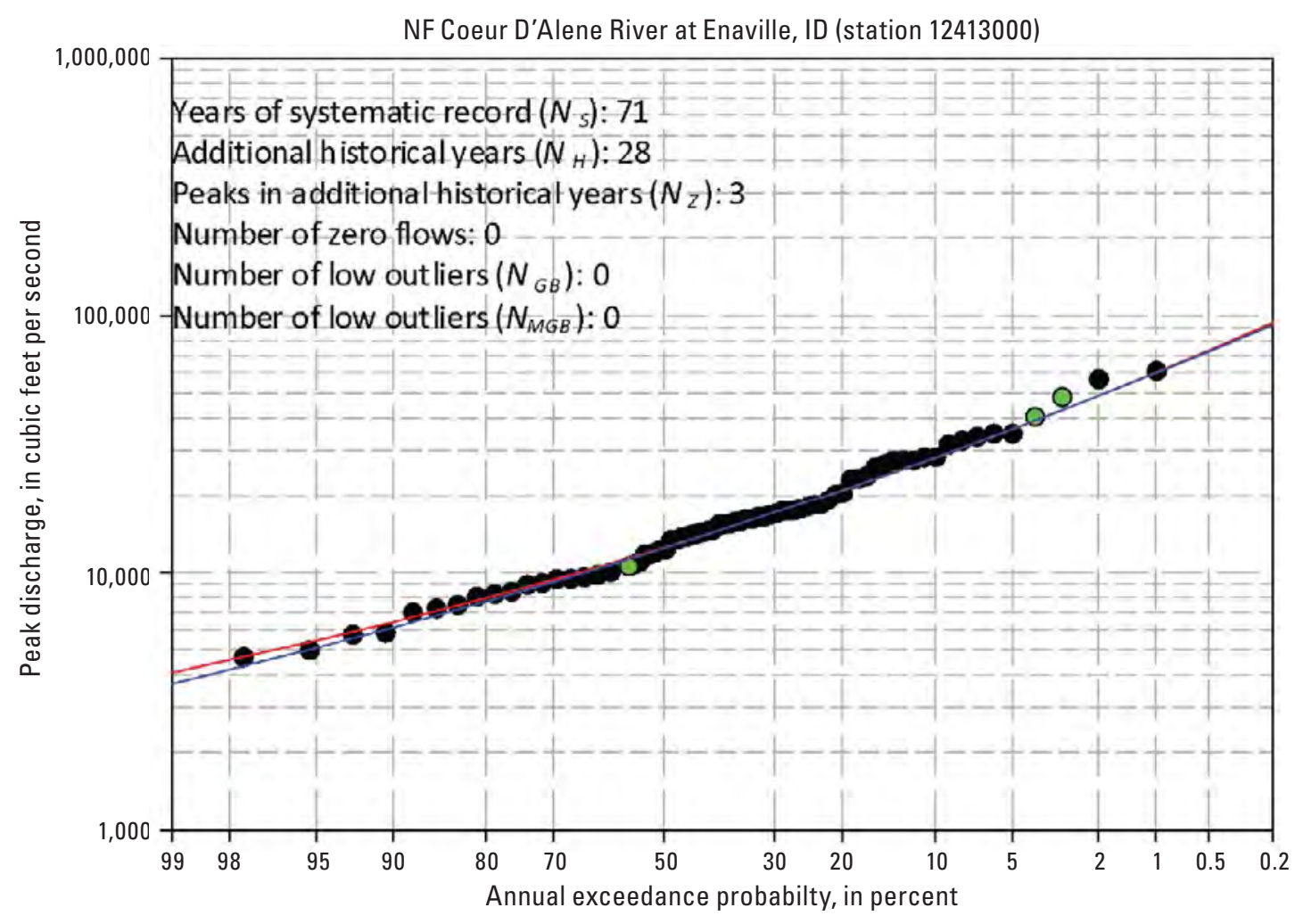

EXPLANATION

_- Bulletin 17B/Grubbs-Beck

_- Expected Moments Algorithm/ multiple Grubbs-Beck

- Systematic data

Historical data

Figure 2-45. Site 12413000-North Fork (NF) Coeur D'Alene River at Enaville, Idaho (ID) with systematic and historical data. 


\section{Sites With Potentially Influential Low Floods}

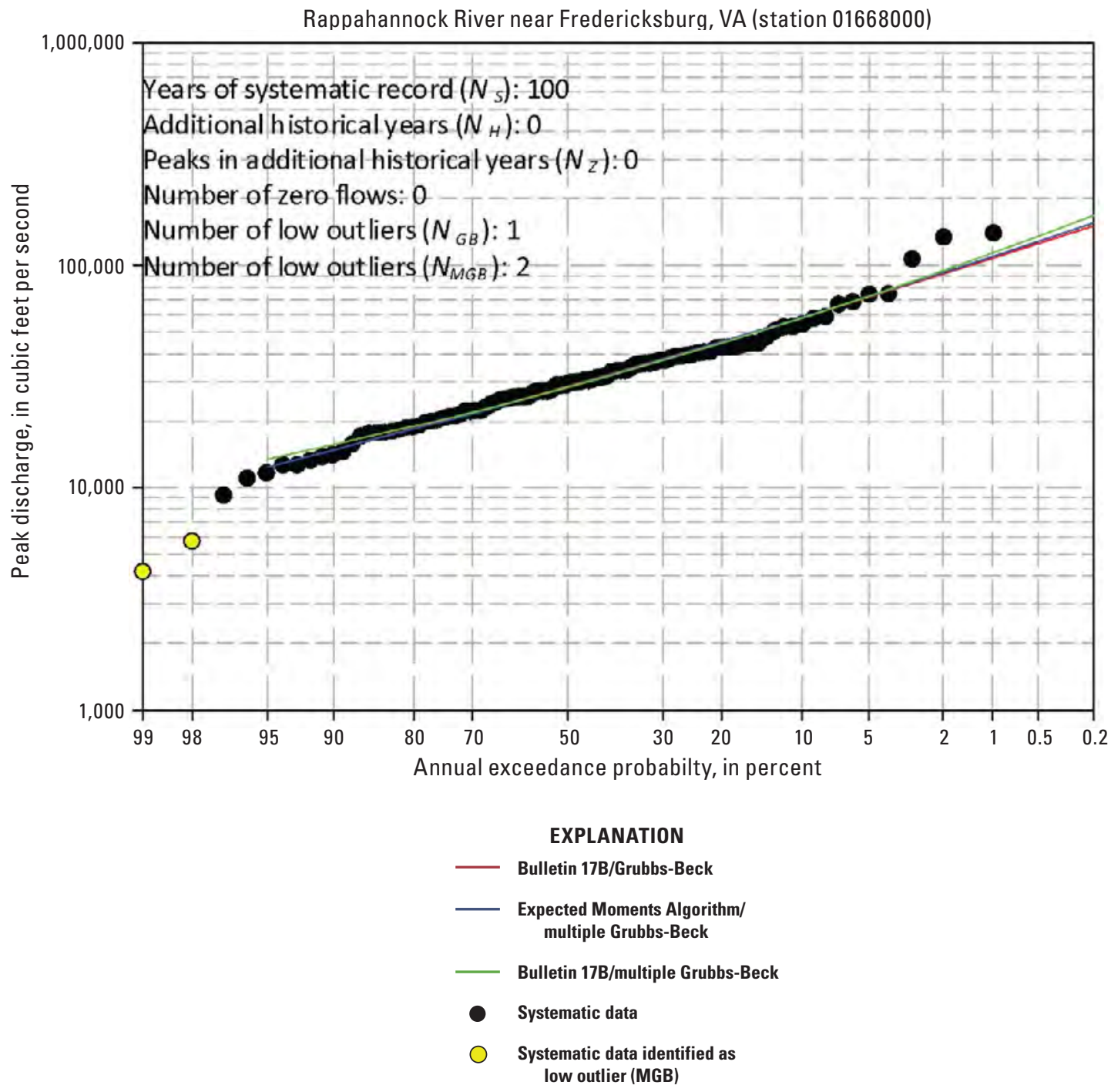

Figure 2-46. Site 01668000-Rappahannock River near Fredericksburg, Virginia (VA) with potentially influential low floods and no historical information. 


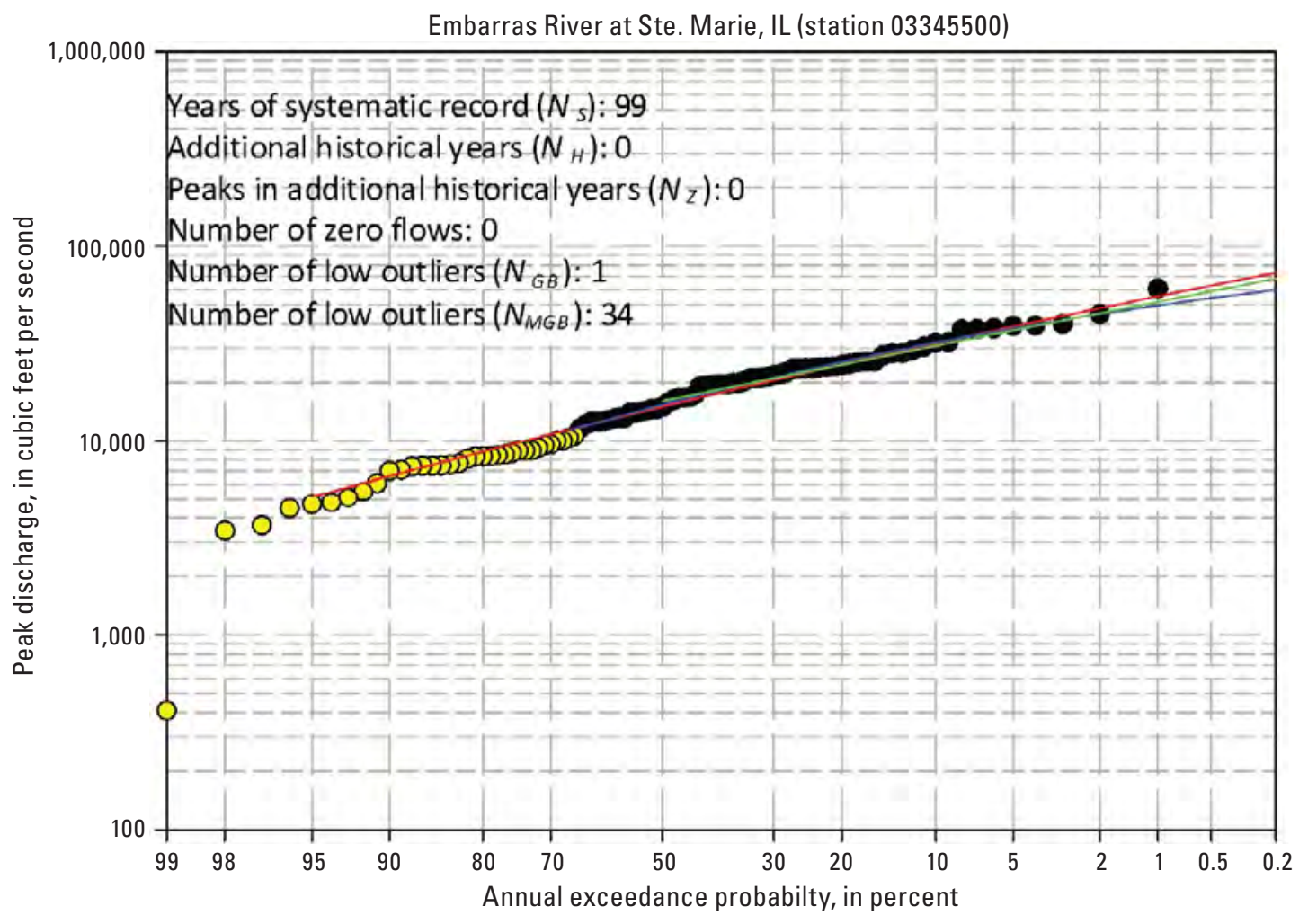

\section{EXPLANATION}

_ Bulletin 17B/Grubbs-Beck

— Expected Moments Algorithm/ multiple Grubbs-Beck

Bulletin 17B/multiple Grubbs-Beck

- Systematic data

Systematic data identified as

low outlier (MGB)

Figure 2-47. Site 03345500-Embarras River at Ste. Marie, Illinois (IL) with potentially influential low floods and no historical information. 


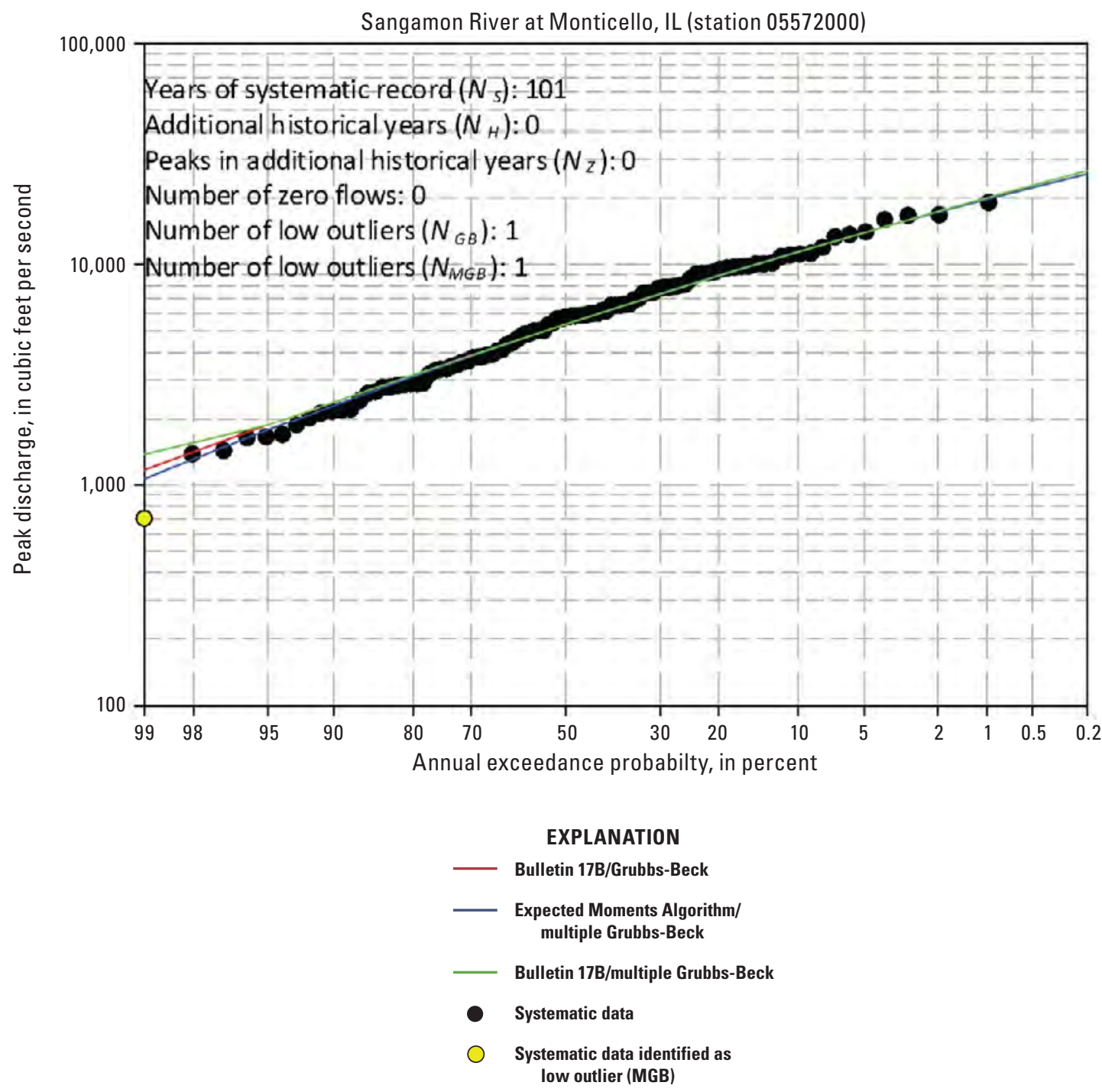

Figure 2-48. Site 05572000-Sangamon River at Monticello, Illinois (IL) with potentially influential low floods and no historical information. 
102 Evaluation of Recommended Revisions to Bulletin 17B

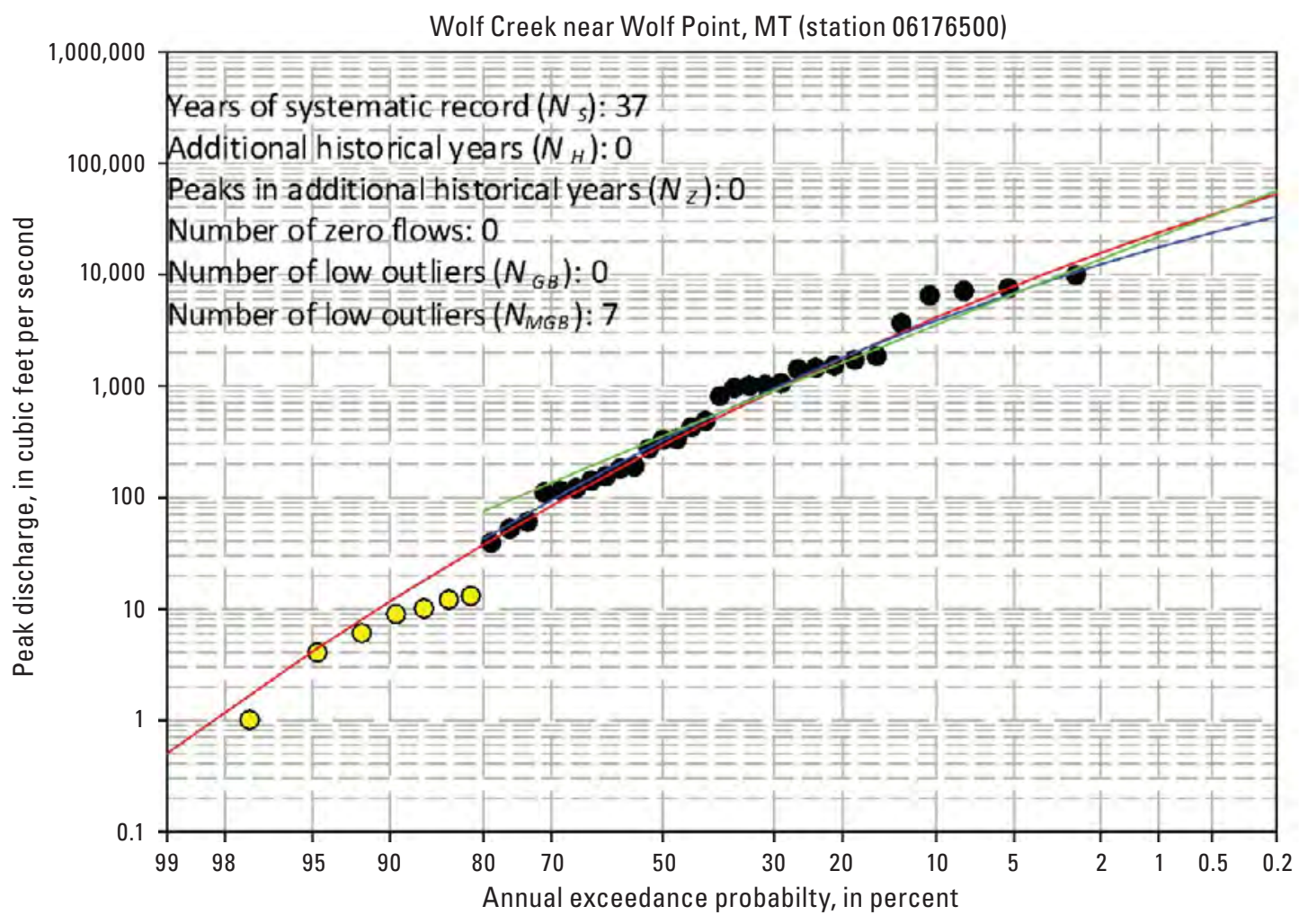

EXPLANATION

- Bulletin 17B/Grubbs-Beck

_ Expected Moments Algorithm/

multiple Grubbs-Beck

Bulletin 17B/multiple Grubbs-Beck

- Systematic data

Systematic data identified as low outlier (MGB)

Figure 2-49. Site 06176500-Wolf Creek near Wolf Point, Montana (MT) with potentially influential low floods and no historical information. 


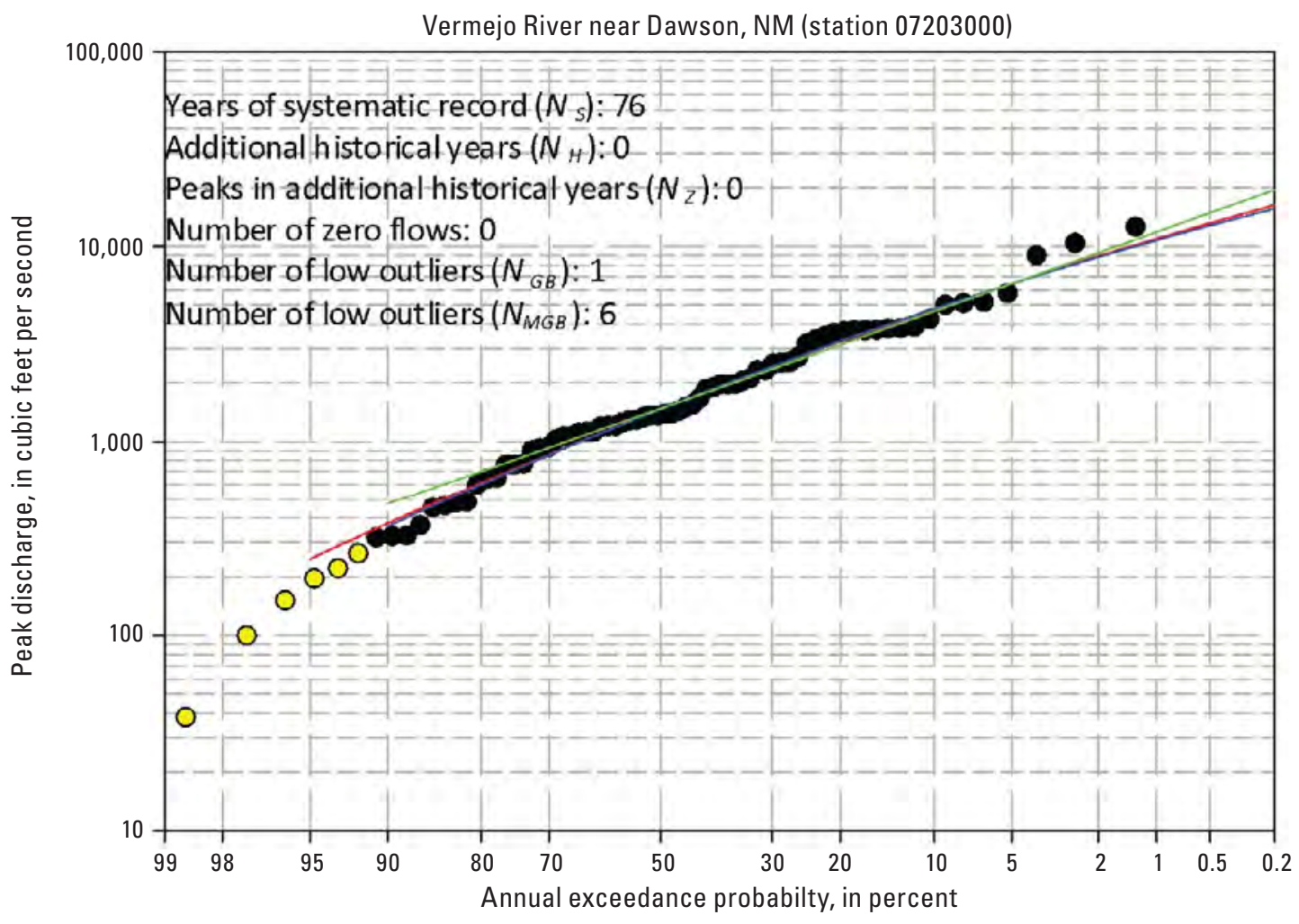

EXPLANATION

Bulletin 17B/Grubbs-Beck

Expected Moments Algorithm/ multiple Grubbs-Beck

Bulletin 17B/multiple Grubbs-Beck

- Systematic data

Systematic data identified as low outlier (MGB)

Figure 2-50. Site 07203000-Vermejo River near Dawson, New Mexico (NM). 


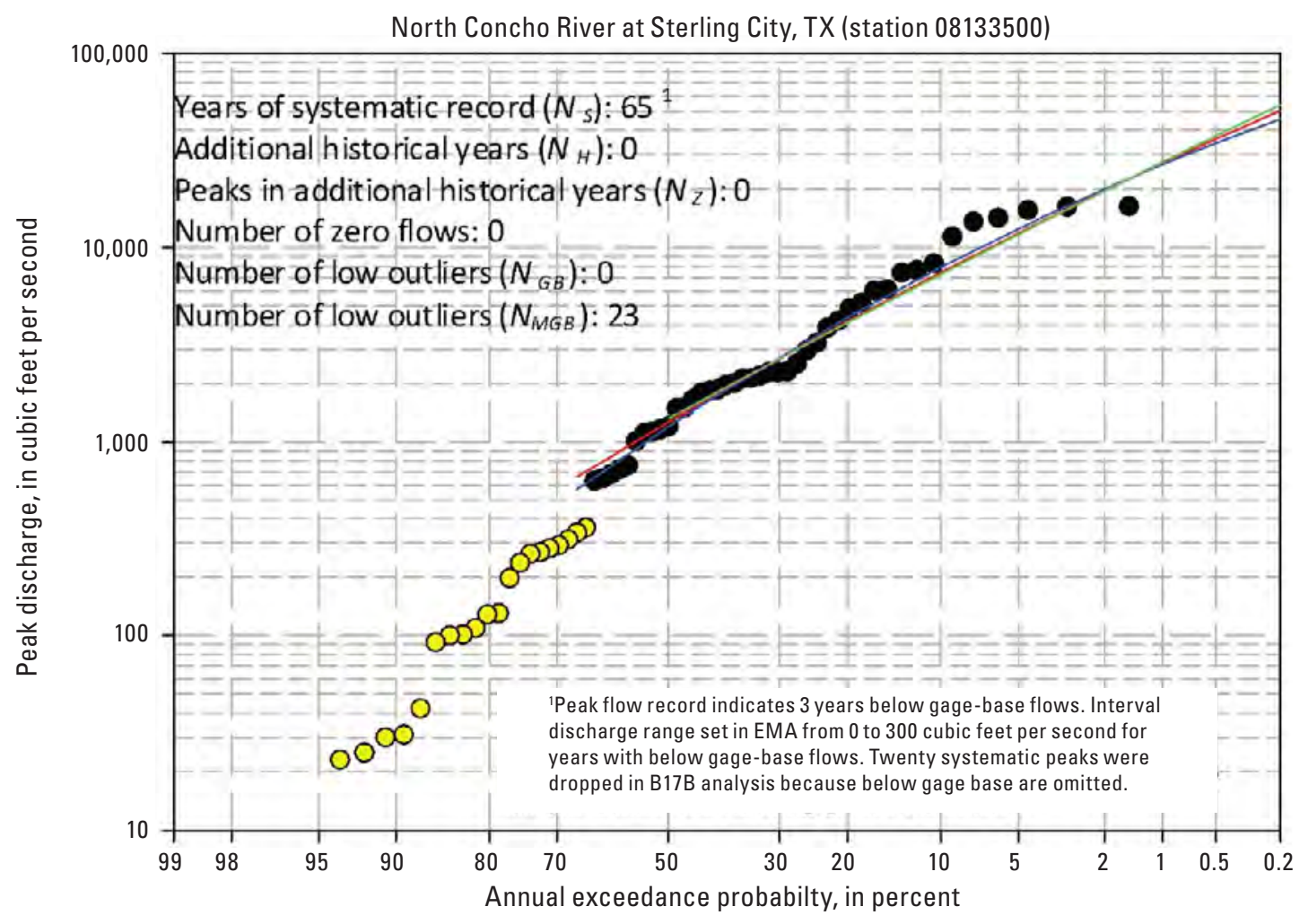

\section{EXPLANATION}

— Bulletin 17B/Grubbs-Beck

_ Expected Moments Algorithm/ multiple Grubbs-Beck

- Bulletin 17B/multiple Grubbs-Beck

- Systematic data

Systematic data identified as low outlier (MGB)

Figure 2-51. Site 08133500-North Concho River at Sterling City, Texas (TX) with potentially influential low floods and no historical information. EMA, Expected Moments Algorithm; B17B, Bulletin 17B. 


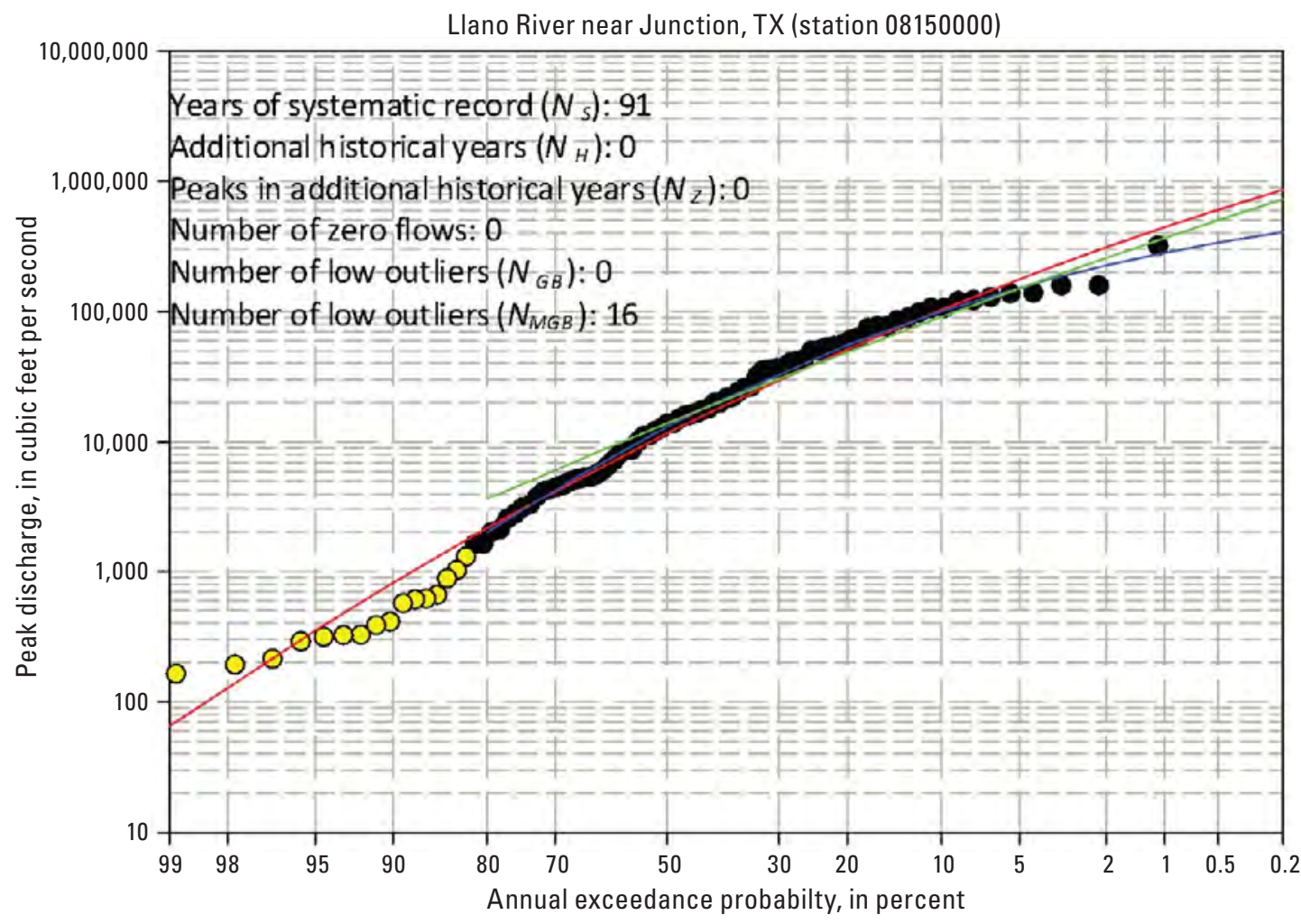

EXPLANATION

Bulletin 17B/Grubbs-Beck

Expected Moments Algorithm/ multiple Grubbs-Beck

Bulletin 17B/multiple Grubbs-Beck

- Systematic data

Systematic data identified as low outlier (MGB)

Figure 2-52. Site 08150000-Llano River near Junction, Texas (TX) with potentially influential low floods and no historical information. 


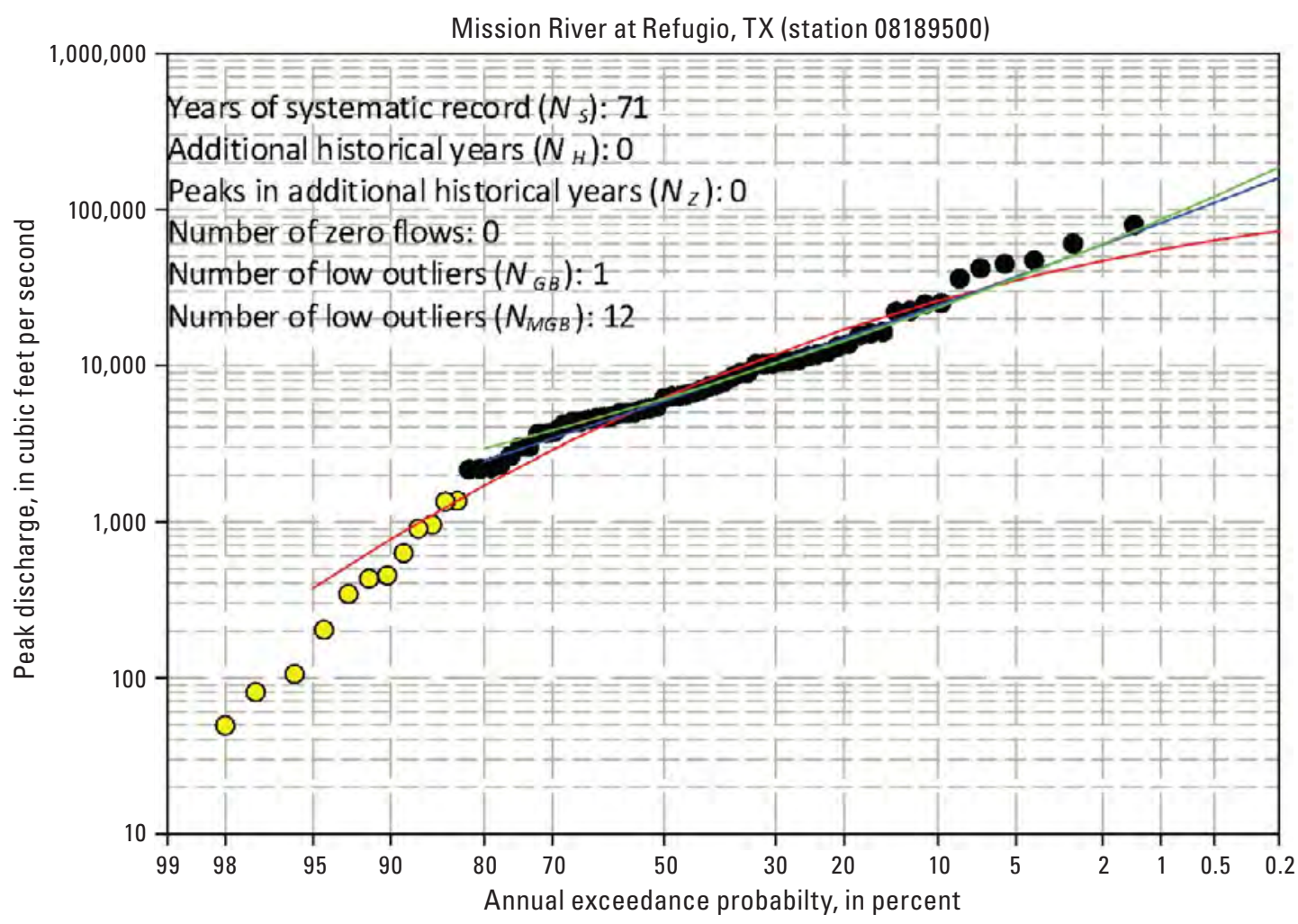

EXPLANATION

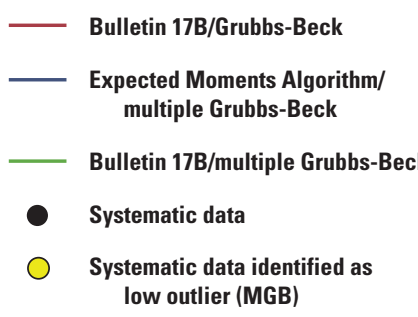

Figure 2-53. Site 08189500-Mission River at Refugio, Texas (TX) with potentially influential low floods and no historical information. 


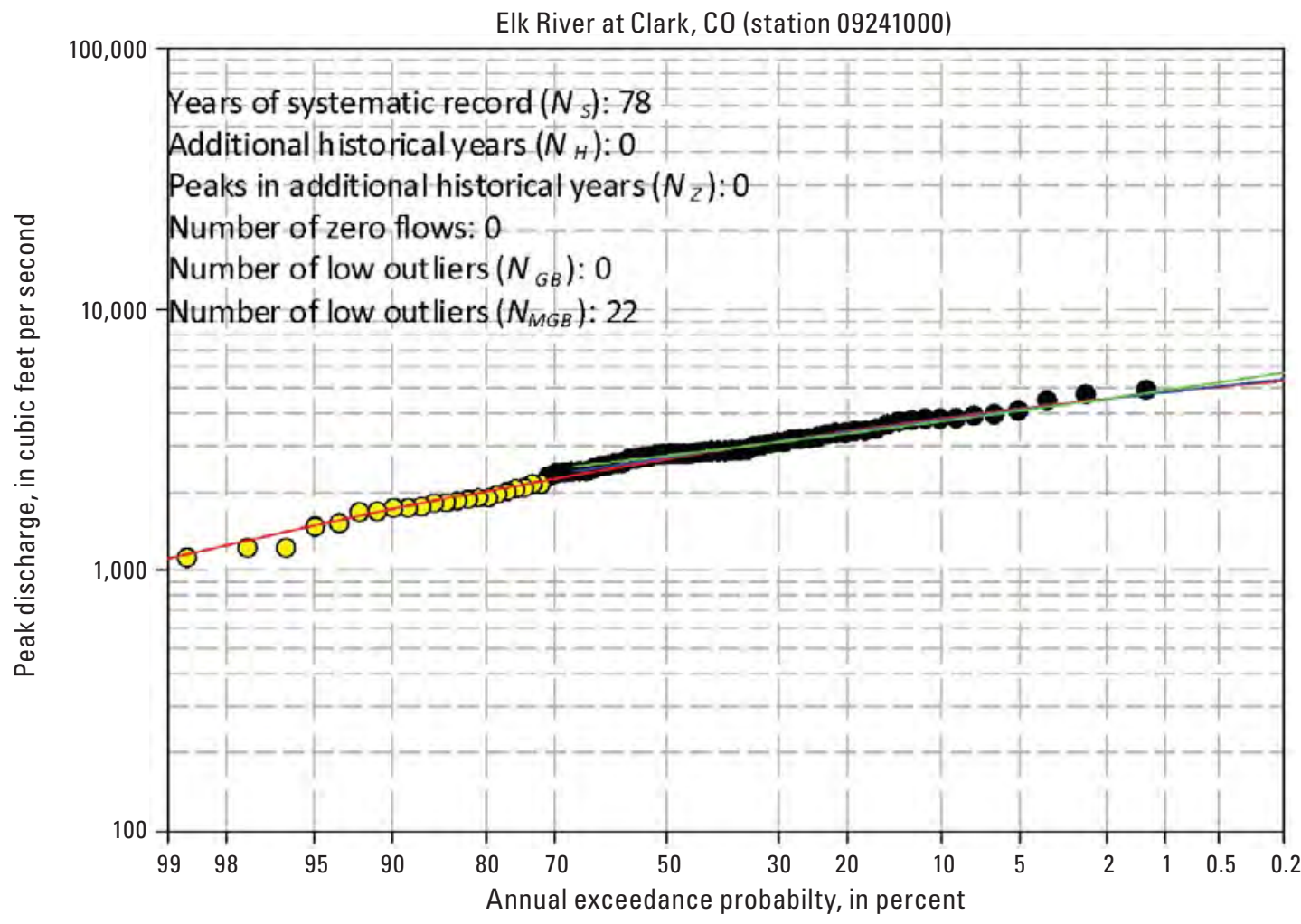

EXPLANATION

- Bulletin 17B/Grubbs-Beck

_ Expected Moments Algorithm/ multiple Grubbs-Beck

- Bulletin 17B/multiple Grubbs-Beck

- Systematic data

Systematic data identified as

low outlier (MGB)

Figure 2-54. Site 09241000-Elk River at Clark, Colorado (CO) with potentially influential low floods and no historical information. 


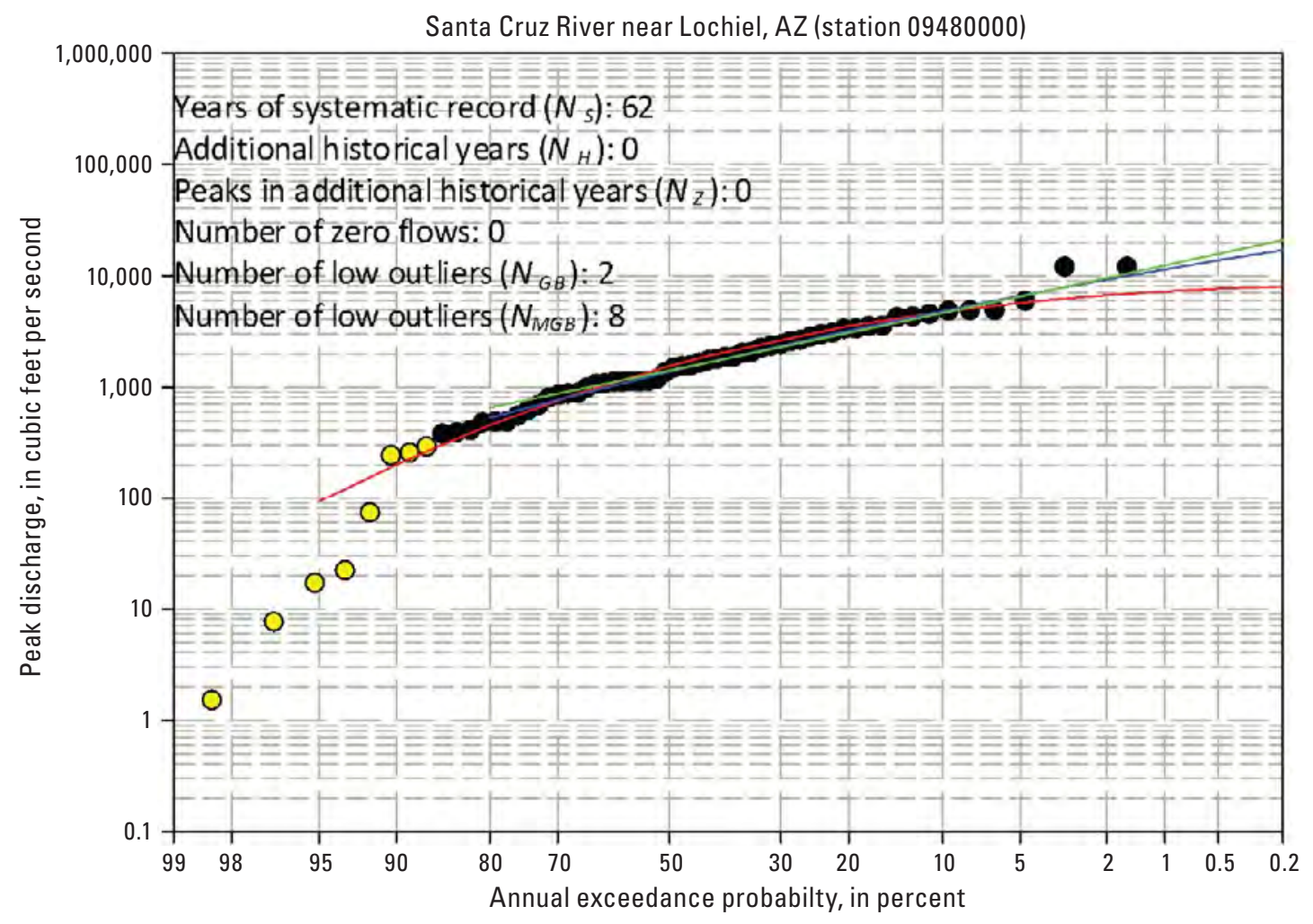

EXPLANATION

—— Bulletin 17B/Grubbs-Beck

Expected Moments Algorithm/ multiple Grubbs-Beck

Bulletin 17B/multiple Grubbs-Beck

- Systematic data

Systematic data identified as low outlier (MGB)

Figure 2-55. Site 09480000-Santa Cruz River near Lochiel, Arizona (AZ) with potentially influential low floods and no historical information. 


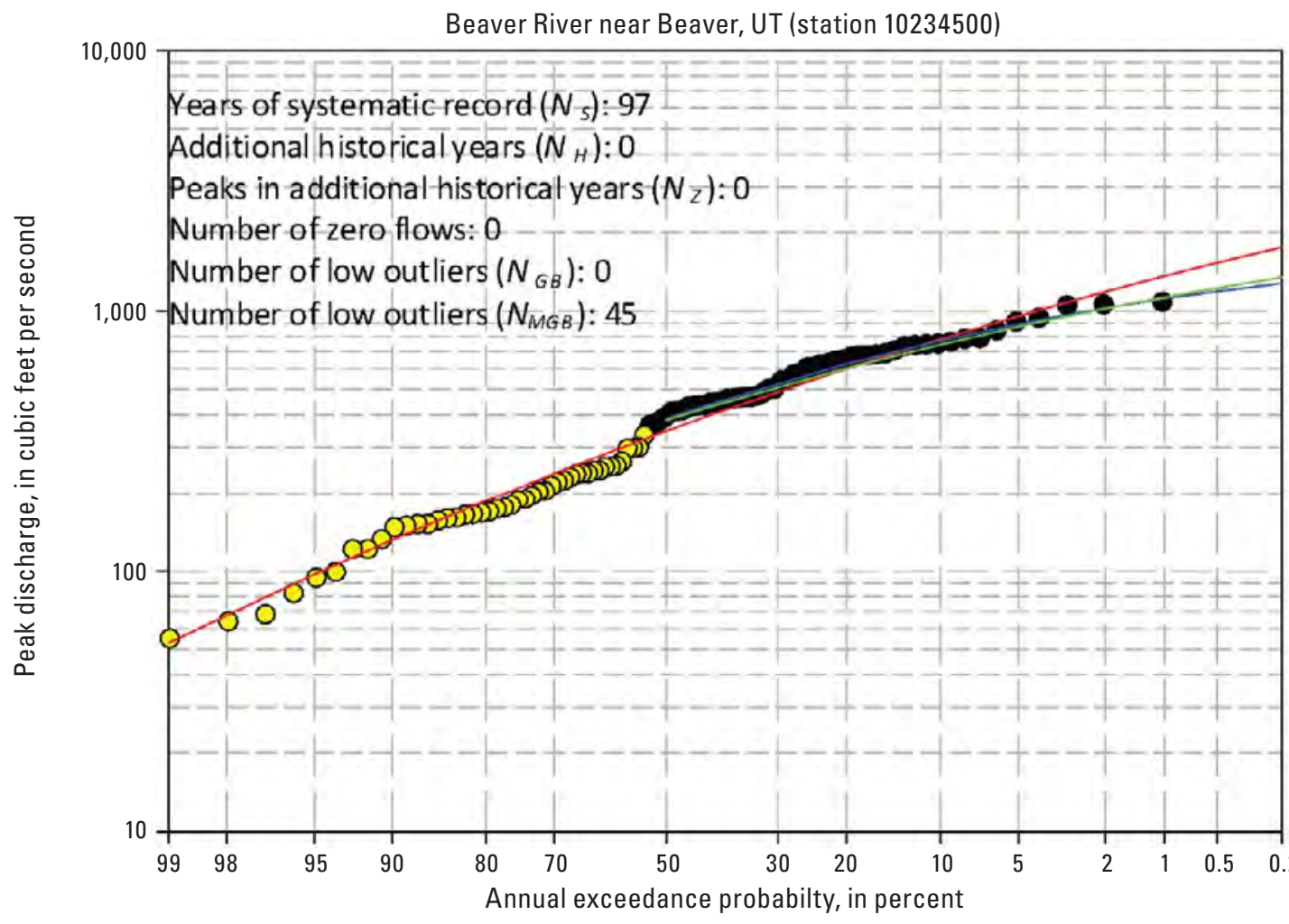

EXPLANATION

Bulletin 17B/Grubbs-Beck

Expected Moments Algorithm/ multiple Grubbs-Beck

Bulletin 17B/multiple Grubbs-Beck

- Systematic data

Systematic data identified as

low outlier (MGB)

Figure 2-56. Site 10234500-Beaver River near Beaver, Utah (UT) with potentially influential low floods and no historical information. 
110 Evaluation of Recommended Revisions to Bulletin 17B

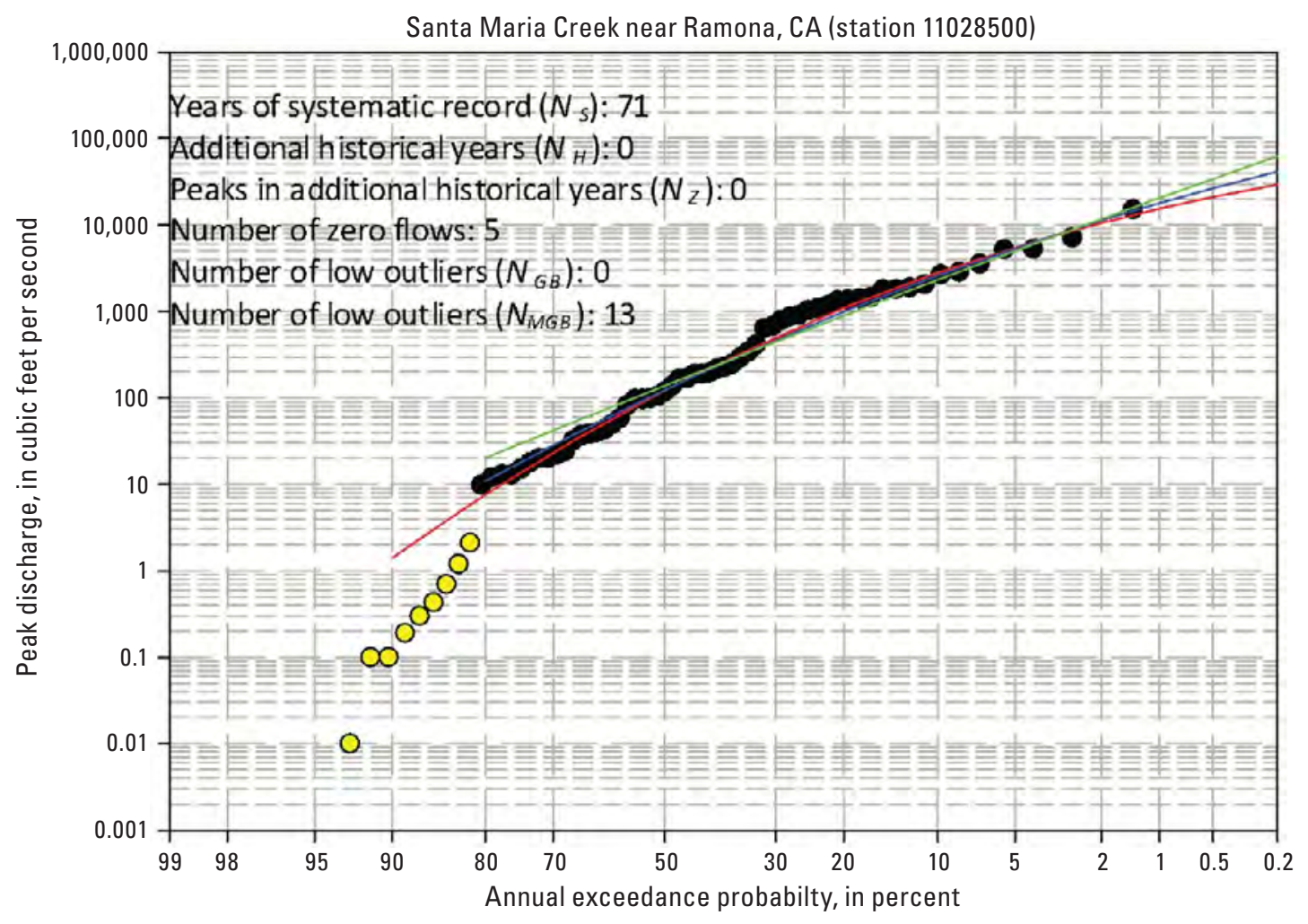

EXPLANATION

- Bulletin 17B/Grubbs-Beck

- Expected Moments Algorithm/ multiple Grubbs-Beck

_ Bulletin 17B/multiple Grubbs-Beck

- Systematic data

Systematic data identified as

low outlier (MGB)

Figure 2-57. Site 11028500-Santa Maria Creek near Ramona, California (CA) with potentially influential low floods and no historical information. 


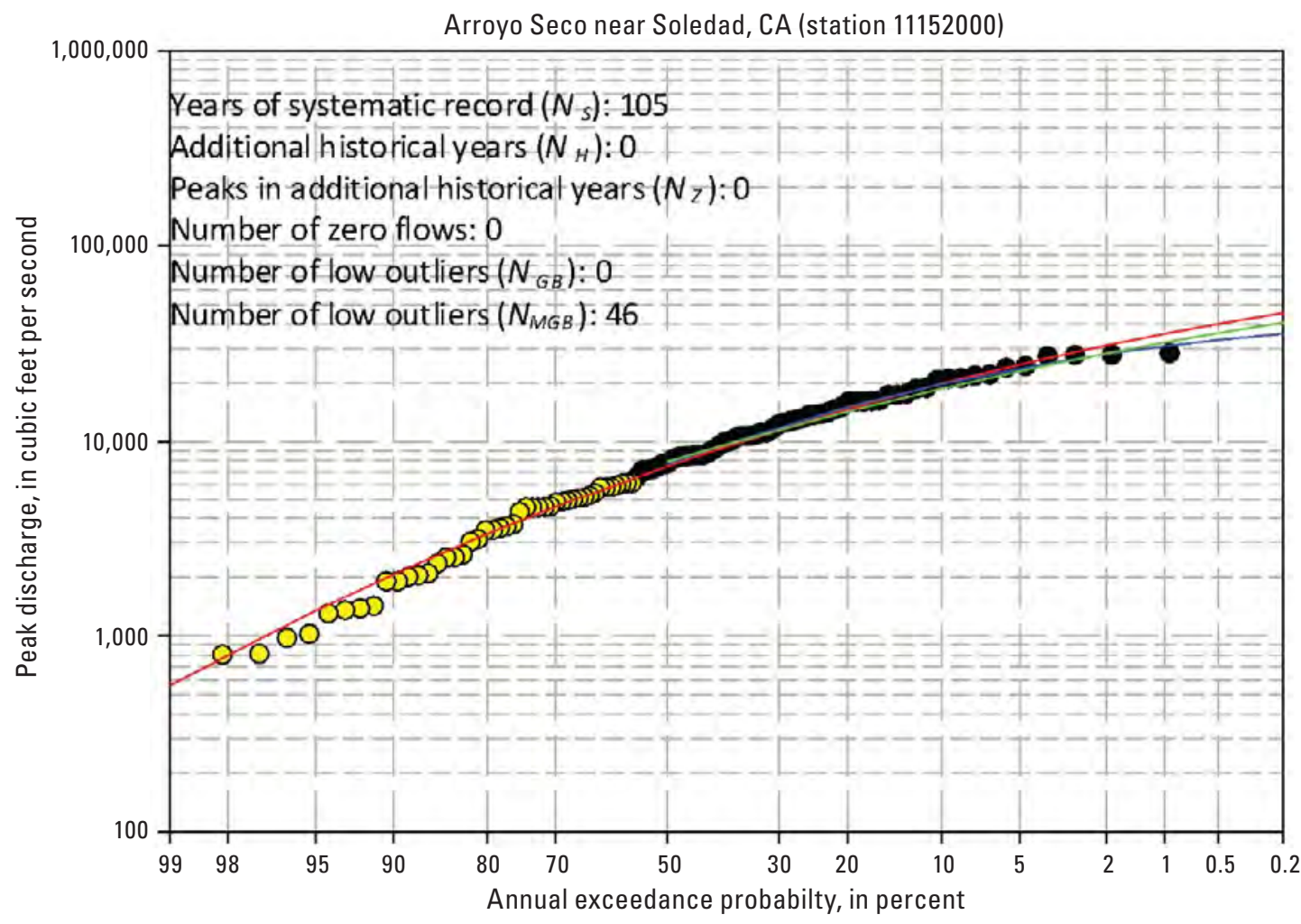

EXPLANATION

Bulletin 17B/Grubbs-Beck

Expected Moments Algorithm/

multiple Grubbs-Beck

Bulletin 17B/multiple Grubbs-Beck

- Systematic data

Systematic data identified as

low outlier (MGB)

Figure 2-58. Site 11152000-Arroyo Seco near Soledad, California (CA) with potentially influential low floods and no historical information. 
112 Evaluation of Recommended Revisions to Bulletin 17B

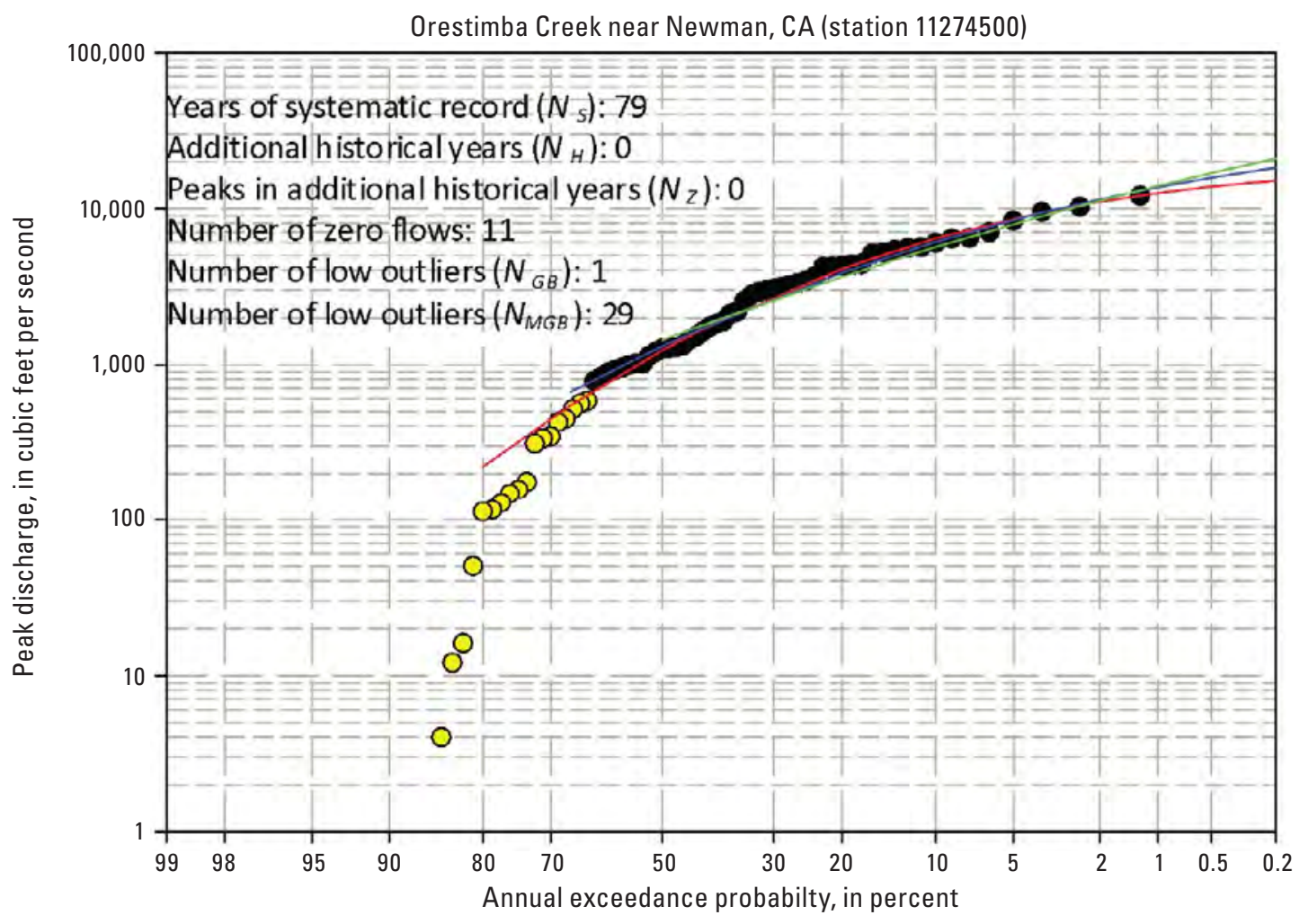

EXPLANATION

_ Bulletin 17B/Grubbs-Beck

Expected Moments Algorithm/ multiple Grubbs-Beck

Bulletin 17B/multiple Grubbs-Beck

- Systematic data

Systematic data identified as low outlier (MGB)

Figure 2-59. Site 11274500-0restimba Creek near Newman, California (CA) with potentially influential low floods and no historical information. 


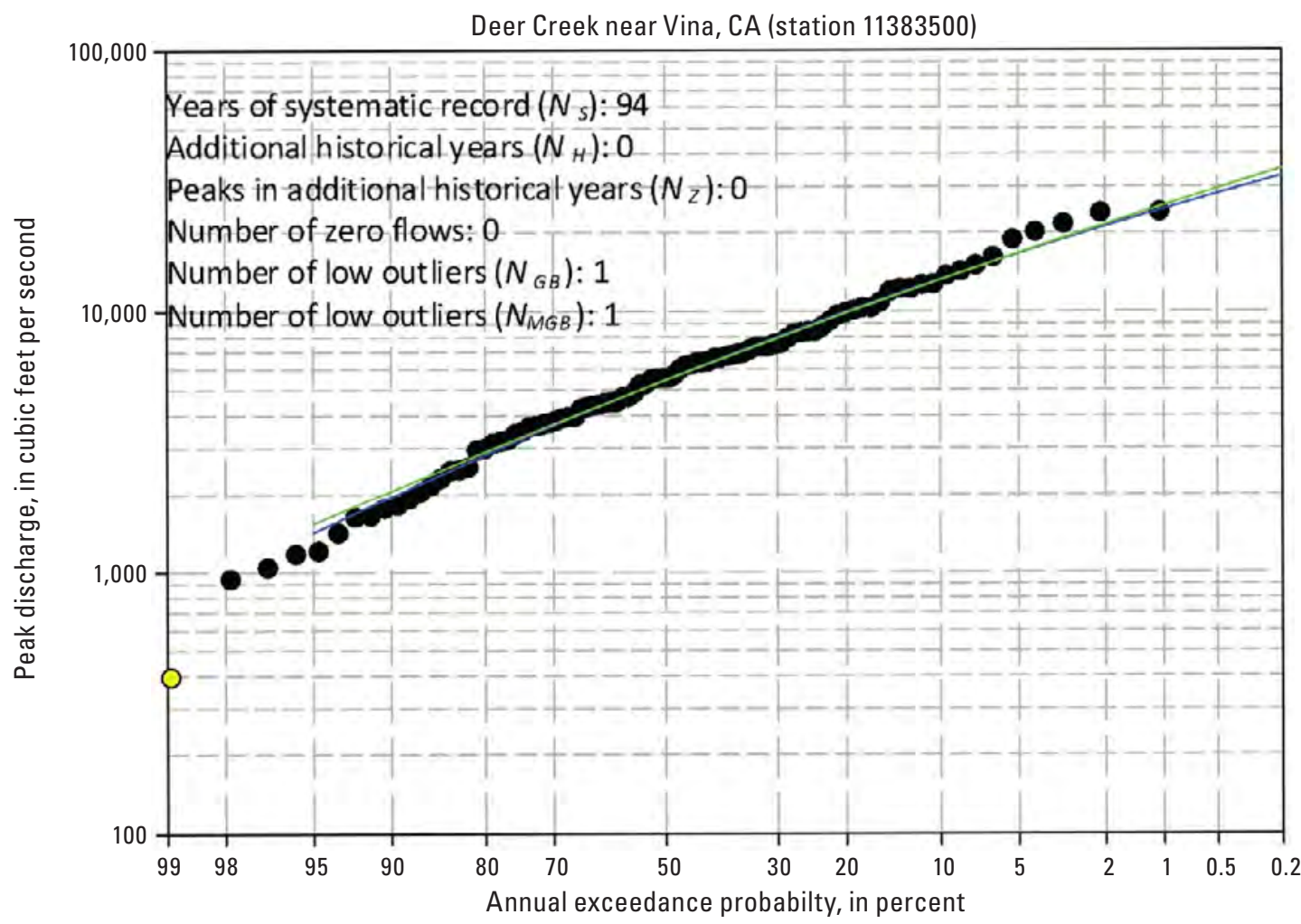

EXPLANATION

Bulletin 17B/Grubbs-Beck

Expected Moments Algorithm/ multiple Grubbs-Beck

Bulletin 17B/multiple Grubbs-Beck

- Systematic data

Systematic data identified as

low outlier (MGB)

Figure 2-60. Site 11383500-Deer Creek near Vina, California (CA) with potentially influential low floods and no historical information. 


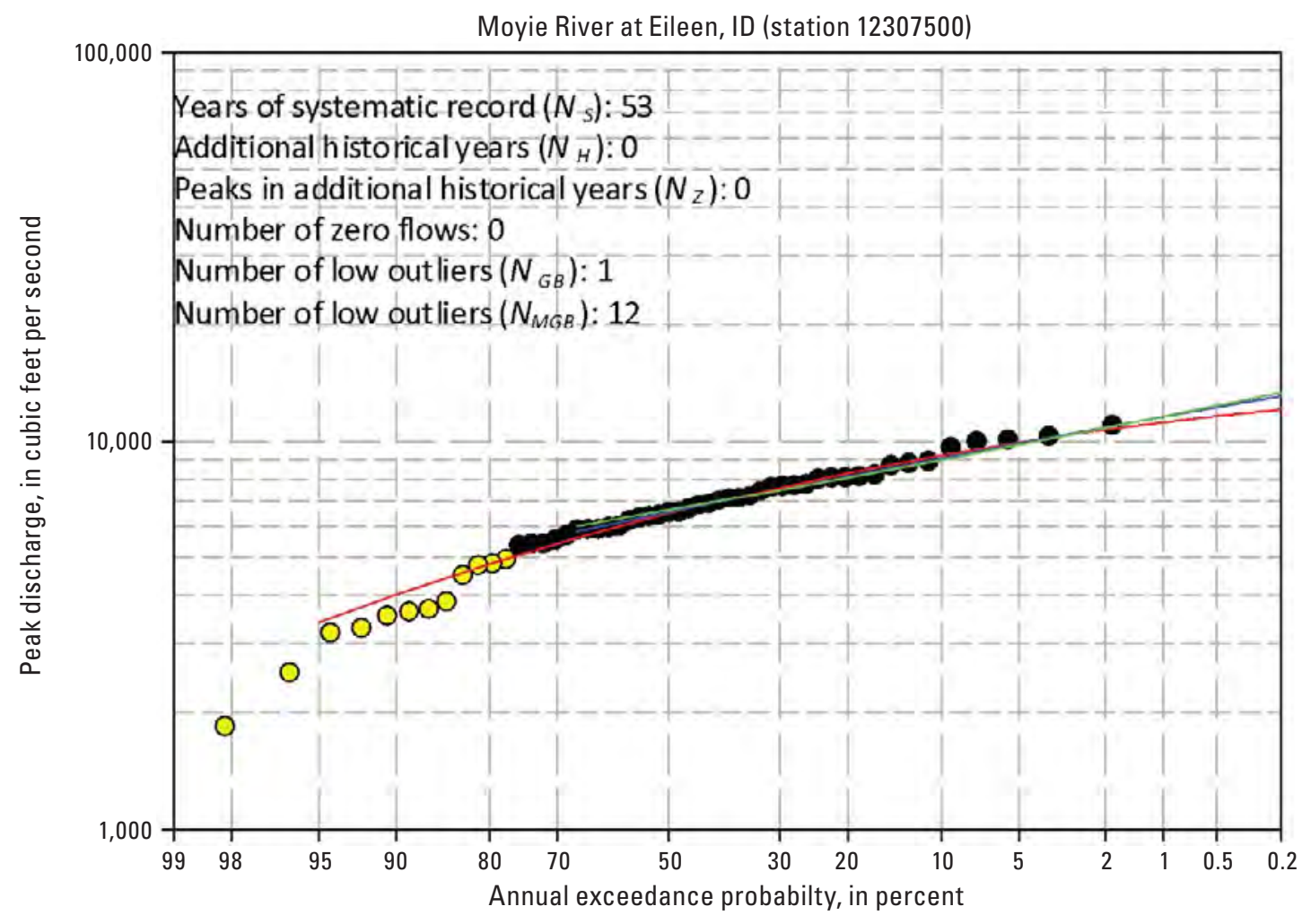

EXPLANATION

\begin{tabular}{cl} 
Bulletin 17B/Grubbs-Beck \\
\hline$\quad \begin{array}{c}\text { Expected Moments Algorithm/ } \\
\text { multiple Grubbs-Beck }\end{array}$ \\
$-\quad$ Bulletin 17B/multiple Grubbs-B \\
$-\quad \begin{array}{l}\text { Systematic data } \\
\text { Systematic data identified as } \\
\text { low outlier (MGB) }\end{array}$
\end{tabular}

Figure 2-61. Site 12307500-Moyie River at Eileen, Idaho (ID) with potentially influential low floods and no historical information. 


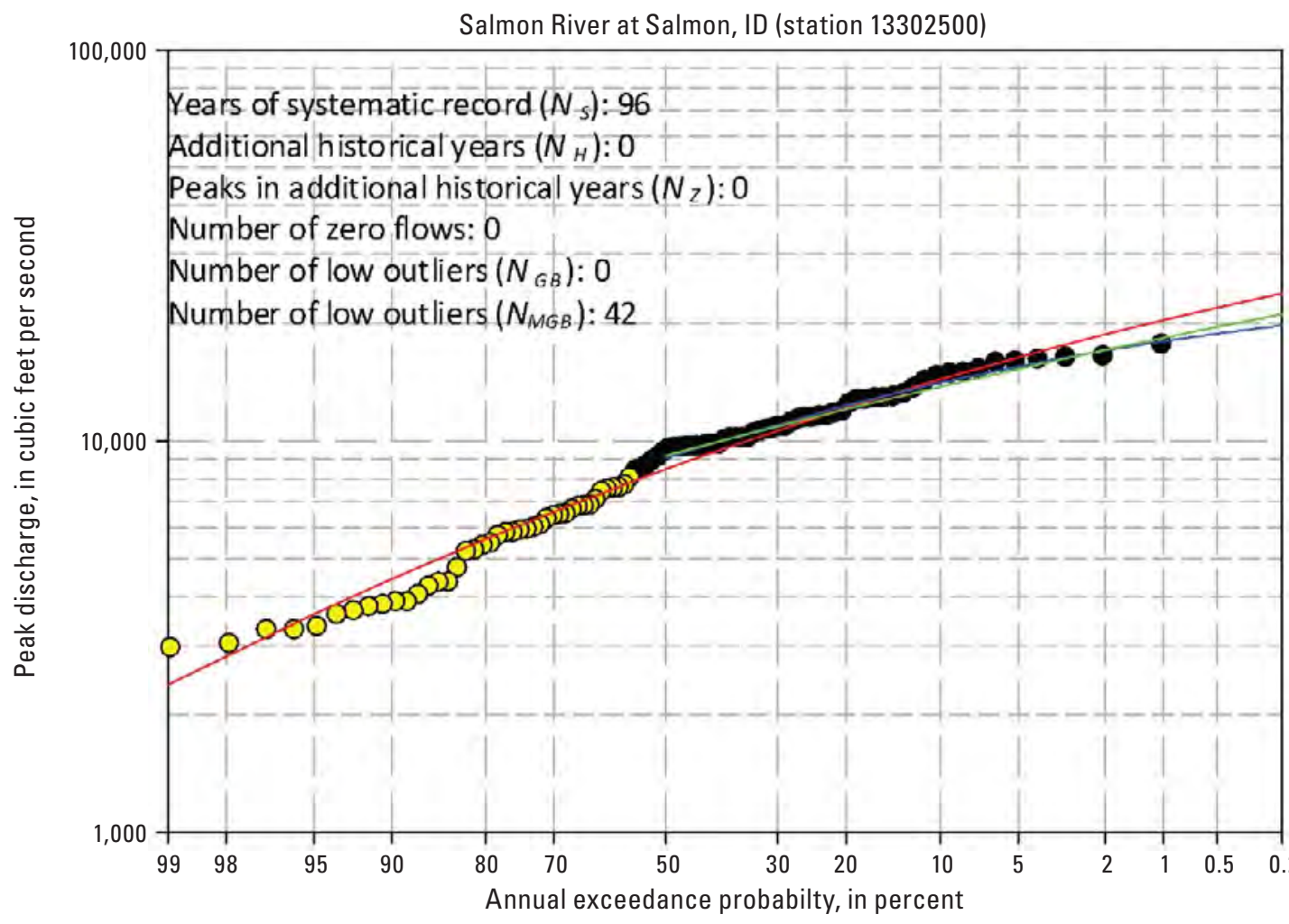

EXPLANATION

Bulletin 17B/Grubbs-Beck

Expected Moments Algorithm/ multiple Grubbs-Beck

Bulletin 17B/multiple Grubbs-Beck

- Systematic data

Systematic data identified as low outlier (MGB)

Figure 2-62. Site 13302500-Salmon River at Salmon, Idaho (ID) with potentially influential low floods and no historical information. 


\section{Evaluation of Recommended Revisions to Bulletin 17B}

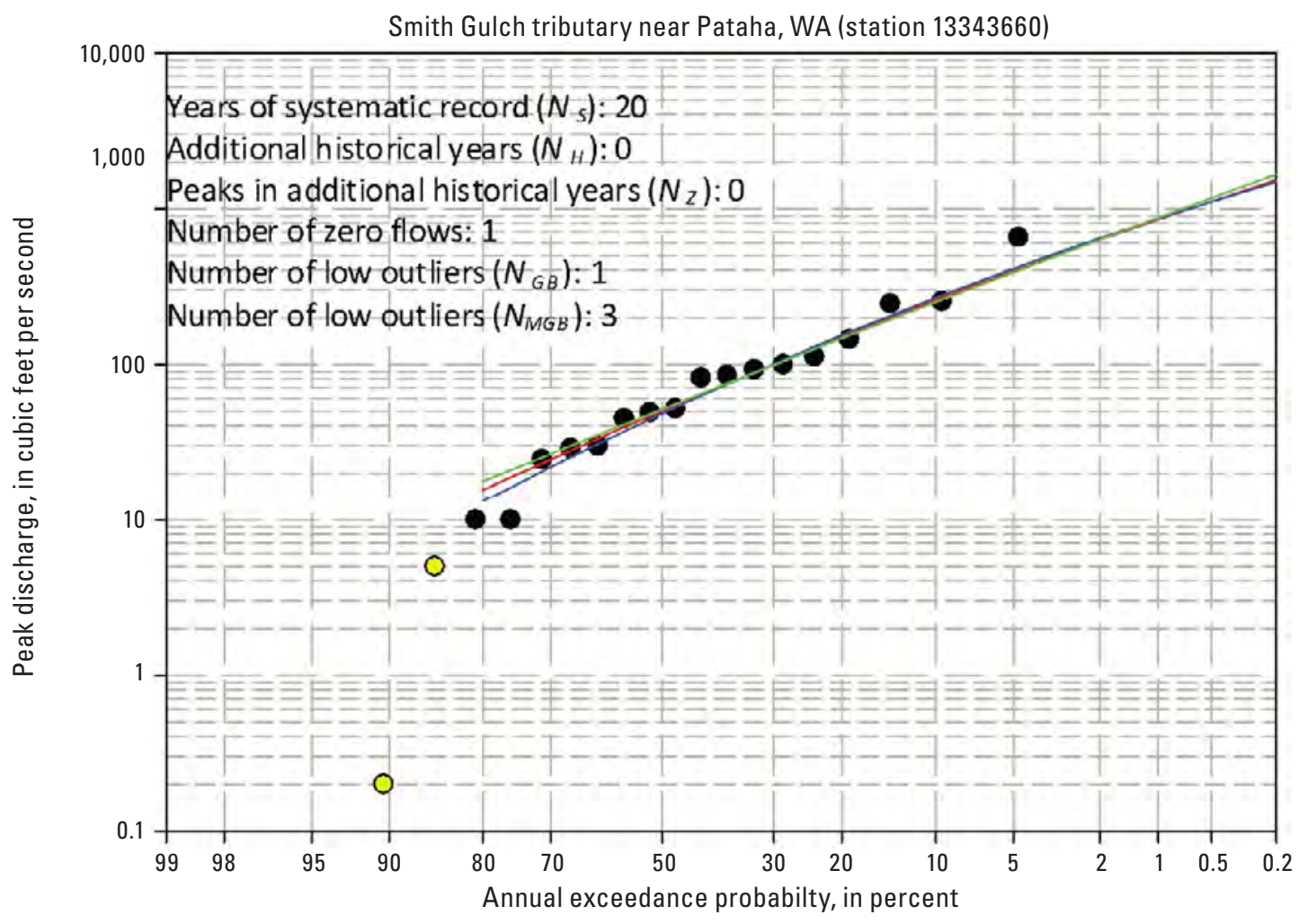

EXPLANATION

_ Bulletin 17B/Grubbs-Beck

Expected Moments Algorithm/ multiple Grubbs-Beck

Bulletin 17B/multiple Grubbs-Beck

- Systematic data

Systematic data identified as

low outlier (MGB)

Figure 2-63. Site 13343660-Smith Gulch tributary near Pataha, Washington (WA) with potentially influential low floods and no historical information. 


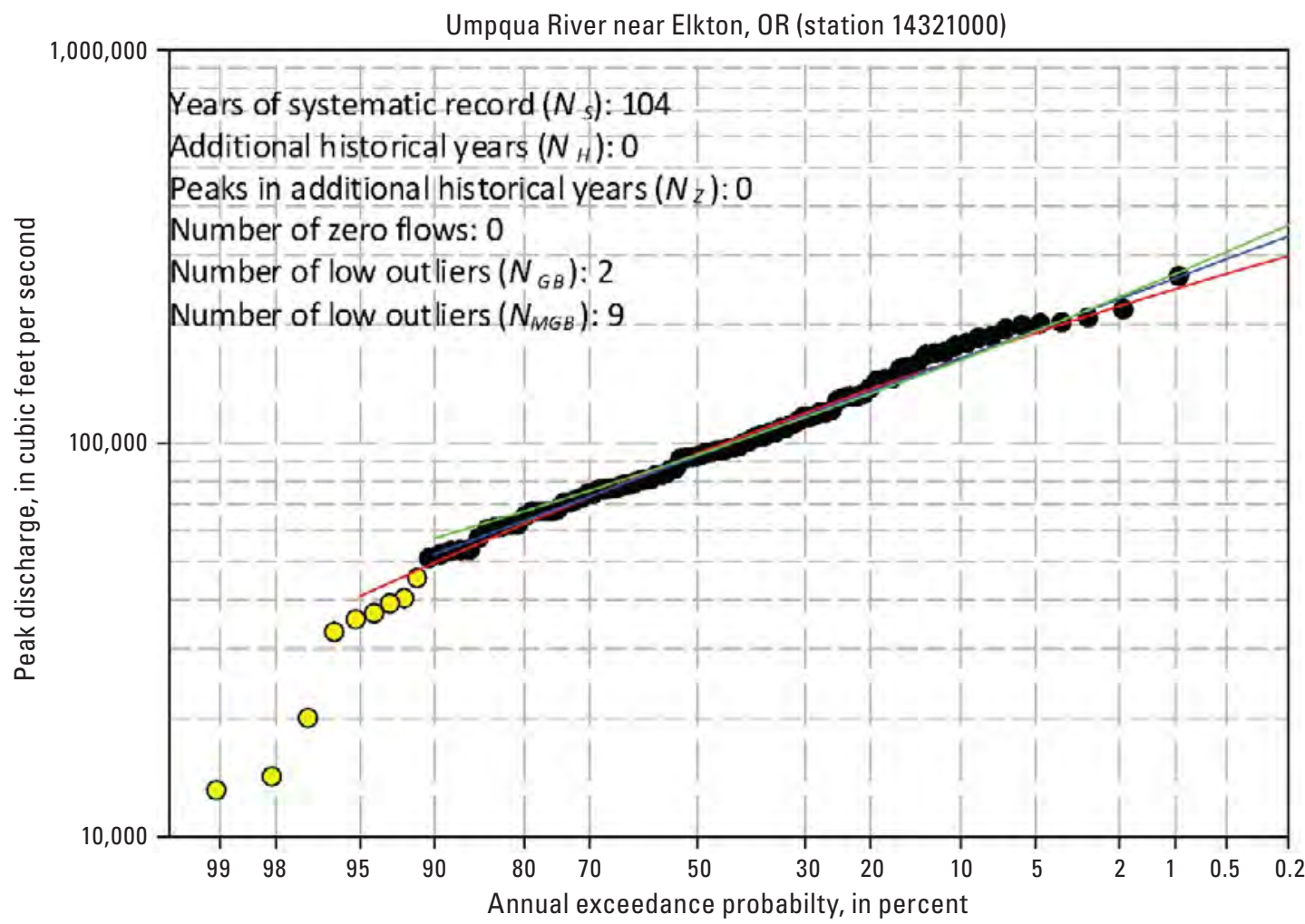

EXPLANATION

Bulletin 17B/Grubbs-Beck

Expected Moments Algorithm/ multiple Grubbs-Beck

Bulletin 17B/multiple Grubbs-Beck

- Systematic data

Systematic data identified as

low outlier (MGB)

Figure 2-64. Site 14321000-Umpqua River near Elkton, Oregon (OR) with potentially influential low floods and no historical information. 


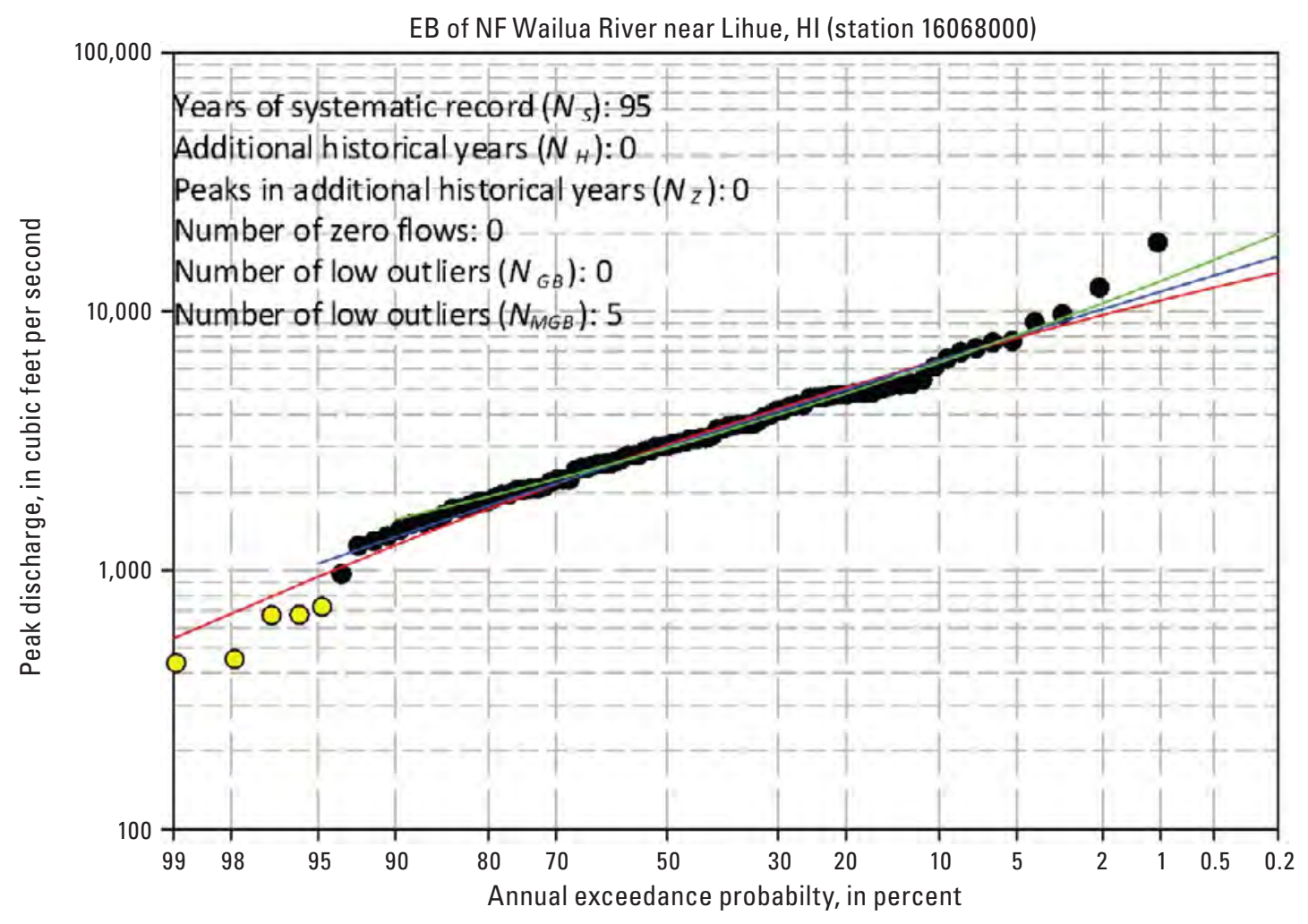

EXPLANATION

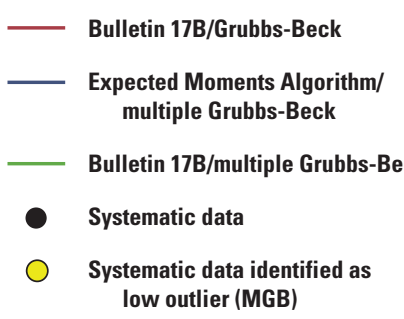

Figure 2-65. Site 16068000-East Branch (EB) of North Fork (NF) Wailua River near Lihue, Hawaii (HI) with potentially influential low floods and no historical information. 


\section{Sites With a Combination of Data Types}

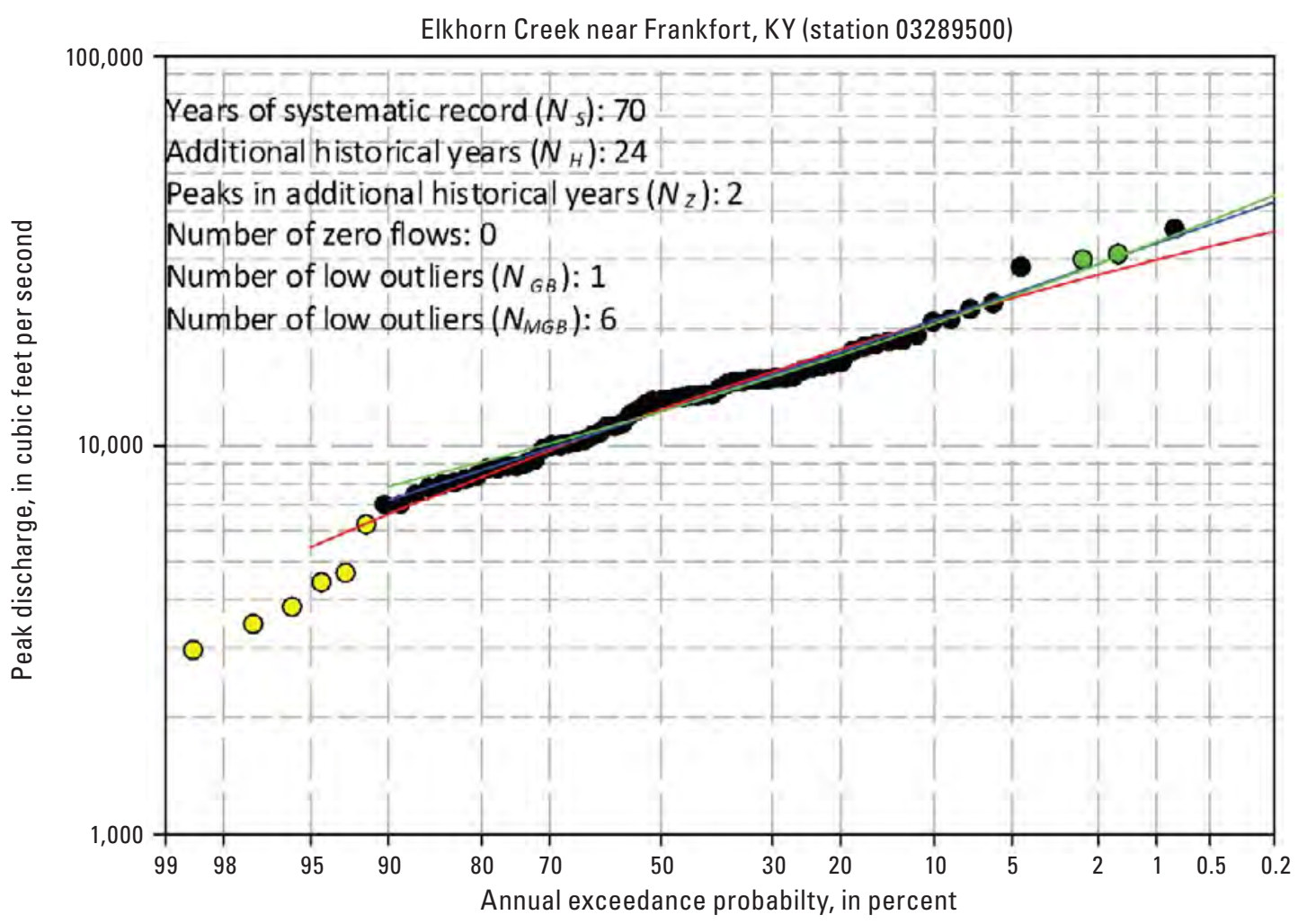

EXPLANATION

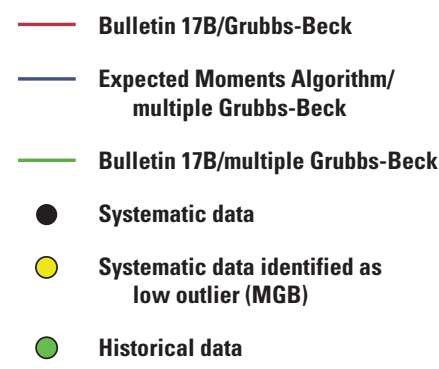

Figure 2-66. Site 03289500-Elkhorn Creek near Frankfort, Kentucky (KY) with a combination of potentially influential low floods, historical, and (or) high outliers in the data. 


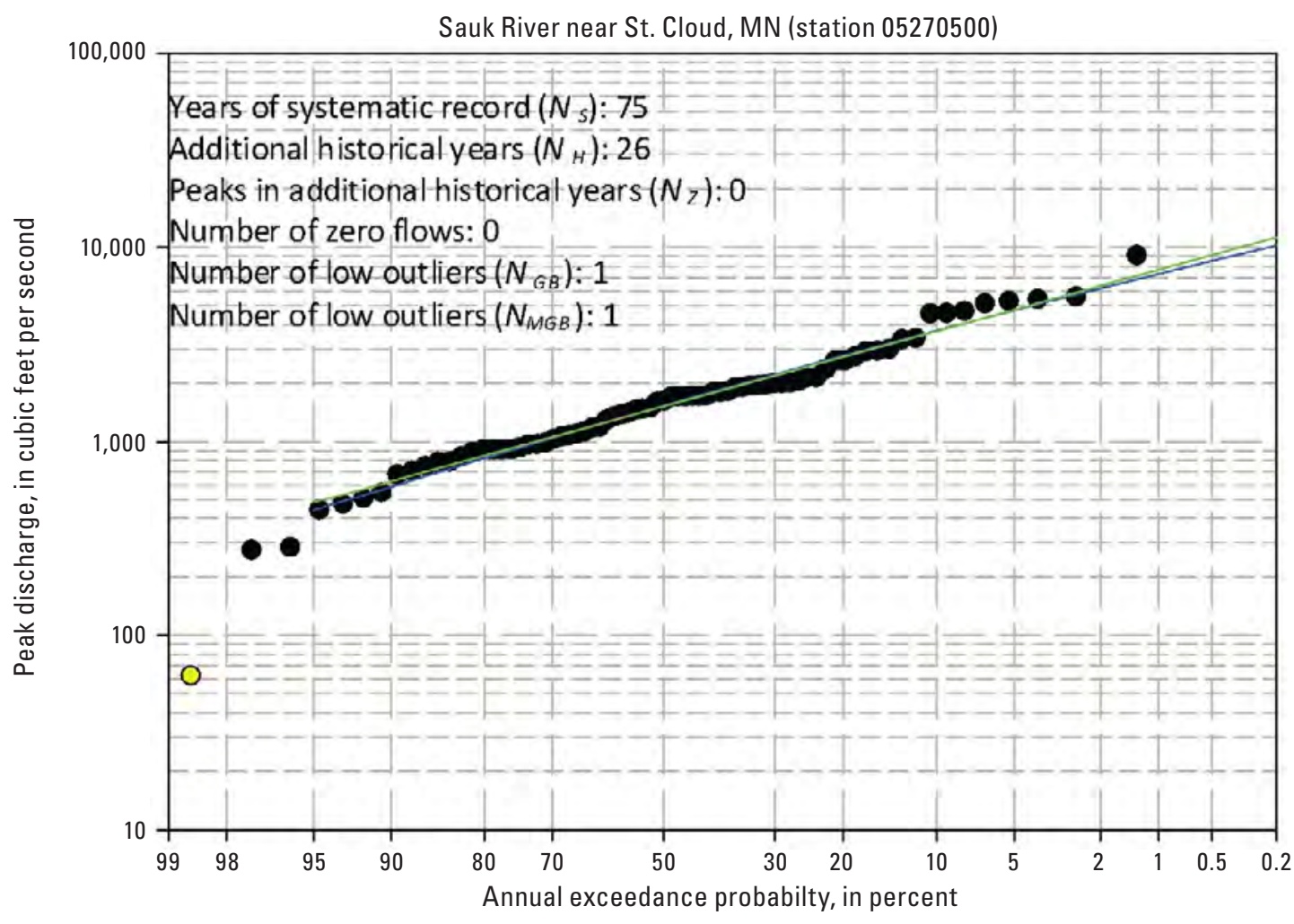

EXPLANATION

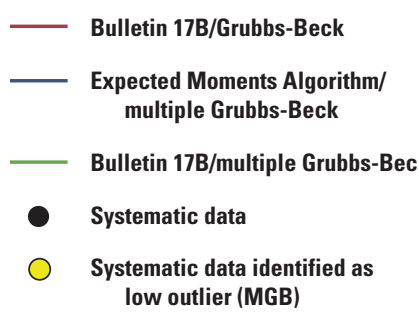

Figure 2-67. Site 05270500-Sauk River near St. Cloud, Minnesota (MN) with a combination of potentially influential low floods, historical, and (or) high outliers in the data. 


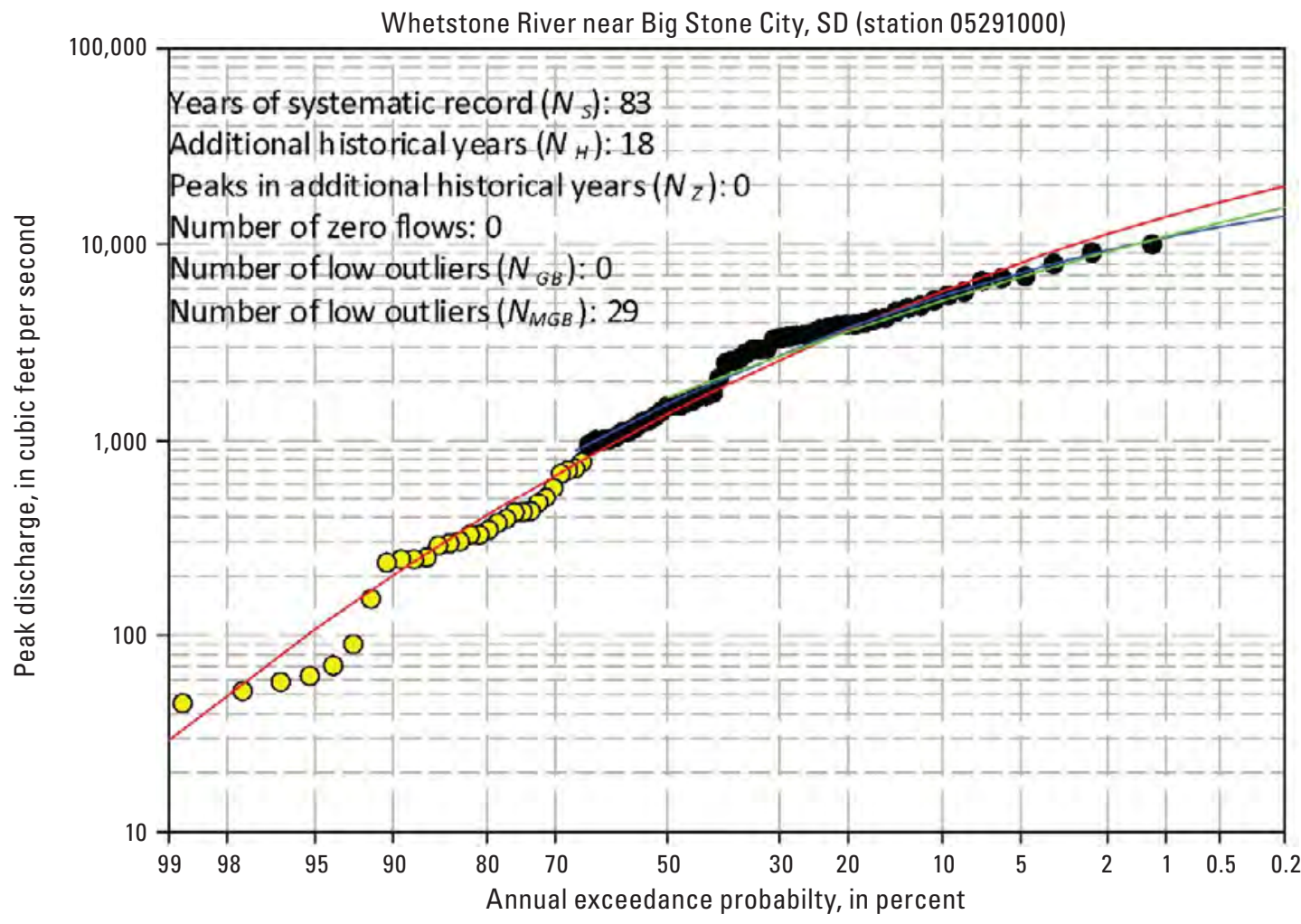

EXPLANATION

Bulletin 17B/Grubbs-Beck

Expected Moments Algorithm/ multiple Grubbs-Beck

Bulletin 17B/multiple Grubbs-Beck

- Systematic data

Systematic data identified as low outlier (MGB)

Figure 2-68. Site 05291000-Whetstone River near Big Stone City, South Dakota (SD) with a combination of potentially influential low floods, historical, and (or) high outliers in the data. 


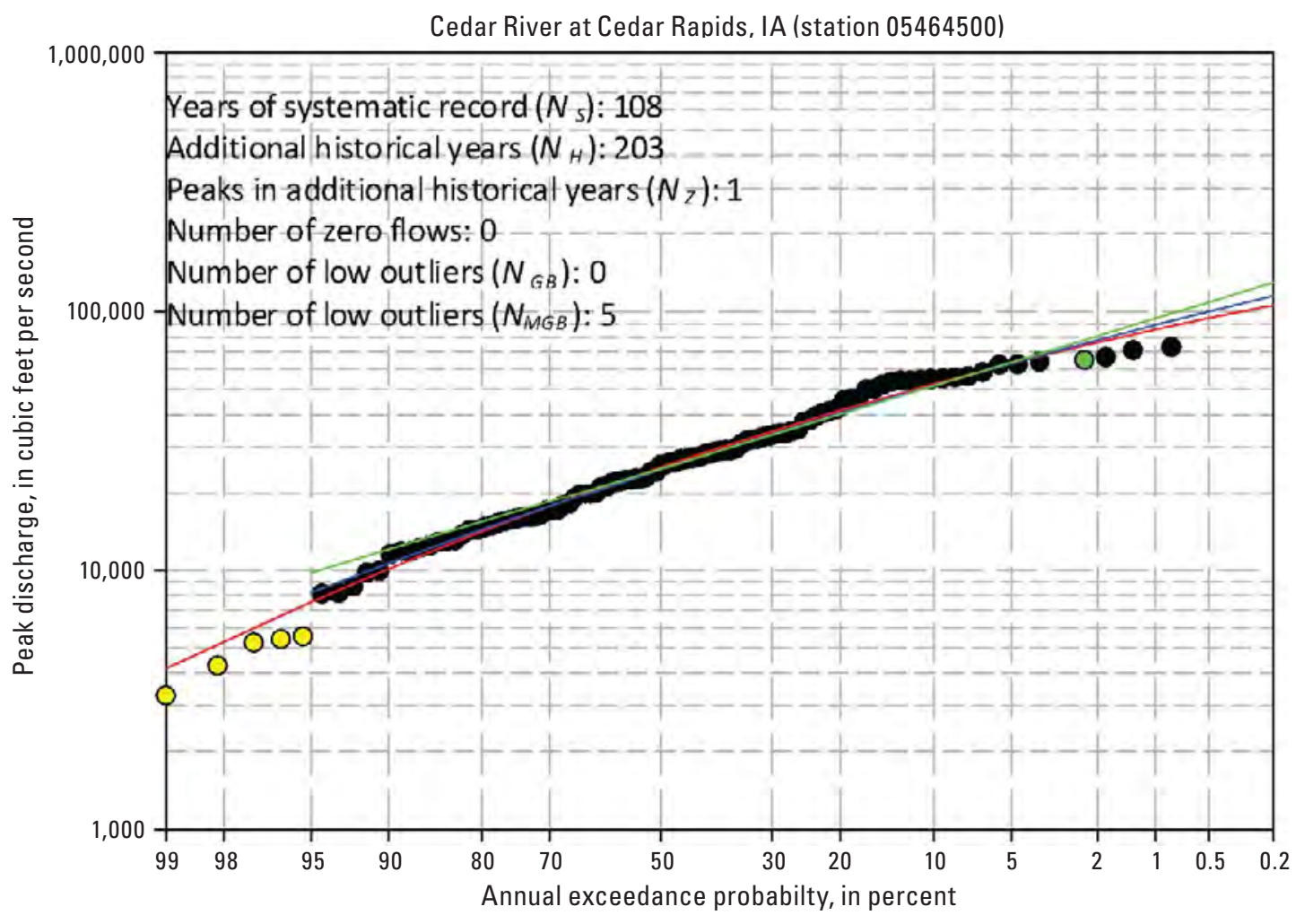

EXPLANATION

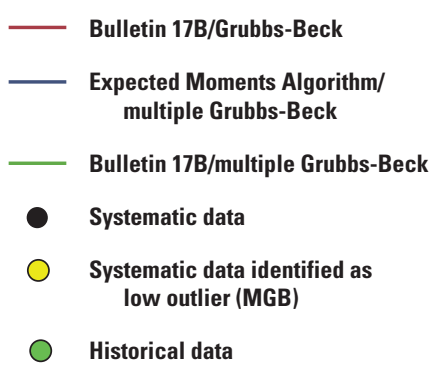

Figure 2-69. Site 05464500-Cedar River at Cedar Rapids, lowa (IA) with a combination of potentially influential low floods, historical, and (or) high outliers in the data. 


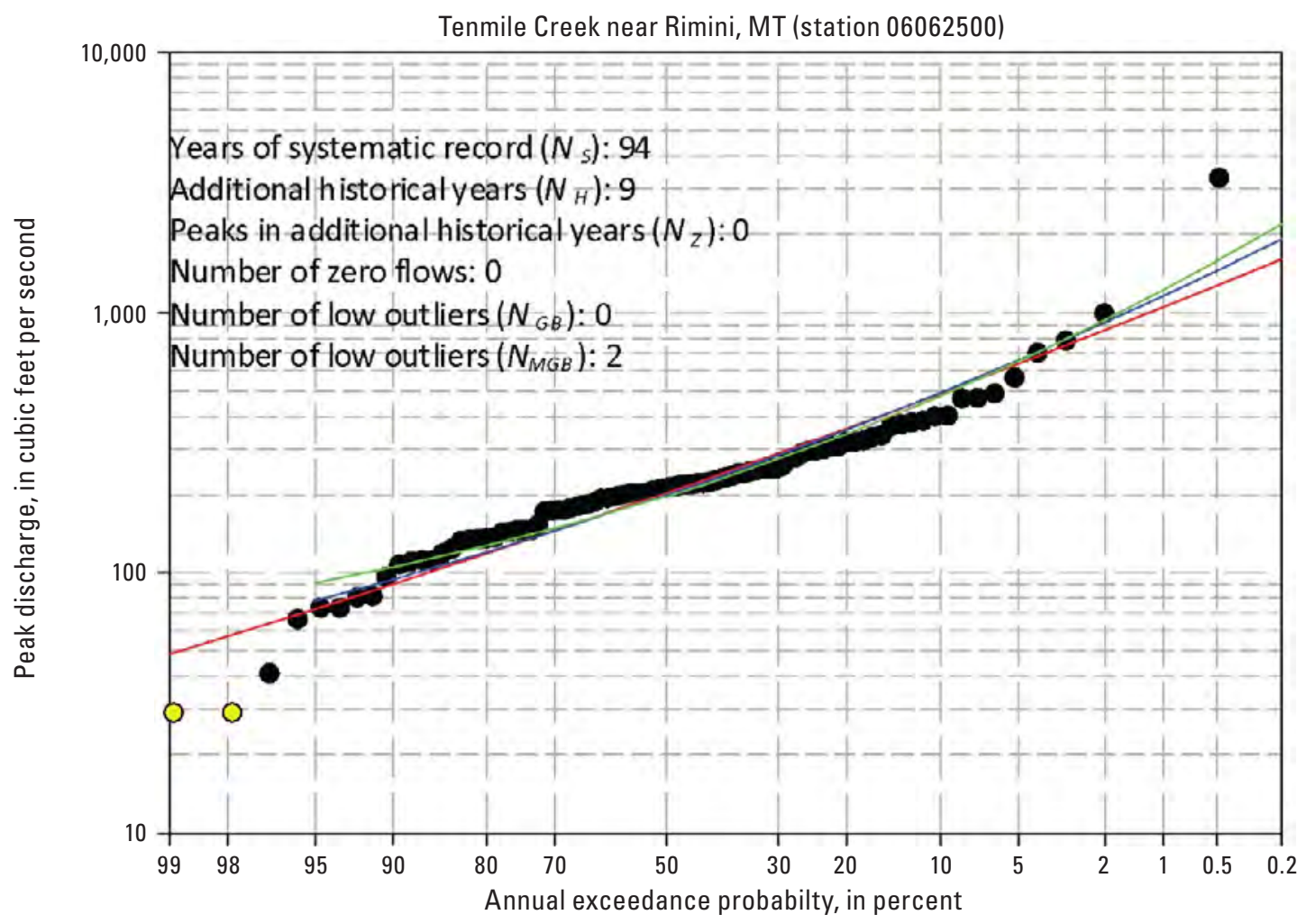

EXPLANATION

Bulletin 17B/Grubbs-Beck

Expected Moments Algorithm/ multiple Grubbs-Beck

Bulletin 17B/multiple Grubbs-Beck

- Systematic data

Systematic data identified as

low outlier (MGB)

Figure 2-70. Site 06062500-Tenmile Creek near Rimini, Montana (MT) with a combination of potentially influential low floods, historical, and (or) high outliers in the data. 


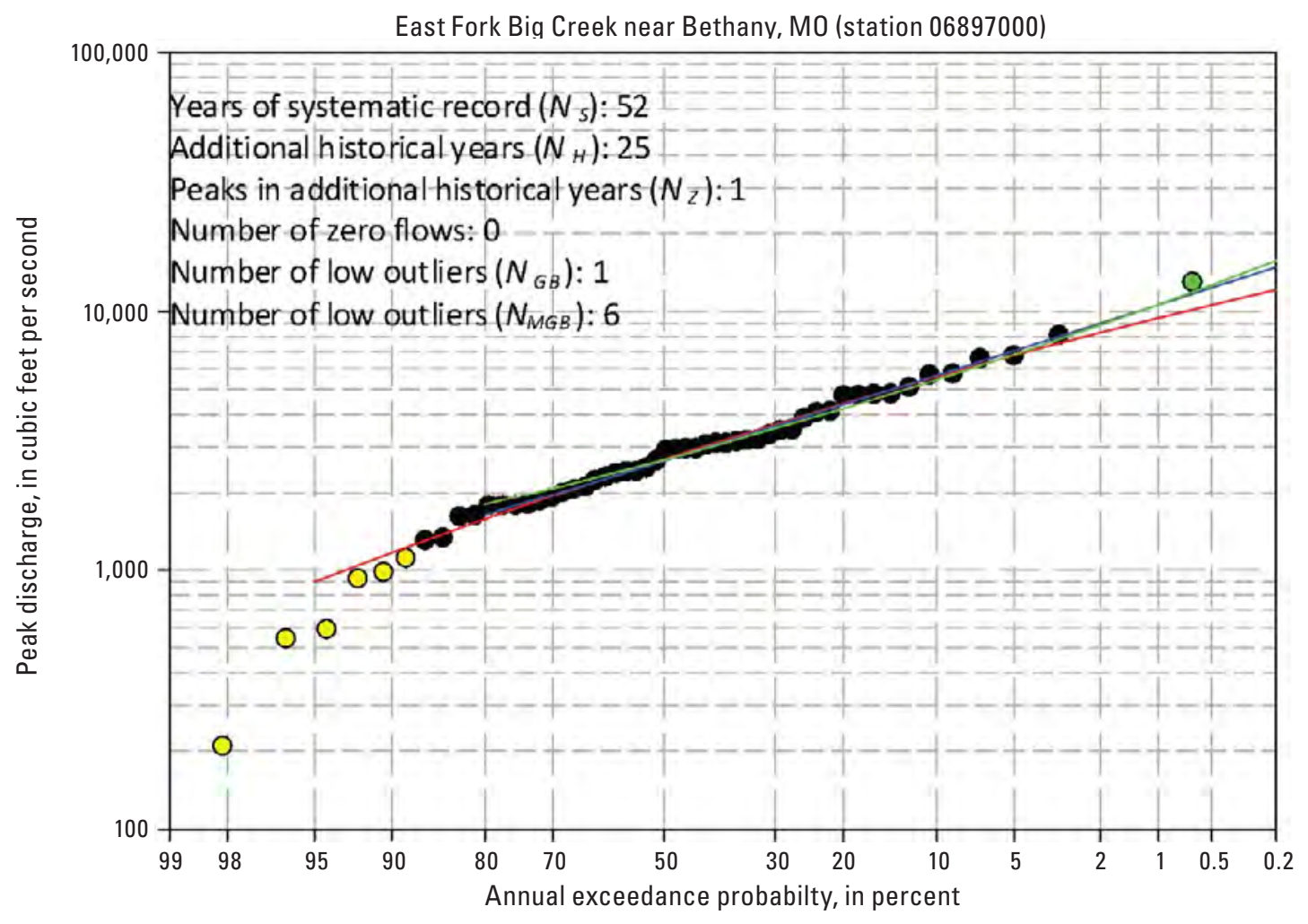

EXPLANATION

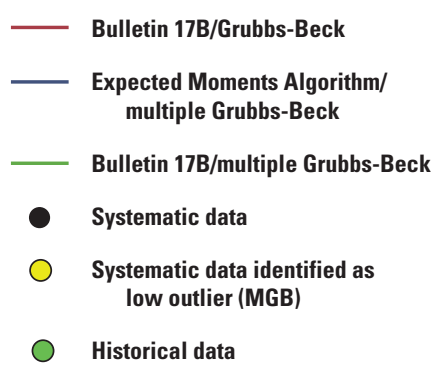

Figure 2-71. Site 06897000-East Fork Big Creek near Bethany, Missouri (M0) with a combination of potentially influential low floods, historical, and (or) high outliers in the data. 


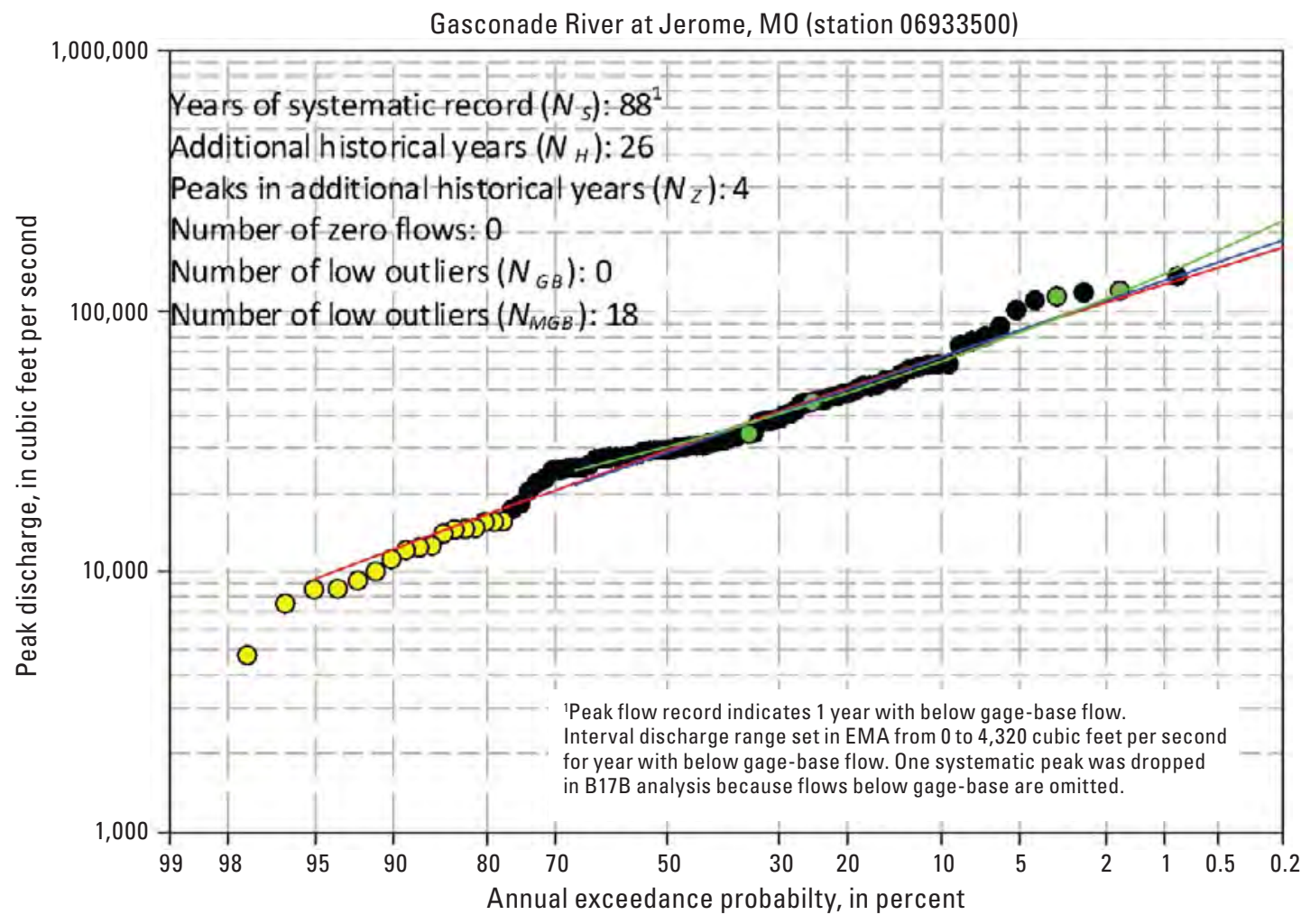

EXPLANATION

Bulletin 17B/Grubbs-Beck

Expected Moments Algorithm/ multiple Grubbs-Beck

Bulletin 17B/multiple Grubbs-Beck

- Systematic data

Systematic data identified as

low outlier (MGB)

Historical data

Figure 2-72. Site 06933500-Gasconade River at Jerome, Missouri (MO) with a combination of potentially influential low floods, historical, and (or) high outliers in the data. EMA, Expected Moments Algorithm; B17B, Bulletin 17B. 


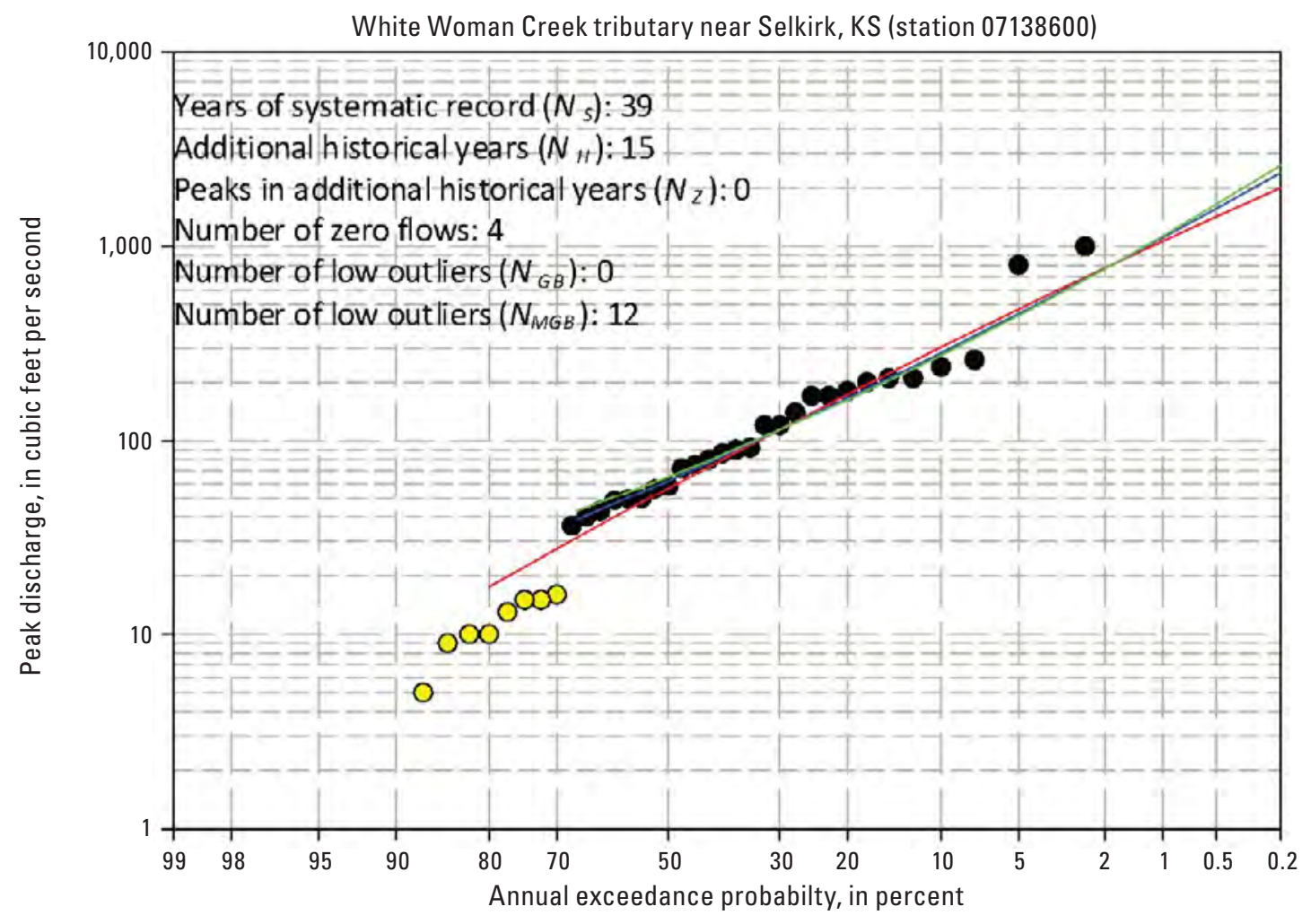

EXPLANATION

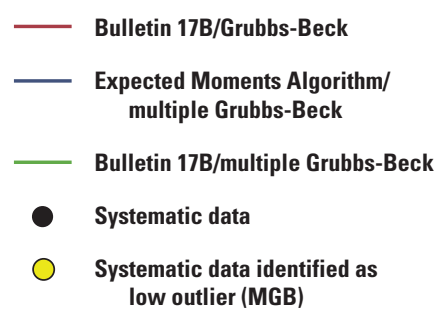

Figure 2-73. Site 07138600-White Woman Creek tributary near Selkirk, Kansas (KS) with a combination of potentially influential low floods, historical, and (or) high outliers in the data. 


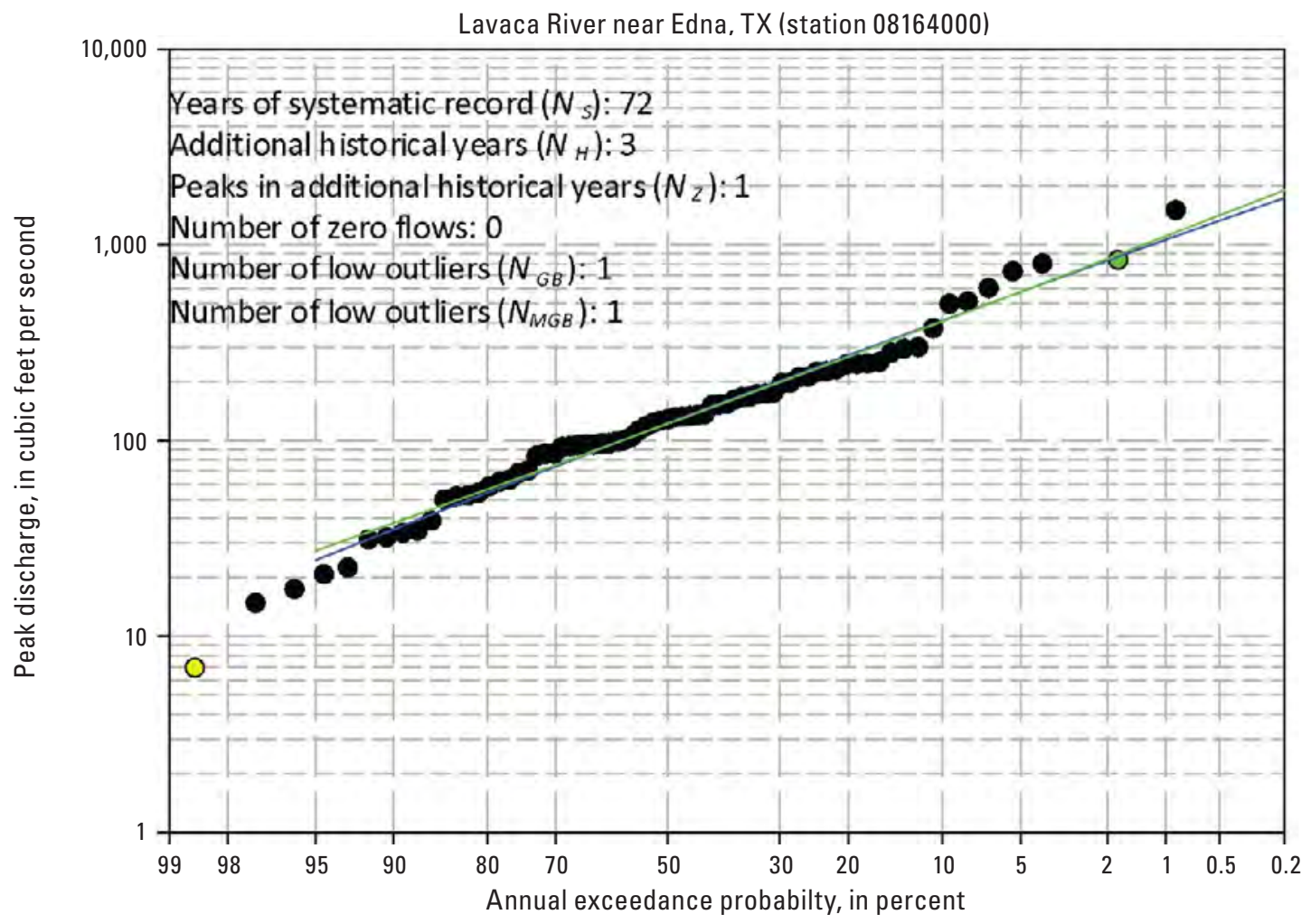

EXPLANATION

Bulletin 17B/Grubbs-Beck

Expected Moments Algorithm/ multiple Grubbs-Beck

Bulletin 17B/multiple Grubbs-Beck

- Systematic data

Systematic data identified as

low outlier (MGB)

Historical data

Figure 2-74. Site 08164000-Lavaca River near Edna, Texas (TX) with a combination of potentially influential low floods, historical, and (or) high outliers in the data. 


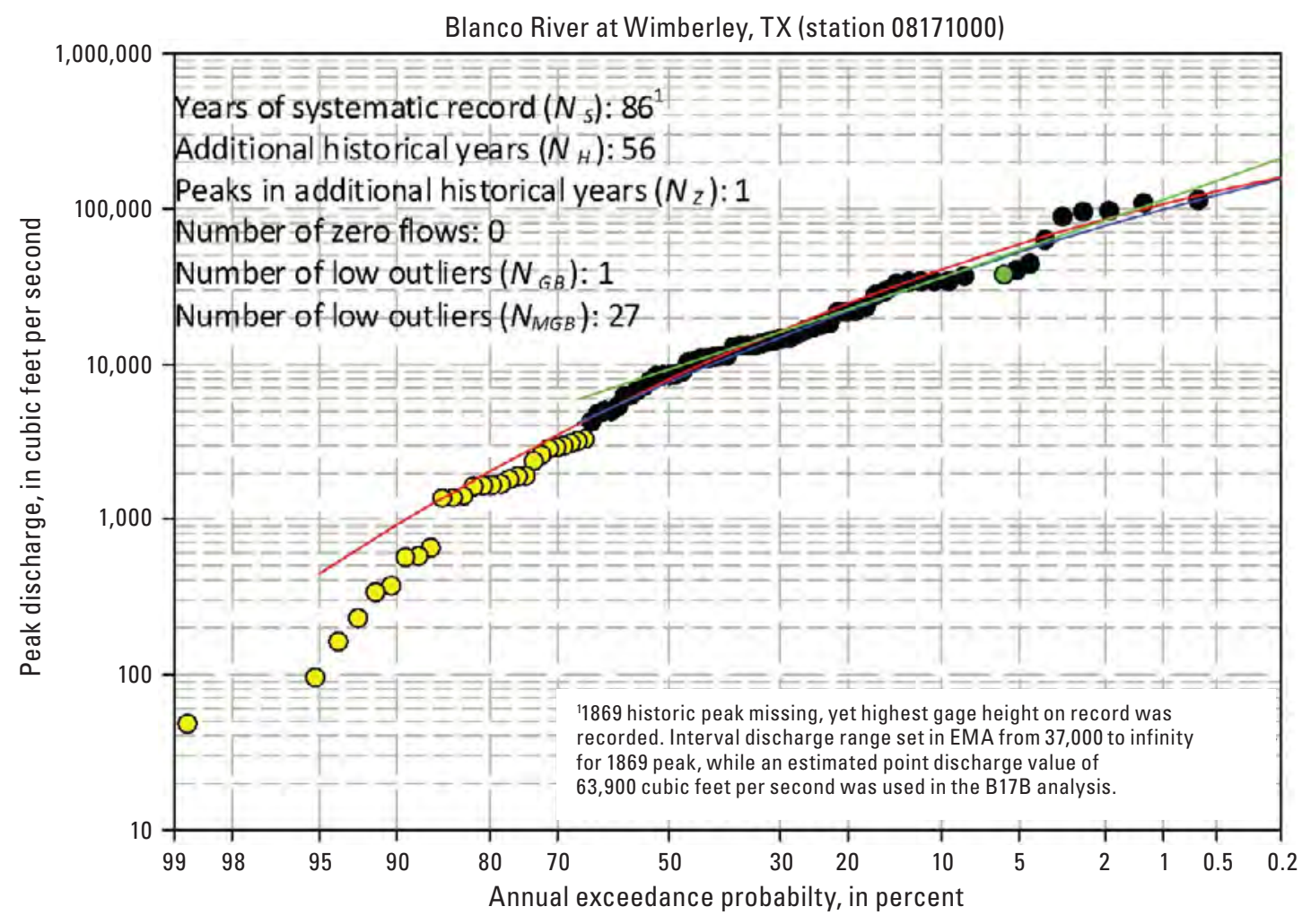

EXPLANATION

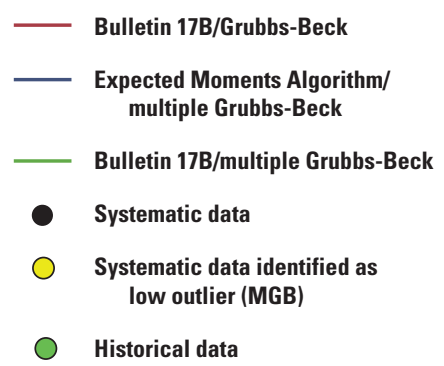

Figure 2-75. Site 08171000-Blanco River at Wimberley, Texas (TX) with a combination of potentially influential low floods, historical, and (or) high outliers in the data. EMA, Expected Moments Algorithm; B17B, Bulletin 17B. 


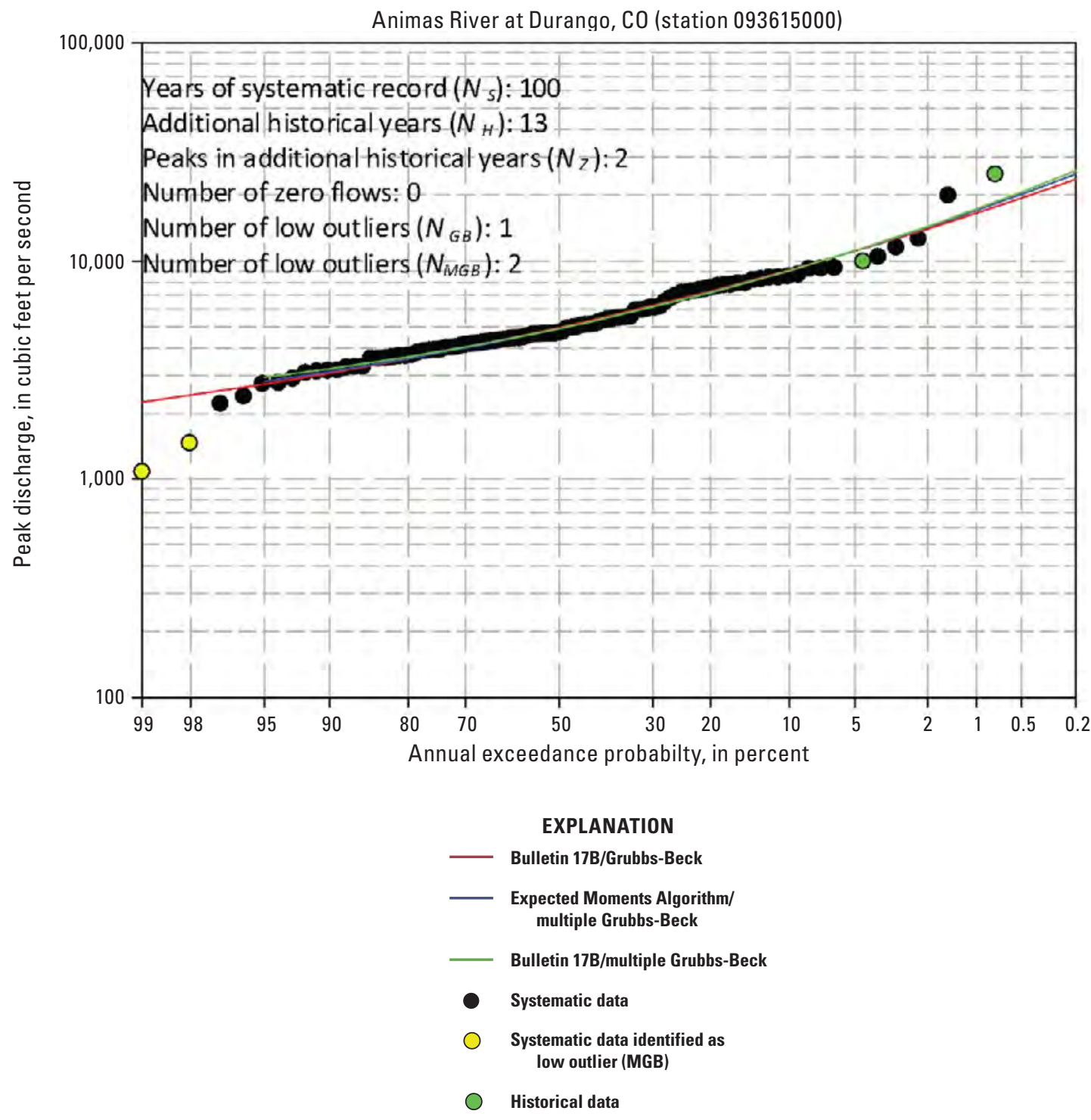

Figure 2-76. Site 09361500-Animas River at Durango, Colorado (CO) with a combination of potentially influential low floods, historical, and (or) high outliers in the data. 


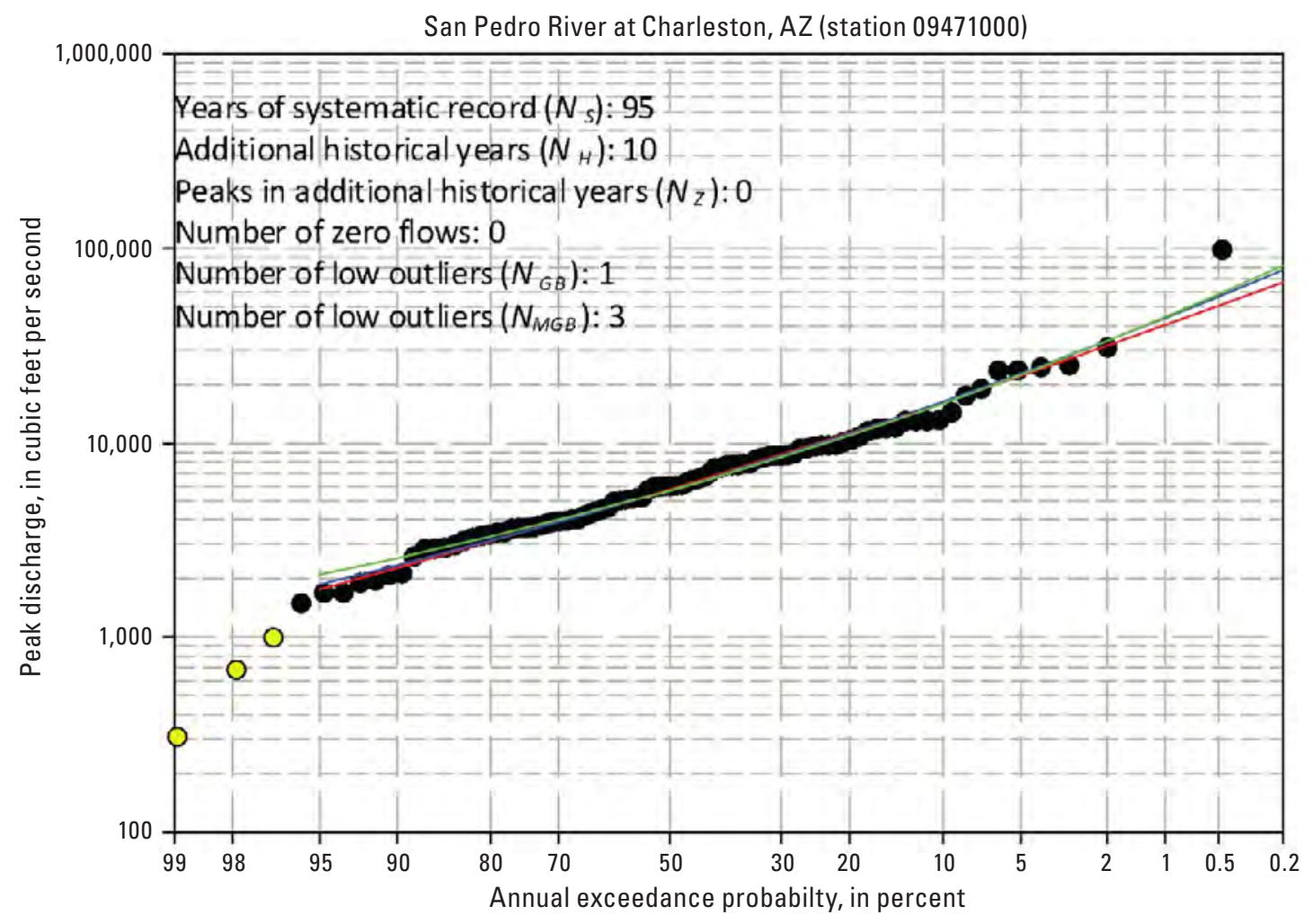

EXPLANATION

- Bulletin 17B/Grubbs-Beck

Expected Moments Algorithm/ multiple Grubbs-Beck

Bulletin 17B/multiple Grubbs-Beck

- Systematic data

Systematic data identified as low outlier (MGB)

Figure 2-77. Site 09471000-San Pedro River at Charleston, Arizona (AZ) with a combination of potentially influential low floods, historical, and (or) high outliers in the data. 


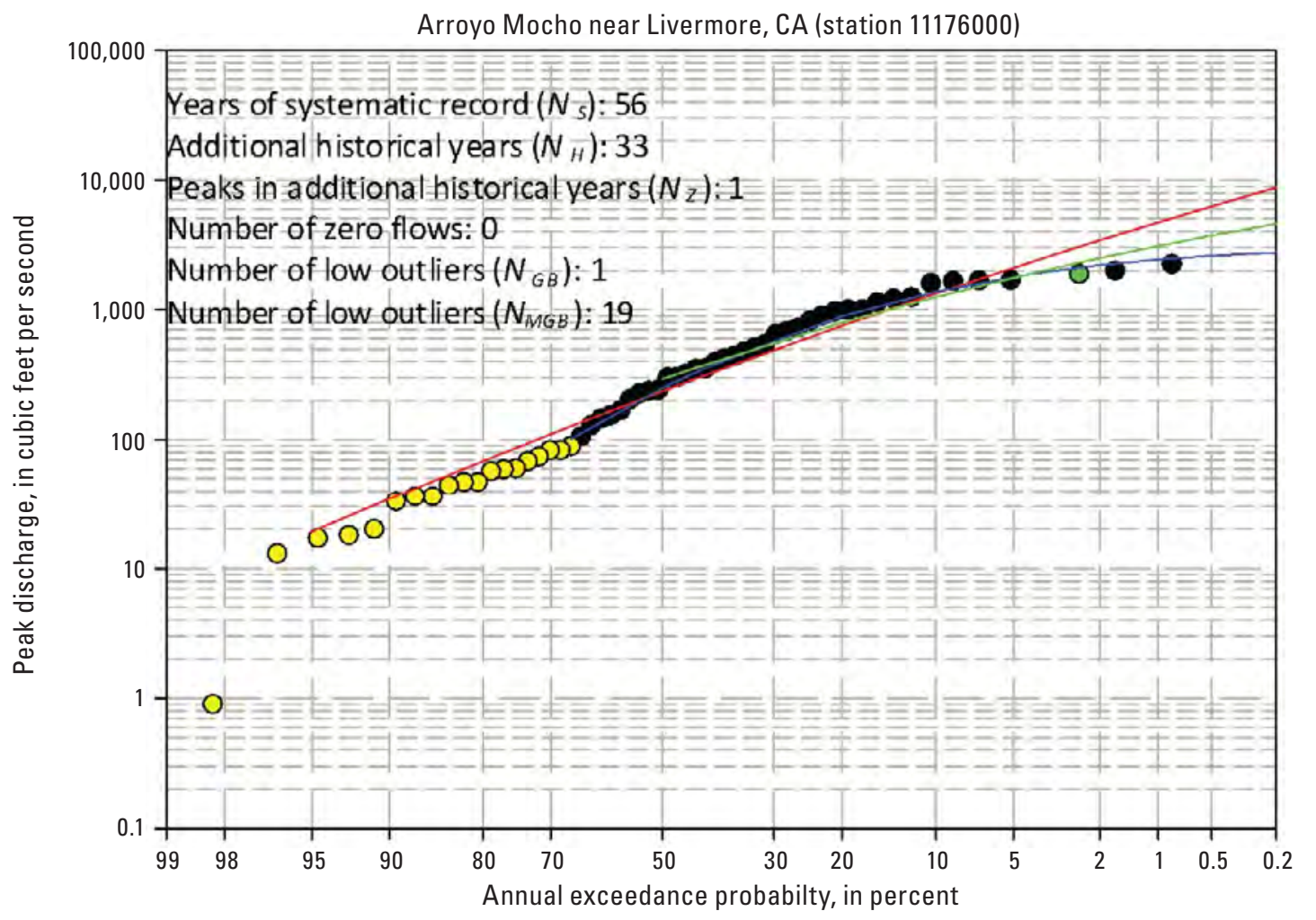

EXPLANATION

Bulletin 17B/Grubbs-Beck

Expected Moments Algorithm/ multiple Grubbs-Beck

Bulletin 17B/multiple Grubbs-Beck

- Systematic data

Systematic data identified as low outlier (MGB)

Historical data

Figure 2-78. Site 11176000-Arroyo Mocho near Livermore, California (CA) with a combination of potentially influential low floods, historical, and (or) high outliers in the data. 


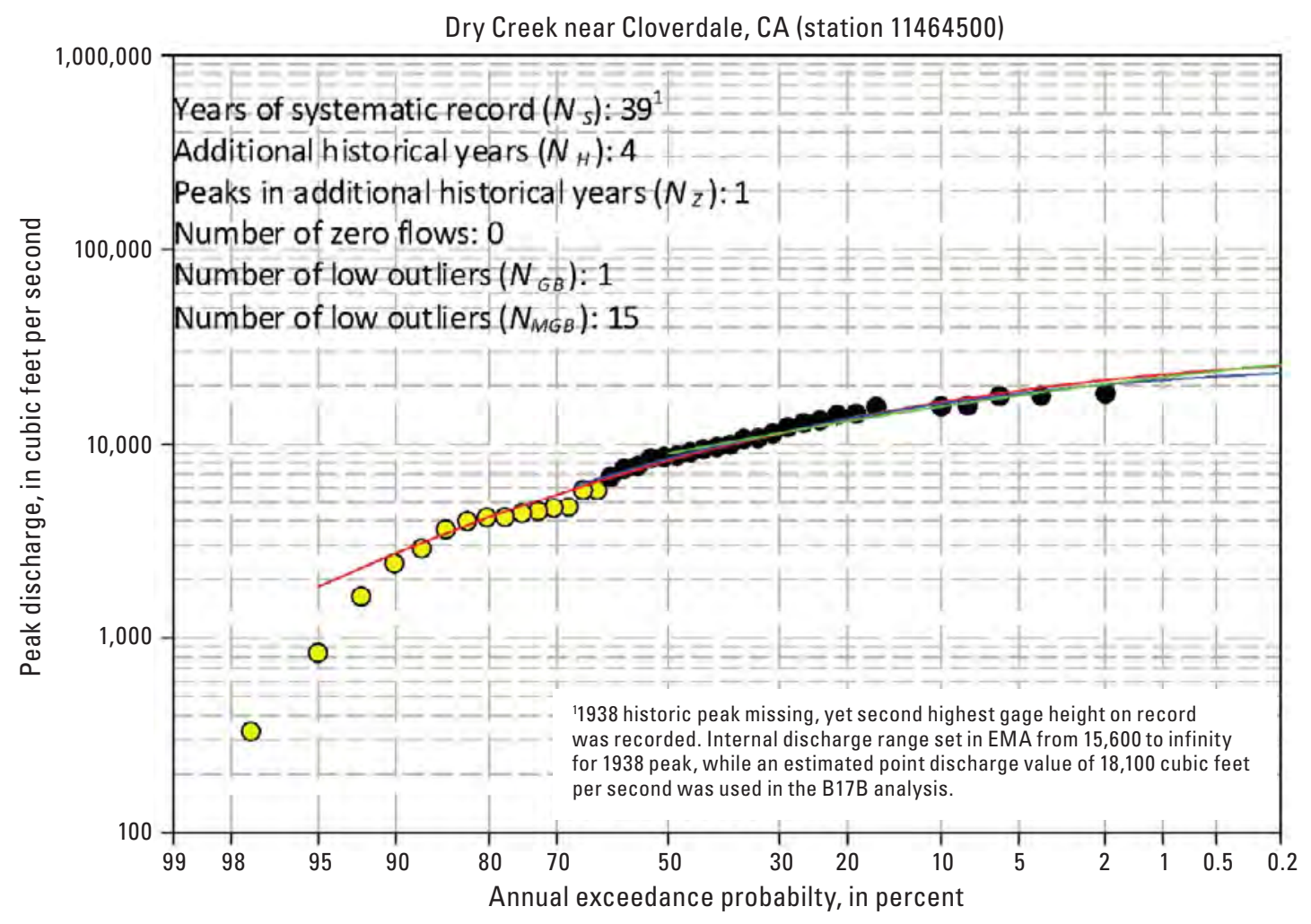

EXPLANATION

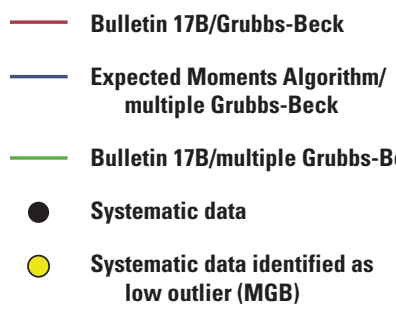

Figure 2-79. Site 11464500-Dry Creek near Cloverdale, California (CA) with a combination of potentially influential low floods, historical, and (or) high outliers in the data. EMA, Expected Moments Algorithm; B17B, Bulletin 17B. 


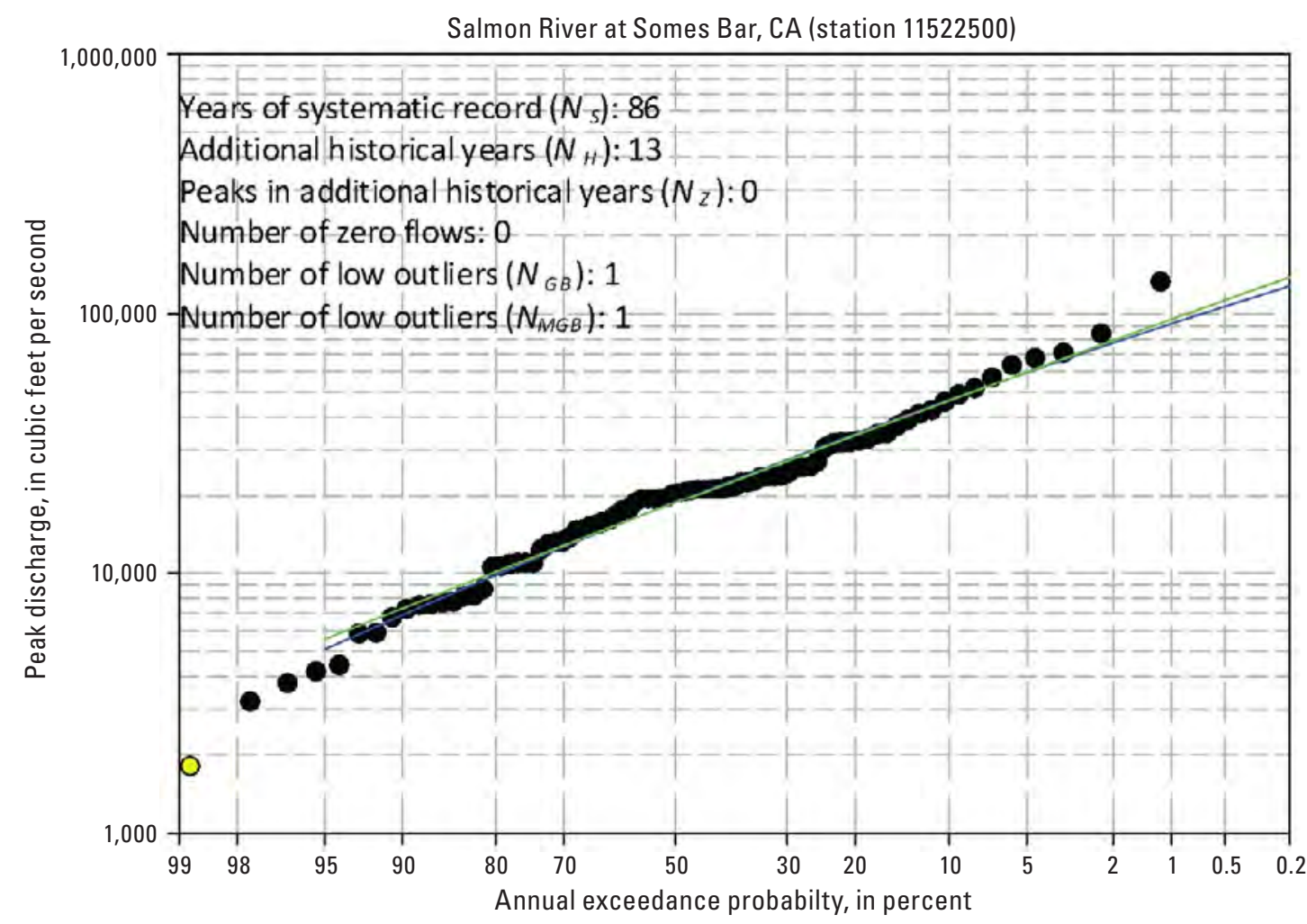

EXPLANATION

Bulletin 17B/Grubbs-Beck

Expected Moments Algorithm/ multiple Grubbs-Beck

Bulletin 17B/multiple Grubbs-Beck

- Systematic data

$\bigcirc$ Systematic data identified as

low outlier (MGB)

Figure 2-80. Site 11522500-Salmon River at Somes Bar, California (CA) with a combination of potentially influential low floods, historical, and (or) high outliers in the data. 


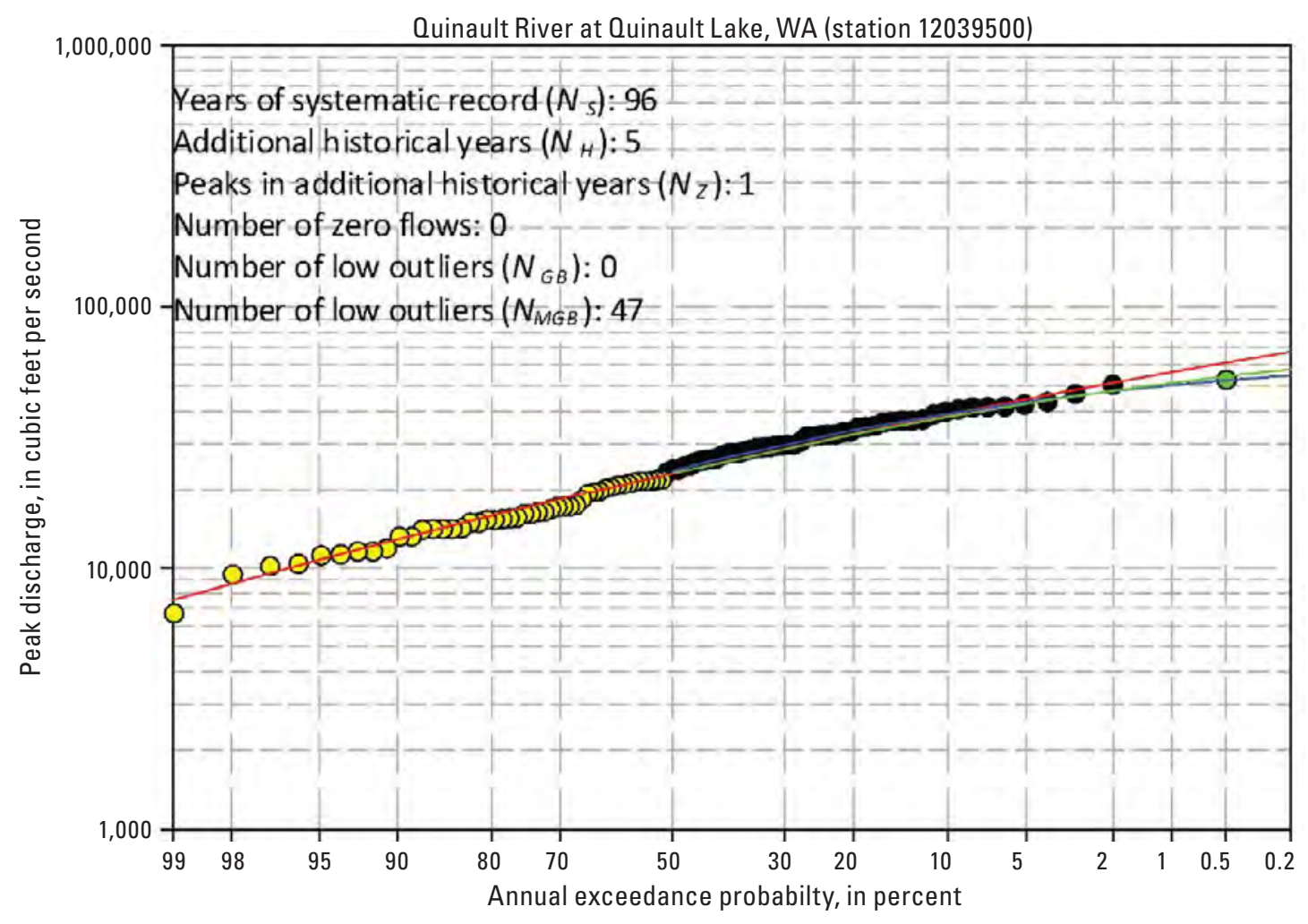

EXPLANATION

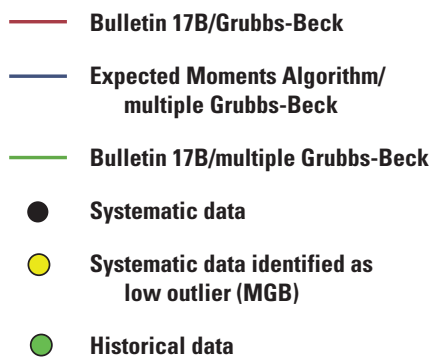

Figure 2-81. Site 12039500-Quinault River at Quinault Lake, Washington (WA) with a combination of potentially influential low floods, historical, and (or) high outliers in the data. 


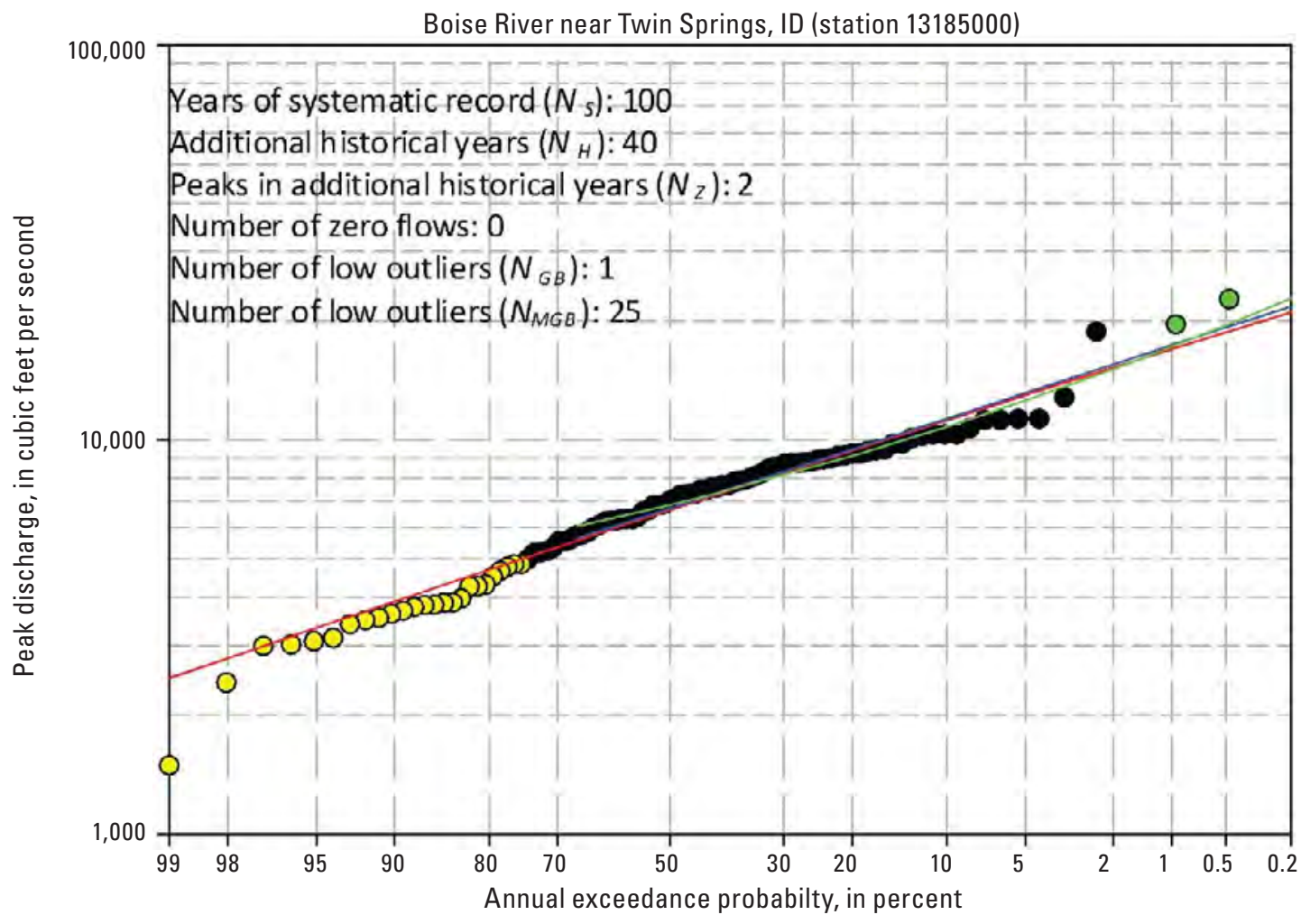

EXPLANATION

Bulletin 17B/Grubbs-Beck

Expected Moments Algorithm/ multiple Grubbs-Beck

Bulletin 17B/multiple Grubbs-Beck

- Systematic data

Systematic data identified as low outlier (MGB)

Historical data

Figure 2-82. Site 13185000-Boise River near Twin Springs, Idaho (ID) with a combination of potentially influential low floods, historical, and (or) high outliers in the data. 


\section{Studies With log-Pearson Type III (LP3) Distribution and Regional Skew}

Figures 2-83 through 2-85 show the same cases as figures 2-4, except that regional skew information has been added with a mean square error (MSE) of 0.15-a typical value consistent with Bayesian/GLS skew maps (Lamontagne and others, 2012; Parrett and others, 2011; Gotvald and others, 2009). As expected, all of the estimators perform better with regional information. Aside from that, however, there is little difference between the corresponding figures.

\section{Additional Studies With Specific Frequency Curves}

Figures 5-8 and 2-86 through 2-87 apply the three estimators-EMA/MGB, B17B/GB, and $\mathrm{B} 17 \mathrm{~B} / \mathrm{MGB}$ - to data drawn from specific populations selected to test the estimators' performance. The cases are labeled "robustness test curve 1 through 6" in recognition of their origins. Figures 5-8 are presented in the main body of this report. Figures 2-86 and 2-87 are presented here in the appendix because they do not actually deal with robustness but rather with specific log-Pearson Type III (LP3) populations. In fact, because the estimators are all invariant with respect to location and scale, these two cases duplicate cases already considered in the report. Figure 2-86 depicts essentially the same case as figure 4 with a population skew of $\gamma=0.5$. Figure 2-87 depicts essentially the same case as figure 3 with a population skew of $\gamma=-0.5$. 


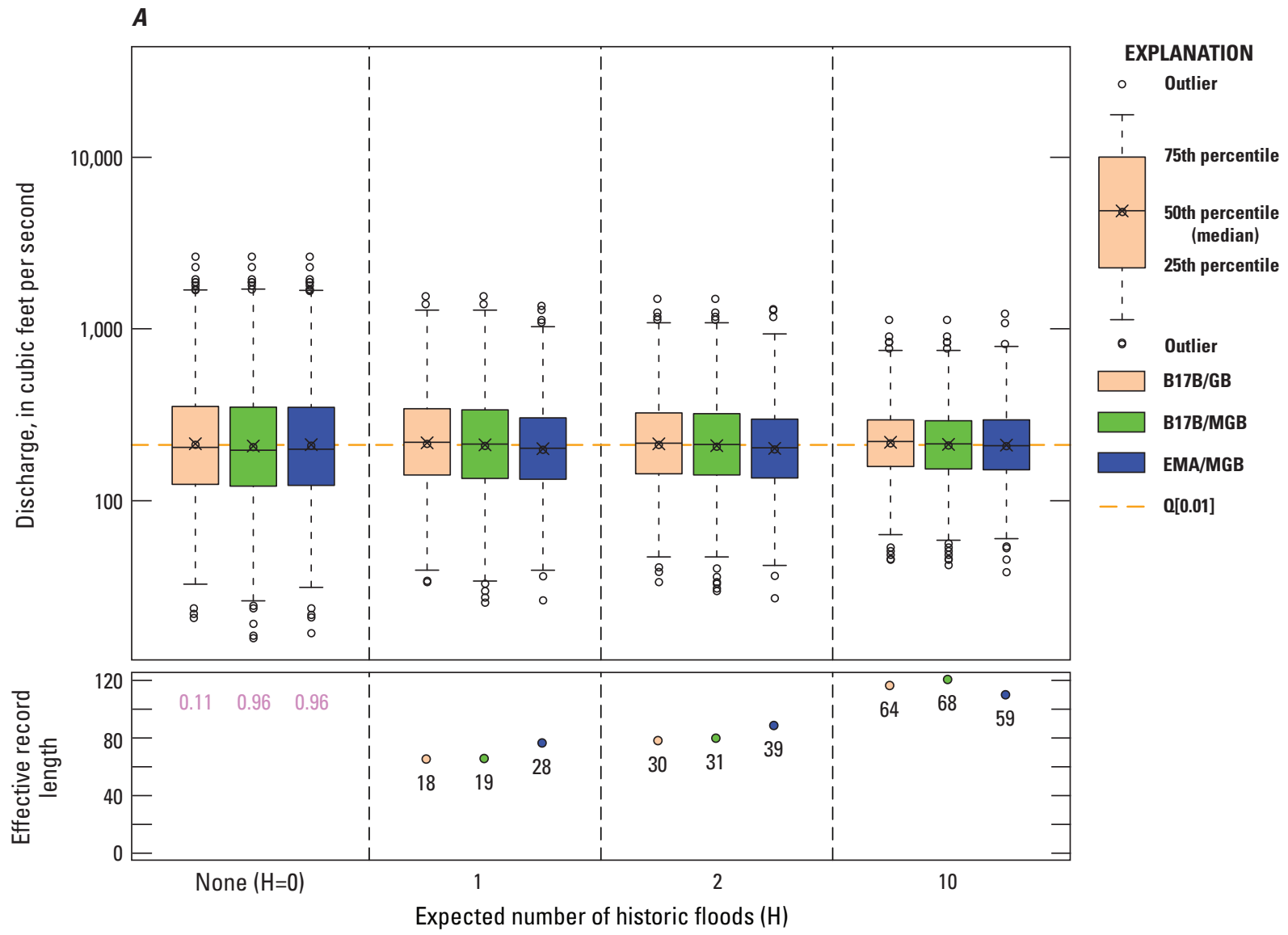

B

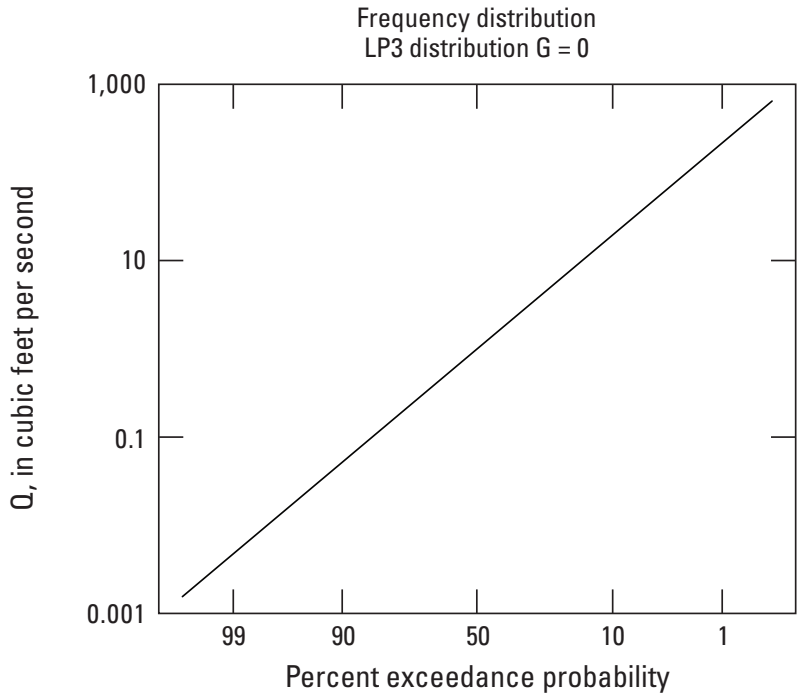

C

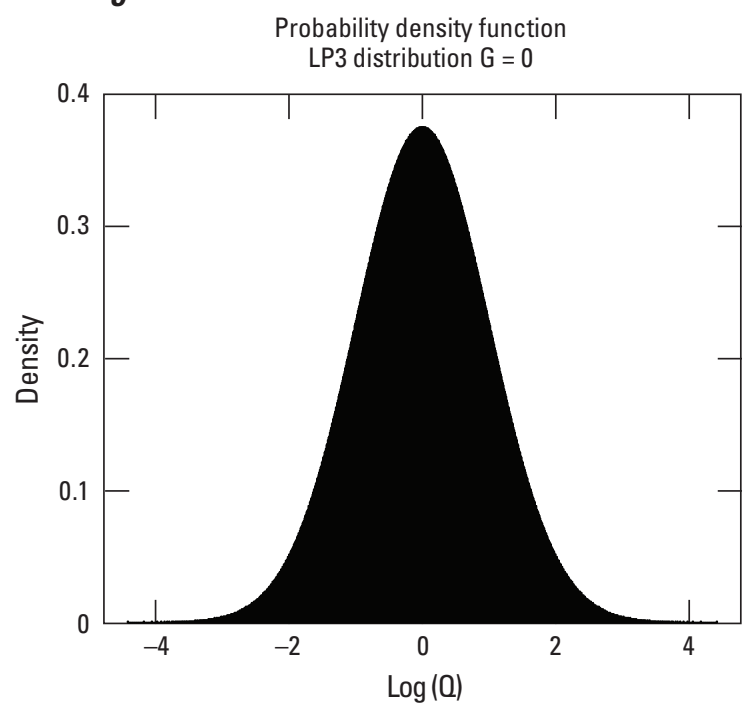

Figure 2-83. Results are based on 10,000 replicate samples with systematic record, $N_{S}=40$, and historical record, $N_{H}=100$, drawn from a log-Pearson type III distribution with skew, $\gamma=0.0$. Regional skew is assumed to be 0.0 with mean square error of 0.15 . 

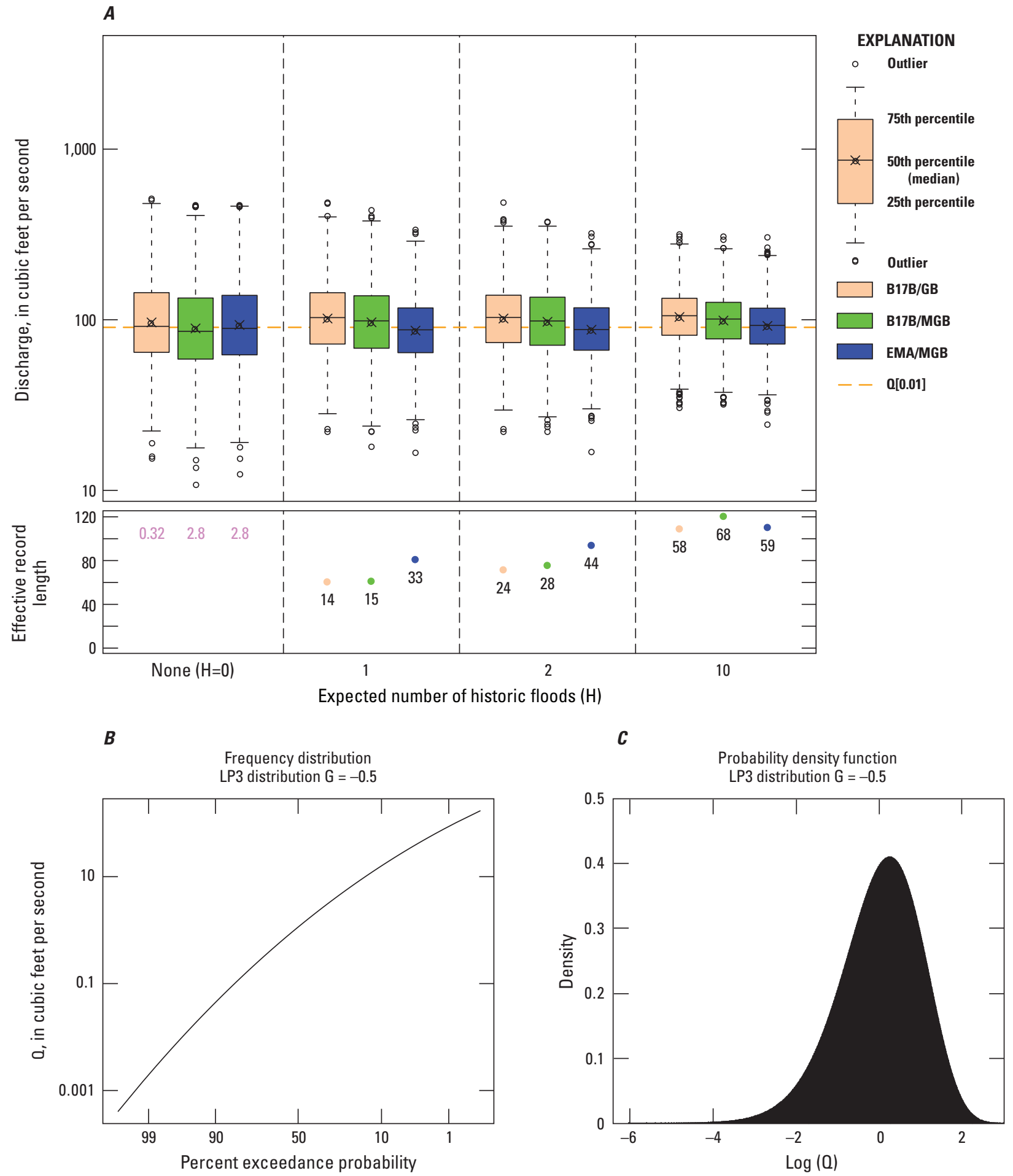

Figure 2-84. Results are based on 10,000 replicate samples with systematic record, $N_{S}=40$, and historical record, $N_{H}=100$, drawn from a log-Pearson type III distribution with skew, $\gamma=-0.5$. Regional skew is assumed to be -0.5 with mean square error of 0.15 . 


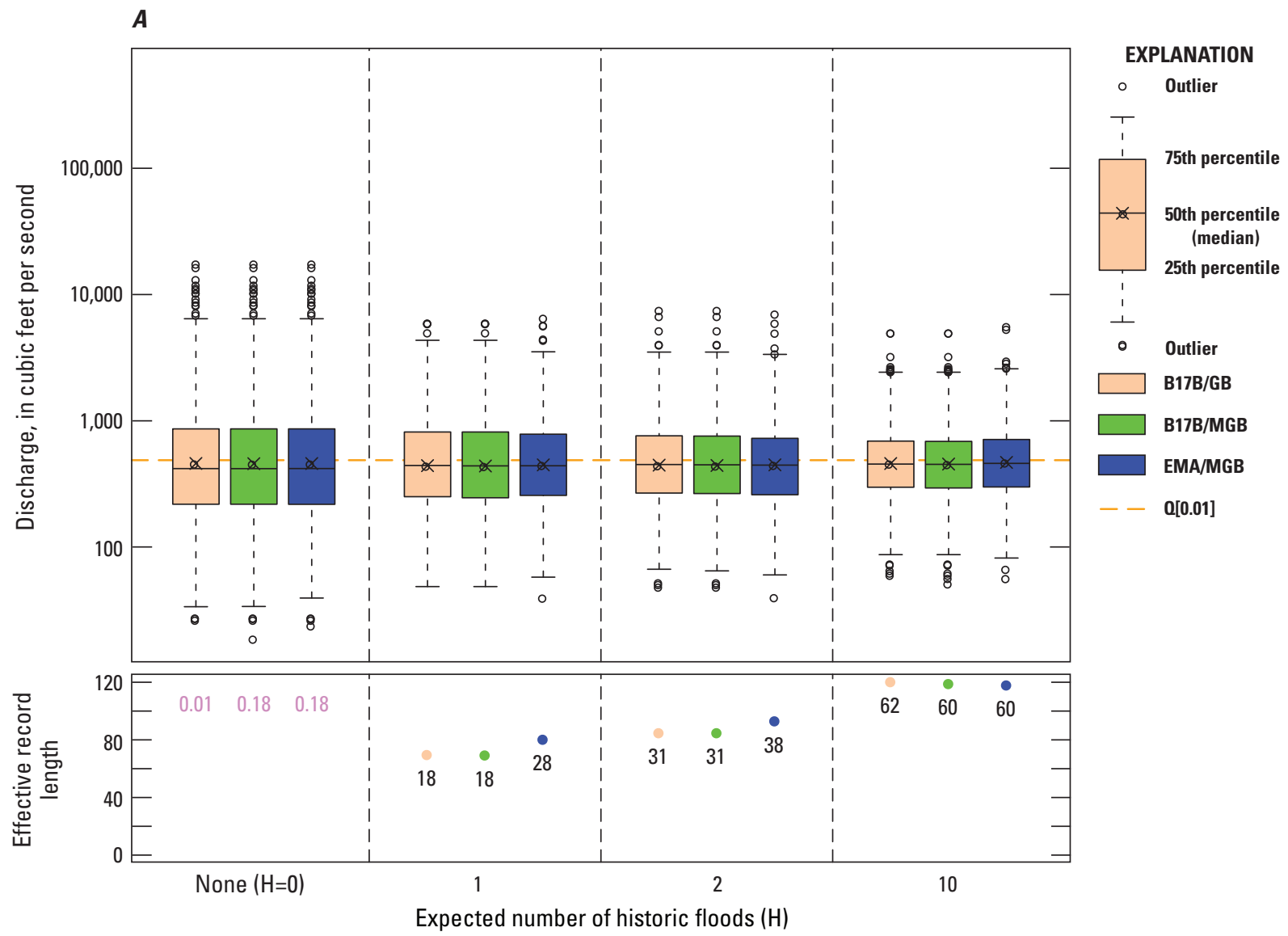

B

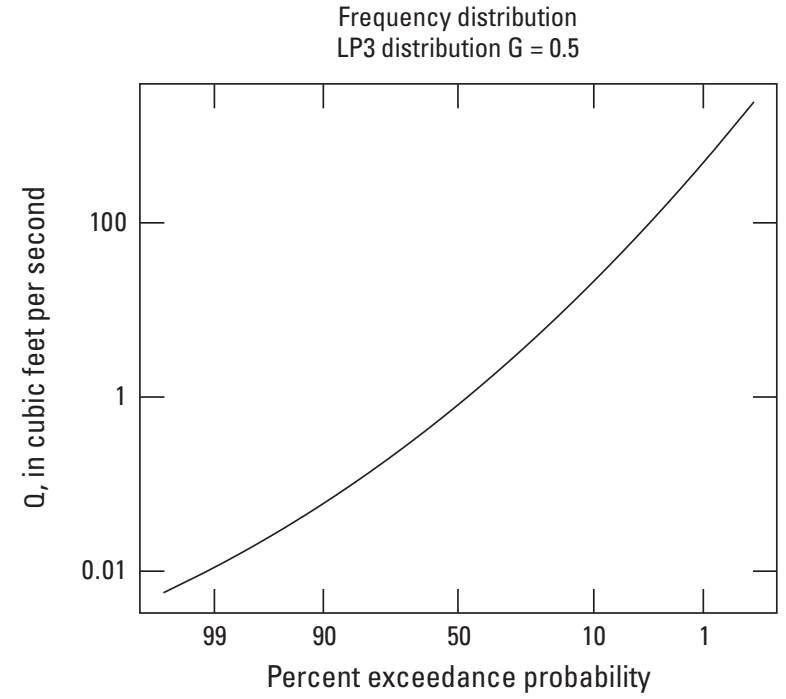

C

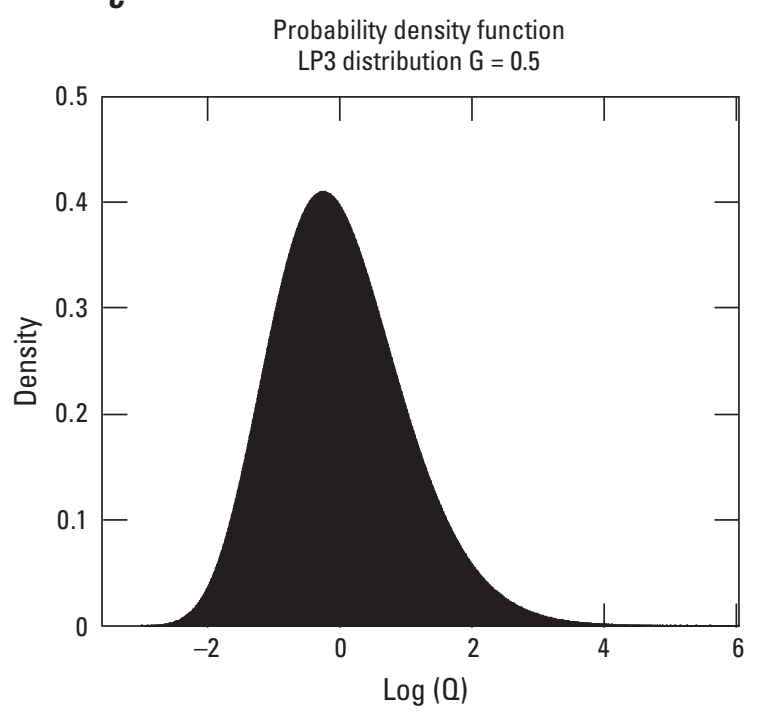

Figure 2-85. Results are based on 10,000 replicate samples with systematic record, $N_{S}=40$, and historical record, $N_{H}=100$, drawn from a log-Pearson type III distribution with skew, $\gamma=0.5$. Regional skew is assumed to be 0.5 with mean square error of 0.15 . 


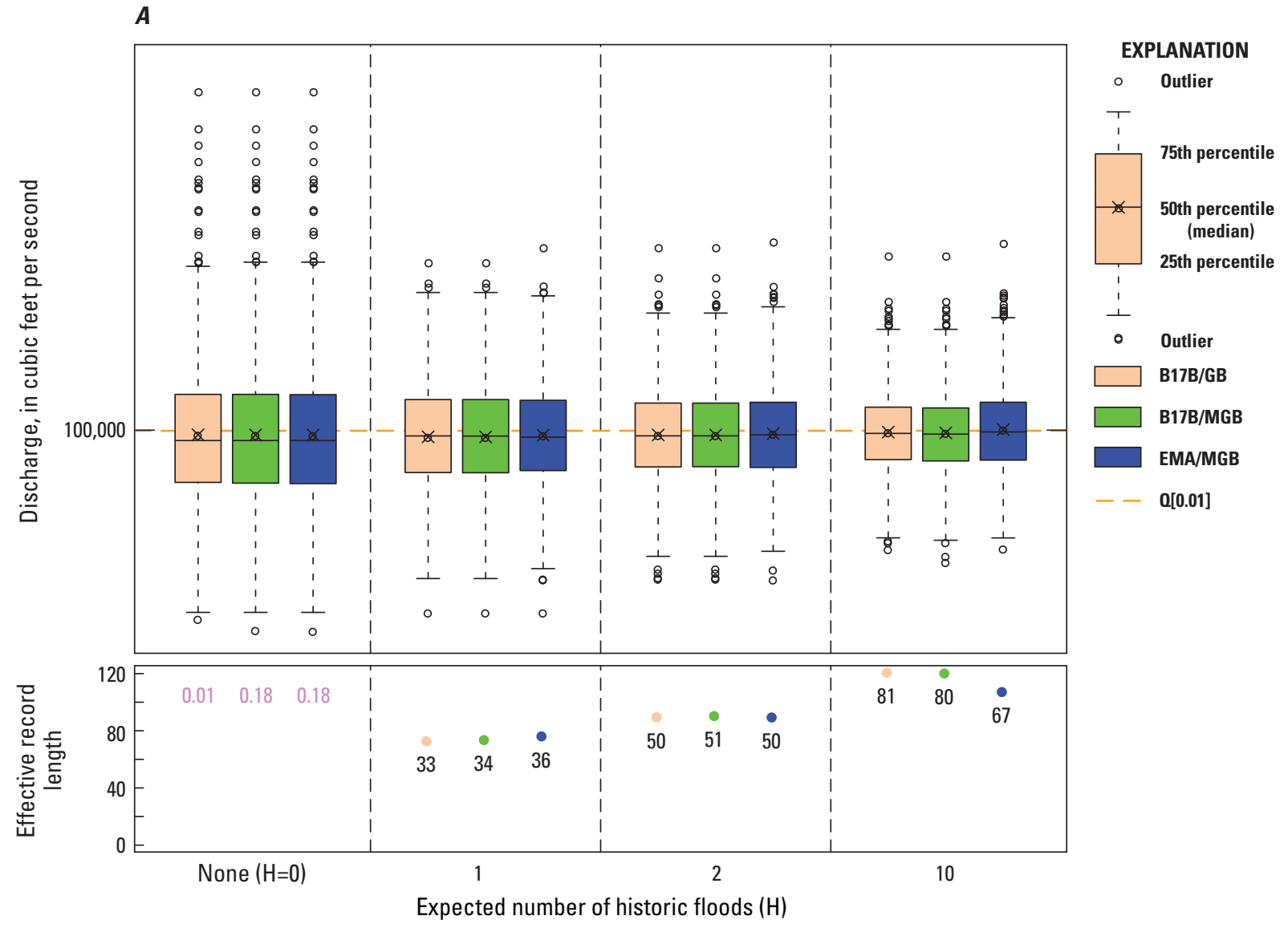

$B$

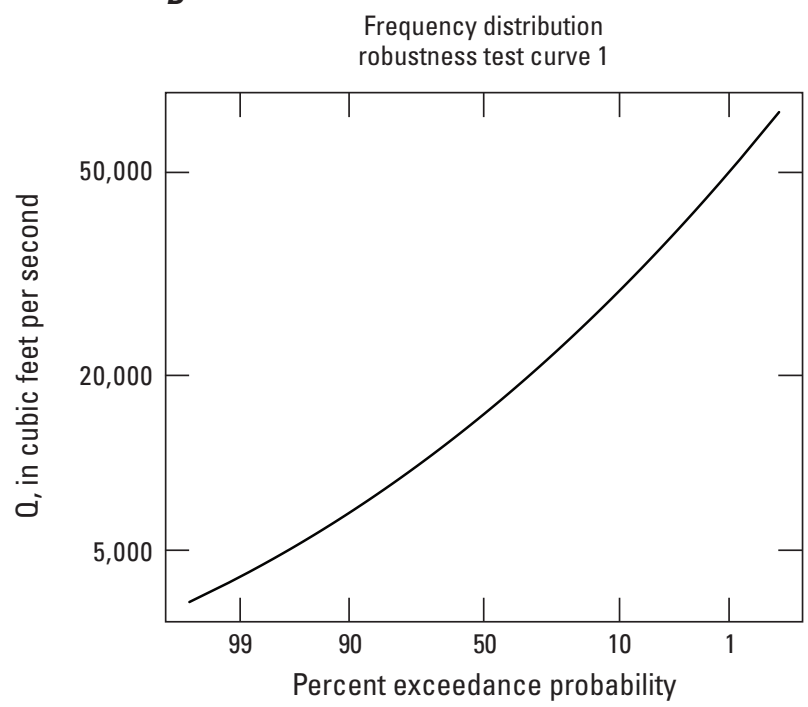

C

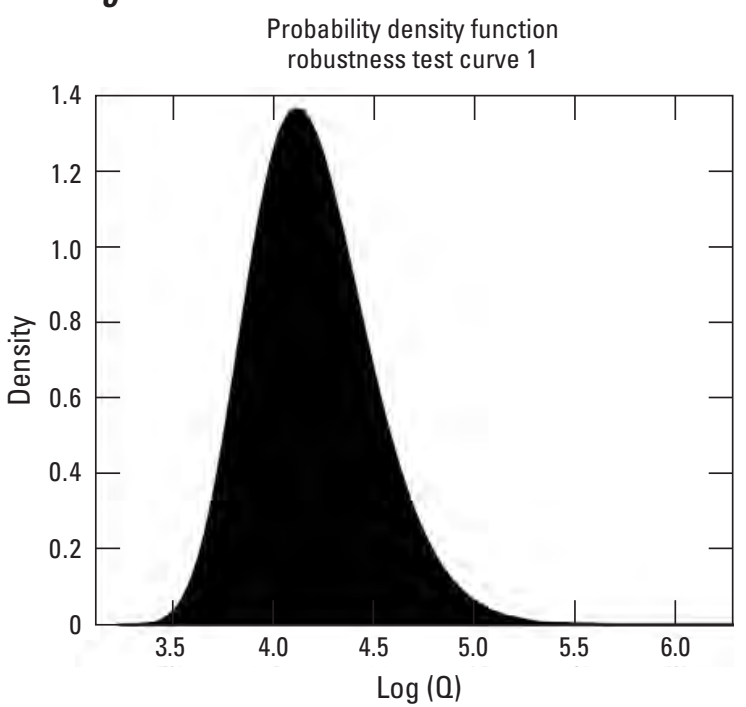

Figure 2-86. Results are based on 10,000 replicate samples with systematic record, $N_{S}=40$, and historical record, $N_{H}=100$, drawn from robustness test curve 1. 

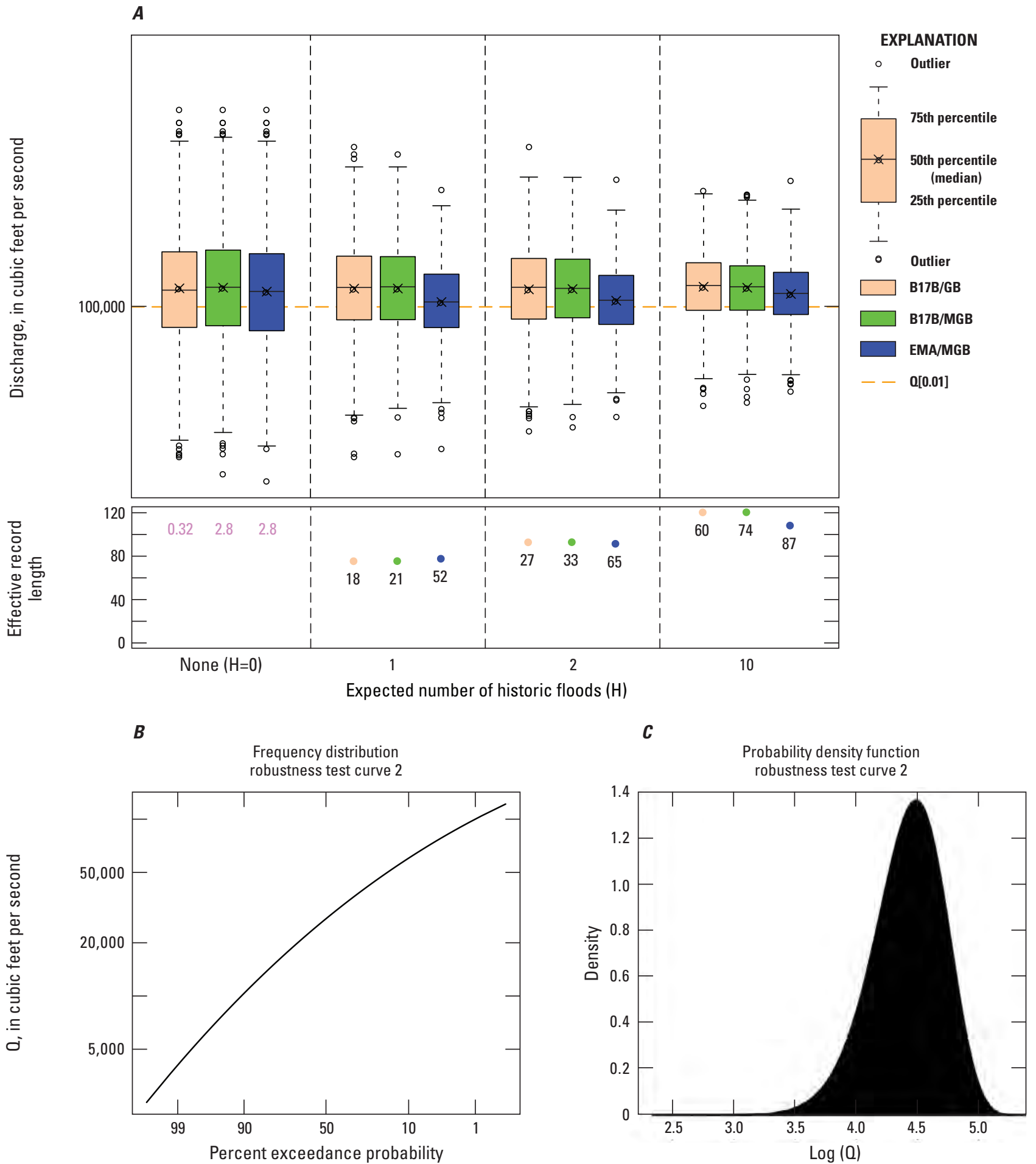

Figure 2-87. Results are based on 10,000 replicate samples with systematic record, $N_{S}=40$, and historical record, $N_{H}=100$, drawn from robustness test curve 2 . 

Publishing support provided by the U.S. Geological Survey Science Publishing Network, Reston Publishing Service Center

For information concerning this publication, please contact:

Chief, Analysis and Prediction Branch

Integrated Modeling and Prediction Division

Water Mission Area

U.S. Geological Survey

12201 Sunrise Valley Drive, Mail Stop 415

Reston, VA 20192

https://water.usgs.gov/ 


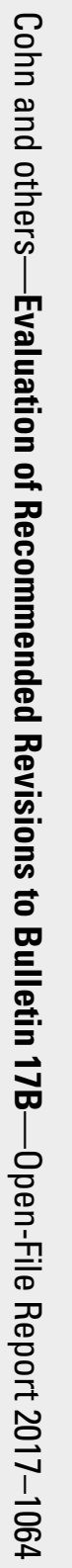

